\title{
Investigation of biologically active peptaibol compounds produced by members of the filamentous fungal genus Trichoderma
}

\author{
Ph.D. dissertation \\ Tamás Marik
}

Supervisors:

Dr. László Kredics, associate professor

Dr. András Szekeres, senior research fellow

\section{Doctoral School of Biology}

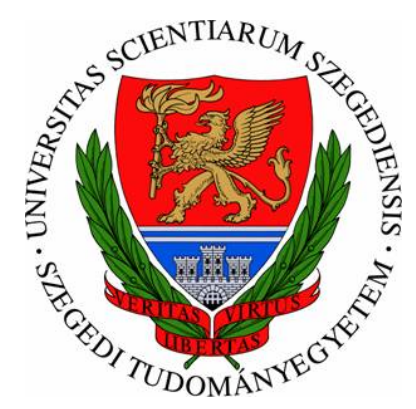

Department of Microbiology

Faculty of Science and Informatics

University of Szeged

2020

Szeged 


\section{TABLE OF CONTENTS}

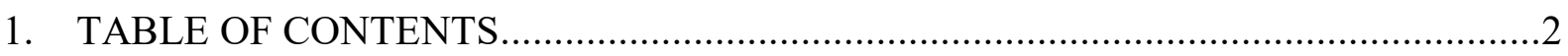

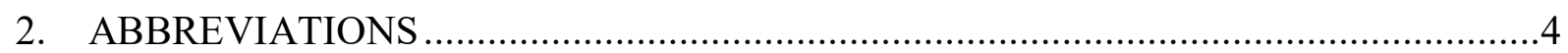

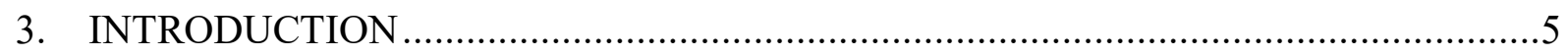

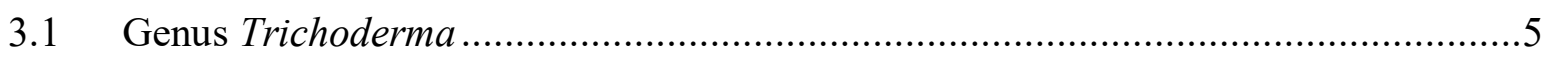

3.1.1 Taxonomy of Trichoderma ........................................................................

3.1.2 Trichoderma species as biocontrol agents..................................................... 8

3.1.3 Trichoderma species as the causal agents of green mould disease in mushroom

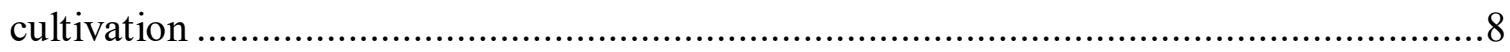

3.1.4 Trichoderma species as opportunistic human pathogens ...................................

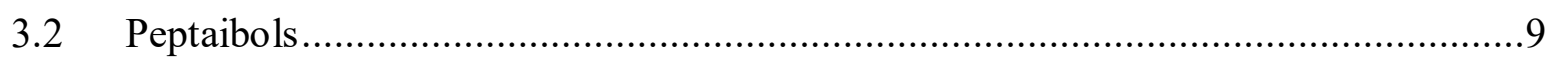

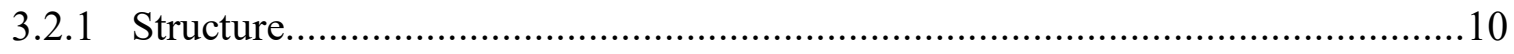

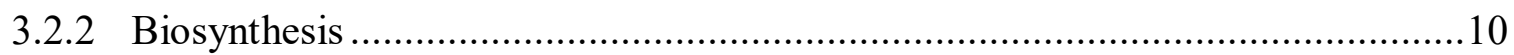

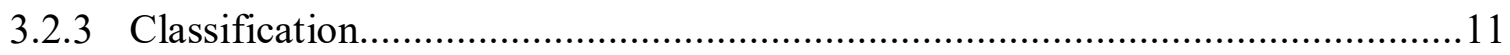

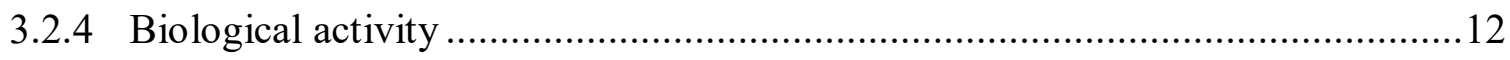

3.2.5 ALM, the most studied peptaibol............................................................... 13

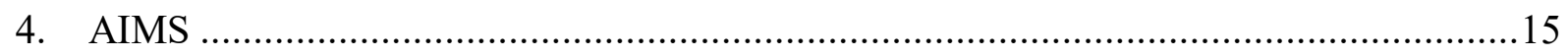

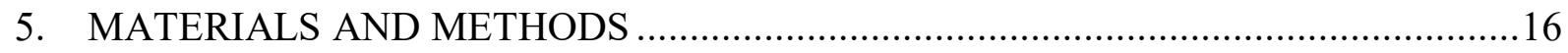

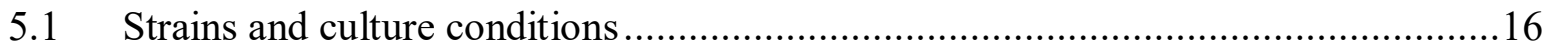

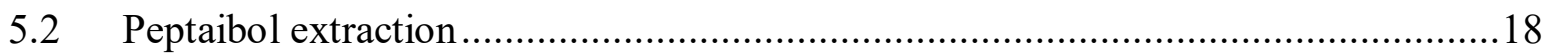

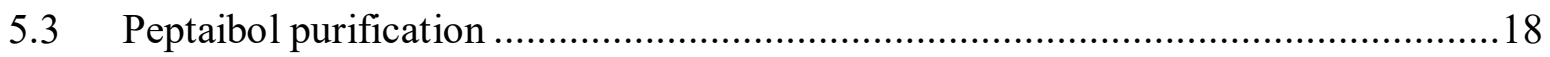

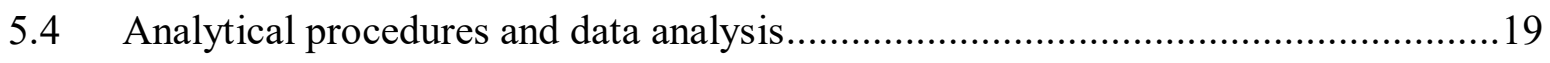

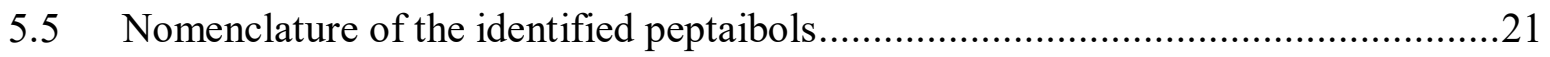

5.6 Testing the effect of peptaibol extracts on bacteria and yeasts..............................22

5.7 Testing the effect of peptaibol extracts on filamentous fungi..............................22

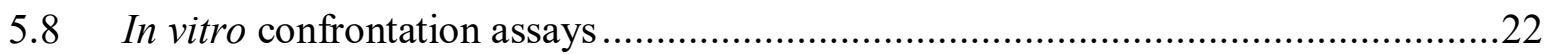

5.9 Bioassays for peptaibol toxicity on mushroom mycelia....................................23

5.10 Bioassays for peptaibol toxicity on filamentous fungi .....................................23

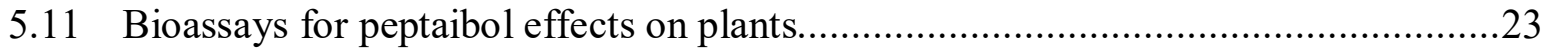

5.12 Peptaibol bioactivity assays against mammalian cells ...........................................24

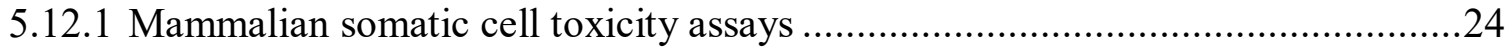


5.12.2 Sperm motility inhibition assay

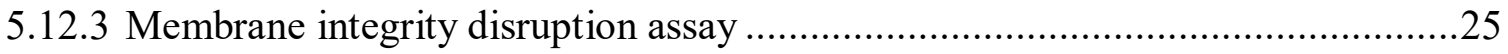

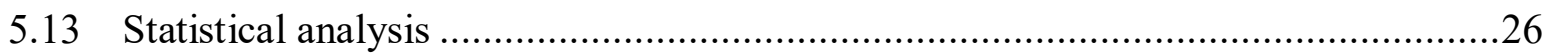

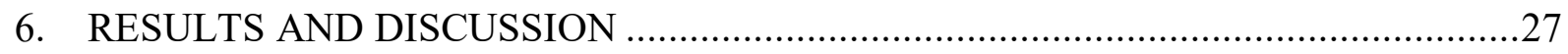

6.1 Optimization of ESI-IT-MS system for the identification of peptaibol compounds .27

6.2 Identification of the peptaibols produced by Trichoderma species .........................32

6.3 Peptaibols from T. gamsii and T. koningiopsis (clade Viride) ...............................33

6.3.1 Peptaibol production of T. gamsii and T. koningiopsis ...................................33

6.3.2 Effect of peptaibol extracts on bacteria, yeasts and filamentous fungi................40

6.4 Peptaibol production of Trichoderma species causing mushroom green mould

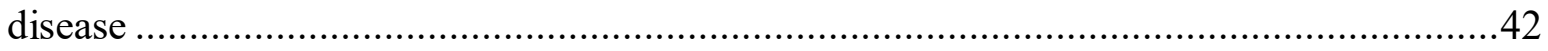

6.4.1 Peptaibols produced by T. aggressivum f. europaeum and T. pleuroti ...............42

6.4.2 Changes in the peptaibol profiles of T. pleuroti and T. aggressivum f. europaeum during in vitro antagonistic interactions with $P$. ostreatus and $A$. bisporus ....................49

6.4.3 Effects of peptaibols on P. ostreatus and A. bisporus ......................................51

6.5 Peptaibol production of Trichoderma species from clade Longibrachiatum ............53

6.5.1 Peptaibols produced by the species selected from clade Longibrachiatum...........53

6.5.2 Qualitative and semi-quantitative peptaibol profiles of the strains.....................68

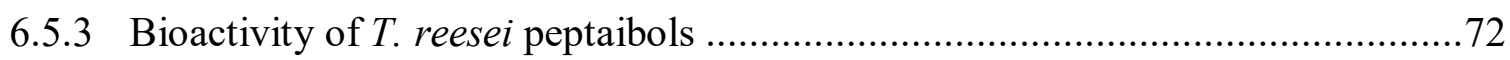

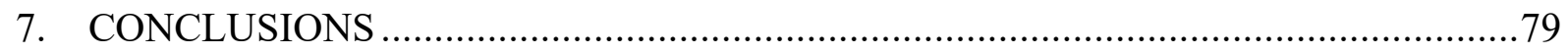

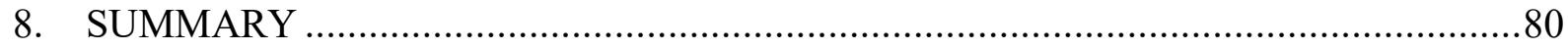

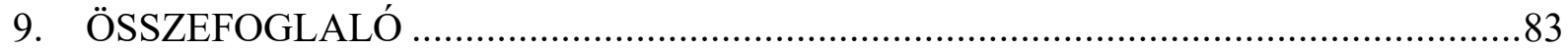

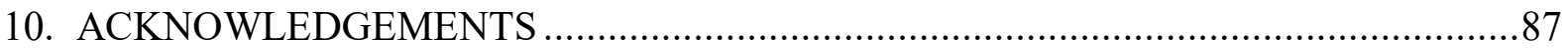

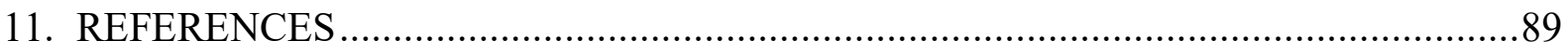

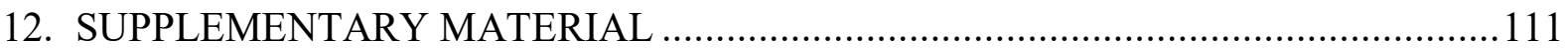




\section{ABBREVIATIONS}

act1: actin 1

Aib: $\alpha$-aminoisobutyric acid

AI: aggressivity index

ALM: alamethicin

cal1: calmodulin

EIC: extracted ion chromatogram

ESI: electrospray ionization

hfb4: hydrophobin 4

HPLC: high-performance liquid chromatography

IT: ion trap

ITS: internal transcribed spacer

LB: Luria-Bertani

Lxx: leucine/isoleucine

MEA: malt extract agar

MIC: minimum inhibitory concentration

MS: mass spectrometry

NRPS: non-ribosomal peptide synthetase

PK-15: porcine kidney tubular epithelial cell line

PI: propidium iodide

rpb2: RNA polymerase B subunit II

SF: subfamily

SZMC: Szeged Microbiological Collection

tef1: translation elongation factor $1 \alpha$

TIC: total ion chromatogram

TUCIM: TU Collection of Industrially Important Microorganisms

Vxx: valine/isovaline 


\section{INTRODUCTION}

\subsection{Genus Trichoderma}

Trichoderma species are cosmopolitan, free-living organisms, which play role mostly in decomposing organic matter in soil (Harman et al. 2004). Certain species have great economic importance as sources of antibiotics, enzymes, as plant growth promoters, decomposers of xenobiotics, and as commercial biofungicides (Chet and Inbar 1994, Harman et al. 2004, Hermosa et al. 2012). Probably the most known species with the ability to produce hydrolytic enzymes degrading cellulose or hemicellulose is $T$. reesei, belonging to the clade Longibrachiatum of the genus (Harman and Kubicek 1998, Kubicek et al. 2009). Species like T. viride, T. virens, T. atroviride, T. asperellum and T. harzianum are also frequently studied due to their ability to produce enzymes and antibiotics valuable in agriculture (Schuster and Schmoll 2010, Contreras-Cornejo et al. 2016), as well as their antagonistic effect against phytopathogenic fungi such as Botrytis cinerea, Alternaria solani and Rhizoctonia solani (Harman et al. 2004). Furthermore, incubation of a "T. harzianum" strain, which was later reidentified as $T$. atroviride (Röhrich et al. 2014), with the cell wall of $B$. cinerea led to the secretion of cell wall hydrolyzing enzymes and antibiotic fractions of peptaibols, which inhibited B. cinerea spore germination, resulting in a fungicidal effect. Also, peptaibols and hydrolytic enzymes were found to act synergistically in this antagonistic interaction (Schirmböck et al. 1994).

\subsubsection{Taxonomy of Trichoderma}

More than 300 species of the genus Trichoderma (Ascomycota, Hypocreales, Hypocreaceae) have been reported so far (Bissett et al. 2015, Zhang and Zhuang 2018). The majority of Trichoderma species was described after the year 2000, only a few species were initially included in the genus (Bisby 1939, Rifai 1969). The last 15 years refined the phylogeny of the genus at the species level. Especially, the sequence analysis of introns 4 and 5 of translation elongation factor $1 \alpha(t e f 1)$ gene provided the highest resolution to distinguish the species from each other, which resulted in the resolution of this hyperdiverse genus (Jaklitsch 2009, Jaklitsch 2011). Trichoderma species are categorised into different clades (Jaklitsch and Voglmayr 2015). Recently, 12 Trichoderma species that are most frequently observed in nature and belonging to three different Trichoderma sections/clades were also selected to study the evolution of their genome sequences (Kubicek et al. 2019). 
Clade Viride contains some of the most complicated groups of species considering species recognition and distinction (Jaklitsch and Voglmayr 2015). It forms one of the largest and most diverse groups of genus Trichoderma. Bissett (1991a) proposed to include Hypocrea rufa/T. viride and its relatives in section Trichoderma along with T. koningii (Oudem.) and $T$. atroviride (P. Karst.). The monophyly of this group, earlier referred to as section Trichoderma (Kullnig-Gradinger et al. 2002) and recently as clade Viride, was confirmed after DNA sequence analysis of the internal transcribed spacer 1 and 2 (ITS1 and 2) regions, as well as fragments of the actin 1 (act1), calmodulin (call) and tefl genes (Samuels et al. 2002). Since the work of Lieckfeldt et al. (1999) many additional species and cultures referable to clade Viride were obtained and the taxonomy of this clade has also been revised (Jaklitsch et al. 2006). The two large subclades of this clade, Koningii and Viride are treated separately and their composition has changed over time (Jaklitsch et al. 2006, Samuels et al. 2006). Among the species of Viride subclade, warted conidia can be found, while species with verruculose conidia occur in the Koningii subclade. Overall, clade Viride is complex and it contains further subclades, such as the Hamatum/Asperellum subclade, the Rogersonii subclade, the Neorufum subclade and several smaller subclades. Hence, Jaklitsch and Voglmayr (2015) integrated these subclades into clade Viride.

The group of Trichoderma species with green ascospores contain two major clades, the clade Harzianum/Virens and a paraphyletic group containing clades Ceramica, Chlorospora, Spinulosa and several smaller clades, such as Strictipilosa, Gelatinosa (Jaklitsch and Voglmayr 2015, Kubicek et al. 2019). The species of these clades all have green ascospores. Clade Helicum is closely related to this group. Clades Stromaticum (Samuels et al. 2012a) and Semiorbis are small clades and the latter one interestingly contains both species with hyaline and green ascospores.

Polysporum group is paraphyletic and does not form a monophyletic clade therefore it is referred as a group rather than a clade. It is correlated to the Pachybasium core group (Jaklitsch and Voglmayr 2015). Species were added to the former section Hypocreanum and revised several times, which resulted in clade Hypocreanum (Overton et al. 2006a, Overton et al. 2006b, Jaklitsch et al. 2008, Jaklitsch 2011, Kim et al. 2012, Kim et al. 2013, Jaklitsch and Voglmayr 2015). Clade Megalocitrina (Chaverri and Samuels 2003) was revised and named as clade Psychrophila (Jaklitsch and Voglmayr 2015, Kubicek et al. 2019), which contains species with characteristic light- or bright-coloured stromata and white-conidial gliocladiumlike Trichoderma asexual morphs. Clade Brevicompactum was defined by Degenkolb et al. 
(2008a) and augmented by Jaklitsch (2011). The formerly called clade Lutea was renamed as clade Deliquescens due to $T$. deliquescens, the asexual form of $H$. lutea (Jaklitsch 2011).

Section Longibrachiatum was one of the five Trichoderma sections according to Bissett (1984, 1991a, b, c). It forms a monophyletic group phylogenetically separated from the other four Trichoderma sections (Kuhls et al. 1997, Samuels et al. 1998) and has been designated recently as clade Longibrachiatum (Druzhinina et al. 2012). It is one of the evolutionarily youngest clades of the genus (Kubicek et al. 2011) and has the largest number of available whole-genome sequence data. This clade is ecologically highly versatile as it contains prominent opportunistic members including both clinically relevant and ecologically restricted species. Trichoderma longibrachiatum, T. bissettii, T. orientale and T. citrinoviride are opportunistic human pathogens causing infections, mainly in immunocompromised patients (Kuhls et al. 1999, Kredics et al. 2003, Sandoval-Denis et al. 2014, Hatvani et al. 2013). T. longibrachiatum or its transformants have also been suggested for use as biocontrol agents against phytopathogens like Pythium ultimum or members of the Fusarium solani species complex (Migheli et al. 1998, Rojo et al. 2007). T. longibrachiatum and T. orientale are sympatric species but have different reproductive strategies, the former being strictly clonal, whereas the latter recombines sexually (Druzhinina et al. 2008). In 2014, SandovalDenis et al. introduced $T$. bissettii as a new species, which was separated from $T$. longibrachiatum. Later, on the basis of ITS1 and 2, act1, call, tefl, hydrophobin 4 ( hfb4), and RNA polymerase B subunit II (rpb2) sequence analysis, T. bissettii was proposed to be a phylotype of T. longibrachiatum - T. longibrachiatum f. bissetti - instead of a distinct species (Hatvani et al. 2019). The cellulase producer T. reesei is also capable of sexual reproduction (Seidl et al. 2009), whereas its sympatric species T. parareesei is genetically isolated and has a clonal lifestyle (Atanasova et al. 2010, Druzhinina et al. 2010). While T. longibrachiatum and $T$. orientale are cosmopolitan, the related $T$. pinnatum and $T$. aethiopicum are rare and restricted species (Druzhinina et al. 2010). Numerous other species, including T. reesei, T. parareesei, T. pseudokoningii, T. sinense, T. effusum, T. konilangbra, T. andinense or $T$. novae-zelandiae are also geographically restricted (Druzhinina et al. 2012). This clade contains species with ornamented conidia, which only occure here apart from clade Viride (Samuels et al. 1998, Jaklitsch 2011, Samuels et al. 2012b).

Several species form lone lineages or miscellaneous species. Few of them have stable phylogenetic sister group relationship with other large clades, e.g. T. voglmayrii is closely related to clade Viride, while $T$. ghanense, T. capillare, T. andinense, T. effusum and T. 
britdaniae to clade Longibrachiatum (Druzhinina et al. 2012). These species usually do not form green conidia, their conidia are either hyaline or there are no asexual morphs at all ( $T$. peltatum) (Samuels et al. 2011, Jaklitsch et al. 2013).

\subsubsection{Trichoderma species as biocontrol agents}

Trichoderma species can directly attack phytopathogenic fungi through their mycoparasitism, meanwhile promoting plant growth. Their fast growth and quick nutrient uptake also contributes to their aggressive competition (Verma et al. 2007, Chaverri et al. 2015, Degenkolb et al. 2015, Waghunde et al. 2016), therefore they can rapidly colonise soil, which rises them into the group of good biocontrol agents against several pathogenic organisms (Olabiyi and Ruocco 2013, Kushwaha and Verma 2014, Shahid et al. 2014). The most important biocontrol agents are T. harzianum, T. atroviride, T. asperellum, $T$. virens and $T$. viride (Hermosa et al. 2004). Tharzianum is thoroughly studied as biocontrol agent against phytopathogenic fungi, such as $F$. oxysporum, Sclerotinia sclerotiorum and $R$. solani (Lopes et al. 2012, Geraldine et al. 2013, Qualhato et al., 2013, Pereira et al. 2014). The species of clade Viride can be isolated from very diverse sources with a wide geographic distribution (Kredics et al. 2014) and apart from their biocontrol ability, they were also reported as beneficial organisms in industrial, agricultural, and medicinal fields (Verma et al. 2007, Schuster and Schmoll 2010).

\subsubsection{Trichoderma species as the causal agents of green mould disease in mush room cultivation}

Certain Trichoderma species can be harmful to cultivated mushrooms such as Agaricus bisporus and Pleurotus ostreatus, commonly known as the white button mushroom and oyster mushroom, respectively. The production of both crops can be seriously affected by the socalled green mould disease caused by certain members of the mycoparasitic fungal genus Trichoderma such as T. aggressivum, T. pleuroti and T. pleuroticola. T. aggressivum from clade Harzianum/Virens of the genus can be most frequently identified as the causal agent of green mould in the cultivation of A. bisporus (Samuels et al. 2002, Hatvani et al. 2007, Kredics et al. 2010). The dominant green mould agents in the cultivation of P. ostreatus proved to be different from T. aggressivum (Woo et al. 2004, Hatvani et al. 2007, Hatvani et al. 2008), and were described as the new clade Harzianum species T. pleuroticola and T. pleuroti (Park et al. 2006, Komoń-Zelazowska et al. 2007). T. pleuroti - originally incorrectly named as T. pleurotum (Park et al. 2006, Komoń-Zelazowska et al. 2007) - possesses Gliocladium-like conidiophore morphology, which is different from that of the genetically 
closely related other oyster mushroom green mould agent $T$. pleuroticola, showing a Pachybasium-like phenotype (Komon-Zelazowska et al. 2007). Most interestingly, to the best of our knowledge, neither T. aggressivum nor T. pleuroti are known from nature so far, but have only been isolated from mushroom farms, which suggests their specialisation to a yet unknown habitat most likely associated with mushrooms of the order Agaricales.

\subsubsection{Trichoderma species as opportunistic human pathogens}

Trichoderma strains - mostly from the clade Longibrachiatum - have also been reported in an increasing number of cases as etiologic agents in human infections (Hatvani et al. 2013). The patients at risk of Trichoderma infections are usually the immunocompromised transplant recipients, patients undergoing continuos ambulatory peritoneal dialysis, those with haematological malignancies or human immunodeficiency virus (HIV) infection (Hatvani et al. 2013). Out of the strains collected from cases of Trichoderma infections, most of them proved to be $T$. longibrachiatum, while a few of them were $T$. orientale or $T$. citrinoviride. Later, Hatvani et al. (2019) reidentified several clinical samples of T. longibrachiatum and certain strains proved to be $T$. bissettii. All these four species are widely distributed, though $T$. orientale is more often found in warmer, tropical areas, while $T$. citrinoviride has never been found in Africa or the Indian subcontinent (Kubicek et al. 2008). The number of infections caused by Trichoderma species is relatively low, only few hundred cases have been reported (Walsh and Groll 1999, Kredics et al. 2003, Hatvani et al. 2013). However, this can be an underestimated number due to the lack of recognition, as Trichoderma strains detected in clinical specimens are usually considered as mere environmental contaminants. These Trichoderma strains are also present in environmental habitats including agricultural systems therefore they can be potential sources of human infections (Hatvani et al. 2019). The idea to use $T$. longibrachiatum as a biocontrol agent appeared in tropical countries, as these fungi can grow at higher temperature, unlike other Trichoderma species (Zhang et al. 2014, Zhang et al. 2015). However, this raises a high risk of human infections as these strains show intensive growth at $36{ }^{\circ} \mathrm{C}$, which is the human body temperature (Antal et al. 2005). Therefore, instead of using the whole organism, an alternative option could be to use only their metabolites with biocontrol activities.

\subsection{Peptaibols}

A number of economically important secondary metabolites and extracellular enzymes are produced by species of the genus Trichoderma (Sivasithamparam and Ghisalberti 1998, Vinale et al. 2014). Trichoderma species also produce a wide range of bioactive secondary 
metabolites with antibacterial, antifungal, and antiviral properties, including a unique peptide group of antibiotics, the peptaibols (Reino et al. 2008). Although these peptide-type molecules are known from other organisms as well, most of them are produced by this genus or by species from closely related genera, such as Stilbella, Gliocladium or Acremonium (Jaworski and Brückner 2001, Degenkolb et al. 2003).

\subsubsection{Structure}

Peptaibols are short peptides, usually 5-20 amino acid residues long, with characteristic molecular weight falling into the range 500-2200 Da, linear sequences and various types of bioactivity (Toniolo and Brückner 2009, Neumann et al. 2015). Characteristic residues of peptaibols include $\alpha$-aminoisobutyric acid (Aib) and isovaline, as well as acetylated $\mathrm{N}$ terminus and 1,2-amino alcohols such as Leuol, Valol, Pheol, Tyrol, Ileol, Alaol, and Prool at the C-terminus (Degenkolb et al. 2008a, Stoppacher et al. 2013, Neumann et al. 2015). Many peptaibol sequences contain an Aib-Pro bond in the middle of the peptide chain, which appears to be the most often fragmented bond in investigations using high-performance liquid chromatography (HPLC) mass spectrometry (MS) instruments. The name 'peptaibol' is formed from the word peptide and the two most characteristic residues, Aib and the Cterminal amino alcohol (Benedetti et al. 1982, Brückner and Graf 1983).

\subsubsection{Biosynthesis}

The sequences of peptaibols usually contain non-proteinogenic amino acids, and large modular enzymes known as non-ribosomal peptide synthetases (NRPSs) assemble them from a remarkable range of precursors by the multiple carrier thiotemplate mechanism (Marahiel 1997, Marahiel et al. 1997, May et al. 2002, Degenkolb et al. 2003, Degenkolb et al. 2007, Bushley and Turgeon 2010). In the case of NRPSs, a single large protein is responsible for the activation, incorporation and elongation of the peptides. Each NRPS module is a semiautonomous unit capable of recognizing, activating and modifying a single amino acid residue. The individual modules consist of distinct domains: (1) adenylation domain for selection and activation of amino acid monomers, (2) thiolation domain for transferring the monomers/growing chain to various catalytic sites and (3) condensation domains for catalysing the formation of peptide bonds, which together represent a minimal repeating unit of NRPSs (Marahiel 1997, Marahiel et al. 1997). NRPSs can also incorporate nonproteinogenic residues, thus increasing the chemical diversity of the products. The lack of specificity of the recognition sites and the three-dimensional structure of the enzyme enable the acceptance of closely related residues (such as valine/isovaline: Vxx vs. 
leucine/isoleucine: Lxx). Consequently, the number of positionally isomeric and homologous peptaibols biosynthesised by a single NRPS can be large. The repair mechanisms, which usually operate during biosynthesis, are also absent in NRPS pathways herewith further increasing the variability of the products (Marahiel 1997, Marahiel et al. 1997). The first Trichoderma NRPS was texl described from T. virens (Wiest et al. 2002).

\subsubsection{Classification}

Peptaibols can be classified based on their length and chemical characteristics into the following three subclasses (Rebuffat et al. 2000). Long-sequence peptaibols consist of 18-20 residues with high Aib content, short peptaibols are 11-16 residues long with several AibPro-Xaa-Xaa motives and lipopeptaibols contain 7-11 residues with high Gly content and an N-terminus acylated by a short lipid chain instead of the acetyl group (Rebuffat et al. 2000). In 2001, Chugh and Wallace also categorised all the peptaibols known that time (more than 200) into subfamilies (SFs) based on the alignments of the sequences. In total, 9 SFs were introduced. SF1 is the largest SF, which contains long peptaibols between the length of 17 and 20 residues. The characteristics of the sequences belonging here are the presence of Gln mostly at the $6^{\text {th }}$ or $7^{\text {th }}$ positions, Aib-Pro bonds near the middle of the sequences and Gln or Glu at the $18^{\text {th }}$ or $19^{\text {th }}$ positions. All sequences belonging to this group can be characterised with the frequent occurrence of Aib, indicating that these molecules often form $\alpha$-helical structures. SF2 contains around 30 compounds, which are the most similar to the peptaibols belonging to SF1. They are shorter peptaibols, consisting of 14-16 residues, still classified to the group of long peptaibols. They have aromatic residues (Phe) at both termini. They all have high Aib content, and Gly and Gln residues conserved in positions 6 and 11, respectively. A crucial difference of this group from SF1 is that the sequences contain Pro or Hyp in both the $10^{\text {th }}$ and $13^{\text {th }}$ positions. The closely related SF3 contains sequences with 2 characteristic differences from the members of SF2: (1) the $6^{\text {th }}$ position is conserved and always contains Thr, (2) and Gly residues are absent from all the sequences. SF4 is completely different from the other SFs and contains either 11- or 14-residue-long peptaibols. The $2^{\text {nd }}$ position always contains Gln or Asn. The 11-residue-long members contain Pro at positions 9 and 13, while the 14-residue-long peptaibols contain one more Pro at the $5^{\text {th }}$ position. Furthermore, no aromatic amino acids or charged residues are present in the sequences of this group. SF5 contains short peptaibols with either 7 or 11 residues. Their sequences never contain Pro, Gln or any charged residues, but many Gly. SFs 6, 7, 8 and 9 are extremely small with only few members. SF6 peptaibols were considered as long peptaibols because the sequences are 15- 
residue-long, while SF7 peptaibols are only 11-residue-long, belonging to the short peptaibols. SF 8 and 9 could not fit into any other group. SF 8 contains Clonostachin, which is 14-residue-long (Chikanishi et al. 1997), while SF9 contains the smallest peptaibol with 5 residues, peptaibolin (Hülsmann et al. 1998).

\subsubsection{Biological activity}

Peptaibols are membrane-active compounds forming several hydrophobic transmembrane helices surrounding a central pore with the ability to aggregate and establish ion channels in lipid bilayer membranes (Duclohier 2004). They usually show bioactivity against bacteria and fungi. Several studies have reported that Gram-positive bacteria are more sensitive to membrane active compounds than Gram-negative bacteria (Brückner and Graf 1983, Lorito et al. 1996a, Benítez et al. 2004). The key variances between the two types of bioactivity rely on the difference of their cell walls. Yeasts are less sensitive against peptaibols than Grampositive bacteria or filamentous fungal cultures (Song et al. 2006). In the antagonistic property of Trichoderma species against phytopathogenic fungi, the production of secondary metabolites such as peptaibols plays a substantial role (Schirmböck et al. 1994, Howell 2003, Benítez et al. 2004, Küçük and Kivanç 2004). Also, synergism between peptaibols and the inhibition of the $\beta$-1,3-glucan synthase could inhibit the re-synthesis of $\beta$-glucans of the host cell wall and sustain the disruptive action of $\beta$-glucanases, which resulted in an enhanced fungicidal activity (Lorito et al. 1996b). Antiviral activity of peptaivirins A and B has also been reported against tobacco mosaic virus infection of tobacco plants (Yun et al. 2000). Nagaraj et al. (2001) reported also antimalarial properties of peptaibols.

Trichoderma species also interact with plants through secondary metabolites. Although several studies reported positive effects of Trichoderma species on the physiological and biochemical responses of plants (Contreras-Cornejo et al. 2016), inhibition of plant growth and primary root development of their secondary metabolites have also been described (Rippa et al. 2010, Shi et al. 2016). Peptaibols can also induce plant defence reactions through salicylate signal pathway, which may lead to systemic acquired resistance (Engelberth et al. 2001, Howell 2003, Harman et al. 2004, Brunner et al. 2005). The most thoroughly investigated model plant, Arabidopsis thaliana, is frequently used to test the bioactivity of the secondary metabolites of Trichoderma species (Kottb et al. 2015). Peptaibols can induce auxin production and disruption of the auxin response gradient in root tips of Arabidopsis (Shi et al. 2016). Alamethicin (ALM) was shown to induce resistance in plants (Engelberth et al. 2000, Engelberth et al. 2001, Maischak et al. 2010, Li et al. 2016), but can also be toxic 
causing lesions on Arabidopsis leaves (Rippa et al. 2010). However, it should also be considered that the commercially available ALM mixture (Sigma-Aldrich A4665) may also contain the trichothecene-type mycotoxin harzianum A produced by the T. brevicompactum strain used for ALM fermentations (Degenkolb et al. 2006a).

Peptabiobls were also tested on animals, such as insect larvae, shrimps, mussels and mice (Hou et al. 1972, Ritieni et al. 1995, Sallenave et al. 1999, Landreau et al. 2002). Peptaibols produced by $T$. koningii (isolated from shellfish) injected into the last abdominal segment of blowfly (Phormia terrae novae) larvae could immobilize them (Landreau et al. 2002). ALM induced changes in the microenvironment of rat lung particulate guanylate cyclase, which resulted in an increased activity (Lad and White 1979). Trichotoxin A proved to be much less toxic to mice by oral administration, than intraperitoneal injection (Hou et al. 1972). Mice fed with $600 \mathrm{mg} \mathrm{kg}^{-1}$ toxin could be maintained even for 4 months under standard conditions with no discernible effects, which was remarkably higher than the lethal intraperitoneal $4.36 \mathrm{mg}$ $\mathrm{kg}^{-1}$ dose. The lack of oral toxicity can be explained either with detoxification by the digestive system or the failure of the toxin to be transported across the intestinal wall (Hou et al. 1972). The neuroleptic activity of peptaibols was also investigated (Berg et al. 2003). Peptaibols could damage the cell membrane of mammalian cell cultures, such as boar spermatozoa and human lung epithelial carcinoma cells (Peltola et al. 2004). Antitumor activity of peptaibols of Culcinomyces clavisporus was also studied by $\mathrm{He}$ et al. (2006). Certain peptaibols showed effect on membrane-bound enzymes, activation of guanylate cyclases or inhibition of adenylate cyclases (Lad and White 1979, Sulakhe and Höehn 1984, Szekeres et al. 2005). Altogether, majority of their bioactivity is the consequence of their pore-forming ability in the cell membrane which results in leakage and cell death.

\subsubsection{ALM, the most studied peptaibol}

The most thoroughly studied peptaibol, ALM (Nagaraj and Balaram 1981, Mathew and Balaram 1983, Mak and Webb 1995, Futaki and Asami 2007, Woolley 2007, Kredics et al. 2013, Forbrig et al. 2018, Tyagi et al. 2019a) was reported first in 1967 and identified from the fermentation broth of ' $T$. viride' NRRL 3199 (Meyer and Reusser 1967). This strain was later reidentified as $T$. arundinaceum, a species belonging to clade Brevicompactum (Degenkolb et al. 2008b). T. brevicompactum, T. protrudens and T. turrialbense - all belonging to clade Brevicompactum - are also capable of producing ALM compounds (Degenkolb et al. 2006a, Degenkolb and Brückner 2008). The first attempt to identify the primary structure of ALM resulted in a cyclic compound (Payne et al. 1970). Later, the 
structure of a linear peptide was confirmed by using nuclear magnetic resonance (NMR) spectroscopy, which also detected the acetylated N-terminus and the C-terminal Pheol, although incorrectly as a sidechain of Gln18 (Martin and Williams 1976). Based on retention factor values in thin layer chromatography, the group of ALMs is composed of two major subgroups, the acidic and the neutral group distinguished by Glu/Gln18 exchange and named ALM F30 (85\%) and ALM F50 (12\%), respectively, and an additional minor component (ALM F20) (Kirschbaum et al. 2003, Degenkolb et al. 2007). T. arundinaceum produces both ALM F30 and F50 compounds depending on the media used for fermentation. The main difference between them is the amino acid exchange of the acidic Glu18 and the neutral Gln18 residues, respectively. Moreover, some further groups of ALM (ALM-F40, ALM-F60 and ALM-F70) were also recognised by thin layer chromatography in low concentrations (Melling and McMullen 1975). ALMs consist of 20 amino acids with the characteristics of long peptaibols or SF1 peptaibols. ALM compounds are available from several companies. The original material of ALM F30 (U-22,324) was released by Upjohn Company and contains equal proportions of ALM F30/3 and ALM F30/7 (Meyer and Reusser 1967). ALM from Sigma-Aldrich (A4665) contains a mixture of 4 compounds of ALM F50. The product of Fluka (product No. 05125) contains $75 \%$ of ALM F50/5 and further minor components of ALM. 


\section{AIMS}

Along with the increasing number of described Trichoderma species, the chances to find novel, yet undescribed peptaibol compounds or even new peptaibol families are promising. Furthermore, peptaibols are bioactive compounds, they can play role in interactions with phytopathogens or during the infection of mushroom crops or humans, therefore the changes in the peptaibol profiles and their bioactivities are important to study. During this work we intended to focus on the following topics:

- Optimization of the HPLC-MS to identify peptaibol compounds

- Investigation of the peptaibol production of Trichoderma species with potential biocontrol abilities

- Investigation of the peptaibol production of Trichoderma species causing green mould disease of cultivated mushrooms

- Comparative investigation of the peptaibol profiles of species from the clinically relevant clade Longibrachiatum

- Examination of the bioactivity of peptaibols on bacteria, fungi, plants and mammalian cells 


\section{MATERIALS AND METHODS}

\subsection{Strains and culture conditions}

All strains used in this study were obtained from the Szeged Microbiological Collection (SZMC, http://www.wfcc.info/ccinfo/collection/by_id/987, Szeged, Hungary). Those Trichoderma species were selected from the literature, which were not investigated for their peptaibol production before (Table 1). Two strains belonging to clade Viride, T. gamsii SZMC 1656 and T. koningiopsis SZMC 12500, were identified by Nucleotide BLAST analysis (https://blast.ncbi.nlm.nih.gov/Blast.cgi) of a fragment of the tefl gene amplified according to Castagnoli et al. (2018a), and proved to be very closely related to T. gamsii S582 (GenBank accession number: KJ665495) and T. koningiopsis UNISS 17b-36a (GenBank accession number: EF488124), respectively. Two strains known to cause green mould infections of cultivated mushrooms were also included in our studies, strain T. aggressivum $\mathrm{f}$. europaeum CBS 433.95 (SZMC 1811) and strain T. pleuroti TPhul (SZMC 12454). Nevertheless, 22 strains from 17 Trichoderma species belonging to clade Longibrachiatum were also obtained from the TU Collection of Industrially Important Microorganisms (TUCIM, www.vt.tuwien.ac.at/tucim/, Vienna, Austria) and from the SZMC for the investigation of their peptaibol production (Table 1). All the selected strains were maintained on yeast extract - glucose agar medium $\left(5 \mathrm{~g} \mathrm{l}^{-1}\right.$ glucose, $1 \mathrm{~g} \mathrm{l}^{-1}$ yeast extract, $5 \mathrm{~g}^{-1} \mathrm{KH}_{2} \mathrm{PO}_{4}$, $20 \mathrm{~g}^{-1}$ agar in distilled water). For peptaibol production, the strains were inoculated on malt extract agar (MEA) medium (30 $\mathrm{g}^{-1}$ malt extract, $3 \mathrm{~g} \mathrm{l}^{-1}$ soy peptone, $15 \mathrm{~g}^{-1}$ agar in distilled water) and incubated for 7 days at $25{ }^{\circ} \mathrm{C}$. The strains used for confrontation and toxicity tests, A. bisporus SZMC 23395, P. ostreatus SZMC 23392, Candida boidinii SZMC 0673, Kluyveromyces lactis SZMC 0683, Saccharomyces cerevisiae SZMC 0425, Schizosaccharomyces pombe SZMC 0142, A. alternata SZMC 16085, Aspergillus fumigatus SZMC 23245, F. falciforme SZMC 11407, F. keratoplasticum SZMC 11414, F. solani species complex SZMC 11467, $R$. solani SZMC 6252J, Phoma cucurbitacearum SZMC 16088 were maintained on MEA supplemented with yeast extract $\left(2.5 \mathrm{~g}^{-1}\right.$ yeast extract, $5 \mathrm{~g}$ $1^{-1}$ malt extract, $10 \mathrm{~g} \mathrm{l}^{-1}$ glucose, $20 \mathrm{~g} \mathrm{l}^{-1}$ agar in distilled water, $\mathrm{pH} \mathrm{6.5).} \mathrm{Escherichia} \mathrm{coli}$ SZMC 0582, Micrococcus luteus SZMC 0264, Pseudomonas aeruginosa SZMC 0568 and Staphylococcus aureus SZMC 0579 were maintained on Luria-Bertani (LB) agar medium (10 $\mathrm{g} \mathrm{l}^{-1}$ tryptone, $5 \mathrm{~g} \mathrm{l}^{-1}$ yeast extract, $10 \mathrm{~g} \mathrm{l}^{-1} \mathrm{NaCl}$ and $20 \mathrm{~g} \mathrm{l}^{-1}$ agar in distilled water). To increase peptaibol production, Trichoderma strains were inoculated on large $(40 \times 40 \mathrm{~cm})$ MEA plates and incubated for 7 days at $25^{\circ} \mathrm{C}$. 
TABLE 1 | Trichoderma strains involved in this study

\begin{tabular}{|c|c|c|c|c|c|}
\hline SZMC identifier & Other identifier & Clade / Subclade & Species & Origin & Reference \\
\hline 1811 & CBS 433.95 & Harzianum/Virens & $\begin{array}{l}\text { T. aggressivum } \mathrm{f} . \\
\text { europaeum }\end{array}$ & A. bisporus compost, Northern Ireland, UK, (1991) & Samuels et al. 2002 \\
\hline 12454 & TPhu1 & Harzianum/Virens & T. pleuroti & $\begin{array}{l}\text { wheet straw of } P \text {. ostreatus cultivation, Kecskemét, } \\
\text { Hungary }\end{array}$ & Marik et al. 2017 \\
\hline 12500 & TWA3a/7 & Viride / Koningii & T. koningiopsis & A. bitorquis natural substrate, Szeged, Hungary & Castagnoli et al. $2018 \mathrm{a}$ \\
\hline 1656 & R19 & Viride / Viridescens & T. gamsii & Wheet rhizosphere, Rúzsa, Hungary & Castagnoli et al. 2018a \\
\hline 1773 & CECT 2412 & Longibrachiatum / Orientale* & T. bissettii** & Mushroom compost, Wales & Druzhinina et al. 2008 \\
\hline 1775 & CECT 2937 & Longibrachiatum / Orientale* & T. longibrachiatum & Antarctica & Kuhls et al. 1997 \\
\hline 1776 & CECT 20105 & Longibrachiatum / Orientale* & T. bissettii ${ }^{* *}$ & Biocontrol strain, Egypt & Antal et al. 2005 \\
\hline 12546 & UAMH 7956 & Longibrachiatum / Orientale* & T. bissettii ${ }^{* *}$ & Bone marrow transplant recipient, lung tissue & $\begin{array}{l}\text { Richter et al. } 1999, \\
\text { Druzhinina et al. } 2008\end{array}$ \\
\hline 12556 & UAMH 9573 & Longibrachiatum / Orientale* & T. orientale & Peritoneal catheter tip, Canada & Kredics et al. 2003 \\
\hline 22602 & TUCIM 1817 & Longibrachiatum / Orientale* & T. aethiopicum & Coffea arabica rhizosphere, Jimma, Ethiopia & Druzhinina et al. 2008 \\
\hline 22603 & TUCIM 3421 & Longibrachiatum / Orientale* & T. pinnatum & Sri Lanka & Samuels et al. $2012 b$ \\
\hline 22614 & TUCIM 917, QM6a & Parareesei / Reesei* & T. reesei & canvas of US army, Solomon Islands & Reese et al. 1950 \\
\hline 22616 & QM9414 & Parareesei / Reesei* & T. reesei & Mutant of QM9123 (which is mutant of QM6a) & Kuhls et al. 1996 \\
\hline 22617 & QM9414 G24lae1 & Parareesei / Reesei* & T. reesei & lae1 null mutant (4lae1) of T. reesei QM9414 & Seiboth et al. 2012 \\
\hline 22615 & TUCIM 661 & Parareesei / Reesei* & T. parareesei & Subtropical rain forest, Iguazu Falls, Argentina & Atanasova et al. 2010 \\
\hline 22606 & TUCIM 1267 & Saturnisporum* & T. saturnisporum & Italy & Samuels et al. $2012 \mathrm{~b}$ \\
\hline 22607 & TUCIM 132 & Konilangbra / Sinensis* & T. konilangbra & Uganda & Samuels et al. 1998 \\
\hline 22608 & TUCIM 3350 & Konilangbra / Sinensis* & T. flagellatum & Coffea arabica rhizosphere, Ethiopia & Belayneh Mulaw et al. 2010 \\
\hline 22609 & TUCIM 527 & Konilangbra / Sinensis* & T. sinensis & Taiwan & Bissett et al. 2003 \\
\hline 22618 & SJ40 & Citrinoviride / Pseudokoningii* & T. citrinoviride & Office bookshelf, settled dust, Espoo, Finland & Castagnoli et al. 2018a \\
\hline 22613 & TUCIM 1277 & Citrinoviride / Pseudokoningii* & T. pseudokoningii & the bark of Beilschmiedia tawa & Samuels et al. 1998 \\
\hline 22612 & TUCIM 4158 & $\begin{array}{l}\text { Novae-zelandiae / } \\
\text { Saturnisporopsis* }\end{array}$ & T. novae-zelandiae & native Notophagus forest, New Zealand & Samuels et al. 1998 \\
\hline 22604 & TUCIM 2057 & lone lineage & T. ghanense & Agaricus compost, Hungary & Hatvani et al. 2007 \\
\hline 22605 & TUCIM 2883 & lone lineage & T. capillare & Wall of a mushroom growing cellar, Hungary & Hatvani et al. 2007 \\
\hline 22610 & TUCIM 1291 & lone lineage & T. andinense & Venezuela, high elevation & Samuels et al. 1998 \\
\hline 22611 & TUCIM 254 & lone lineage & T. effusum & Soil isolation, Himalaya, India & Bissett et al. 2003 \\
\hline
\end{tabular}

* Subclades were defined based on Samuels et al. (2012b). ** Proposed as T. longibrachiatum f. bissettii (Hatvani et al. 2019) 


\subsection{Peptaibol extraction}

After 7 days of incubation on MEA, peptaibols were extracted from the cultures with chloroform $(3 \times 5 \mathrm{ml}$ per Petri dish) for identification of the compounds produced. Crude extracts were evaporated to dryness on a rotary evaporator (IKA RV 10, IKA Works, USA), then dissolved in $1.5 \mathrm{ml}$ methanol (analytical reagent grade, VWR International, Hungary) and centrifuged $(10000 \times \mathrm{g}$ for $10 \mathrm{~min})$ in a Biofuge Primo (Heraeus, Germany) to remove the insoluble particles from the solutions. Finally, the crude extracts were evaporated under nitrogen blow down, re-suspended in methanol $(200 \mu \mathrm{l})$ and stored at $-20{ }^{\circ} \mathrm{C}$. Peptaibols were directly extracted also from the surface of in vitro confrontation plates $(n=3$, see below) with chloroform $(3 \times 5 \mathrm{ml})$. Extracts were evaporated and re-dissolved in methanol $(1 \mathrm{ml})$ in order to pellet the insoluble residues. Finally, the supernatants were collected, evaporated and dissolved in $200 \mu 1$ methanol (HPLC grade, VWR International, Hungary).

From the large plates, after 7 days of incubation of the strains on MEA medium, mycelium of the cultures was harvested and collected. Then, $300 \mathrm{ml}$ chloroform/methanol (analytical reagent grade, VWR International, Hungary) 2/1 (v/v) solution was added, and the mixture was shaken for $2 \mathrm{~h}$ (100 rpm). The lower phase was collected and evaporated to dryness (IKA RV 10, IKA Works, Wilmington, NC, USA). The extraction steps were repeated three times in total. After the extraction, the dry residue was dissolved in methanol (HPLC grade, VWR International, Hungary), centrifuged $(10000 \times \mathrm{g}$ for $10 \mathrm{~min})$ in a Biofuge Primo centrifuge (Heraeus, Hanau, Germany) and stored at $-20{ }^{\circ} \mathrm{C}$. The samples were diluted $100 \times$ for HPLCMS analysis and set to $100 \mathrm{mg} \mathrm{ml}^{-1}$ for inhibition tests.

\subsection{Peptaibol purification}

The extracted crude samples were purified on a Flash chromatograph (CombiFlash EZ Prep UV-VIS Teledyne Isco). The peptaibol compounds could not be separated from each other, but this method resulted in a pure mixture containing only the peptaibol compounds with the same rate of the compounds as in the original crude extracts. The cartridge (CombiFlash EZ Prep) was filled with $60 \mathrm{~cm}^{3}$ silica $(30-40 \mu \mathrm{m})$, and $1.5 \mathrm{~g}$ of crude peptaibol extract was applied above the septum. The flow rate was set to $35 \mathrm{ml} \mathrm{min}^{-1}$ and the wavelength of the UV detector to 270/320 nm. Solvents A and B were chloroform and methanol (HPLC grade, VWR International, Hungary), respectively (gradient solvent B: $0 \%-0 \mathrm{~min}, 0 \%-5 \mathrm{~min}$, $100 \%-15 \mathrm{~min}, 100 \%$ - $18 \mathrm{~min}$ ). Fractions were automatically collected into collector tubes $(18 \times 180 \mathrm{~mm}, 30 \mathrm{ml})$ based on the slope of the UV signal. Fractions were evaporated, 
dissolved in methanol (100 $\mathrm{mg} \mathrm{ml}^{-1}$, HPLC-MS grade, VWR International, Hungary) and stored at $-20{ }^{\circ} \mathrm{C}$. The purity of the samples was checked by HPLC-MS as described by Van Bohemen et al. (2016). For this analysis, a calibration curve was prepared from the integrated peaks area of all $\mathrm{y}_{7}$-ion fragments of the ALM mixture (Sigma-Aldrich A-4665, Hungary), which was dissolved in methanol (HPLC-MS grade, VWR International, Hungary) in different concentrations. After this, the summarized integrated peaks area of all the appearing $\mathrm{y}_{7}$-ion fragments of the purified samples were compared to this calibration curve.

\subsection{Analytical procedures and data analysis}

HPLC parameters after the optimization of the system: Agilent 1100 system (Agilent Technologies, Palo Alto, CA, USA) controlled by a ChemStation software (A09.03, Agilent Technologies, Palo Alto, CA, USA) and equipped with a binary pump, a vacuum degasser and a $\mu$ Well-plate autosampler as well as a Jones Model 7990 Space column heater (Jones Chromatography Ltd., Lakewood, CO, USA), Gemini NX-C18 HPLC column $(150 \mathrm{~mm} \times 2.0$ $\mathrm{mm}, 3 \mu \mathrm{m}$, Phenomenex Inc., Torrance, CA, USA), guard column with the same phase (C18), Solvent A: $\mathrm{H}_{2} \mathrm{O}$ (Gradient A10) with $0.05 \%$ (v/v) trifluoroacetic acid, Solvent B: acetonitrile/methanol (HPLC-MS grade, VWR International, Hungary) 1/1 (v/v) with 0.05\% (v/v) trifluoroacetic acid (HPLC-MS grade, VWR International, Hungary), flow rate: $0.2 \mathrm{ml}$ $\min ^{-1}$, gradient program for Solvent B: $65 \%-0 \mathrm{~min}, 65 \%-5 \mathrm{~min}, 80 \%-45 \mathrm{~min}, 100 \%-70$ $\min , 100 \%-75 \mathrm{~min}, 65 \%-76 \mathrm{~min}, 65 \%-81 \mathrm{~min}$, column temperature: $40{ }^{\circ} \mathrm{C}$, injection volume: $5 \mu$ l. Electrospray ionization (ESI) - ion trap (IT) - MS parameters: Varian $500 \mathrm{MS}$ (Agilent Technologies, Palo Alto, CA, USA) with ESI source in positive mode at normal scan speed controlled by the 500-MS Mass Spec module driver of the Varian Workstation software (6.6/SP1, Varian Inc., Palo Alto, CA, USA), ESI parameters: spray chamber temperature 50 ${ }^{\circ} \mathrm{C}$, drying gas $\left(\mathrm{N}_{2}\right)$ pressure $30 \mathrm{psi}$, drying gas temperature $350{ }^{\circ} \mathrm{C}$, nebulizer gas $\left(\mathrm{N}_{2}\right)$ pressure $50 \mathrm{psi}$, needle voltage $5704 \mathrm{~V}$, spray shield voltage $600 \mathrm{~V}$, General parameters: maximum scan times 2.78, $2 \mu$ Scans averaged, data rate $0.36 \mathrm{~Hz}$, multiplier offset 0 . Ionization control parameters: target total ion chromatogram (TIC) 100\%, max ion time 250 $000 \mu \mathrm{s}$, Scan parameters: capillary voltage $66 \mathrm{~V}$, RF loading 147\%, MS scan parameters: Low mass $m / z$ 200, High mass $m / z$ 2000, $\mathrm{MS}^{2}$ measurements of selected $\mathrm{y}_{6}$ and $\mathrm{y}_{7}$ fragments were carried out with the following excitation storage level $(\mathrm{m} / \mathrm{z}) /$ excitation amplitude (V) conditions: $m / z 612.3$ (170.1/2.42), $\mathrm{m} / \mathrm{z} 626.3$ (173.4/2.47) $\mathrm{m} / \mathrm{z} 660.4$ (181.5/2.60), $\mathrm{m} / \mathrm{z} 674.4$ (184.9/2.65), $\mathrm{m} / \mathrm{z} 754.5$ (204.5/2.95), $\mathrm{m} / \mathrm{z} 755.5$ (204.8/2.96) $\mathrm{m} / \mathrm{z} 768.5$ (208.0/3.00), $\mathrm{m} / \mathrm{z}$ 
$769.5(208.3 / 3.00), \mathrm{m} / \mathrm{z}$ of $774.4(209.4 / 3.02), \mathrm{m} / \mathrm{z}$ of $775.4(209.7 / 3.03), \mathrm{m} / \mathrm{z}$ of 788.4 (212.9/3.08), and $m / z$ of $789.4(213.2 / 3.08)$.

From the year 2019, the initial Varian 500MS data were further confirmed by a newly acquired HPLC-Orbitrap-MS: Dionex UltiMate 3000 system (Thermo Scientific, CA, USA), which was controlled by the Xcalibur 4.2 software (Thermo Scientific, CA, USA) and equipped with a quaternary pump, a vacuum degasser, an autosampler and a column heater. Gemini NX-C18 HPLC column $(50 \times 2.0$ mm, $3 \mu \mathrm{m}$, Phenomenex Inc., Torrance, CA, USA) was used for the separation with a guard column containing the same phase (C18). Solvent A was $\mathrm{H}_{2} \mathrm{O} /$ methanol/acetonitrile (HPLC-MS grade, VWR International, Hungary) 8/1/1 with $10 \mathrm{mM}$ ammonium-acetate (HPLC-MS grade, VWR International, Hungary) and $0.1 \%$ (v/v) acetic acid (HPLC-MS grade, VWR International, Hungary), while solvent B was acetonitrile/methanol 1/1 (v/v) with $10 \mathrm{mM}$ ammonium-acetate and $0.1 \%(\mathrm{v} / \mathrm{v})$ acetic acid. The flow rate was set to $0.2 \mathrm{ml} \mathrm{min}^{-1}$ and the gradient program for Solvent B was $10 \%-0$ $\min , 10 \%-2 \min , 78 \%-3 \min , 89 \%-16 \min , 95 \%$ - $16.5 \min , 95 \%-19.5 \min , 10 \%-20$ $\min , 10 \%-24 \mathrm{~min}$. The column temperature was kept at $30{ }^{\circ} \mathrm{C}$ and the injection volume was $5 \mu$ l. An Orbitrap-MS, Thermo Scientific Q Exactive Plus (Thermo Scientific, CA, USA) with heated ESI source in positivemode controlled by Xcalibur 4.2 software (Thermo Scientific, CA, USA) was used for the MS measurements. Heated ESI parameters: spray voltage $3 \mathrm{kV}$, sheath gas flow rate 30 arbitrary units, aux gas flow rate 15 arbitrary units, capillary temperature $350{ }^{\circ} \mathrm{C}$, aux gas heater $250{ }^{\circ} \mathrm{C}$. The acquisition mode was Full-MSddMS ${ }^{2}$. FullMS paramteres: resolution 70,000 at $\mathrm{m} / \mathrm{z} 200$, AGC target 3e6, maximum injection time 100 ms, scan range 350-2200 m/z. The ddMS ${ }^{2}$ parameters: fixed first scan at $m / z$ 80, resolution 17500 at $\mathrm{m} / \mathrm{z} 200$, AGC target 1e6, maximum injection time $50 \mathrm{~ms}$, isolation window $1 \mathrm{~m} / \mathrm{z}$, collusion energy $30 \mathrm{NCE}$. The minimum AGC target for ddMS ${ }^{2}$ triggering was $1 \mathrm{e} 5$.

Based on a calibration with ALM standard (Sigma-Aldrich A-4665, Hungary), the peptaibol contents of the crude extracts were also calculated based on the method explained in paragraph 5.3. To avoid false results due to the eventual harzianum A contamination of the ALM standard solution, its detection was carried out based on a previous article (Nielsen et al. 2005). The flow rate was set to $0.2 \mathrm{ml} \mathrm{min}^{-1}$ on a Phenomenex Gemini $50 \times 2 \mathrm{~mm}, 3 \mu \mathrm{m}$ HPLC column, which was attached to a guard column containing the same phase (C18). The column heater was set to $30{ }^{\circ} \mathrm{C}$ and the injection volume was $5 \mu$ l. An Orbitrap-MS detector was attached to the HPLC system and the parameters were set according to the Orbitrap MS 
parameters described above. The measurements ran in negative ionization mode, the spray voltage was set to $-3 \mathrm{kV}$.

Peptaibol profiles of individual strains were analyzed using cluster analysis in the ClustVis web tool (Metsalu and Vilo 2015), and a heat map was constructed using the complete linkage and Euclidian distance settings applied to the columns (strains).

\subsection{Nomenclature of the identified peptaibols}

As no amino acid analysis was carried out for the determination of the Val/Iva and Leu/Ile isomers, the $\mathrm{Vxx} / \mathrm{Lxx}$ nomenclature was used for the peptaibol sequences.

The novelty of the sequences was validated according to the "Comprehensive Peptaibiotics Database" (Stoppacher et al. 2013). The former online resource (Neumann et al. 2015) is unavailable since the autumn of 2017, therefore the latest offline version of the "Peptaibiotics Database", which was kindly provided by Prof. Rainer Schuhmacher, and PubMed searches of publications since 2017 were also performed with the keyword "peptaibol."

The newly identified peptaibol compounds obtained from $T$. gamsii SZMC 1656 were named according to their elution order (I, II, ... n), attached to the prefix 'Pept'. In the case of compounds eluting close to each other and differing in their characteristic ion fragments $\left(b_{12}\right.$ and $\mathrm{y}_{7}$ ), Latin letters ( $\mathrm{a}$ and $\mathrm{b}$ ) are following the Roman numerals. The sequences obtained from T. koningiopsis SZMC 12500 were named koningiopsins and numbered with Roman numerals (I, II, ... n) based on the elution order, and the different variants are distinguished by Latin letters ( $\mathrm{a}$ and $\mathrm{b}$ ) as mentioned before (Marik et al. 2018).

The hypomurocin B-like compounds were named according to the following three descriptive characters of the peptaibols: molar mass, the y-ion part after the fragmentation of the most unstable Aib-Pro bond ( $\mathrm{a}$ or $\mathrm{b}$ ) and the elution order of the compounds $(1,2, \ldots \mathrm{n})$, attached to 'Pept'. Tripleurins were named with Roman numerals according to their elution order. Where the difference between compounds was detected only in the retention time, suggesting that the compounds differ in the isoforms of amino acids at certain positions with Vxx or Lxx, Latin letters (a, b, c) were added after the Roman numerals (Marik et al. 2017).

All the peptaibol compounds produced by the species of clade Longibrachiatum were named according to the group to which they belong to (A or B) and the elution order of the compounds on the HPLC-Varian MS system (I, II, .., n), appended to "Pept." Compounds with the same retention time but different sequences were considered as variants and named 
with small latin letters ( $a, b, \ldots, n$, in decreasing order of amount the variants were produced). Group C peptaibols were named as brevicelsins and numbered according to their elution order (Marik et al. 2019).

\subsection{Testing the effect of peptaibol extracts on bacteria and yeasts}

For activity tests with bacteria, LB agar medium was prepared. The plates contained $20 \mathrm{ml}$ media LB agar medium as base. Bacteria $\left(10^{5}\right.$ cells per plates) from fresh cultures were mixed into $5 \mathrm{ml}$ covering agar (LB with $10 \mathrm{~g}^{-1}$ agar) at $40{ }^{\circ} \mathrm{C}$ and poured onto the surface of the basal medium. Fifty $\mu 1$ amounts of the methanolic extracts of the peptaibol extracts were filled into holes ( $5 \mathrm{~mm}$ in diameter) bored into the agar plates. The diameters of the inhibition zones were recorded after 2 days of incubation at $37{ }^{\circ} \mathrm{C}$. The same protocol was used for the inhibition assays with yeasts but using MEA medium supplemented with yeast extract. A 10step 2-fold dilution series of the $100 \mathrm{mg} \mathrm{ml}^{-1}$ crude peptaibol extracts - which were also examined for their peptaibol composition - were tested, with methanol as control. The yeast cultures were incubated at $25{ }^{\circ} \mathrm{C}$. Photographs were taken with a Nikon Coolpix S2600 camera after 2 days of incubation. Three parallel experiments were set up to measure the inhibition zones.

\subsection{Testing the effect of peptaibol extracts on filamentous fungi}

MEA medium supplemented with yeast extract was used for the inhibition tests with filamentous fungi. Agar plugs cut from the colonies of the fungal strains were placed in the centre of the plates containing MEA medium supplemented with yeast extract and holes (5 $\mathrm{mm}$ in diameter) were bored around in $3 \mathrm{~cm}$ distance from the centre of the plate. A 10-step 2fold dilution series of the $100 \mathrm{mg} \mathrm{ml}^{-1}$ crude peptaibol extracts - which were also examined for their peptaibol composition - were tested, using methanol as control. The cultures were incubated at $25{ }^{\circ} \mathrm{C}$. Photographs were taken by a Nikon Coolpix S2600 camera at two stages, (1) when the edge of the culture reached the control hole and (2) when it reached the edge of the Petri-dish. Three parallel experiments were set up to measure the inhibition zones.

\subsection{In vitro confrontation assays}

Agar plugs $5 \mathrm{~mm}$ in diameter, cut from the edge of $A$. bisporus and $P$. ostreatus colonies freshly growing on MEA were inoculated $1.5 \mathrm{~cm}$ apart from the centre of MEA plates $(90 \mathrm{~mm}$ in diameter). When the colony reached the central point of the plate (after 3 and 8 days for $P$. ostreatus and A. bisporus, respectively), the Trichoderma strains were inoculated to the opposite side at $1.5 \mathrm{~cm}$ distance from the center of the plates. Seven days later, photographs 
were taken from the plates by a Nikon Coolpix S2600 camera to calculate aggressivity index (AI) values. Calculation of AI is principally based on the image analysis-based biocontrol index (BCI) determination method of Szekeres et al. (2006) optimized to mushroom green mould strains of Trichoderma by Körmöczi et al. (2009). The AI value is given in percentage and calculated from the area covered by the Trichoderma strain, which is divided by the total area covered by Trichoderma and the confronted mushroom. Each experiment was set in three parallel tests. Self-confrontations of the examined Trichoderma strains were used as controls.

\subsection{Bioassays for peptaibol toxicity on mushroom mycelia}

Agar plugs (5 $\mathrm{mm}$ in diameter), cut from the edge of A. bisporus or P. ostreatus colonies freshly grown on MEA were inoculated to the center of MEA plates and incubated at $25^{\circ} \mathrm{C}$. After the cultures reached the colony diameter of $30 \mathrm{~mm}$, holes $5 \mathrm{~mm}$ in diameter were bored into the media at $1 \mathrm{~cm}$ distance from the edge of the mushroom colony and immediately filled with the crude extracts $(40 \mu \mathrm{l})$. Three parallel tests were set of each experiment and $A$. bisporus or $P$. ostreatus colonies without treatement were inoculated as controls. The inhibitory effects were observed and recorded after 3 days of incubation at $25^{\circ} \mathrm{C}$.

\subsection{Bioassays for peptaibol toxicity on filamentous fungi}

For inhibition tests with filamentous fungi, MEA medium completed with yeast extract was used at $25{ }^{\circ} \mathrm{C}$, following the method described above. The purified peptaibol extract of $T$. reesei QM9414 was tested in an agar plate well-diffusion assay with methanol as a control, as well as ALM (Sigma-Aldrich A-4665, Hungary) and nystatin (Nystatin 2-hydrate BioChemica, AppliChem A3811,0025, Germany) as reference compounds. All solutions were prepared in two-fold dilution series from $0.4 \mathrm{mg} \mathrm{ml}^{-1}$ to $0.0036125 \mathrm{mg} \mathrm{ml}^{-1}$. The inhibition zones were measured as the distance between the edge of the fungal colonies and the edge of the holes containing the peptaibol solutions at the time when the edge of the colony reached the edge of the control hole filled with methanol. At the same time, plates were photographed using a Coolpix S2600 digital camera (Nikon). Minimum inhibitory concentration (MIC) values were defined as the lowest concentrations where an inhibition zone could be detected. Experiments were carried out in triplicate.

\subsection{Bioassays for peptaibol effects on plants}

In order to investigate the biological effects of peptaibols on plants, A. thaliana (Col-0 ecotype) seeds were planted on $0.5 \times$ Murashige and Skoog agar (8\%) medium (Horváth et al. 2015 ) with the addition of $0.5 \%$ sucrose (w/v) ( $\mathrm{pH}$ adjusted to 5.5 with $1 \mathrm{M} \mathrm{NaOH}$ ) in Petri 
dishes $(90 \times 17 \mathrm{~mm})$ five seeds per Petri dish in a single row. Seeds were surface sterilized with $70 \%$ ethanol for $1 \mathrm{~min}$, treated with $4 \%$ hypochlorite for $15 \mathrm{~min}$ and washed with sterile distilled water. After vernalisation at $4{ }^{\circ} \mathrm{C}$ for $24 \mathrm{~h}$, seeds were sown onto the agar plates. Arabidopsis seedlings were placed in a greenhouse with a photoperiod of $12 \mathrm{~h}$ of light and 12 $\mathrm{h}$ of darkness, a light intensity of $300 \mu \mathrm{mol} \mathrm{m} \mathrm{s}^{-2}$ and a temperature of $25 \pm 1{ }^{\circ} \mathrm{C}$. On third day post germination, plates were placed at an angle of $50^{\circ}$ to allow root growth along the agar surface and to promote aerial growth of the hypocotyls. Four $5 \mathrm{~mm}$ holes were bored with a sterile cork borer $0.5 \mathrm{~cm}$ from the root tips of 5-day-old Arabidopsis seedlings (five seedlings per plate) and filled with $40 \mu \mathrm{l}$ of peptaibol extract and methanol solvent as the control. Plants without any treatment were also used as absolute control. The length of primary roots was measured every $24 \mathrm{~h}$ for 4 days. Photographs of 15 -day-old plants were taken using a Coolpix S2600 digital camera (Nikon). The fresh weights of the plants from each plate were measured, and photosynthetic pigments were extracted by acetone (analytical reagent grade, VWR International, Hungary) and quantified based on their OD (at $470 \mathrm{~nm}$, $534 \mathrm{~nm}, 643 \mathrm{~nm}$ and $661 \mathrm{~nm}$ wavelengts) as described by Lichtenthaler (1987).

\subsection{Peptaibol bioactivity assays against mammalian cells}

\subsubsection{Mammalian somatic cell toxicity assays}

The porcine kidney tubular epithelial cell line (PK-15) was pre-cultivated in BioWhittaker RPMI 1640 medium supplemented with L-glutamine at $37{ }^{\circ} \mathrm{C}$ in an atmosphere of $95 \%$ air and $5 \% \mathrm{CO}_{2}$ in a cell culture cabinet (Heracell 150i, Thermo Fisher Scientific, Vantaa, Finland). For the bioassays, separated and detached cells were used in 96-well microtiter plates based on the method of Castagnoli et al. (2018a) in three parallel experiments. Initially, the wells of the first columns were filled with $180 \mu 1$, while the rest with $100 \mu 1$ medium. Into the wells in the first column, $20 \mu 1$ of the samples were added, mixed and $100 \mu 1$ amounts were transferred to the next columns. Next, $100 \mu 1$ of the media containing mammalian cells were added to each well except for the control ones, which contained only the medium without cells. After 2 days of incubation at $37{ }^{\circ} \mathrm{C}, 10 \mu \mathrm{l}$ resazurin (Sigma Chemical Co., St. Louis, MO, USA) (400 $\mu \mathrm{g} \mathrm{ml}^{-1}$ in physiological saline) was added to each well and incubated for $2 \mathrm{~h}$ under the same conditions. After incubation, the plates were investigated by a microtiter plate reader (Fluoroskan Ascent, Thermo Scientific, Vantaa, Finland) at the excitation wavelength of $544 \mathrm{~nm}$ and the emission wavelength of $590 \mathrm{~nm}$. The endpoints of toxicity were specified by the differences from the OD of the control holes that means the living cells were less than 50\%. Typically, peptaibols have very sharp endpoints between two 
dilution steps. After 2 more days of incubation, the $\mathrm{NADH}^{+}$production of the living cells causes a colour changing to red for visible examination. Purified ophiobolins were used for references for our peptaibol inhibitions in the bioassays (Bencsik et al. 2014).

\subsubsection{Sperm motility inhibition assay}

The sperm motility bioassays were performed by using the method of Castagnoli et al. (2018b) in three parallel tests of each experiment. The boar semen was obtained from Figen Oy (Finland) and extended in MR-A (Kubus, S.A., Madrid, Spain) containing $27 \times 10^{6}$ spermatozoa $\mathrm{ml}^{-1}$. Four different amounts, $10 \mu \mathrm{l}, 5 \mu \mathrm{l}, 2 \mu \mathrm{l}$ and $1 \mu \mathrm{l}$ of the samples were added to $2 \mathrm{ml}$ of $100 \times$ diluted MR-A boar semen stock solution, while $20 \mu$ methanol (analytical reagent grade, VWR International, Hungary) was added to the blank assay. Two different incubation times, $30 \mathrm{~min}$ and $24 \mathrm{~h}$ were used for the short- and long-term bioassays, respectively, at room temperature. After the incubation, optimal conditions (shaken by hand for few seconds at $37^{\circ} \mathrm{C}$ to provide them oxygen) were ensured for $5 \mathrm{~min}$ to the sperm cells as a pre-incubation step before the examination of their motility. For the detection of the living, motile sperm cells, a phase contrast microscope (Olympus CKX31 and Software CellSens standard version 11.0.06, Olympus Soft Imaging Solution GmbH, Münster, Germany, 20092012) was used to check the tail beating of the sperm cells proving that they are alive. A normal living cell seems as if it had two tails by looking at the pictures of the microscope and the ratio of these "two-tailed" cells were compared to the blank samples in order to define the effect of the peptaibol samples.

\subsubsection{Membrane integrity disruption assay}

Disruption of the cell membrane integrity of motile sperm cells was assayed by staining with propidium iodide (PI) (Molecular Probes, Eugene, OR, USA) in sperm cells induced by shaking to swim at $37{ }^{\circ} \mathrm{C}$ as described by Bencsik et al. (2014) with small modifications. The test was performed as follows: $50 \mu 1$ aliquots of Dulbeco's phosphate buffered saline were pipetted into 96 wells of a microtiter plate. Fifty $\mu$ l of the test suspension (methanol extracts of peptaibols) was added to the first column of the wells and a 2-fold serial dilution was prepared until the $11^{\text {th }}$ column. The wells of the $12^{\text {th }}$ column representing reagent blank was filled with $200 \mu$ l Dulbeco's phosphate buffered saline and with methanol (analytical reagent grade, VWR International, Hungary) as solution control. One hundred and fifty $\mu 1$ aliquots of commercially extended boar semen $\left(27 \times 10^{6}\right.$ sperm cells $\left.\mathrm{ml}^{-1}\right)$ were pipetted into the microtiter plate wells and pre-incubated for $2 \mathrm{~h}$ on an orbital shaker (Innova 5000, New Brunswick Scientific, Enfield, CT, USA) at $160 \mathrm{rpm}$ and $37{ }^{\circ} \mathrm{C}$. Three parallel dilutions were 
performed for each sample. After incubation, PI solution (stock solution stored as frozen $1 \mathrm{mg}$ $\mathrm{ml}^{-1}$ in Dulbeco's phosphate buffered saline) was diluted to a concentration of $10 \mu \mathrm{g} \mathrm{ml}^{-1}$. One hundred $\mu$ of this stain mixture was added to the exposed boar semen. This suspension was incubated at $37{ }^{\circ} \mathrm{C}$ in darkness for $15 \mathrm{~min}$ and examined by a Fluoroskan Ascent microplate reader (Thermo Scientific, Vantaa, Finland) at excitation and emission wavelengths of $544 \mathrm{~nm}$ and $600 \mathrm{~nm}$, respectively. During the observation of plasma membrane damage by staining with PI, the positive control was frozen-thawed semen (for mortality of $100 \%$ ) representing the maximal fluorescence emitted by the cells permeable to PI. Dulbeco's phosphate buffered saline was used as the background control (blank). The frozen semen was represented by the wells in the last horizontal row. Loss of viability in the sample was calculated as described by Alm et al. (2001). The frozen sample represented $100 \%$ loss of viability. The assay was calibrated with triclosan (Sigma Chemical Co., St. Louis, MO, USA), in 5 parallel tests, the $\mathrm{EC}_{50}$ was $2 \mu \mathrm{g} \mathrm{ml}^{-1}(\mathrm{SD} \pm 0.6)$. The cell membrane permeability assay on static sperm cells at room temperature was performed by viability staining with PI and calcein-acetoxymethil (calcein-AM, Molecular Probes, Eugene, OR, USA) as described by Hoornstra et al. (2003).

\subsection{Statistical analysis}

All the statistical analyses were performed using GraphPad Prism Version 6.00 for Windows (GraphPad Software, San Diego, CA, USA, 2007, www.graphpad.com). The significant differences between the peptaibol production of the strains in in vitro confrontation assays and their respective controls were determined by unpaired t-analysis using parametric test. Statistical analyses of the peptaibols' effect on Arabidopsis plants were performed using Bonferroni's multiple comparison tests with the GraphPad Prism software version 6.00 (GraphPad Software, San Diego, CA, USA, www.graphpad.com) using 25 samples. 


\section{RESULTS AND DISCUSSION}

\subsection{Optimization of ESI-IT-MS system for the identification of peptaibol compounds}

At first, the ESI-IT-MS system was set for peptaibol identification using ALM standard (Sigma-Aldrich A-4665, Hungary) to examine whether the compounds produced by Trichoderma strains can be identified using our HPLC-ESI-IT-MS system. In order to optimize the system, the MS parameters including RF loading, capillary- and needle voltages were tuned in both positive and negative modes by continuous infusion $\left(5 \mu 1 \mathrm{~min}^{-1}\right)$ of an ALM standard solution (100 ng $\mu^{-1}$ ) with the built-in syringe pump of the instrument. Based on the reported data, the purchased standard mainly represents the neutral ALM F50 peptides (Kirschbaum et al. 2003), thus during the optimization, the following protonated/deprotonated molecular ions $\left([\mathrm{M}+\mathrm{H}]^{+} /[\mathrm{M}-\mathrm{H}]\right)$ of microheterogenity mixture of ALM components were monitored in positive/negative mode: $m / z$ 1963/1961 for ALM F50-5, m/z 1977/1975 for ALM F50-6a/6b/7 and $m / z$ 1991/1989 for ALM F50-8b/8c. After the setup of ion optic parameters, the optimal ion source conditions such as nebulizer gas- and drying gas pressures and source temperatures were estimated via flow injection analysis in the mobile phase constitution $1 / 1(\mathrm{v} / \mathrm{v})$ of eluent $\mathrm{A} / \mathrm{B}$.

For further investigations, ALM compounds were separated by HPLC on an analytical octadecil silica (ODS) column equivalent to the stationary phase used by Krause et al. (2006a) as the general method for the peptaibol analysis, but other than applied by Kirschbaum et al. (2003) specifically for the ALM separation (Figure 1). 


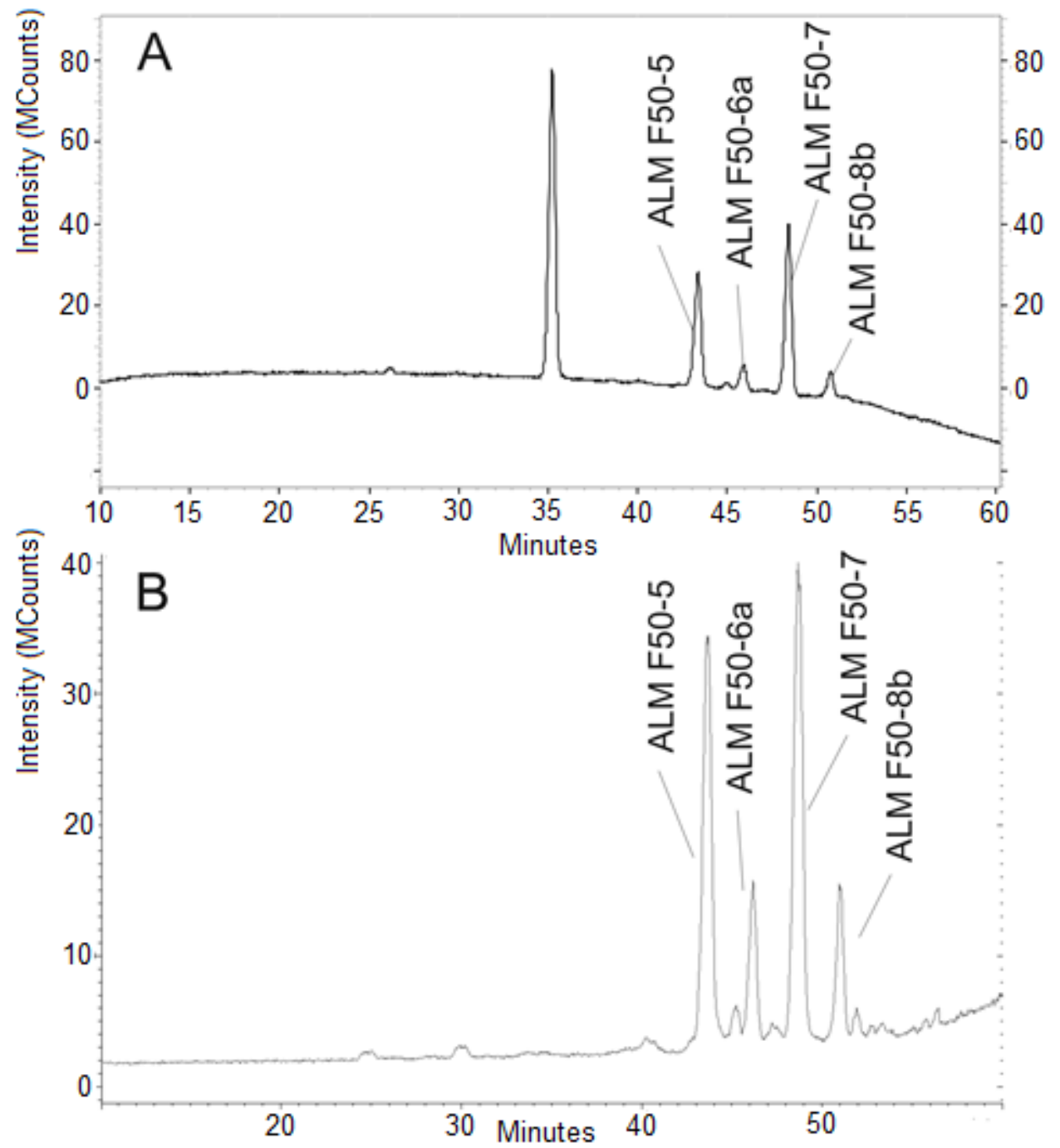

Figure 1 I HPLC-UV (A) and HPLC-ESI-MS (B) chromatogram of ALM components

MS measurements of peptaibols usually generate molecular ions and more-or-less complete series of characteristic fragment ions (Kirschbaum et al. 2003, Krause et al. 2006a). However, in our case, the molecular ions showed much lower abundance due to their disintegration than the sodium adduct form in positive mode with exception of ALM-F50-8b falling its correspondent $\mathrm{m} / \mathrm{z}$ value out of the examined mass range (Figure 2 and 3), which could make the identification of the unknown peptaibols difficult in our further screening studies. With the ESI negative mode ionization the $[\mathrm{M}-\mathrm{H}]^{-}$masses were visible only with moderate intensity. 


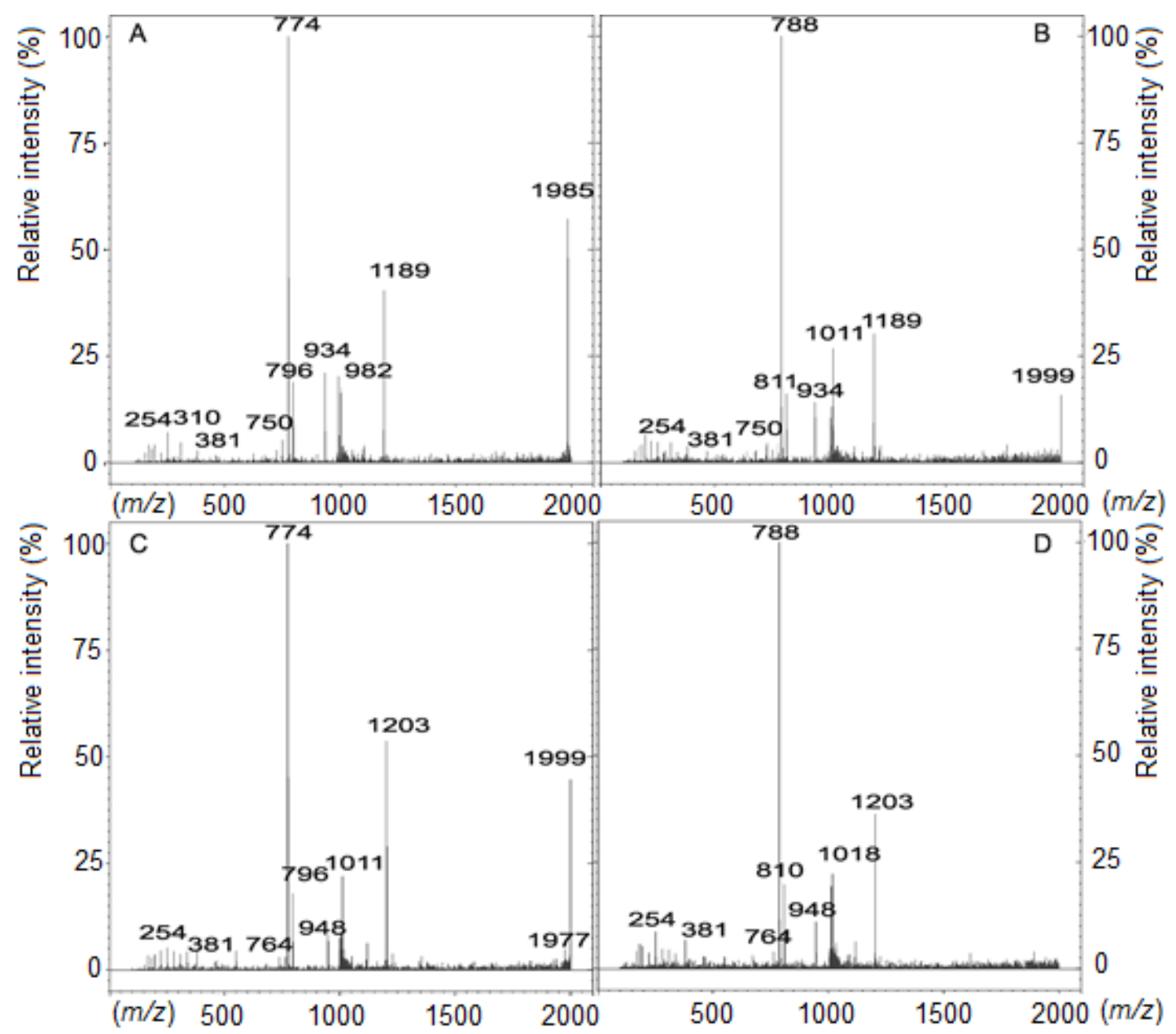

Figure 2 | HPLC-ESI-MS spectra of ALM-F50-5 (A), ALM-F50-6a (B), ALM-F50-7 (C) and ALM-F50-8b (D)

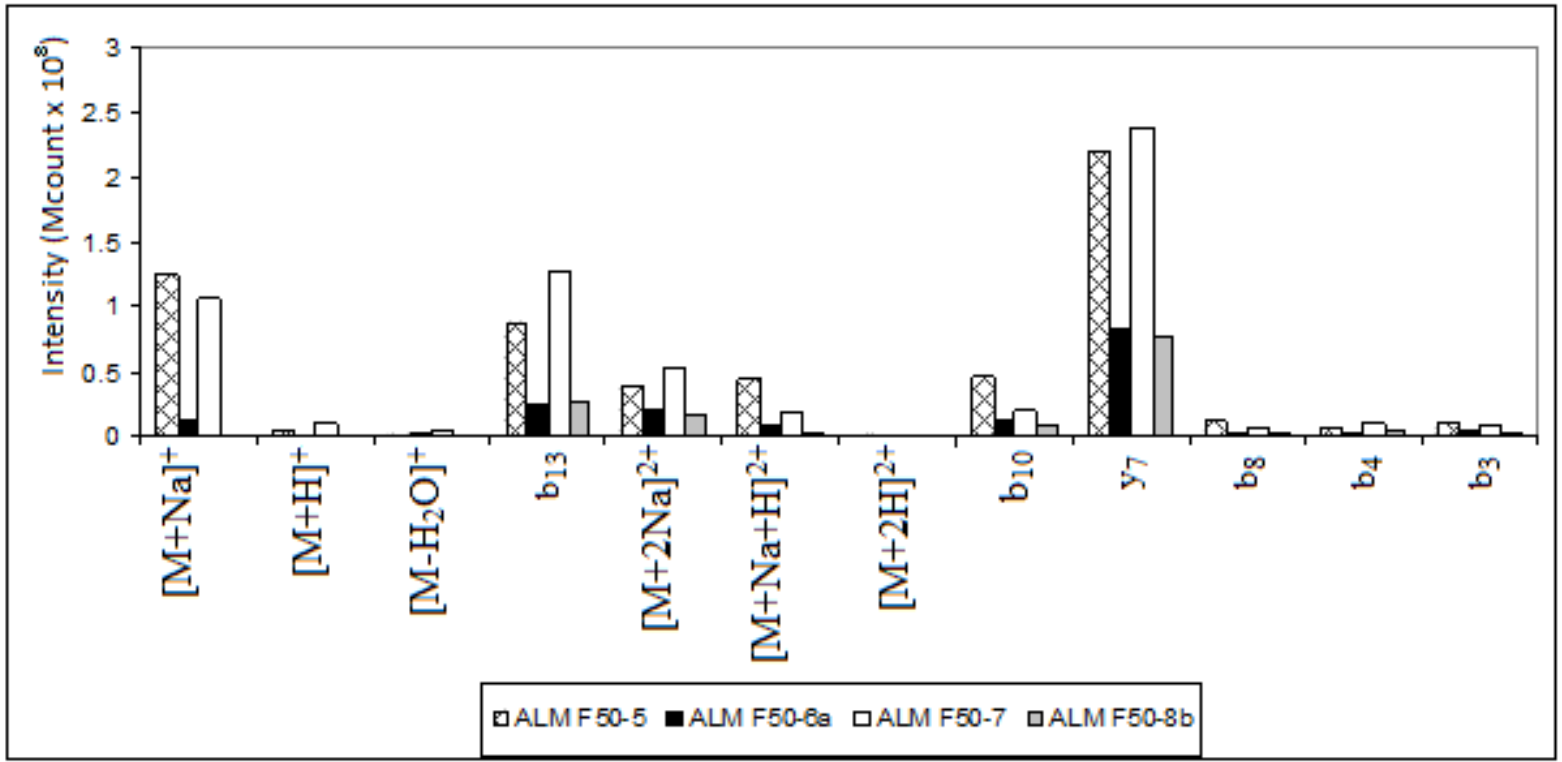

Figure 3 | Abundances of the characteristic fragments of ALM components appearing on the HPLC-ESI-MS spectra 
The most abundant ions among the fragment ions were the $\mathrm{y}_{7}$ and $\mathrm{b}_{13}$ fragments resulting from cleavage of the extremely unstable Aib-Pro bond of the 20 residue peptides at position 6-7 from the carboxyl terminus in positive mode. Thus, the summation of the proper $y$ and $b$ ions could serve the mass of hydrogen adduct of the molecular ion. It is interesting that the doublecharged adduct ions showed high intensity in the used MS instrument such as $(\mathrm{M}+2 \mathrm{Na})^{2+}$ and $(\mathrm{M}+\mathrm{Na}+\mathrm{H})^{2+}$ (Figure 2 and 3), which was not observed earlier. The signals of the $b_{10}$ fragments due to the fragmentation of the Aib-Gly bond were relatively high, although their $\mathrm{y}_{10}$ counter-fragments were not detected. At the lower $\mathrm{m} / \mathrm{z}$ values with lower intensity, but detectable level, the series of shorter $b$ fragments were recorded including $b_{10}, b_{8}, b_{4}$ and $b_{3}$ ions (Figure 2 and 3). From the mass differences $(\Delta m)$ of fragment ions, the presence of the marker amino acid Aib, characterised by $m / z$ 85.1 Da (Krause et al. 2006a) could not be deduced. The fragment ions and the acquired corresponding masses are shown in Table 2. 
TABLE 2 | Identifications of characteristic ions $(\mathrm{m} / \mathrm{z})$ of ALM components acquired in positive mode

\begin{tabular}{|c|c|c|c|c|}
\hline & \multicolumn{4}{|c|}{ ALM components } \\
\hline & 5 & $6 a$ & 7 & $8 b$ \\
\hline Rt (min) & 43.7 & 46.2 & 48.5 & 51.1 \\
\hline$[\mathbf{M}+\mathbf{H}]^{+}$ & 1963 & 1977 & 1977 & 1991 \\
\hline$[\mathbf{M}+\mathbf{N a}]^{+}$ & 1985 & 1999 & 1999 & Out of range \\
\hline$[\mathrm{M}+2 \mathrm{Na}]^{2+}$ & 1004 & 1011 & 1011 & 1018 \\
\hline$[\mathbf{M}+\mathbf{N a}+\mathbf{H}]^{2+}$ & 993 & 1000 & 1000 & 1007 \\
\hline$[\mathrm{M}+2 \mathrm{H}]^{2+}$ & 982 & 989 & 989 & 996 \\
\hline$\left[\mathbf{M}-\mathbf{H}_{2} \mathbf{O}\right]^{+}$ & 1945 & 1959 & 1959 & 1973 \\
\hline $\mathbf{b}_{13}$ & 1189 & 1189 & 1203 & 1203 \\
\hline $\mathbf{b}_{10}$ & 934 & 934 & 948 & 948 \\
\hline $\mathbf{b}_{8}$ & 750 & 750 & 764 & 764 \\
\hline $\mathbf{b}_{4}$ & 381 & 381 & 381 & 381 \\
\hline $\mathbf{b}_{3}$ & 310 & 310 & 310 & 310 \\
\hline $\mathbf{y}_{7}$ & 774 & 788 & 774 & 788 \\
\hline
\end{tabular}

The resulting peaks were in accordance with the ALM components reported previously (Kirschbaum et al. 2003), eluted with proper resolutions (Figure 1). Furthermore, based on the mass spectra acquired from certain peaks, the different components could be identified, some of which were denoted earlier only as mixture of isomers including ALM-F50-4b/5, ALMF50-6a/6b and ALM-F50-8b/8c (Kirschbaum et al. 2003). In the case of ALM-F50-4b/5 eluted at $43.7 \mathrm{~min}$, the characteristic ions of the $4 \mathrm{~b}$ component were not detectable due to the single charged and double charged sodium adducts at the $m / z 1971$ and 998, respectively (Figure 2A). The peak of ALM-F50-6a/6b at 46.2 min contains also only the $6 \mathrm{a}$ component, because of the absence of $m / z 930$ ( $b_{10}$ fragment) of ALM-F50-6b (Figure 2B). Similarly, in the case of ALM-F50-8b/8c at $51.1 \mathrm{~min}$, only the ALM-F50-8b was involved due to the lack of $\mathrm{y}_{7}(\mathrm{~m} / \mathrm{z} 744)$ and $\mathrm{b}_{10}(\mathrm{~m} / \mathrm{z}$ 962) fragments originated from the fragmentation of ALM-F50- 
8c (Figure 2D), while the ALM-F50-8c, eluted at 48.5 min showing the highest peak area (Figure 2C). There was a peak with a remarkable area on the UV chromatogram at approximately $35 \mathrm{~min}$, but it was not active mass spectrometrically.

The results achieved here could contribute to the identification of other unknown peptaibol molecules isolated from different Trichoderma species based on the gathered data about the MS fragmentation properties.

\subsection{Identification of the peptaibols produced by Trichoderma species}

The method applied for peptaibol identification described in the Materials and Methods section 5.4 was based on the strategy developed during the investigation of ALM, which was described above. The sequences were determined based on the observation of the characteristic ions of the compounds $\left([\mathrm{M}+\mathrm{Na}]^{+},[\mathrm{M}+2 \mathrm{Na}]^{2+}, \mathrm{b}_{12}\right.$ and $\mathrm{y}_{7}$ ion) and the retention time. Throughout the investigation of the species causing green mould disease and the species from clade Viride, the $[\mathrm{M}+\mathrm{Na}]^{+}$ions were clearly detected. All through the investigation of the species belonging to clade Longibraciatum, the single-charged pseudomolecular ions, such as $[\mathrm{M}+\mathrm{Na}]^{+}$or $[\mathrm{M}+\mathrm{H}]^{+}$, were scarcely detectable in the spectra, whereas double-charged $\left([\mathrm{M}+2 \mathrm{Na}]^{2+}\right)$ ions were present and could be used for identification. All full scan MS spectra contained the series of the fragment ions from the N-terminal part (shown in Supplementary Figures 1-5), except for the ion fragment where the Gln-Aib bond is present in the compounds (Krause et al. 2006a). This is shown on the spectra as the characteristic mass difference $\Delta m=213 \mathrm{Da}$, due to the stability of this bond under the fragmentation conditions of ESI-MS (Jaworski et al. 1999, Kirschbaum et al. 2003, Krause et al. 2006a). The Cterminal $\mathrm{y}_{7}$ fragment was consistently observed and could also provide a good reference for the quantification of the peptides, where $[\mathrm{M}+\mathrm{Na}]^{+}$ions could not be observed on the MS spectra. The first part of the sequences till the Aib-Pro bond could be identified from the full scan MS spectra, but $\mathrm{MS}^{2}$ experiments were performed for the identification of residues at the C-terminus. Usually, the last four residues could be identified directly from the $\mathrm{MS}^{2}$ spectra (Supplementary Figures 6-8) measured on the Varian MS system. The $\mathrm{y}_{7}-\mathrm{AA}(19-15)$ could not be detected with $\mathrm{MS}^{2}$ during the investigations of the species from the clade Viride, therefore the amino acids in positions 14 and 15 (Vxx14-Aib15) were predicted based on the Comprehensive Peptaibotics Database showing the frequent presence of the Aib-Pro-VxxAib motif in this region (Stoppacher et al. 2013, Neumann et al. 2015). The $\mathrm{y}_{7}-\mathrm{AA}(19-15)$ ions (Pro-AA) were also not shown on the spectra during the investigation of the species belonging to clade Longibrachiatum, therefore another $\mathrm{MS}^{2}$ fragmentation was performed on 
an Orbitrap-MS system from these $y_{7}$ ions (Supplementary Figure 9). Thus, all the detected peaks could also be reidentified at high resolution on the HPLC-Orbitrap-MS system, except for $\mathrm{y}_{7}-\mathrm{H}_{2} \mathrm{O}$ (Supplementary Tables $1-6$ ). Instead of $[\mathrm{M}+\mathrm{Na}]^{+}$and $[\mathrm{M}+2 \mathrm{Na}]^{2+}$ ions, $[\mathrm{M}+\mathrm{H}]^{+}$ could be observed on the spectra of the reidentification. As no amino acid analysis has been performed, discrimination between isobaric amino acids was not possible.

\subsection{Peptaibols from $T$. gamsii and T. koningiopsis (clade Viride)}

\subsubsection{Peptaibol production of $T$. gamsii and T. koningiopsis}

The sequences of the compounds identified from the two examined strains and listed in Table 3 and Table 4 are derived from the de novo MS-based sequencing. The diagnostic fragment ions of the peptaibols found in this study are shown in Supplementary Tables 7-10, presented according to Röhrich et al. (2013). The peptaibols produced by T. gamsii SZMC 1656 strain (Table 3, Supplementary Table 7, 9, Supplementary Figures 1, 6 and 10) proved to be completely different from the ones detected in the extract of T. koningiopsis SZMC 12500 (Table 4, Supplementary Table 8, 10, Supplementary Figures 2, 6 and 11). The main differences between the peptaibols of the two species could be identified in 4 positions of their sequences. In the $2^{\text {nd }}$ position, peptaibols produced by $T$. gamsii SZMC 1656 contain Gly or Ala in Pept-X, -XI, and -XII, while only Ala was observed in this position in the peptaibol sequences identified from T. koningiopsis SZMC 12500. Another difference is at the $5^{\text {th }}$ residue of the sequences, where mostly Lxx, in some cases Vxx was identified in the sequences of T. gamsii SZMC 1656, while the compounds of T. koningiopsis SZMC 12500 exhibited mostly Aib at this position. The third main difference between the sequences of the two examined species was observed at the $9^{\text {th }}$ position, where mostly Aib was identified in the peptaibols produced by $T$. gamsii SZMC 1656, while those from $T$. koningiopsis SZMC 12500 mostly showed Lxx and in some cases Aib. The $18^{\text {th }}$ position contains Gln in the sequences of $T$. gamsii SZMC 1656, but T. koningiopsis SZMC 12500 produces compounds with Glu in this position causing 2 more variants of the $\mathrm{y}_{7}$ ion. The sequences Pept-Vb, -VIb, and -VII were matching with trikoningin $\mathrm{KA} \mathrm{V}$, though the isomeric positions of Vxx and Lxx were not identified. All other sequences proved to be new and showed similarities to the peptaibol groups of trikoningins, tricholongins, trichostrigocins, and trichorzianins (see references in Tables 3 and 4). 
TABLE 3 I Sequences of the newly identified peptaibol compounds produced by Trichoderma gamsii SZMC 1656 and their similarity to known peptaibols available in the "Comprehensive Peptaibiotics Database"

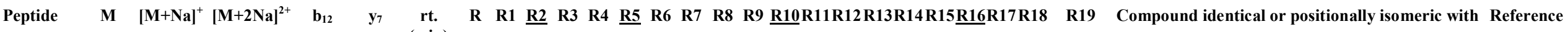 (min)}

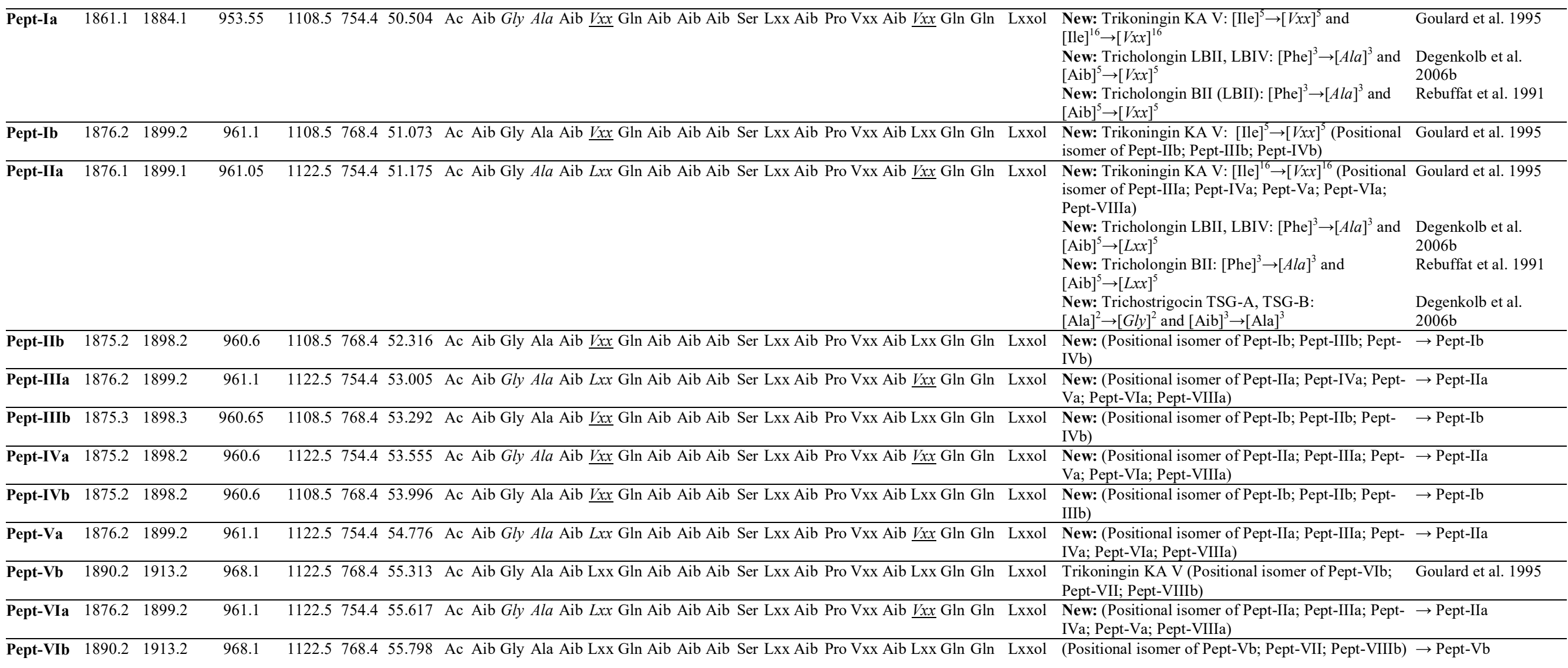

Variable residues are underlined in the table header, minor sequence variants are underlined in the sequences. Amino acid exchanges in new compounds are set in italic. 
TABLE 3 | Continued

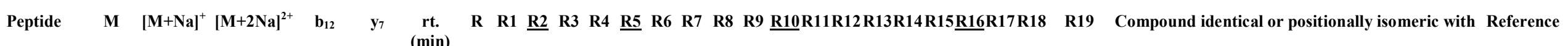

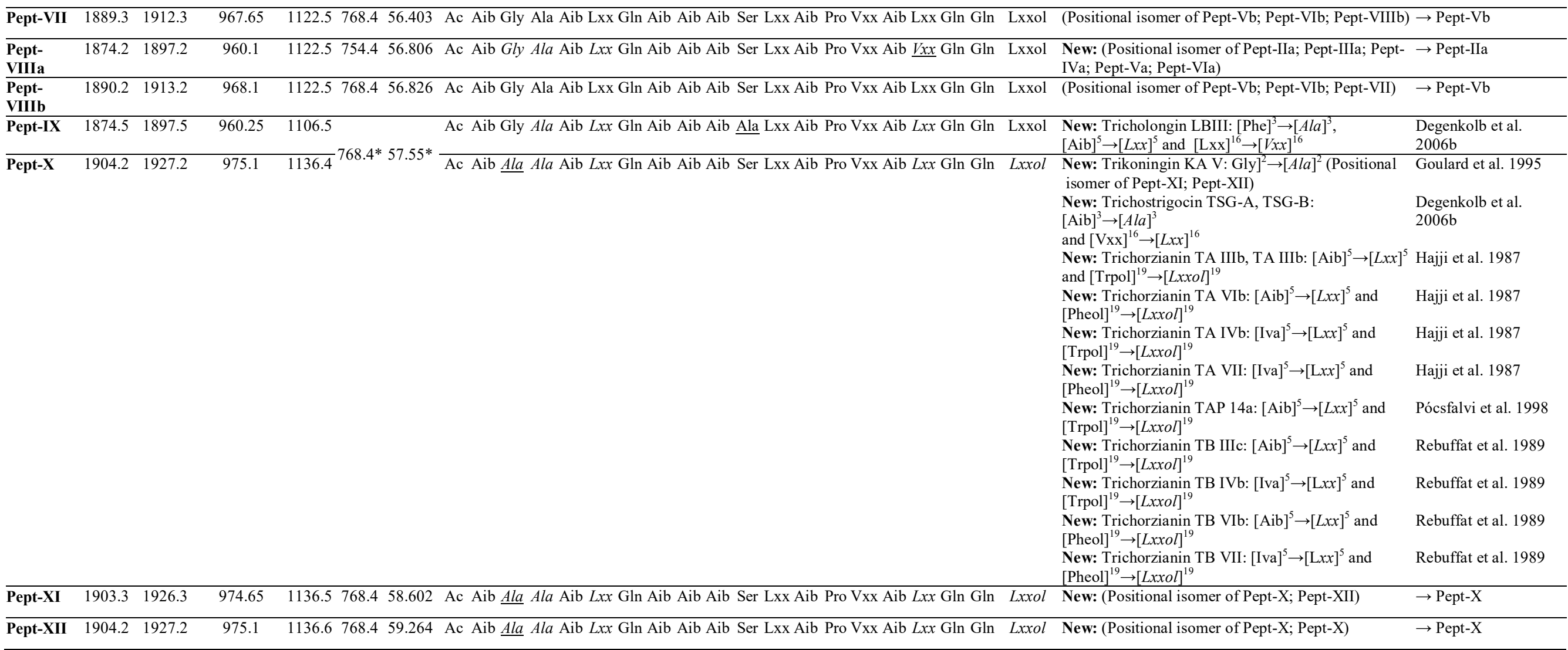

*value belonging to both peptides (result of the same peak of $\mathrm{y}_{7}$ ion) 
TABLE 4 I Sequences of the newly identified peptaibol compounds produced by Trichoderma koningiopsis SZMC 12500 and their similarity to known peptaibols available in the "Comprehensive Peptaibiotics Database"

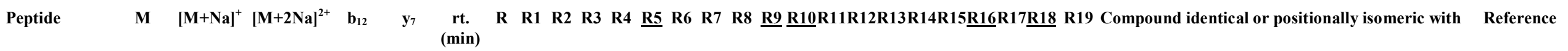


TABLE 4 | Continued

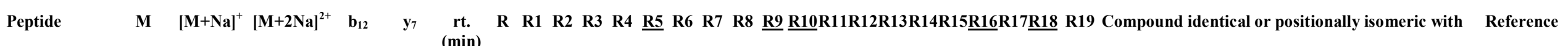

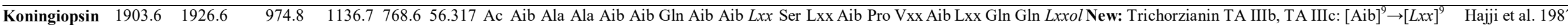
IV 
The information available in the literature about the peptaibol profiles of T. koningiopsis and T. gamsii is limited. Peptaibols produced by T. koningiopsis were previously identified as trikoningin $\mathrm{KA} \mathrm{V}$, together with other 11-residue-long compounds, trikoningin $\mathrm{KB}$ I and $\mathrm{KB}$ II (McMullin et al. 2017). To the best of our knowledge, other peptaibol compounds produced by T. koningiopsis were not reported in the literature previously. Apart from the groups shown in Table 3, the newly identified sequences also showed high similarity to trichorzin HAs, which, however, are only 18-residue-long peptaibols devoid of the Gln/Glu residue (Goulard et al. 1995). Trikoningin KA V, identified firstly from T. koningii (Auvin-Guette et al. 1993), is a peptaibol sequence positionally isomeric with sequences Pept-Vb, -VIb, and -VII. This compound was also found to be produced by T. koningiopsis, along with the 11-residues lipopeptaibols trikoningin KB I and KB II (McMullin et al. 2017). Other 19-residue-long peptaibols such as trichostrigocins were previously identified from T. strigosum (Degenkolb et al. 2006b, Neuhof et al. 2007, Degenkolb et al. 2008a) and later also from the extracts of $T$. paraviridescens and T. trixiae as trichostrigocin-like compounds (Castagnoli et al. 2018a). Tricholongins were detected in T. longibrachiatum (Rebuffat et al. 1991) and T. strigosum (Degenkolb et al. 2006b), while trichorzianins are known from T. atroviride (Hajji et al. 1987, Rebuffat et al 1989, Pócsfalvi et al. 1998, Röhrich et al. 2014). Further 19-residue-long peptaibols closely related to those of the present study include hypophellins from $T$. phellinicola (syn. H. phellinicola), hypopulvins from T. pulvinatum (syn. H. pulvinata), gelatinosins from $T$. gelatinosum (syn. H. gelatinosa), voglmayrins from $T$. voglmayrii (syn. H. voglmayrii), minutisporins from T. minutisporum (syn. H. minutispora) and hypocitrins from T. citrinum (syn. H. citrina) (Röhrich et al. 2012, Röhrich et al. 2013, Röhrich et al. 2014). This indicates that within the genus the ability to produce 19-residue-long peptaibols is not restricted to clade Viride of section Trichoderma, it also occurs in sections Hypocreanum (T. phellinicola, T. pulvinatum, T. citrinum) and Pachybasium (T. minutisporum), as well as in lone lineages (T. voglmayrii, T. gelatinosum). T. gamsii is a widespread species of the genus, also known as an endophyte of the traditional Chinese medicinal plant Panax notoginseng (Dang et al. 2010). Although, the investigation of peptaibol production was not yet carried out for this species, T. gamsii was shown to produce numerous secondary metabolites including cytochalasans (Ding et al. 2012a, Ding et al. 2012b, Chen et al. 2014, Ding et al. 2014), the spiro-cytochalasan trichodermone (Ding et al. 2014), trichoderamides A and B originating from the PKS-NRPS hybrid pathway (Ding et al. 2015), trichodenols A and B (Ding et al. 2015), trichoderpyrone (Chen et al. 2017), as well as volatile organic compounds like dimethyl disulfide, dibenzofuran, methanethiol, and ketones (Chen et al. 2016). Among the 
detected cytochalasans (trichalasins A, B, C, D, E, F, G, H, aspochalasins D, I, J, K, M, P, and aspergillin PZ), aspochalasins D and I displayed weak inhibitory activity against the HeLa cancer cell line (Ding et al. 2012a, Ding et al. 2012b), trichalasin G proved to be modestly inhibitory to the human cancer cell line MDA-MB-231 (Chen et al. 2016), while trichoderpyrone displayed weak cytotoxic activities against A549, HepG2, and HeLa cancer cell lines (Chen et al 2017).

In certain cases, minor differences were observed between the presently detected and the previously reported peptaibol sequences showing amino acid exchanges only at selected positions of the peptide chain (Table 3 and Table 4). Trichorzianins differ in the position 19 of the peptide chain. This position plays a critical role in the lifetime of the opened ion channel as the substitution of Pheol to Leuol/Ileol has led to increased lifetime of the open channel (Koide et al. 1997). This was also observed previously in the case of peptaibol-formed channels, where the Pheol was substituted with Trpol in both trichorzianin B-IIIc (Trpol) and B-VII (Pheol) (Duclohier et al. 1989). On the other hand, the investigation of synthetic ALM analogues - where all Aib residues were replaced with Leu - revealed that the substitution of the C-terminal residues did not affect the lifetime of the open channel (Molle et al. 1991). A secondary structural study was also carried out in the case of the purified compound trichorzianin TA VII in association with sodium dodecyl sulfate (SDS) micelles, which revealed formation of two right-handed helical segments (1-8 and 11-19) linked by a $\beta$-turn (Condamine et al. 1998). The novelty of the peptaibols produced by T. koningiopsis SZMC 12500 is in the variation of the C-terminus, which is critical in the lifetime of the ion channels. The name "Koningiopsin" was introduced for these novel compounds.

Based on the calibration made using ALM standard (Sigma-Aldrich Ltd., Budapest, Hungary), the amount of the peptaibol mixture of the crude extracts was determined. This new method for quantification of peptaibols based on the length of different peptides was described by Van Bohemen et al. (2016) and mentioned in the Materials and Methods section. The different length of peptaibols results in different structures, furthermore, shorter peptaibols (11-14 residues) contain more Pro leading to a structural deformation (Rebuffat et al. 1999). Based on the ALM standard, only the longer (17-20-residue-long) peptaibols can be quantified with high accuracy. The calculated concentration of the whole peptaibol molecules were $214.28 \mu \mathrm{g} \mathrm{ml}^{-1}$ and $101.26 \mu \mathrm{g} \mathrm{ml}^{-1}$ in the crude extracts of $T$. gamsii SZMC 1656 and T. koningiopsis SZMC 12500, respectively. In the case of T. gamsii SZMC 1656, Pept VIIIb and Pept VIb were the most abundant sequences of peptaibols (Supplementary 
Table 7, 9). The sum of the amount of these two molecules was approximately $50 \%$, while the concentration of other peptaibols remained below $10 \%$. In the extract of $T$. koningiopsis SZMC 12500, Pept XVIIa accounted for almost half of the peptaibols produced (Supplementary Table 8, 10).

\subsubsection{Effect of peptaibol extracts on bacteria, yeasts and filamentous fungi}

$M$. luteus and S. aureus proved to be highly sensitive to both peptaibol extracts (Table 5), E. coli was more resistant, while $P$. aeruginosa showed higher sensitivity to the extracts from $T$. koningiopsis than to those from T. gamsii. M. luteus and S. aureus are Gram-positive bacteria, while E. coli and P. aeruginosa are Gram-negative ones, thus their sensitivity showed correlation with the type of their cell wall. Studies on the bioactivity of paracelsins (Brückner and Graf 1983) or ALM (Jen et al. 1987) showed similar results, i.e., that Gram-positive bacteria proved to be more sensitive to peptaibols. Testing the peptaibols trichorzianine A1 and B1 on Gram-positive and Gram-negative bacteria also revealed similar results, furthermore, synergistic effect could also be detected between peptaibols and different membrane-affecting compounds (MACs) and cell wall-degrading enzymes (CWDEs) (Lorito et al. 1996b, Benítez et al. 2004). In a study of Lorito et al. (1996a), the inhibition of $\beta$-Dglucan synthase was reported as a specific effect of peptaibol antibiotics. On the other hand, in the study of Cutler et al. (1991), the purified peptaibol identified as trikoningin KA V (also known as koningin A) seemed to be inactive against both Gram-positive and Gram-negative bacteria. No inhibition zones could be observed in the case of the tested yeasts (Table 5), though in another study, minimum inhibition could be observed after the treatment of trichokonins produced by $T$. koningii on S. cerevisiae CGMCC2.395 and C. albicans CGMCC2.538 (Song et al. 2006). Complete inhibition could not be observed among the fastgrowing fungi (Trichoderma and Fusarium species), only the speed of their mycelial growth was limited (Table 6). Interestingly, the producer T. koningiopsis and T. gamsii strains seemed to be more sensitive to their own peptaibol extracts than T. aggressivum f. europaeum and $T$. pleuroti, known as the causal agents of green mould disease occurring in mushroom cultivation (Table 6). 
TABLE 5 | Bioactivity of crude peptaibol extracts $\left(100 \mathrm{mg} \mathrm{ml}^{-1}\right)$ from Trichoderma gamsii SZMC 1656 and T. koningiopsis SZMC 12500 towards bacteria and yeasts

\begin{tabular}{lcc}
\hline Tested microbial strains & $\begin{array}{c}\text { Sensitivity to } \boldsymbol{T} \text {. gamsii } \\
\text { SZMC } \mathbf{1 6 5 6} \text { extract }\end{array}$ & $\begin{array}{c}\text { Sensitivity to } \boldsymbol{T} . \\
\text { koningiopsis SZMC } \\
\mathbf{1 2 5 0 0} \text { extract }\end{array}$ \\
\hline Micrococcus luteus SZMC 0264 & ++++ & ++++ \\
Staphylococcus aureus SZMC 0579 & ++++ & +++ \\
Escherichia coli SZMC 0582 & + & - \\
Pseudomonas aeruginosa SZMC 0568 & + & ++ \\
Candida boidinii SZMC 0673 & - & - \\
Kluyveromyces lactis SZMC 0683 & - & - \\
Saccharomyces cerevisiae SZMC 0425 & - & - \\
Schizosaccharomyces pombe SZMC 0142 & - & - \\
\hline
\end{tabular}

- , absence of inhibition, diameter of inhibition zone: $+, 5-7 \mathrm{~mm},++, 7-9 \mathrm{~mm},+++, 9-11$ $\mathrm{mm},++++, 11-13 \mathrm{~mm},+++++, 13-15 \mathrm{~mm}$ diameter.

TABLE 6 | Bioactivity of crude peptaibol extracts $\left(100 \mathrm{mg} \mathrm{ml}^{-1}\right)$ and their 2-fold serial dilutions from Trichoderma gamsii SZMC 1656 and T. koningiopsis SZMC 12500 towards cultures of filamentous fungi

\begin{tabular}{|c|c|c|}
\hline Tested filamentous fungal strains & $\begin{array}{c}\text { Sensitivity to } T \text {. } \\
\text { gamsii SZMC } 1656 \\
\text { extract } \\
\left(\mathrm{MIC}, \mathrm{mg} \mathrm{ml}^{-1}\right)\end{array}$ & $\begin{array}{c}\text { Sensitivity to } T \text {. } \\
\text { koningiopsis SZMC } \\
12500 \text { extract } \\
\left(\mathrm{MIC}, \mathrm{mg} \mathrm{ml}^{-1}\right)\end{array}$ \\
\hline Alternaria alternata SZMC 16085 & $1.563 *$ & $3.125 *$ \\
\hline Fusarium solani SC SZMC 11467 & 6.25 & 12.5 \\
\hline Rhizoctonia solani $\mathrm{SZMC}$ 6252J & $12.5 *$ & $6.25 *$ \\
\hline Phoma cucurbitacearum SZMC 16088 & $12.5^{*}$ & $3.125 *$ \\
\hline Trichoderma aggressivum f. europaeum & 12.5 & 25 \\
\hline \multicolumn{3}{|l|}{ SZMC 1811} \\
\hline Trichoderma pleuroti SZMC 12454 & 12.5 & 25 \\
\hline Trichoderma gamsii SZMC 1656 & 6.25 & 6.25 \\
\hline Trichoderma koningiopsis SZMC 12500 & 6.25 & 6.25 \\
\hline
\end{tabular}

SC: species complex

*, mycelial growth was completely stopped. 
The $F$. solani species complex member appeared to be more sensitive to the peptaibol extract of $T$. gamsii than to the one of T. koningiopsis. Inhibition could also be detected in the case of A. alternata, $R$. solani and $P$. cucurbitacearum, all growing very slowly ( 8 days, 12 days, and 11 days, respectively, till they reach the hole containing methanol on the plates), and interestingly, the mycelial growth of these filamentous fungi stopped where the peptaibols were added into the holes and could not reach the edge of the plates (Table 6).

\subsection{Peptaibol production of Trichoderma species causing mushroom green mould disease}

\subsubsection{Peptaibols produced by $T$. aggressivum f. europaeum and $T$. pleuroti}

From the crude extracts of T. aggressivum f. europaeum CBS 433.95, peptaibols positionally isomeric with hypomurocins B1, B3a, B3b and B4, (Becker et al. 1997) as well as several new, yet unreported compounds with sequences very similar to hypomurocin B were identified based on the MS and $\mathrm{MS}^{2}$ spectra (Table 7). The detection of hypomurocin B-like peptaibols in T. aggressivum f. europaeum CBS 433.95 is also in agreement with the partial sequence data published by Krause et al. (2006b) for isolate CBS 100526, the type strain of $T$. aggressivum f. europaeum. The fragment sequence 4 ([286]-Lxx-Aib-213-Vxx-Aib-142Aib-210-Aib-Aib-Gln-Valol) reported in this previous study corresponds with sequences Pept-1719-a-1 and Pept-1719-a-2 detected in strain CBS 433.95. A further set of our sequences differ from fragment sequence 6 ([286]-Lxx-Vxx-Gln-Aib-170-Ala-Vxx-Aib210-Aib-Aib-Gln-Valol) of Krause et al. (2006b) by containing Gly instead of Ala in the R10 position. Peptaibols corresponding with fragment sequence 5 or with the 11-residue-long hypomurocin A-like compounds were not detected in strain CBS 433.95. Differences in peptaibol profiles between different strains of the same species were reported in the literature also for T. virens (Wei et al. 2005). Another possible explanation for the lack of detection of hypomurocin A-like compounds may be the application of chloroform as an extraction solvent, which is less polar than dichloromethane/methanol (1/1) used in the study of Krause et al. (2006b). 
TABLE 7 I Sequences of peptaibols produced by strain Trichoderma aggressivum f. europaeum CBS 433.95 and their similarity to known peptaibols available in the "Comprehensive Peptaibiotics Database"

Peptide $\quad M \quad[M+N a]^{+}[M+2 N a]^{2+} b_{12} \quad y_{7} \quad$ rt. $\quad$ R R1 R2 R3 R4 $\underline{\text { R5 }}$ R6 R7 R8 $\underline{\text { R9 }} \underline{\mathrm{R} 10 R 11 R 12 R 13 R 14 R 15 R 16 R 17} \underline{\text { R18 }}$ Compound identical or positionally isomeric with (min)

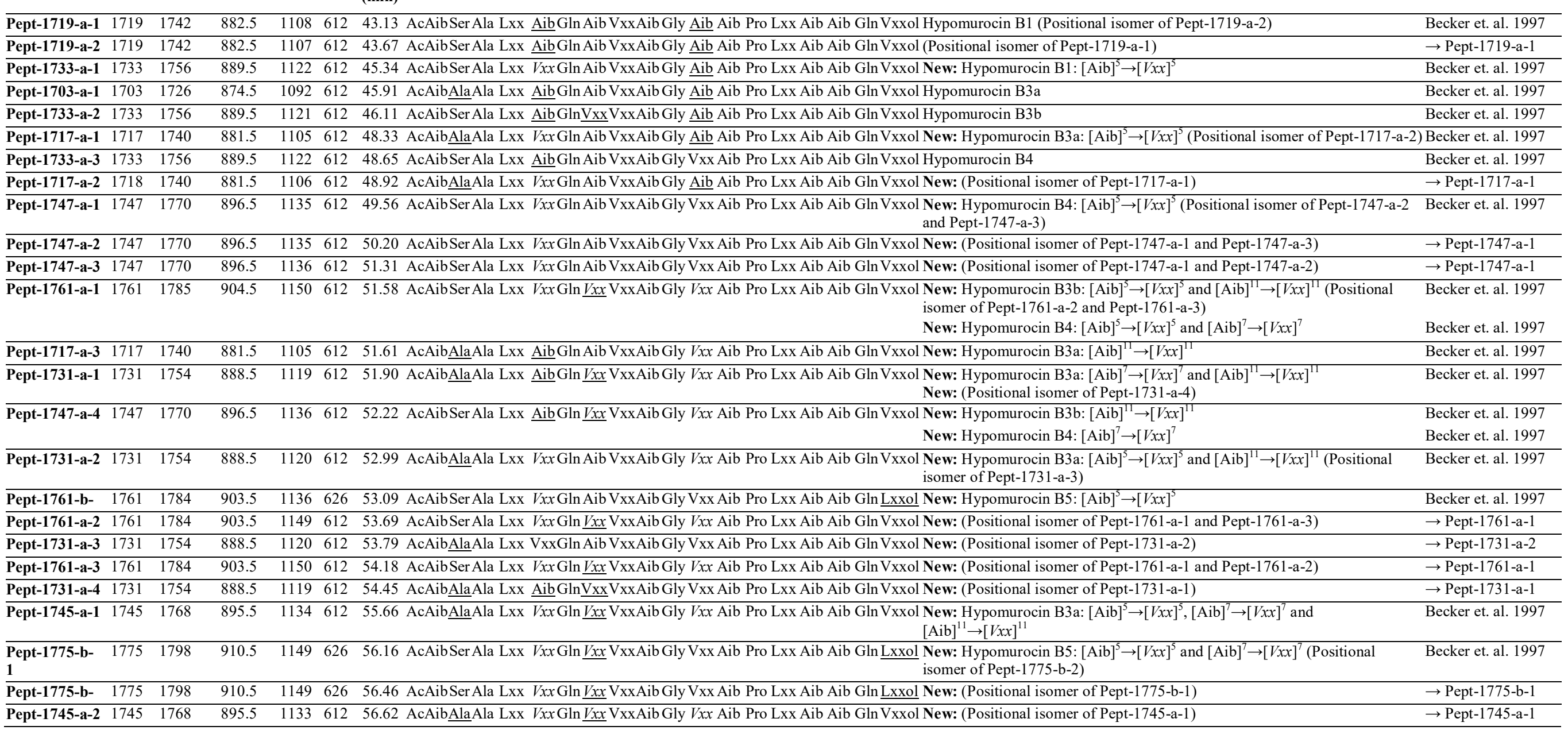

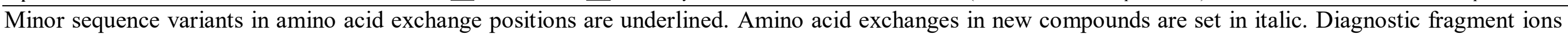
and extracted ion chromatograms (EICs) are shown in Supplementary Tables 11 and 12, and Supplementary Figure 12. 
Hypomurocin B-like compounds were first identified from an antagonist of shiitake mushroom (Lentinula edodes) in Japan, originally misidentified as H. muroiana (Becker et al. 1997) and later reidentified as T. atroviride (Samuels et al. 2006). These compounds have a characteristic amino acid sequence with four variable positions (R2, R7, R11 and R18). The sequences reported in our study contain one more variable position, R5 with a Vxx/Aib exchange. 18-residue-long peptaibols relatively close to hypomurocins were also found in a biocontrol strain of $T$. simmonsii, where the sequences had an R3 position different in an Ala/Aib exchange from hypomurocin B1 or B4, while a further 18-residue-long peptaibol similar to hypomurocin B5 with the same difference in the R3 position was identified from $T$. harzianum (Degenkolb et al. 2015). The 3D-structural and folding properties of hypomurocins were recently characterised by Horváth et al (2016).

Six compounds with the highest concentrations (Pept-1733-a-1, Pept-1733-a-3, Pept-1747-a3, Pept-1747-a-4, Pept-1731-a-3 and Pept-1761-a-3, Supplementary Table 11) account for $57.3 \%$ of the microheterogeneous peptaibol mixture, which consists of 25 compounds, all of them identified as 18-residue-long peptaibols. Compounds Pept-1719-a-1, Pept-1703-a-1, Pept-1733-a-2 and Pept-1733-a-3 show sequence similarity to hypomurocins B1, B3a, B3b and B4, respectively, while the other 21 compounds are new (see references in Table 7). During the full scan MS measurements, $b_{12}$ and $y_{6}$ ions along the fragment ions resulted from the unstable Aib-Pro bond were the most intensively observed fragments. Based on the $\mathrm{MS}^{2}$ experiments, the $\mathrm{y}_{6}$ ions had the same sequence in 22 compounds with the mass of $\mathrm{m} / \mathrm{z} 612$, while the remaining three compounds contained a $\mathrm{y}_{6}$ ion of $m / z 626$ (Supplementary Table 12). According to the $\mathrm{MS}^{2}$ spectra, all $\mathrm{y}_{6}$ sequences with $m / z 612$ have an Lxx residue in the $\mathrm{R} 14$ position and a Vxxol residue at the end of the sequence in the R18 position, while the $\mathrm{m} / \mathrm{z}$ $626 y_{6}$ ions have Lxxol instead of Vxxol at the terminus.

In T. pleuroti strain TPhu1, a new group of compounds was detected, which does not match any of the known groups of peptaibols (Table 8). A relatively close group according to the $b_{12}$ ion is the group of trichokindins (Iida et al. 1994, Peltola et al. 2004), which, however, have a leucine in the R8 position and a completely different $\mathrm{y}_{6}$ ion part with $\mathrm{m} / \mathrm{z} 625$. According to the $\mathrm{MS}^{2}$ investigations of the $\mathrm{y}_{6}$ ion part with $\mathrm{m} / z 660$ and $\mathrm{m} / \mathrm{z} 674$, the closest group is the trichorzin PA group described from T. harzianum (Leclerc et al. 1988, Duval et al. 1997), however, trichorzins PA have Gly-Leu in the R10-R11 positions of the $b_{12}$ ion part and not Ala-Vxx or Ala-Aib like the peptaibols produced by T. pleuroti. Furthermore, although the $\mathrm{m} / \mathrm{z}$ values of the $\mathrm{y}_{6}$ ion part are the same in the trichorzin PA group as in our sequences, the 
variable residue is in position R18 and not in R16 as in the T. pleuroti sequences. Another group, trichorzin $\mathrm{PA}_{U}$ was also reported with a further Iva/Aib exchange in position R5 (Urbán et al. 2016). For this new group of peptaibols detected in our study, we introduced the name 'tripleurin'. The compounds present in highest concentrations were tripleurins VI, VIIIb and XIIc with $7.9 \%, 10.0 \%$ and $12.0 \%$ of the $[\mathrm{M}+\mathrm{Na}]^{+}$area, respectively. These three compounds gave almost 1/3 (29.9\%) of the total peptaibol fraction consisting of 22 compounds, all of them being new (Supplementary Table 13). The 3D-structural and folding property of tripleurin XIIc was recently characterised by Tyagi et al. (2019b). 
TABLE 8 I Sequences of peptaibols produced by strain Trichoderma pleuroti TPhu1 and their similarity to known peptaibols available in the "Comprehensive Peptaibiotics Database"

\section{Peptide \\ $\mathbf{M}[\mathbf{M}+\mathrm{Na}]^{+}[\mathbf{M}+\mathbf{2 N a}]^{2+} \mathbf{b}_{12} \quad \mathbf{y}_{7} \quad \mathbf{r t}$. \\ Reference}

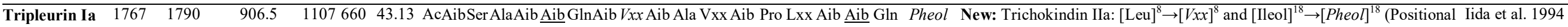
New: Trichokindin Ia: $[\mathrm{Iva}]^{7} \rightarrow[\mathrm{Aib}]^{7},[\mathrm{Leu}]^{8} \rightarrow[\mathrm{Vxx}]^{8},[\mathrm{Aib}]^{16} \rightarrow[\mathrm{Vxx}]^{16} \quad$ lida et al. 1994 and $[\text { Ileol }]^{18} \rightarrow[\text { Pheol }]^{18}$ New: Trichokindin Ib: $[\mathrm{Iva}]^{5} \rightarrow[\mathrm{Aib}]^{5},[\mathrm{Leu}]^{8} \rightarrow[\mathrm{Vxx}]^{8},[\mathrm{Aib}]^{16} \rightarrow\left[V_{V x}\right]^{16} \quad$ Iida et al. 1994 and $[\text { Ileol }]^{18} \rightarrow[\text { Pheol }]^{18}$

New: Trichokindin IIa: $[\mathrm{Leu}]^{8} \rightarrow[V x x]^{8}$, [Iva $]^{11} \rightarrow[\mathrm{Aib}]^{11},[\mathrm{Aib}]^{16} \rightarrow[V x x]^{16}$ Iida et al. 1994 and $[\text { Ileol }]^{18} \rightarrow[\text { Pheol }]^{18}$

\begin{tabular}{|c|c|c|c|c|c|c|}
\hline Tripleurin Ib 1767 & 1790 & 906.5 & 110766045.34 & AcAibSer AlaAib Aib GlnAibVxxAib Ala Vxx Aib Pro Lxx Aib Aib Gln Pheol & New: (Positional isomer of Tripleurin Ia) & $\rightarrow$ Tripleurin Ia \\
\hline Tripleurin IIIa 1782 & 1805 & 914.0 & $1107674 \quad 45.91$ & AcAibSer AlaAibVxxGlnAib $V x x$ Aib Ala Aib Aib Pro Lxx Aib $V x x$ Gln Pheol & $\begin{array}{l}\text { New: Trichokindin Ib: }[\mathrm{Leu}]^{8} \rightarrow[\mathrm{Vxx}]^{8},[\mathrm{Aib}]^{16} \rightarrow[\mathrm{Vxx}]^{16} \text { and } \\
{[\mathrm{Ileol}]^{18} \rightarrow[\text { Pheol }]^{18} \text { (Positional isomer of Tripleurin IIIb) }}\end{array}$ & Iida et al. 1994 \\
\hline Tripleurin IIIb 1782 & 1805 & 914.0 & 110867446.11 & AcAibSer AlaAibVxxGlnAib $V x x$ Aib Ala Aib Aib Pro Lxx Aib $V x x$ Gln Pheol & New: (Positional isomer of Tripleurin IIIa) & $\rightarrow$ Tripleurin IIIa \\
\hline $\begin{array}{ll}\text { Tripleurin IV } 1752 \\
\end{array}$ & 1775 & 899.2 & $1077674 \quad 48.33$ & AcAib $\underline{A l a}$ AlaAib $\underline{A i b}$ GlnAib $V x x$ Aib Ala $\underline{\text { Aib }}$ Aib Pro Lxx Aib $V x x$ Gln Pheol & $\begin{array}{l}\text { New: Trichokindin Ib: }[\mathrm{Ser}]^{2} \rightarrow[\mathrm{Ala}]^{2},[\mathrm{Iva}]^{5} \rightarrow[\mathrm{Aib}]^{5},[\mathrm{Leu}]^{8} \rightarrow[\mathrm{V} x \mathrm{Kx}]^{8}, \\
{[\text { Aib }]^{16} \rightarrow[\text { Vxx }]^{16} \text { and }[\mathrm{Ileol}]^{18} \rightarrow[\text { Pheol }]^{18}}\end{array}$ & Iida et al. 1994 \\
\hline Tripleurin V & 1805 & 914.0 & 112266048.65 & AcAibSer AlaAib Aib GlnAib $V x x \underline{V x x}$ Ala Vxx Aib Pro Lxx Aib $\underline{\text { Aib Gln Pheol }}$ & $\begin{array}{l}\text { New: Trichokindin IIa: }[\mathrm{Leu}]^{8} \rightarrow[V x x]^{8},[\mathrm{Aib}]^{9} \rightarrow[V x x]^{9} \text {, and } \\
{[\text { [leol }]^{18} \rightarrow[\text { Pheol }]^{18}}\end{array}$ & Iida et al. 1994 \\
\hline \multirow[t]{4}{*}{ Tripleurin VI } & 1805 & 914.0 & 110767448.92 & AcAibSer AlaAibVxx Gln $\underline{\text { Ala } V x x}$ Aib Ala Vxx Aib Pro Lxx Aib Vxx Gln Pheol & $\begin{array}{l}\text { New: Trichokindin IIIb: }[\mathrm{Aib}]^{7} \rightarrow[\text { Ala }]^{7},[\mathrm{Leu}]^{8} \rightarrow[\mathrm{Vxx}]^{8},[\mathrm{Aib}]^{16} \rightarrow[\mathrm{Vxx}]^{16} \\
\text { and }[\mathrm{Il} \text { leol }]^{18} \rightarrow[\text { Pheol }]^{18}\end{array}$ & Iida et al. 1994 \\
\hline & & & & & $\begin{array}{l}\text { New: Trichokindin Vb: }[\text { Aib }]^{7} \rightarrow[\text { Ala }]^{7},[\mathrm{Leu}]^{8} \rightarrow[\text { Vxx }]^{8},[\text { Aib }]^{16} \rightarrow[\text { Vxx }]^{16} \\
\text { and }[\text { Ileol }]^{18} \rightarrow[\text { Pheol }]^{18}\end{array}$ & Iida et al. 1994 \\
\hline & & & & & $\begin{array}{l}\text { New: Trichokindin VI: }[\mathrm{Iva}]^{7} \rightarrow[\text { Ala }]^{7},[\mathrm{Leu}]^{8} \rightarrow[\mathrm{Vxx}]^{8},[\mathrm{Aib}]^{16} \rightarrow[\mathrm{Vxx}]^{16} \\
\text { and [Ileol }]^{18} \rightarrow[\text { Pheol }]^{18}\end{array}$ & Iida et al. 1994 \\
\hline & & & & & $\begin{array}{l}\text { New: Trichokindin VII }:[\mathrm{Iva}]^{7} \rightarrow[\text { Ala }]^{7},[\mathrm{Leu}]^{8} \rightarrow[\mathrm{Vxx}]^{8},[\mathrm{Aib}]^{16} \rightarrow[\mathrm{Vxx}]^{16} \\
\text { and }[\mathrm{Il} \text { leol }]^{18} \rightarrow[\text { Pheol }]^{16}\end{array}$ & Iida et al. 1994 \\
\hline Tripleurin VII 1752 & 1775 & 899.2 & 109266049.56 & 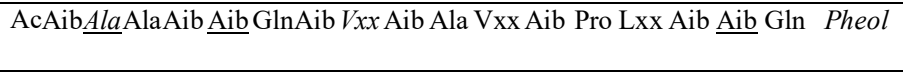 & $\begin{array}{l}\text { New: Trichokindin IIa: }[\mathrm{Ser}]^{2} \rightarrow[\text { Ala }]^{9},[\mathrm{Leu}]^{2} \rightarrow[\text { Vxx }]^{8} \text {, and } \\
{[\text { Ileol }]^{18} \rightarrow[\text { Pheol }]^{18}}\end{array}$ & Iida et al. 1994 \\
\hline
\end{tabular}

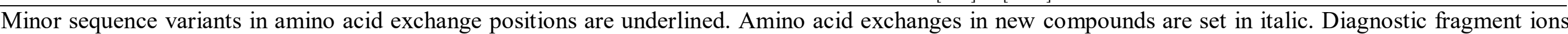
and EICs are shown in Supplementary Tables 11 and 12, and Supplementary Figure 12. 


\section{TABLE 8 | Continued}

Tripleurin VIIIa $1796 \quad 1819 \quad 921.0 \quad 1121674 \quad 50.20$ AcAibSerAlaAibVxxGlnVxxVxxAib Ala Aib Aib Pro Lxx Aib Vxx Gln Pheol New: Trichokindin IIb: [Leu $]^{8} \rightarrow[\text { Vxx }]^{8}$, [Aib $]^{16} \rightarrow[\text { V } x x]^{16}$ New: Trichokindin IIb:
and [Leuol $]^{18} \rightarrow[$ Pheol $]$ New: Trichokindin IV: $[\mathrm{Leu}]^{8} \rightarrow[\mathrm{Vxx}]^{8},[\mathrm{Aib}]^{16} \rightarrow[\mathrm{Vxx}]^{16}$ and $[\text { Ileol }]^{18} \rightarrow[\text { Pheol }]^{1}$

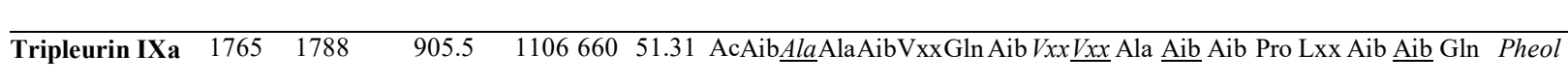
and [Ileol $]^{18} \rightarrow[$ Pheol $]$

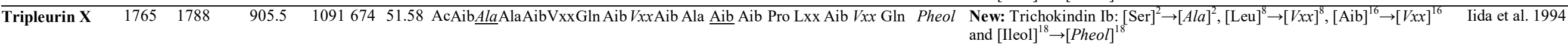

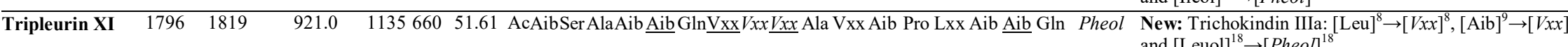
and $[\text { Leuol }]^{18} \rightarrow[\text { Pheol }]^{18}$ New: Trichokindin Va:
and $[\text { [leol }]^{18} \rightarrow[\text { Pheol }]^{18}$

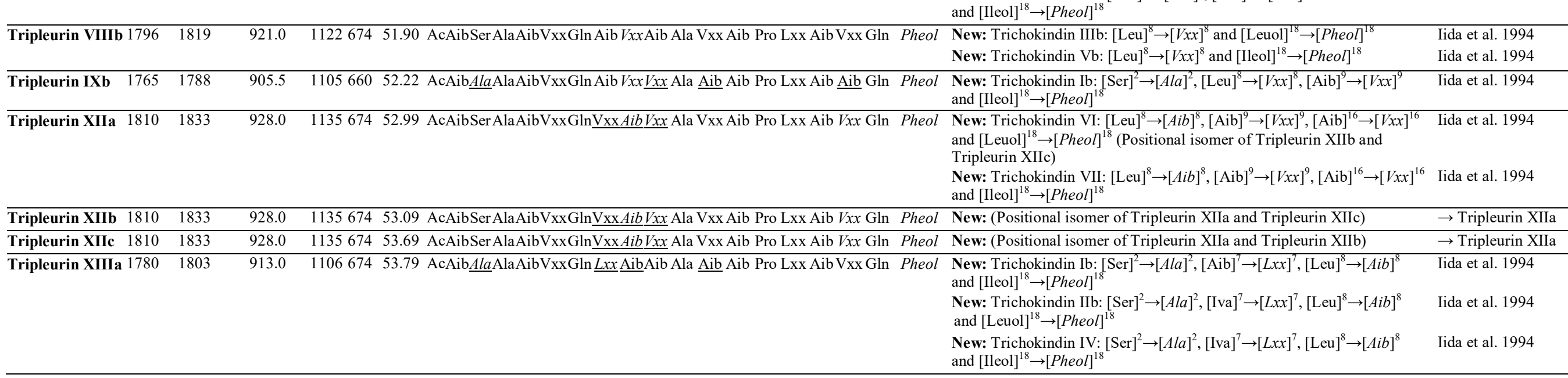




\section{TABLE 8 | Continued}

Peptide

$M \quad[\mathrm{M}+\mathrm{Na}]^{+}[\mathrm{M}+\mathbf{2 N a}]^{2+} \mathbf{b}_{12}$

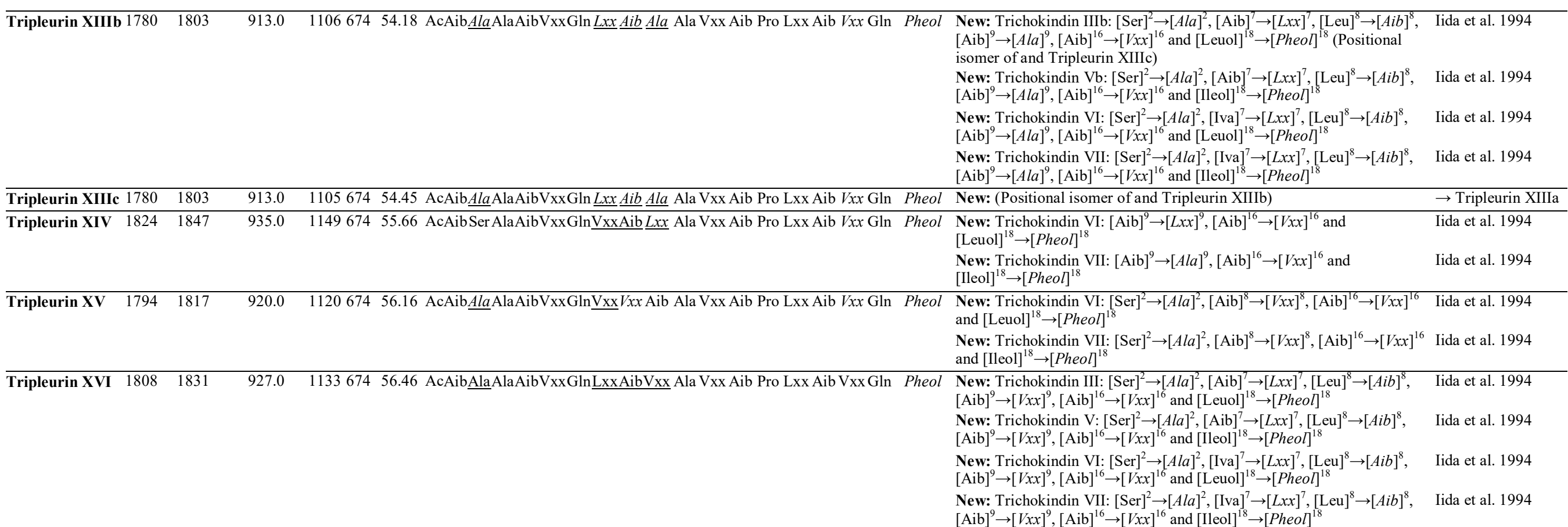




\subsubsection{Changes in the peptaibol profiles of $T$. pleuroti and T. aggressivum $\mathrm{f}$.}

europaeum during in vitro antagonistic interactions with $P$. ostreatus and $A$. bisporus

Peptaibol profiles of the green mould agents T. pleuroti and T. aggressivum f. europaeum during interactions with mushroom mycelia were measured in in vitro antagonism experiments by confronting the Trichoderma strains with A. bisporus SZMC 23395 and $P$. ostreatus SZMC 23392. AI values were calculated according to the method of Körmöczi et al. (2009). Strain T. aggressivum f. europaeum CBS 433.95 - a green mould isolate from Agaricus compost - antagonised A. bisporus SZMC 23395 after 1 week of incubation with an AI value of $91 \%$ (Figure 4). T. pleuroti TPhu1 - isolated from Pleurotus cultivation substrate affected by green mould - proved to be more effective against P. ostreatus SZMC 23392 (AI: 100\%) than the T. aggressivum strain (AI: 61\%). Furthermore, strain TPhu1 was also more aggressive against A. bisporus (AI: 98\%) than its infectious agent T. aggressivum f. europaeum (AI: 91\%).

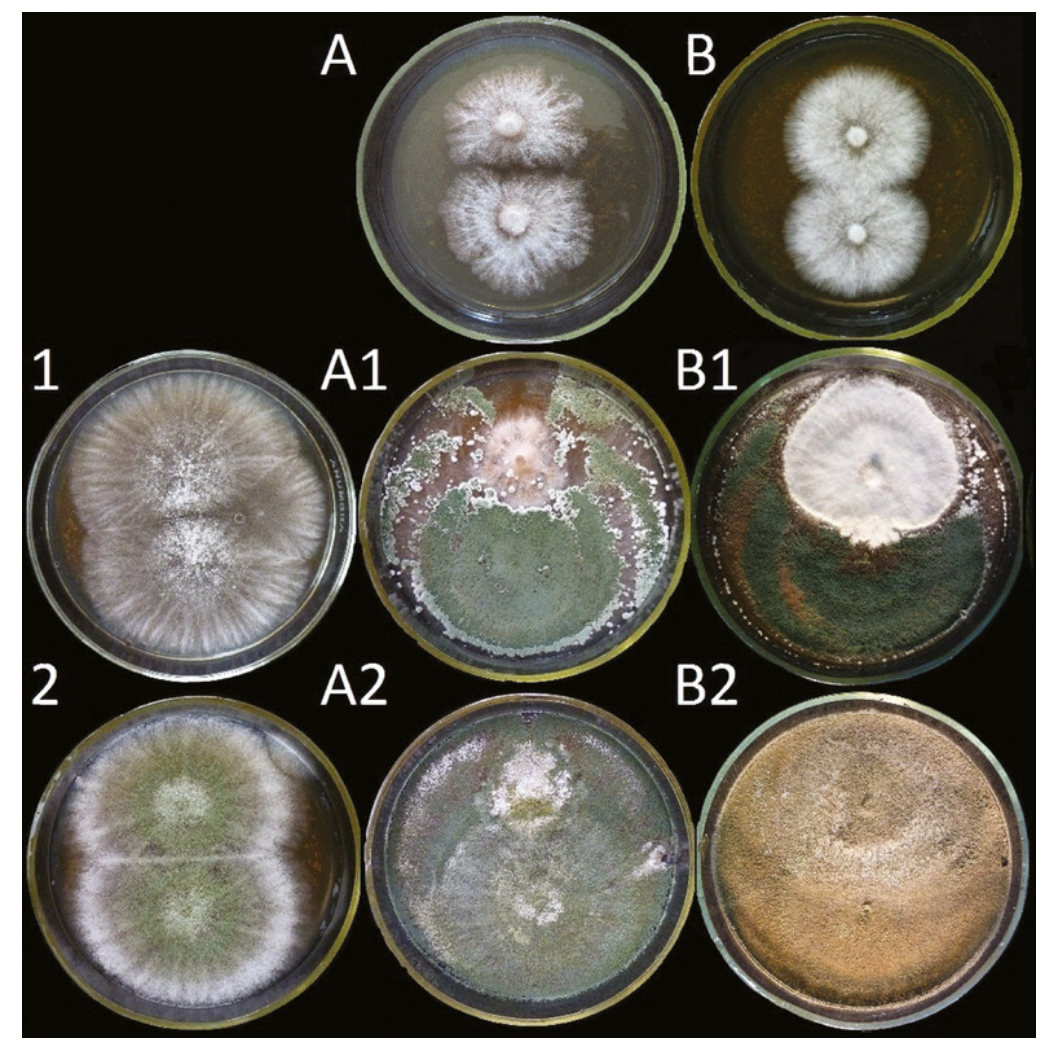

Figure 4 I Interaction of Trichoderma strains with A. bisporus SZMC 23395 and P. ostreatus SZMC 23392. A) A. bisporus self confrontation, B) $P$. ostreatus self confrontation, 1) $T$. aggressivum f. europaeum CBS 433.95 self confrontation, 2) T. pleuroti TPhu1 self 
confrontation, A1 - B2): interactions in different combinations (A: A. bisporus, B: P. ostreatus, 1: T. aggressivum f. europaeum CBS 433.95, 2: T. pleuroti TPhu1).

Although the production of certain peptaibol compounds, e.g., Pept-1733-a-3 and Pept-1747a-3 by $T$. aggressivum f. europaeum CBS 433.95 was higher during confrontation with Agaricus or Pleurotus than in the case of the control (self confrontation), a significant increase could be detected only in the case of Pept-1717-a-1 $(P=0.0152)$ during the confrontation with $P$. ostreatus (Figure 5). On the other hand, during confrontation with $A$. bisporus and $P$. ostreatus, the amounts of certain compounds including Pept-1733-a-1 ( $P=$ 0.0052 and 0.0395 , respectively), Pept-1717-a-2 $(P=0.0120$ and 0.0480 , respectively) and Pept-1745-a-2 ( $P=0.0007$ and 0.0011 , respectively) were significantly lower.

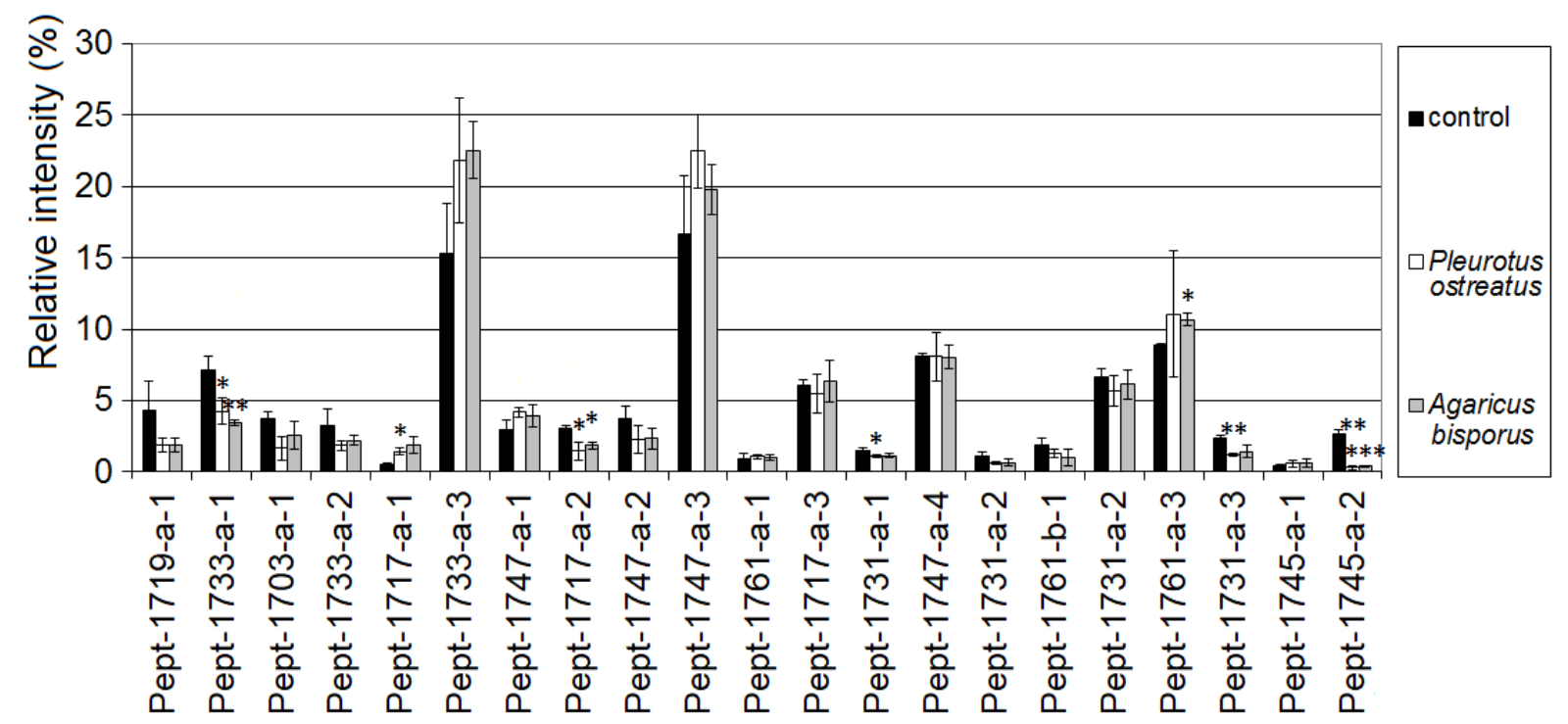

Figure 5 I Effects of the in vitro confrontation of T. aggressivum f. europaeum CBS 433.95 with $P$. ostreatus and A. bisporus on the production of peptaibols. Significance levels of differences from the control are marked with asterisks: $* * * P<0.001, * * P<0.01, * P<0.05$ $(n=3)$.

Changes in the peptaibol profiles could also be observed during the confrontation of $T$. pleuroti TPhu1 with the two mushrooms (Figure 6). The amount of tripleurin VIIIb increased significantly during the confrontation with both $A$. bisporus $(P=0.0336)$ and $P$. ostreatus $(P$ $=0.0484$ ), while a significantly decreased production in the presence of both mushrooms was measured for tripleurins $\mathrm{Ib}$ ( $P$ values of 0.0020 and 0.0392 , respectively) and XIIIb ( $P$ values of 0.0255 and 0.0180 , respectively). Further significant increase (tripleurins IXb and XIIIc, with $P$ values of 0.0008 and 0.0168 , respectively) or decrease (tripleurin IIIa with a $P$ value of 
0.0025) in the amount of compounds could be detected during the confrontation of T.pleuroti with $A$. bisporus. The results suggest that the mushroom hosts may have an impact on the peptaibol profiles of Trichoderma species causing green mould problems. Differences in the production of 18-residue-long trichotoxins could also be recently detected during the in vitro confrontation of a mycoparasitic $T$. asperellum strain with phytopathogenic fungi $(F$. moniliforme, F. culmorum, $F$. graminearum, F. oxysporum species complex, $A$. solani and $R$. solani) (Tamandegani et al. 2020).

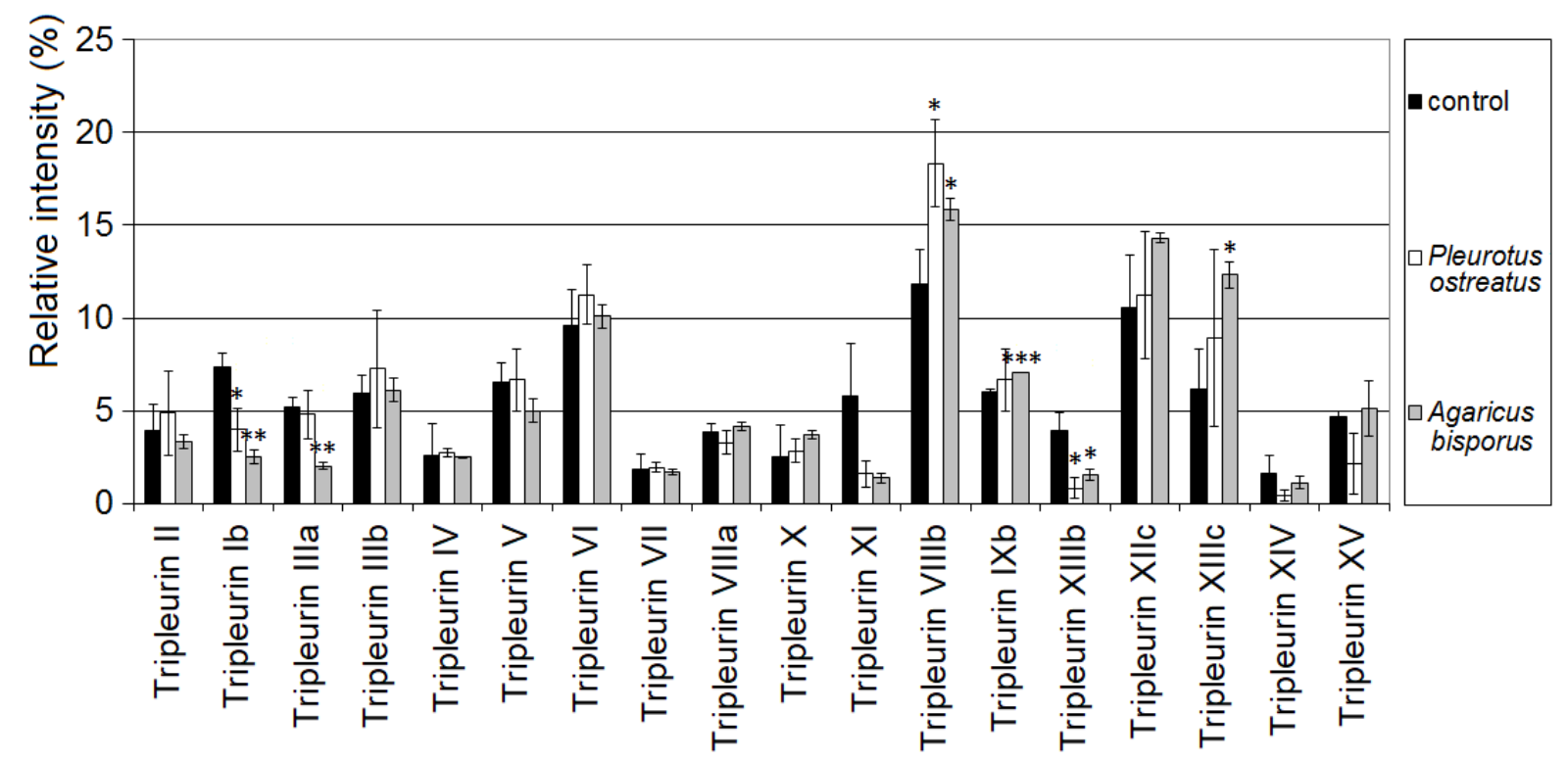

Figure 6 I Effects of the in vitro confrontation of $T$. pleuroti TPhu1 with $P$. ostreatus and $A$. bisporus on the production of peptaibols. Significance levels of differences from the control are marked with asterisks: $* * * P<0.001, * * P<0.01, * P<0.05(n=3)$.

\subsubsection{Effects of peptaibols on $P$. ostreatus and $A$. bisporus}

The effects of the crude peptaibol extracts filled into wells bored into the agar plate were also examined. Inhibition could be observed in the growth of A. bisporus and P. ostreatus after 3 days of incubation (Figure 7), suggesting that peptaibols may play a role during the antagonistic action of aggressive Trichoderma species against cultivated mushrooms. The inhibition zones disappeared after further incubation, as the mushroom mycelia could slowly overgrow the holes that contained the extracts. The antifungal activities of certain Trichoderma peptaibols are long known from the literature. The review of Szekeres et al. (2005) summarized the previously published information about the biological activities of Trichoderma peptaibols, including antifungal properties. The authors discussed the inhibitory activity of 10-residue-long trichopolyns I and II towards the basidiomycete mushrooms 
Lentinula edodes, Flammulina velutipes and P. ostreatus, the yeasts C. albicans, C. utilis and Cryptococcus neoformans, and the filamentous ascomycetes Penicillium chrysogenum, A. niger, A. fumigatus and Trichophyton mentagrophytes, as well as the antifungal activities of trichorzins HA/harzianins HC and trichotoxin A against Sclerotium cepivorum and Mucor ramannianus, respectively. A synergism between membrane-affecting peptaibols and hydrolytic enzymes was also observed during the antifungal antagonism of Trichoderma strain ATCC 36042 (Schirmböck et al. 1994) originally identified as T. harzianum, then reidentified as T. atroviride (Kuhls et al. 1996). This was later explained by inhibition of the membrane-bound $\beta-1,3$-glucan synthase of the host by the peptaibols, which inhibit the resynthesis of cell wall $\beta$-glucans, sustain the disruptive action of $\beta$-glucanases, and thereby enhance the fungicidal activity (Lorito et al. 1996a). A more recent study revealed the antibiotic mechanism of the 20-residue-long trichokonin VI (produced by T. pseudokoningii SMF2) against $F$. oxysporum by showing that this peptaibol induces a metacaspaseindependent apoptotic programmed cell death in parallel with the accumulation of cytoplasmic vacuoles (Shi et al. 2012).

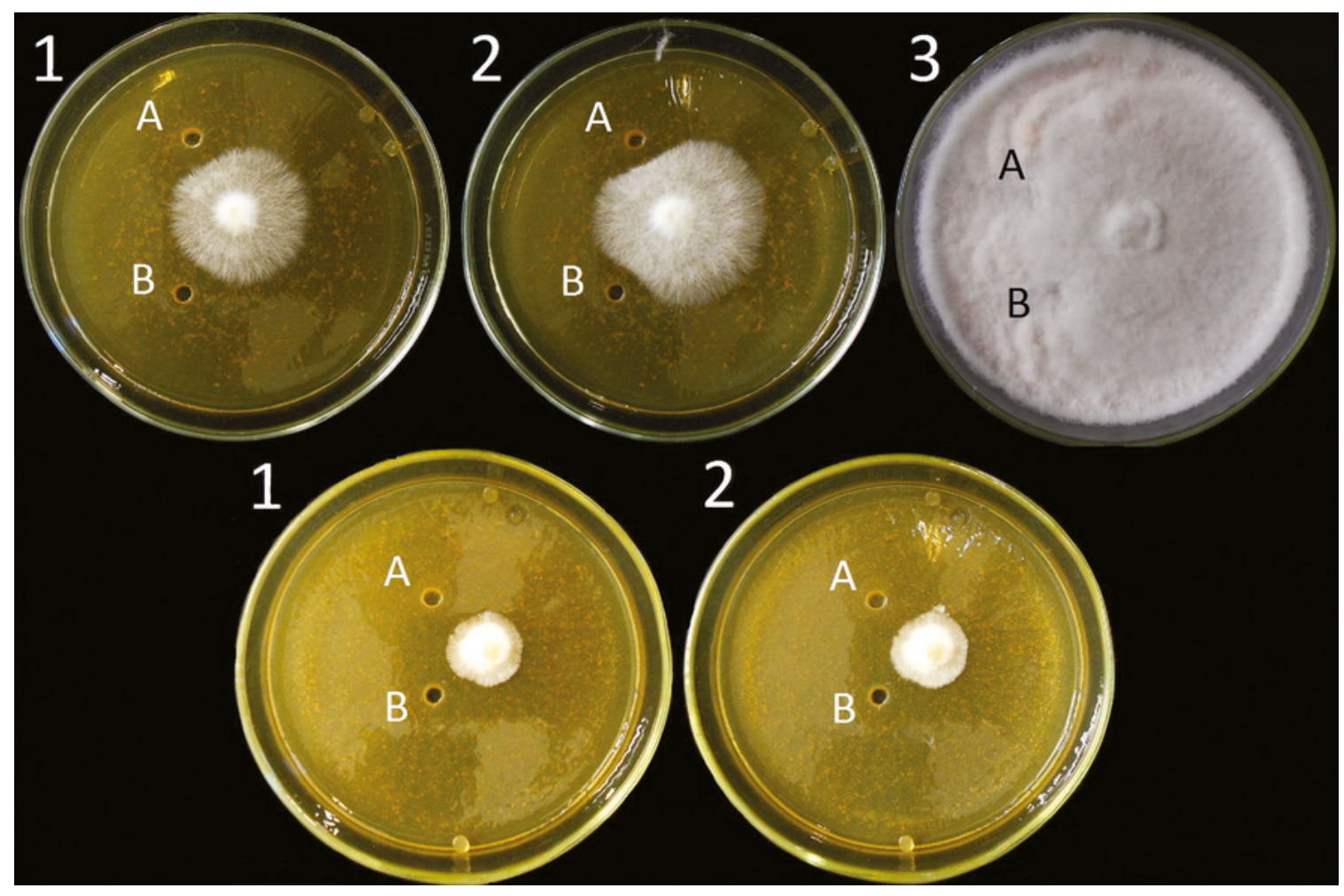

Figure 7 I Inhibition of $P$. ostreatus SZMC 23392 - upper plates, and A. bisporus SZMC 23395 - lower plates, by crude extracts from A) T. aggressivum f. europaeum CBS 433.95 and B) T. pleuroti TPhu1 after 1) 1 day, 2) 2 days, and 3) 1 week of incubation. The $A$. bisporus could not grow further most probably due to lack of nutrients. 


\subsection{Peptaibol production of Trichoderma species from clade Longibrachiatum}

\subsubsection{Peptaibols produced by the species selected from clade Longibrachiatum}

The peptaibol sequences could be categorized into three groups, designated as A (Table 9, Supplementary Tables 1, 4), B (Table 10, Supplementary Tables 2, 5) and C (Table 11, Supplementary Tables 3, 6). EICs resulting from full scan measurements of crude extracts from the examined Trichoderma strains are shown in Supplementary Figures 14-35. The producer species of the compounds are listed in Supplementary Tables 15-16. Groups A and B contain 20-residue-long peptaibols, whereas group C sequences had lost a residue in position R6. Several sequences proved to be homologous or positionally isomeric to the peptaibol subgroups of trichobrachins, paracelsins, suzukacillins, saturnisporins, trichoaureocins, trichocellins, longibrachins, hyporientalins, trichokonins, trilongins, metanicins, trichosporins, gliodeliquescins, ALMs, and hypophellins (see references in Tables 9-11). Some sequences had amino acid exchanges in comparison with previously described compounds from the peptaibol groups listed above. 
TABLE 9 | Sequences of the newly identified group A peptaibol compounds from Trichoderma species of clade Longibrachiatum and their similarities to known peptaibols available in the "Comprehensive Peptaibiotics Database"

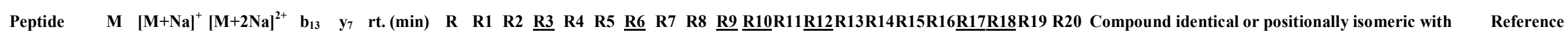

\begin{tabular}{|c|c|c|c|c|c|c|c|}
\hline Pept-A-Ia & 1922 & 1945 & 984 & 1149774 & 35.35 & Ac Aib Ala Aib Ala Aib Ala Gln Aib Vxx Ala Gly Lxx Aib Pro Vxx Aib Aib Gln Gln Pheol Trichoaureocin 1d & Brückner et al. 2002 \\
\hline Pept-A-Ib & 1922 & 1945 & 984 & 1149774 & 36.88 & Ac Aib Ala Aib Ala Aib $\underline{A i b}$ Gln Aib Vxx Ala Gly $\underline{V x x}$ Aib Pro Vxx Aib Aib Gln Gln Pheol New: Trichoaureocin 1d: [Lxx $]^{12} \rightarrow[V x x]^{12}$ & Brückner et al. 2002 \\
\hline \multirow[t]{4}{*}{ Pept-A-IIa } & 1923 & 1946 & 984.5 & 1149775 & 38.26 & 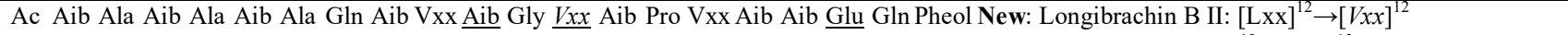 & Leclerc et al. 1998 \\
\hline & & & & & & New: Trilongin CI: $[\mathrm{Lxx}]^{12} \rightarrow[\operatorname{Vxx}]^{12}$ & Mikkola et al. 2012 \\
\hline & & & & & & New: Hypophellin 2: $[\mathrm{Lxx}] 12 \rightarrow[V x x] 12$ & Röhrich et al. 2013 \\
\hline & & & & & & New: Longibrachin B II, Trilongin CI: $[\mathrm{Lxx}]^{12} \rightarrow[V x x]^{12}$ & $\begin{array}{l}\text { Tamandegani et al. } \\
2016\end{array}$ \\
\hline Pept-A-IIb & 1923 & 1946 & 984.5 & 1149775 & 37.46 & Ac Aib Ala Aib Ala Aib Ala Gln Aib Vxx Ala Gly Lxx Aib Pro Vxx Aib Aib Glu Gln Pheol New: Trichoaureocin 1d: [Gln $]^{17} \rightarrow[\text { Glu }]^{17}$ & Brückner et al. 2002 \\
\hline \multirow{12}{*}{$\begin{array}{l}\text { Pept-A- } \\
\text { IIIa }\end{array}$} & 1936 & 1959 & 991 & $1149 \overline{788}$ & 39.82 & 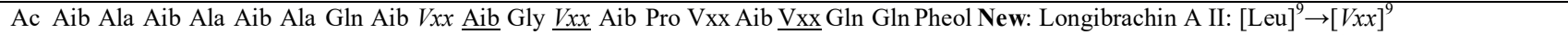 & Leclerc et al. 1998 \\
\hline & & & & & & $\quad \quad-\quad$ New: Paracelsin F: $[\text { Aib }]^{12} \rightarrow[\operatorname{Vxx}]^{12}$ & Pócsfalvi et al. 1997 \\
\hline & & & & & & New: Suzukacillin A 03: $[\mathrm{Aib}]^{12} \rightarrow[V x x]^{12}$ & Krause et al. 2006b \\
\hline & & & & & & New: Suzukacillin A 10a: $[\mathrm{Lxx}]^{12} \rightarrow[V x x]^{12}$ & Krause et al. 2006b \\
\hline & & & & & & New: Trichoaureocin $4:[\mathrm{Lxx}]^{12} \rightarrow[V x x]^{12}$ & Brückner et al. 2002 \\
\hline & & & & & & New: Trichobrachin II 07, 08, 09 IIb B: $[\mathrm{Lxx}]^{12} \rightarrow[V x x]^{12}$ & Krause et al. 2007 \\
\hline & & & & & & New: Trichokonin VII: $[\mathrm{Leu}]^{12} \rightarrow[V x x]^{12^{2}}$ & Huang et al. 1996 \\
\hline & & & & & & New: Trilongin BII: $[\mathrm{Lxx}]^{12} \rightarrow[V x x]^{12}$ & Mikkola et al. 2012 \\
\hline & & & & & & New: Metanicin B: $[\mathrm{Leu}]^{12} \rightarrow[V x x]^{12}$ & $\begin{array}{l}\text { Kimonyo and Brückner } \\
2013\end{array}$ \\
\hline & & & & & & New: Hypophellin 3: $[\mathrm{Lxx}]^{12} \rightarrow[V x x]^{12}$ & Röhrich et al. 2013 \\
\hline & & & & & & New: Pept-1951-c: $[\mathrm{Lxx}]^{12} \rightarrow[V x x]^{12}$ & $\begin{array}{l}\text { Tamandegani et al. } \\
2016\end{array}$ \\
\hline & & & & & & New: Hyporientalin A: $[\text { Aib }]^{12} \rightarrow[V x x]^{12}$ & Touati et al. 2018 \\
\hline \multirow{10}{*}{$\begin{array}{l}\text { Pept-A- } \\
\text { IIIb }\end{array}$} & 1936 & 1959 & 991 & 1149788 & 38.17 & Ac Aib Ala Aib Ala Aib Ala Gln Aib Vxx Ala Gly Lxx Aib Pro Vxx Aib Vxx Gln Gln Pheol New: Longibrachin A II: [Aib $]^{10} \rightarrow[\text { Ala }]^{10}$ & Leclerc et al. 1998 \\
\hline & & & & & & $\quad$ New: Suzukacillin A 10a: $[\text { Aib }]^{10} \rightarrow[\text { Ala }]^{10}$ & Krause et al. 2006b \\
\hline & & & & & & New: Trichoaureocin 4: $[\mathrm{Aib}]^{10} \rightarrow[\text { Ala }]^{10}$ & Brückner et al. 2002 \\
\hline & & & & & & New: Trichoaureocin 1d: $[\mathrm{Aib}]^{17} \rightarrow[\text { Ala }]^{17}$ & Brückner et al. 2002 \\
\hline & & & & & & New: Trichobrachin II 07, 08, 09, IIb B: $[\mathrm{Aib}]^{10} \rightarrow[\mathrm{Ala}]^{10}$ & Krause et al. 2007 \\
\hline & & & & & & New: Trichokonin VII: $[\text { Aib }]^{10} \rightarrow[\text { Ala }]^{10}$ & Huang et al. 1996 \\
\hline & & & & & & New: Trilongin BII: $[\mathrm{Aib}]^{10} \rightarrow[\mathrm{Ala}]^{10}$ & Mikkola et al. 2012 \\
\hline & & & & & & New: Metanicin B: $[\text { Aib }]^{10} \rightarrow[\text { Ala }]^{10}$ & $\begin{array}{l}\text { Kimonyo and Brückner } \\
2013\end{array}$ \\
\hline & & & & & & New: Hypophellin 3: $[\mathrm{Aib}]^{10} \rightarrow[\mathrm{Ala}]^{10}$ & Röhrich et al. 2013 \\
\hline & & & & & & New: Pept-1951-c: $[\text { Aib }]^{10} \rightarrow[\text { Ala }]^{10}$ & $\begin{array}{l}\text { Tamandegani et al. } \\
2016\end{array}$ \\
\hline $\begin{array}{l}\text { Pept-A- } \\
\text { IIIc }\end{array}$ & 1936 & 1959 & 991 & 1149788 & 39.89 & 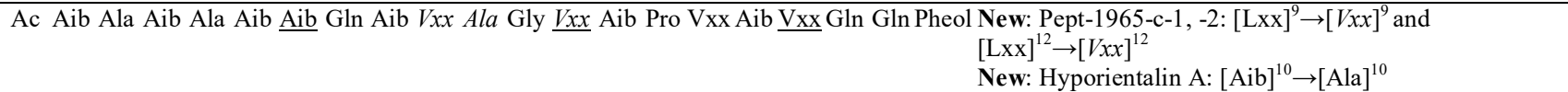 & $\begin{array}{l}\text { Tamandegani et al. } \\
2016 \\
\text { Touati et al. } 2018\end{array}$ \\
\hline
\end{tabular}

Variable residues in table header and minor sequence variants in sequences are underlined. Amino acid exchanges in new compounds are set in italic. 
TABLE 9 | Continued

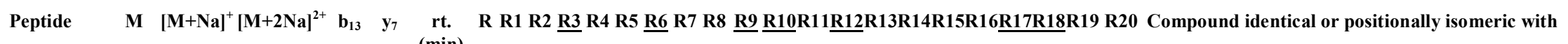

Reference

Pept-A-IVa $1936 \quad 1959 \quad 991 \quad 1163774 \quad 40.21$ AcAibAlaAibAlaAibAla GlnAibVxx Aib Gly Lxx Aib Pro Vxx Aib Aib Gln Gln Pheol Longibrachin A I (Positional isomer of Pept-A-VIIa) Trichoaureocin 3

Trichobrachin II 05, 06 IIb A

Trichokonin VI

Trilongin BI

Metanicin A

Gliodeliquescin A

Hypophellin 1

Longibrachin A I, Trilongin B

Leclerc et al. 1998 Brückner et al. 2002 Krause et al. 2007

Huang et al. 1994

Mikkola et al. 2012

Kimonyo and Brückner

2013

Brückner et al. 1984

Röhrich et al. 2013

Tamandegani et al. 2016

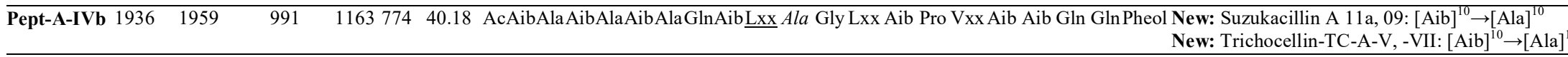

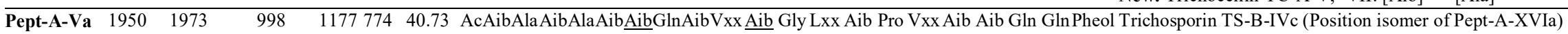
Longibrachin A III

Trichoaureocin 5

Trichobrachin IIb C

Trichokonin VIII

Trilongin BIII

Metanicin C

rause et al. 2006b

Wada et al. 1994

Iida et al. 1990

Leclerc et al. 1998

Brückner et al. 2002

Krause et al. 2007

Huang et al. 1996

Mikkola et al. 2012

Hypophellin 5

Kimonyo and Brückner

2013

Longibrachin A III

Tamandegani et al. 2016

\begin{tabular}{|c|c|c|c|c|c|c|}
\hline Pept-A-Vb & 1950 & 1973 & 998 & 117777441.40 & 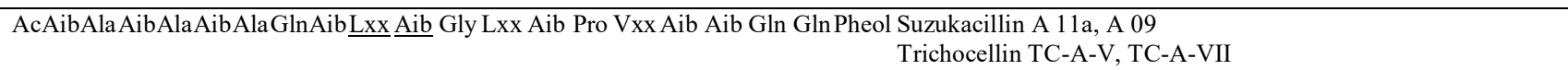 & $\begin{array}{l}\text { Krause et al. 2006b. } \\
\text { Wada et al. } 1994\end{array}$ \\
\hline Pept-A-VIa & 1937 & 1960 & 991.5 & $1163775 \quad 41.46$ & $\begin{array}{ll}\text { AcAibAlaAibAlaAibAlaGlnAibVxx Aib Gly Lxx Aib Pro Vxx Aib Aib Glu GlnPheol Longibrachin B II } & \text { Trilongin CI } \\
& \text { Hypophellin 2 } \\
& \text { Longibrachin B II., Trilongin CI. }\end{array}$ & $\begin{array}{l}\text { Leclerc et al. } 1998 \\
\text { Mikkola et al. } 2012 \\
\text { Röhrich et al. } 2013 \\
\text { Tamandegani et al. } 2016\end{array}$ \\
\hline Pept-A-VIb & 1937 & 1960 & 991.5 & 116377541.50 & 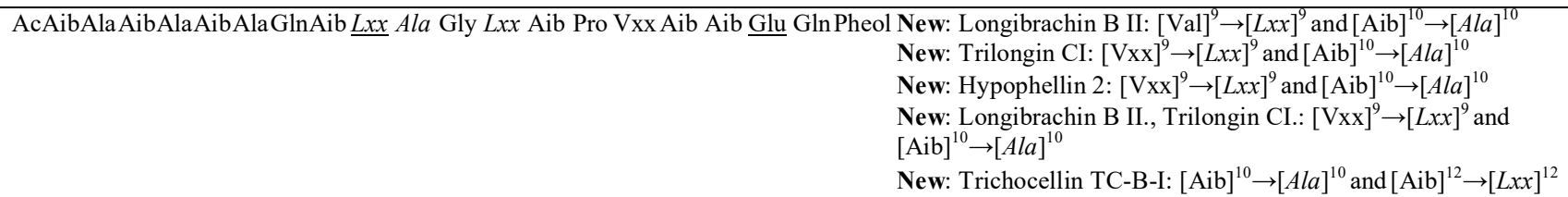 & $\begin{array}{l}\text { Leclerc et al. } 1998 \\
\text { Mikkola et al. } 2012 \\
\text { Röhrich et al. } 2013 \\
\text { Tamandegani et al. } 2016 \\
\text { Wada et al. } 1994\end{array}$ \\
\hline $\begin{array}{l}\text { Pept-A- } \\
\text { VIIa }\end{array}$ & 1936 & 1959 & 991 & $1163774 \quad 41.00$ & AcAibAlaAibAlaAibAlaGlnAibVxx Aib Gly Lxx Aib Pro Vxx Aib Aib Gln Gln Pheol (Positional isomer of Pept-A-IVa) & $\rightarrow$ Pept-A-IVa \\
\hline $\begin{array}{l}\text { Pept-A- } \\
\text { VIIb }\end{array}$ & 1936 & 1959 & 991 & 63774 & xx Aib Aib Gln GlnPheol New: Trichoaureocin 1d: $[\mathrm{Aib}]^{3} \rightarrow[\text { V } x x]^{3}$ & Brückner et al. 2002 \\
\hline
\end{tabular}


TABLE 9 | Continued

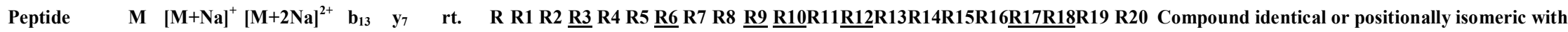
(min)

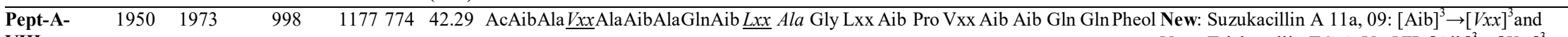

New: Trichocellin-TC-A-V, -VII: $[\mathrm{Aib}]^{3} \rightarrow[V x x]^{3}$ and

Reference

Pept-A-

$[\mathrm{Aib}]^{10} \rightarrow[\text { Ala }]^{10}$

New: Trichoaureocin 1d: $[\mathrm{Aib}]^{3} \rightarrow[V x x]^{3}$ and $[\mathrm{Val}]^{9} \rightarrow[L x x]^{9}$

Krause et al. 2006b Wada et al. 1994

Brückner et al. 2002

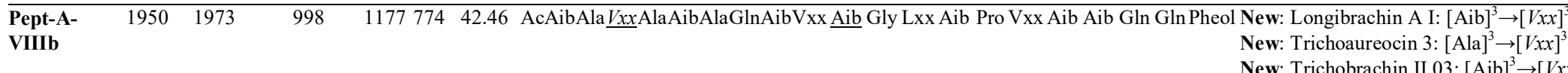

New: Trichoaureocin $3:[\mathrm{Ala}]^{3} \rightarrow[\mathrm{Vxx}]^{3} \quad$ Brückner et 1998

New: Trichobrachin II 03: $[\mathrm{Aib}]^{3} \rightarrow\left[V_{x x}\right]^{3}$

New: Trichobrachin II 05, 06 IIb A: $[\mathrm{Aib}]^{3} \rightarrow[V x x]^{3} \quad$ Krause et al. 2007

New: Trichokonin IIc: $[\mathrm{Ala}]^{3} \rightarrow[\mathrm{Vxx}]^{3} \quad$ Huang et al. 1996

New: Trichokonin VI: $[\mathrm{Aib}]^{3} \rightarrow[\mathrm{Vxx}]^{3}$

Huang et al. 1994

New: Trilongin BI: $[\mathrm{Aib}]^{3} \rightarrow[\mathrm{Vxx}]^{3}$

Muang et al. 1994

New: Metanicin A: $[\mathrm{Aib}]^{3} \rightarrow[\mathrm{Vxx}]^{3}$

Kimonyo and Brückner

New: Gliodeliquescin A: $[\mathrm{Aib}]^{3} \rightarrow[\mathrm{Vxx}]^{3}$

New: Hypophellin 1: $[\mathrm{Aib}]^{3} \rightarrow[V x x]^{3}$

2013

New: Longibrachin A I, Trilongin BI: $[\mathrm{Aib}]^{3} \rightarrow[\mathrm{Vxx}]^{3}$

Brückner et al. 1984

Röhrich et al. 2013

Tamandegani et al. 2016

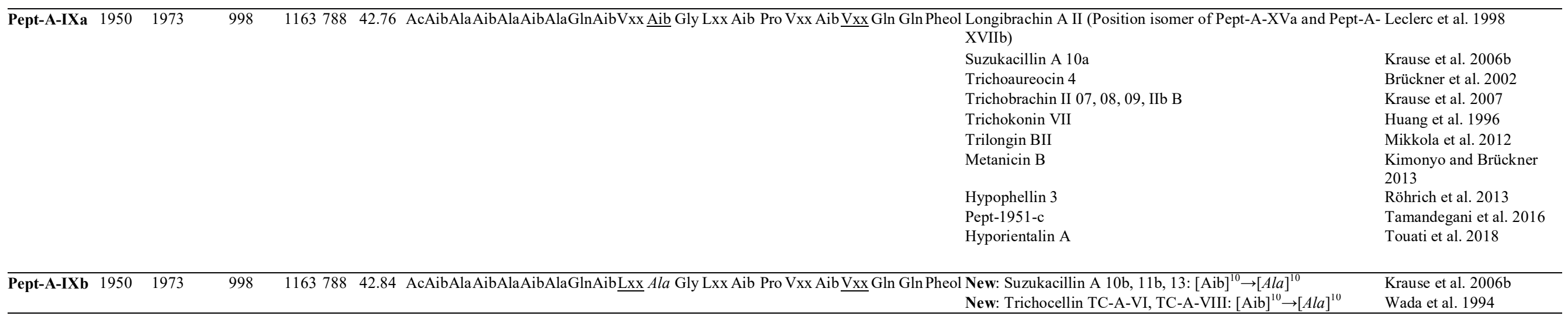


TABLE 9 | Continued

Peptide $\quad M \quad[M+N a]^{+}[M+2 N a]^{2+} \quad b_{13} \quad y_{7} \quad$ rt. $\quad$ R R1 R2 R3 R4 R5 R6 R7 R8 R9 R10R11R12R13R14R15R16R17R18R19 R20 Compound identical or positionally isomeric with

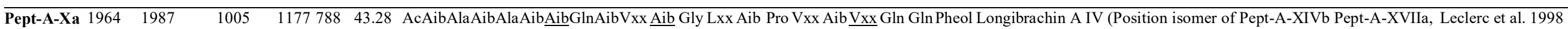
Pept-A-XXIa and Pept-XXVa)

Trichoaureocin $6 \quad$ Brückner et al. 2002

Trichobrachin II 10, IIb D

Trichokonin IX

Trilongin BIV

Metanicin D

Krause et al. 2007

Huang et al. 1995

Mikkola et al. 2012

Hypophellin 7

Kimonyo and

Brückner 2013

Pept-A-Xb $1964 \quad 1987 \quad 1005 \quad 1177788 \quad 42.89$ AcAibAlaAibAlaAibAla GlnAibLxx Aib Gly Lxx Aib Pro Vxx Aib Vxx Gln Gln Pheol Suzukacillin A 10b, 11b, 13

Trichocellin TC-A-VI, TC-A-VIII

Röhrich et al. 2013

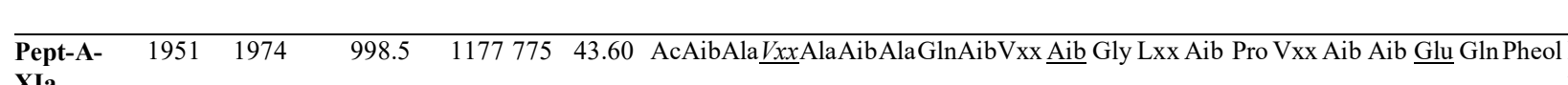

New: Longibrachin B II: $[\mathrm{Aib}]^{3} \rightarrow[V x x]^{3}$

Wada et al. 1994

Xer

New: Trilongin CI: $[\mathrm{Aib}]^{3} \rightarrow[\mathrm{Vxx}]^{3}$

New: Hypophellin 2: $[\mathrm{Aib}]^{3} \rightarrow[\mathrm{Vxx}]^{3}$

Leclerc et al. 1998

New: Longibrachin B II., Trilongin CI.: $[\mathrm{Aib}]^{3} \rightarrow[V x x]^{3}$

Mikkola et al. 2012

Röhrich et al. 2013

Tamandegani et al.

2016

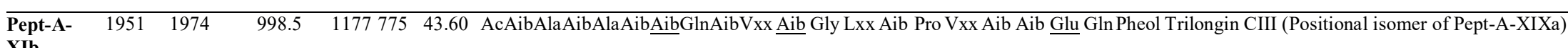

Mikkola et al. 2012

XI

Hypophellin 6

Longibrachin B III., Trilongin CIII.

Röhrich et al. 201

Tamandegani et al.

2016

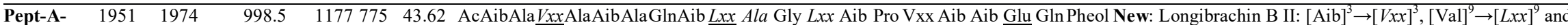

Leclerc et al. 1998

XIc

$[\text { Aib }]^{10} \rightarrow[\text { Ala }]^{10}$

New: Trilongin CI: $[\mathrm{Aib}]^{3} \rightarrow[V x x]^{3},[\mathrm{Vxx}]^{9} \rightarrow[L x x]^{9}$ and

$[\text { Aib }]^{10} \rightarrow[\text { Ala }]^{10}$

New: Hypophellin 2: $[\mathrm{Aib}]^{3} \rightarrow[\mathrm{Vxx}]^{3},[\mathrm{Vxx}]^{9} \rightarrow[L x x]^{9}$ and

Mikkola et al. 2012

$[\mathrm{Aib}]^{10} \rightarrow[\text { Ala }]^{10}$

New: Longibrachin B II., Trilongin CI.: $[\mathrm{Aib}]^{3} \rightarrow[\mathrm{Vxx}]^{3}$,

$[\mathrm{Vxx}]^{9} \rightarrow[\text { Lxx }]^{9}$ and $[\mathrm{Aib}]^{10} \rightarrow[\text { Ala }]^{10}$

New: Trichocellin TC-B-I: $[\text { Aib }]^{3} \rightarrow[V x x]^{3},[\text { Aib }]^{10} \rightarrow[\text { Ala }]^{10}$ and

$[\mathrm{Aib}]^{12} \rightarrow[L x x]^{12}$

Pept-A- $1937 \quad 1960 \quad 991.5 \quad 1163775 \quad 42.81$ AcAibAlaAibAlaAibAlaGlnAib Lxx Ala Gly Lxx Aib Pro Vxx Aib Aib Glu Gln Pheol (Positional isomer of Pept-A-VIb)

Röhrich et al. 2013

Tamandegani et al.

2016

Wada et al. 1994

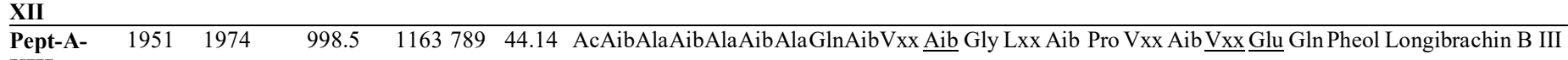

$\rightarrow$ Pept-A-VIb

XIIIa

Trilongin CII

Hypophellin 4

Pept-1952-d

Mikkola et al. 2012

Röhrich et al. 2013

Tamandegani et al.

2016

Longibrachin A II., Trilongin BII.

016 
TABLE 9 | Continued

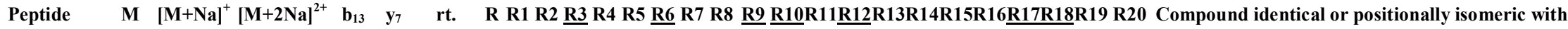

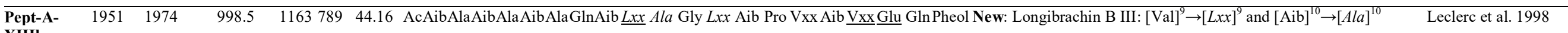
XIIIb

New: Trilongin CII: $[\mathrm{Vxx}]^{9} \rightarrow[L x x]^{9}$ and $[\mathrm{Aib}]^{10} \rightarrow[\text { Ala }]^{10}$

Mikkola et al. 2012 New: Hypophellin 4: $[\mathrm{Vxx}]^{9} \rightarrow[L x x]^{9}$ and $[\text { Aib }]^{10} \rightarrow[\text { Ala }]^{10}$ Röhrich et al. 2013

New: Pept-1952-d: $[\mathrm{Vxx}]^{9} \rightarrow[L x x]^{9}$ and $[\mathrm{Aib}]^{10} \rightarrow[\text { Ala }]^{1}$

Tamandegani et al

New: Longibrachin B II., Trilongin CI.: $[\mathrm{Vxx}]^{9} \rightarrow[L x x]^{9}$ and 2016

New: Longibrac
$[\text { Aib }]^{10} \rightarrow[\text { Ala }]^{10}$

Tamandegani et al

New: Trichocel

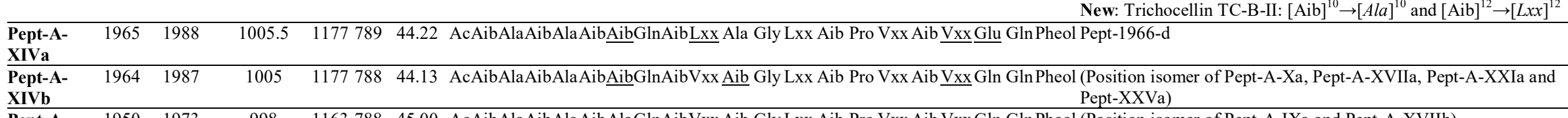

2016

Wada et al. 1994 Tamandegani et al. 016

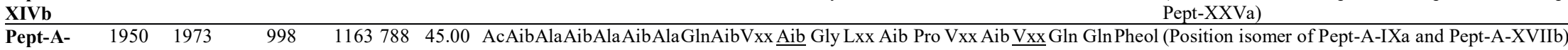

$\rightarrow$ Pept-A-Xa

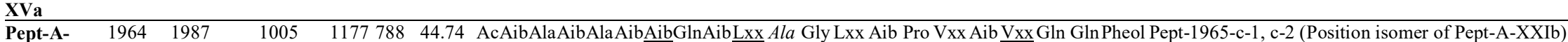

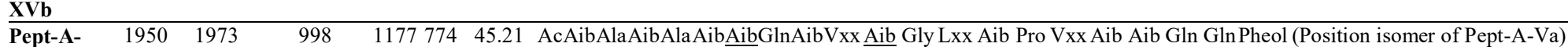

$\begin{array}{lllllll}\text { Pept-A- } & 1950 & 1973 & 998 & 1177 & 774 & 45.21 \text { AcAibAlaAibAlaAibAibGlnAibVxx Aib Gly Lxx Aib Pro Vxx Aib Aib Gln Gln Pheol (Position isomer of Pept-A-Va) }\end{array}$

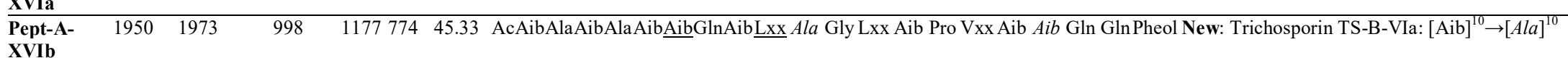

2016

New: Trichoderma citrinoviride sequence 7: $[\text { Aib }]^{10} \rightarrow[\text { Ala }]^{10}$

New: Pept-1965-c-1, c-2: [Vxx $]^{17} \rightarrow[A i b]$

Tida et al. 1990 Tamandegani et al. 2016

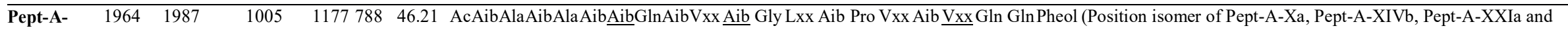

$\rightarrow$ Pept-A-Xa

XVIIa

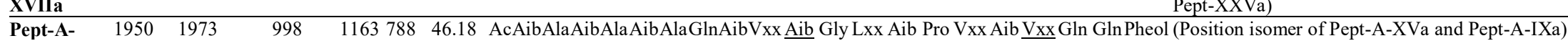

$\rightarrow$ Pept-A-IXa

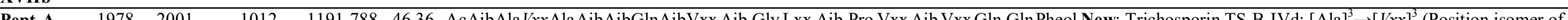

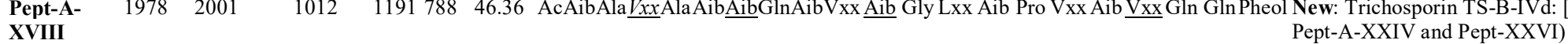

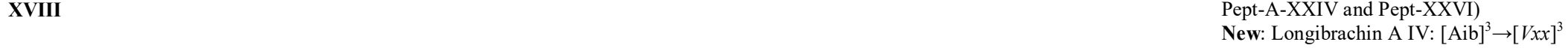

New: Trichoaureocin 6: $[\mathrm{Aib}]^{3} \rightarrow[\operatorname{Vxx}]^{3}$

New: Trichobrachin II 10 , IIb D: $[\mathrm{Aib}]^{3} \rightarrow[\mathrm{Vxx}]^{3}$

New: Trichokonin IX: $[\mathrm{Aib}]^{3} \rightarrow[\mathrm{Vxx}]^{3}$

New: Trilongin BIV: $[\mathrm{Aib}]^{3} \rightarrow[V x x]^{3}$

New: Metanicin D: $[\mathrm{Aib}]^{3} \rightarrow[\mathrm{Vxx}]^{3}$

New: Hypophellin 7: $[\mathrm{Aib}]^{3} \rightarrow[V x x]^{3}$

lida et al. 1990

Leclerc et al. 1998 Brückner et al. 2002 Krause et al. 2007

Huang et al. 1995

Mikkola et al. 2012

Kimonyo and Brückner

2013

Röhrich et al. 2013 
TABLE 9 | Continued

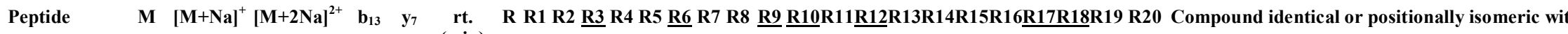

\begin{tabular}{|c|c|c|c|c|c|c|c|}
\hline Pept-A-XIXb & 1951 & 1974 & 998.5 & 1177775 & 46.86 & $\begin{aligned} \text { AcAibAla AibAlaAibAibGlnAibLxx } \underline{\text { Ala }} \text { Gly } \underline{\text { Lxx }} \text { Aib Pro Vxx Aib Aib } \underline{\text { Glu }} \text { GlnPheol New: Trichosporin TS-B-VIa: }[\text { Aib }]^{10} \rightarrow[\text { Ala }]^{10} \text { and } & \\
& {[\text { Gln }]^{18} \rightarrow[\text { Glu }]^{18} } \\
& \text { New: Trichoderma citrinoviride sequence } 7,[\text { Aib }]^{10} \rightarrow[\text { Ala }]^{10} \\
& \text { and }[\text { Gln }]^{18} \rightarrow[\text { Glu }]^{18} \\
& \text { New: Pept-1965-c-1, c-2: }[\text { Vxx }]^{17} \rightarrow[\text { Aib }]^{17} \text { and }[\text { Gln }]^{18} \rightarrow[\text { Glu }]^{18}\end{aligned}$ & $\begin{array}{l}\text { Iida et al. } 1990 \\
\text { Maddau et al. } 2009 \\
{ }^{8} \text { Tamandegani et al. } 2016\end{array}$ \\
\hline Pept-A-XX & 1964 & 1987 & 1005 & 1191774 & 47.30 & 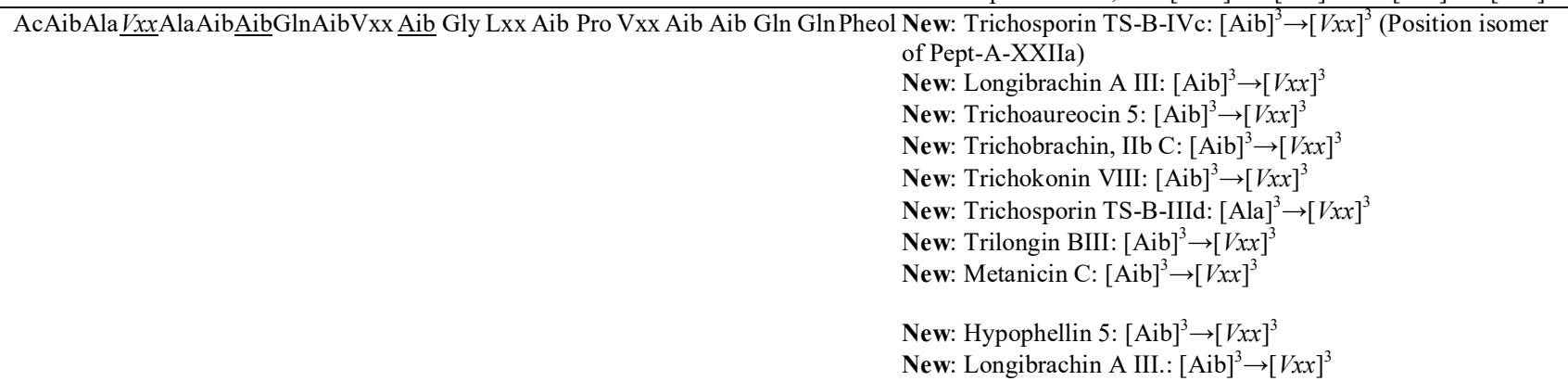 & $\begin{array}{l}\text { Iida et al. } 1990 \\
\text { Leclerc et al. } 1998 \\
\text { Brückner et al. } 2002 \\
\text { Krause et al. } 2007 \\
\text { Huang et al. } 1996 \\
\text { Iida et al. } 1990 \\
\text { Mikkola et al. } 2012 \\
\text { Kimonyo and Brückner } \\
2013 \\
\text { Röhrich et al. } 2013 \\
\text { Tamandegani et al. } 2016\end{array}$ \\
\hline Pept-A-XXIa & 1964 & 1987 & 1005 & 1177788 & 47.85 & 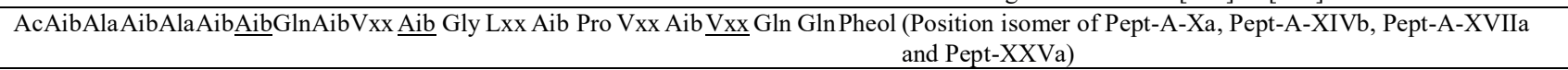 & $\rightarrow$ Pept-A-Xa \\
\hline Pept-A-XXIb & 1964 & 1987 & 1005 & 1177788 & 47.75 & AcAibAlaAibAlaAibAibGlnAibLxx Ala Gly Lxx Aib Pro Vxx AibVxx Gln GlnPheol (Position isomer of Pept-A-XVb) & $\rightarrow$ Pept-A-XVb \\
\hline $\begin{array}{l}\text { Pept-A- } \\
\text { XXIIa }\end{array}$ & 1964 & 1987 & 1005 & 1191774 & 48.93 & AcAibAla $\underline{V x}$ AlaAibAibGlnAibVxx Aib Gly Lxx Aib Pro Vxx Aib Aib Gln GlnPheol New: (Position isomer of Pept-A-XX) & $\rightarrow$ Pept-A-XX \\
\hline $\begin{array}{l}\text { Pept-A- } \\
\text { XXIII }\end{array}$ & 1965 & 1988 & 1005.5 & 1177789 & 49.13 & 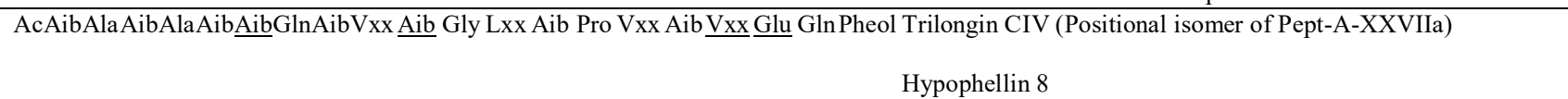 & $\begin{array}{l}\text { Mikkola et al. } 2012 \\
\text { Röhrich et al. } 2013\end{array}$ \\
\hline 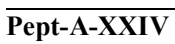 & 1978 & 2001 & 1012 & 1191788 & 49.89 & 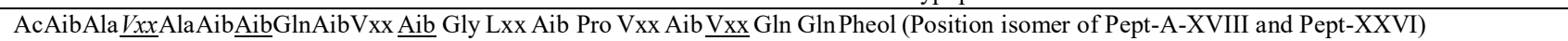 & $\rightarrow$ Pept-A-XVIII \\
\hline $\begin{array}{l}\text { Pept-A- } \\
\text { XXVa }\end{array}$ & 1964 & 1987 & 1005 & 1177788 & 49.65 & 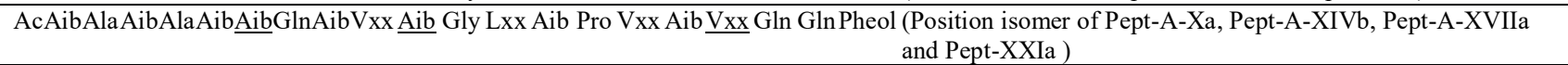 & $\rightarrow$ Pept-A-Xa \\
\hline $\begin{array}{l}\text { Pept-A- } \\
\text { XXVb }\end{array}$ & 1978 & 2001 & 1012 & 1191788 & 49.72 & 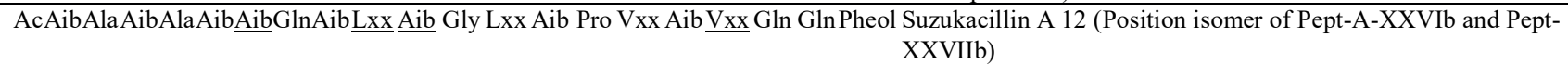 & Krause et al. 2006b \\
\hline $\begin{array}{l}\text { Pept-A- } \\
\text { XXVIa }\end{array}$ & 1978 & 2001 & 1012 & 1191788 & 51.29 & 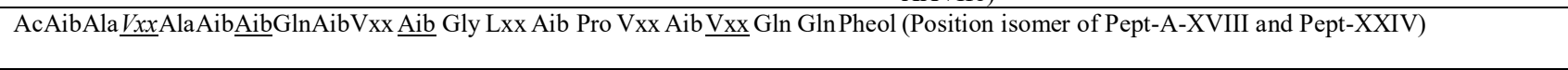 & $\rightarrow$ Pept-A-XVIII \\
\hline $\begin{array}{l}\text { Pept-A- } \\
\text { XXVIb }\end{array}$ & 1978 & 2001 & 1012 & 1191788 & 50.85 & 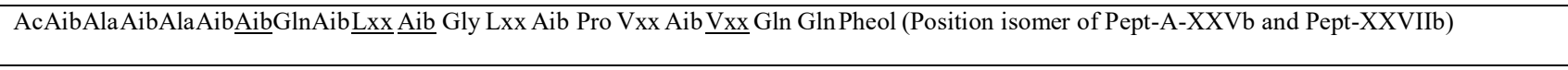 & $\rightarrow$ Pept-A-XVb \\
\hline $\begin{array}{l}\text { Pept-A- } \\
\text { XXVIIa }\end{array}$ & 1965 & 1988 & 1005.5 & 1177789 & 51.44 & 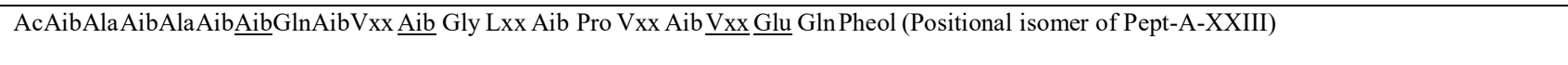 & $\rightarrow$ Pept-A-XXIII \\
\hline $\begin{array}{l}\text { Pept-A- } \\
\text { XXVIIb } \\
\end{array}$ & 1978 & 2001 & 1012 & 1191788 & 51.59 & 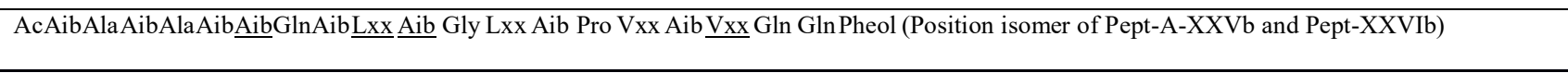 & $\rightarrow$ Pept-A-XVb \\
\hline
\end{tabular}


TABLE 10 I Sequences of the newly identified group B peptaibol compounds from Trichoderma species of clade Longibrachiatum and their similarities to known peptaibols available in the "Comprehensive Peptaibiotics Database"

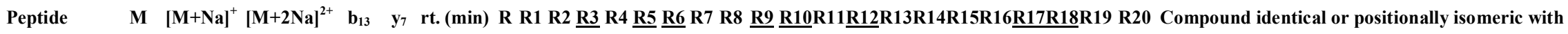

Reference

\begin{tabular}{|c|c|c|c|c|c|c|c|}
\hline Pept-B-I & 1908 & 1931 & 977 & 1135774 & 22.59 & $\begin{array}{l}\text { AcAibAla AlaAlaAibAlaGlnAibLxx Aib Gly Aib Aib Pro Vxx Aib Aib Gln Gln Pheol New: Paracelsin B: }[\text { Aib }]^{3} \rightarrow[\text { Ala }]^{3} \text { (Positional isomer of Pept-B-II, } \\
\text { III and V) } \\
\text { New: Saturnisporin SA I: }[\text { Aib }]^{3} \rightarrow[\text { Ala }]^{3} \\
\text { New: Suzukacillin A 02, A 06: }[\text { Aib }]^{3} \rightarrow[\text { Ala }]^{3} \\
\text { New: Trichocellin TC-A-I, TC-A-III: }[\text { Aib }]^{3} \rightarrow[\text { Ala }]^{3}\end{array}$ & $\begin{array}{l}\text { Pócsfalvi et al. } 1997 \\
\text { Rebuffat et al. } 1993 \\
\text { Krause et al. } 2006 \mathrm{~b} \\
\text { Wada et al. } 1994\end{array}$ \\
\hline Pept-B-II & 1908 & 1931 & 977 & 1135774 & 24.79 & AcAibAla Ala AlaAibAlaGlnAibLxx Aib Gly Aib Aib Pro Vxx Aib Aib Gln Gln Pheol New: (Positional isomer of Pept-B-I, III and V) & $\rightarrow$ Pept-B-I \\
\hline Pept-B-III & 1908 & 1931 & 977 & 1135774 & 25.62 & AcAibAla_AlaAlaAibAlaGlnAibLxx Aib Gly Aib Aib Pro Vxx Aib Aib Gln Gln Pheol New: (Positional isomer of Pept-B-I, II and V) & $\rightarrow$ Pept-B-I \\
\hline Pept-B-IV & 1922 & 1945 & 984 & 1135788 & 25.72 & 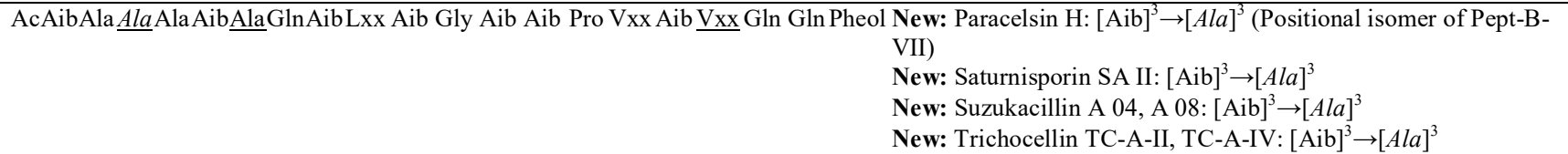 & $\begin{array}{l}\text { Pócsfalvi et al. } 1997 \\
\text { Rebuffat et al. } 1993 \\
\text { Krause et al. } 2006 \mathrm{~b} \\
\text { Wada et al. } 1994\end{array}$ \\
\hline Pept-B-V & 1908 & 1931 & 977 & 1135774 & 26.35 & AcAibAla AlaAla AibAlaGlnAibLxx Aib Gly Aib Aib Pro Vxx Aib Aib Gln Gln Pheol New: (Positional isomer of Pept-B-I, II and III) & $\rightarrow$ Pept-B-I \\
\hline Pept-B-VI & 1922 & 1945 & 984 & 1149774 & 27.22 & $\begin{array}{l}\text { AcAibAlaAibAlaAibAla GlnAibLxx Aib Gly Aib Aib Pro Vxx Aib Aib Gln Gln Pheol Paracelsin B (Positional isomer of Pept-B-XII, XVIII and XXIII) } \\
\text { Saturnisporin SA I } \\
\text { Suzukacillin A 02, A 06 } \\
\text { Trichocellin TC-A-I, TC-A-III }\end{array}$ & $\begin{array}{l}\text { Pócsfalvi et al. } 1997 \\
\text { Rebuffat et al. } 1993 \\
\text { Krause et al. } 2006 \mathrm{~b} \\
\text { Wada et al. } 1994\end{array}$ \\
\hline Pept-B-VII & 1922 & 1945 & 984 & 1135788 & 27.80 & AcAibAla Ala AlaAibAla GlnAibLxx Aib Gly Aib Aib Pro Vxx AibVxx Gln Gln Pheol New: (Positional isomer of Pept-B-IV) & $\rightarrow$ Pept-B-IV \\
\hline$\overline{\text { Pept-B-VIII }}$ & 1936 & 1959 & 991 & 1149788 & 27.27 & $\begin{array}{ll}\text { AcAibAlaAibAla AibAla GlnAibLxx Aib Gly Aib Aib Pro Vxx Aib } \underline{\overline{V x x}} \text { Gln Gln Pheol Paracelsin H (Positional isomer of Pept-B-XVII, XIX, XXII and } & \text { XXIXb) } \\
& \text { Saturnisporin SA II } \\
& \text { Suzukacillin A 04, A 08 } \\
& \text { Trichocellin TC-A-II, TC-A-IV }\end{array}$ & $\begin{array}{l}\text { Pócsfalvi et al. } 1997 \\
\text { Rebuffat et al. } 1993 \\
\text { Krause et al. } 2006 \mathrm{~b} \\
\text { Wada et al. } 1994\end{array}$ \\
\hline Pept-B-IXa & 1908 & 1931 & 977 & 1135774 & 28.44 & $\begin{array}{c}\text { AcAibAlaAibAlaAibAlaGlnAibVxx Aib Gly Aib Aib Pro Vxx Aib Aib Gln Gln Pheol Paracelsin A } \\
\text { Suzukacillin A } 01\end{array}$ & $\begin{array}{l}\text { Pócsfalvi et al. } 1997 \\
\text { Krause et al. } 2006 \mathrm{~b}\end{array}$ \\
\hline Pept-B-IXb & 1908 & 1931 & 977 & 1135774 & 28.38 & AcAibAlaAibAlaAibAlaGlnAibLxx Aib Gly Ala Aib Pro Vxx Aib Aib Gln Gln Pheol New: Trichoderma citrinoviride sequence 1: [Vxx $]^{17} \rightarrow[\text { Aib }]^{17}$ & Maddau et al. 2009 \\
\hline Pept-B-X & 1922 & 1945 & 984 & 1135788 & 28.77 & 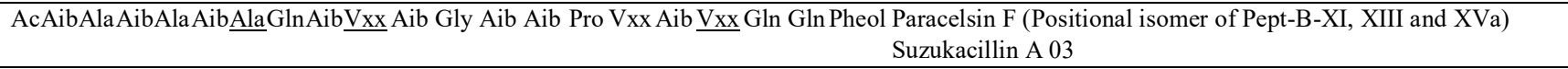 & $\begin{array}{l}\text { Pócsfalvi et al. } 1997 \\
\text { Krause et al. } 2006 \mathrm{~b}\end{array}$ \\
\hline Pept-B-XI & 1922 & 1945 & 984 & 1135788 & 29.25 & 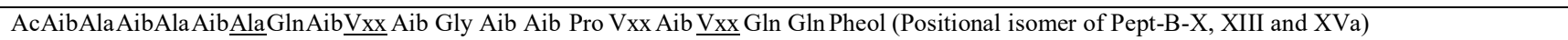 & $\rightarrow$ Pept-B-X \\
\hline Pept-B-XII & 1922 & 1945 & 984 & 1149774 & 29.90 & AcAibAlaAibAla AibAlaGlnAibLxx Aib Gly Aib Aib Pro Vxx Aib Aib Gln Gln Pheol (Positional isomer of Pept-B-VI, XVIII and XXIII) & $\rightarrow$ Pept-B-VI \\
\hline Pept-B-XIII & 1922 & 1945 & 984 & 1135788 & 30.28 & AcAibAlaAibAla AibAlaGlnAibVxx Aib Gly Aib Aib Pro Vxx Aib Vxx Gln Gln Pheol (Positional isomer of Pept-B-X, XI and XVa) & $\rightarrow$ Pept-B-X \\
\hline 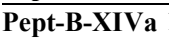 & 1923 & 1946 & 984.5 & 1149775 & 31.36 & AcAibAlaAibAlaAibAlaGlnAibLxx Aib Gly Aib Aib Pro Vxx Aib Aib Glu Gln Pheol Trichocellin TC-B-I & Wada et al. 1994 \\
\hline Pept-B-XIVb & 1923 & 1946 & 984.5 & 1149775 & 31.40 & AcAibAlaAibAlaAib $A i b$ GlnAib $V x x$ Aib Gly Aib Aib Pro Vxx Aib Aib Glu Gln Pheol New: Trichocellin TC-B-I: $[\text { Ala }]^{6} \rightarrow[A i b]^{6}$ and [Leu $]^{9} \rightarrow[V x x]^{9}$ & Wada et al. 1994 \\
\hline
\end{tabular}

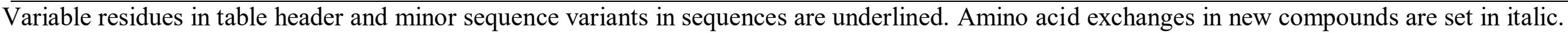


TABLE 10 | Continued

\begin{tabular}{|c|c|c|c|c|c|c|c|}
\hline ept-B-XVa & 1922 & 1945 & 984 & 1135788 & 31.48 & 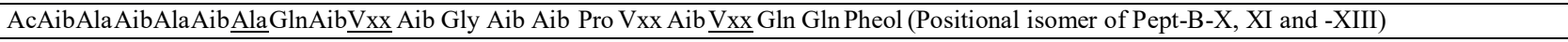 & $\rightarrow$ Pept-B-X \\
\hline Pept-B-XVb & 1922 & 1945 & 984 & 1135788 & 31.53 & 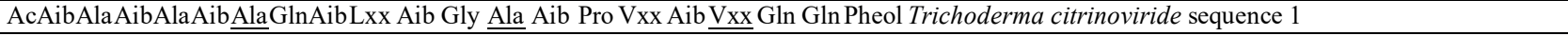 & Maddau et al. 2009 \\
\hline ept-B-XVI & 1922 & 1945 & 984 & 1149774 & 31.98 & AcAibAlaAibAlaAibAibGlnAibVxx Aib Gly Aib Aib Pro Vxx Aib Aib Gln Gln Pheol Paracelsin C & Pócsfalvi et al. 1997 \\
\hline Pept-B-XVII & 1936 & 1959 & 991 & 1149788 & 32.67 & AcAibAlaAibAlaAib AlaGlnAibLxx Aib Gly Aib Aib Pro Vxx Aib Vxx Gln Gln Pheol (Positional isomer of Pept-B-VIII, XIX, XXII and XXIXb) & $\rightarrow$ Pept-B-VIII \\
\hline Pept-B-XVIII & 1922 & 1945 & 984 & 1149774 & 33.49 & AcAibAlaAibAlaAibAlaGlnAibLxx Aib Gly Aib Aib Pro Vxx Aib Aib Gln Gln Pheol (Positional isomer of Pept-B-VI, XII and XXIII) & $\rightarrow$ Pept-B-VI \\
\hline ept-B-XIX & 1936 & 1959 & 991 & 1149788 & 33.55 & 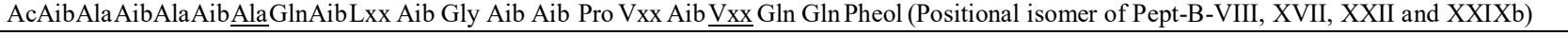 & $\rightarrow$ Pept-B-VIII \\
\hline 'ept-B-XX & 1936 & 959 & 991 & 1163774 & 34.41 & $\begin{array}{l}\text { AcAibAlaAibAlaAibAibGlnAibLxx Aib Gly Aib Aib Pro Vxx Aib Aib Gln Gln Pheol Paracelsin D (Positional isomer of Pept-B-XXXIIIa, XXXVa, } \\
\text { XLIIb, XLVIa and LVIII) } \\
\text { Saturnisporin SA III } \\
\text { Suzukacillin A 05 }\end{array}$ & $\begin{array}{l}\text { Rebuffat et al. } 1993 \\
\text { Krause et al. 2006b }\end{array}$ \\
\hline ept-B- & 1937 & 960 & 991.5 & 149789 & 34.15 & 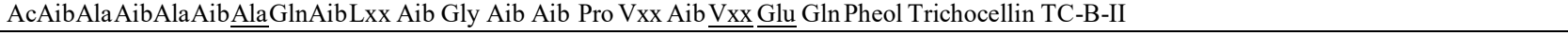 & 1994 \\
\hline ept-B-XXII & 1936 & 1959 & 991 & 1149788 & 34.59 & AcAibAlaAibAlaAibAla GlnAibLxx Aib Gly Aib Aib Pro Vxx Aib Vxx Gln Gln Pheol (Posi & -VIIII \\
\hline Pept-B-XXIII & 1922 & 1945 & 984 & 1149774 & 35.25 & AcAibAlaAibAlaAibAlaGlnAibLxx Aib Gly Aib Aib Pro Vxx Aib Aib Gln Gln Pheol (Positional isomer of Pept-B-VI, XII and XVIII) & $\rightarrow$ Pept-B-VI \\
\hline
\end{tabular}

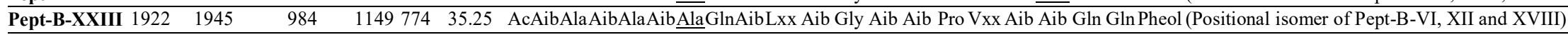

Pept-B-VI

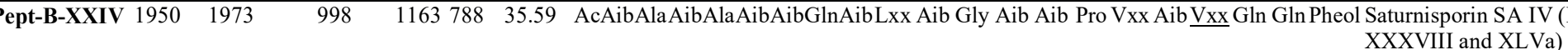

XXXVIII and XLVa)
Suzukacillin A 07

Longibrachin B II., Trilongin CI.

Krause et al. 2006b

Tamandegani et al.

2016

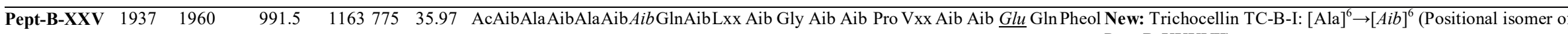
Pept-B-XXXVII)

New: Paracelsin D: $[\mathrm{Gln}]^{18} \rightarrow[G l u]^{18}$

New: Saturnisporin SA III: $[\mathrm{Gln}]^{18} \rightarrow[G l u]^{18}$

New: Suzukacillin A 05: $[\mathrm{Gln}]^{18} \rightarrow[\mathrm{Glu}]^{18}$

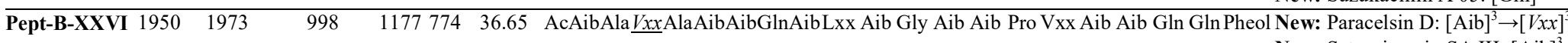

New: Saturnisporin SA III: $[\mathrm{Aib}]^{3} \rightarrow[\mathrm{V} x x]^{3}$

Wada et al. 1994

Pócsfalvi et al. 1997 Rebuffat et al. 1993 Krause et al. 2006b Pócsfalvi et al. 1997 Rebuffat et al. 1993 New: Suzukacillin A $05:[\mathrm{Aib}]^{3} \rightarrow[V x x]^{3}$ Krause et al. 2006b

Pept-B19501973

998 7.31 AcA (Positional isomer of Pept-B-XXIV,

Pócsfalvi et al. 1997

Pept-B-

9501973

998

New: Saturnisporin SA III: $[\mathrm{Aib}]^{5} \rightarrow[V x x]^{3}$ New: Suzukacillin A 05: $[\mathrm{Aib}]^{5} \rightarrow[V x x]^{5}$

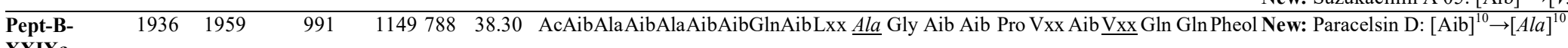
Krause et al. 2006b XXIXa 


\section{TABLE 10 | Continued}

\begin{tabular}{|c|c|c|c|c|c|c|c|}
\hline Pept-B-XXIXb & 1936 & 1959 & 991 & 1149788 & 37.80 & cAibAlaAibAlaAibAlaGlnAibLxx Aib Gly Aib Aib Pro Vxx Aib Vxx Gln Gln Pheol (Positional isomer of Pept-B-VIII, XVII, XIX and XXII) & $\rightarrow$ Pept-B-VIII \\
\hline 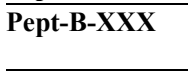 & 1950 & 1973 & 998 & 1177774 & 38.51 & $\begin{array}{c}\text { AcAibAlaAibAla AibAibGlnAibLxx Aib Gly Vxx Aib Pro Vxx Aib Aib Gln Gln Pheol Trichoderma citrinoviride sequence } 4 \text { (Positional isomer of Pept- } \\
\text { B-XXXIIIc, XLIIa, XLVIb and LIII) }\end{array}$ & Maddau et al. 2009 \\
\hline Pept-B-XXXI & 1951 & 1974 & 998.5 & 163789 & 39.13 & 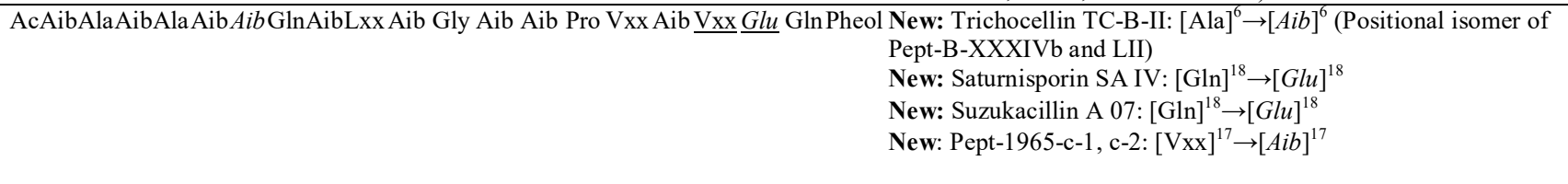 & $\begin{array}{l}\text { Wada et al. } 1994 \\
\text { Rebuffat et al. } 1993 \\
\text { Krause et al. } 2006 \mathrm{~b} \\
\text { Tamandegani et al. } \\
2016\end{array}$ \\
\hline $\begin{array}{l}\text { Pept-B- } \\
\text { XXXIIa }\end{array}$ & 1950 & 1973 & 998 & 163788 & 39.15 & 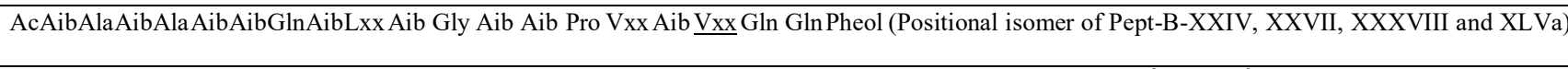 & $\rightarrow$ Pept-B-XXIV \\
\hline $\begin{array}{l}\text { Pept-B- } \\
\text { XXXIIb }\end{array}$ & 1964 & 1987 & 1005 & 1177788 & 39.20 & 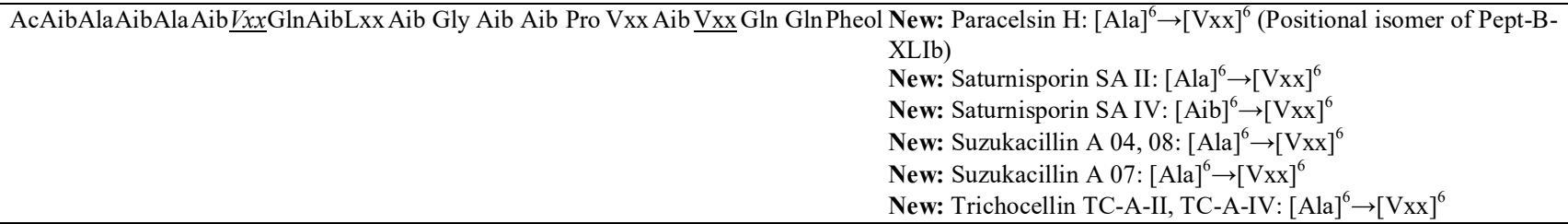 & $\begin{array}{l}\text { Pócsfalvi et al. } 1997 \\
\text { Rebuffat et al. } 1993 \\
\text { Rebuffat et al. } 1993 \\
\text { Krause et al. 2006b } \\
\text { Krause et al. 2006b } \\
\text { Wada et al. } 1994\end{array}$ \\
\hline $\begin{array}{l}\text { Pept-B- } \\
\text { XXXIIIa }\end{array}$ & 1936 & 1959 & 991 & 1163774 & 38.98 & $\begin{array}{l}\text { AcAibAlaAibAlaAibAibGlnAibLxx Aib Gly Aib Aib Pro Vxx Aib Aib Gln Gln Pheol (Positional isomer of Pept-B-XX, XXXVa, XLIIb, XLVIa and } \\
\text { LVIII) }\end{array}$ & $\rightarrow$ Pept-B-XX \\
\hline $\begin{array}{l}\text { Pept-B- } \\
\text { XXXIIIb }\end{array}$ & 1936 & 1959 & 991 & 1163774 & 39.25 & 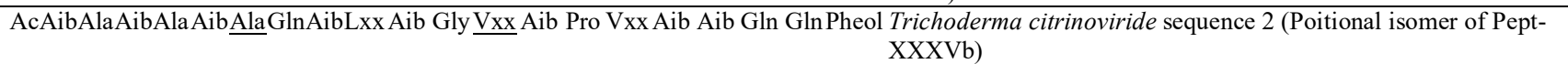 & Maddau et al. 2009 \\
\hline $\begin{array}{l}\text { Pept-B- } \\
\text { XXXIIIc }\end{array}$ & 1950 & 1973 & 998 & 177774 & 39.20 & AcAibAlaAibAlaAibAibGlnAibLxx Aib GlyVxx Aib Pro Vxx Aib Aib Gln Gln Pheol (Positional isomer of Pept-B-XXX, XLIIa, XLVIb and LIII) & $\rightarrow$ Pept-B-XXX \\
\hline $\begin{array}{l}\text { Pept-B- } \\
\text { XXXIIId }\end{array}$ & 1951 & 1974 & 998.5 & 1177775 & 39.31 & 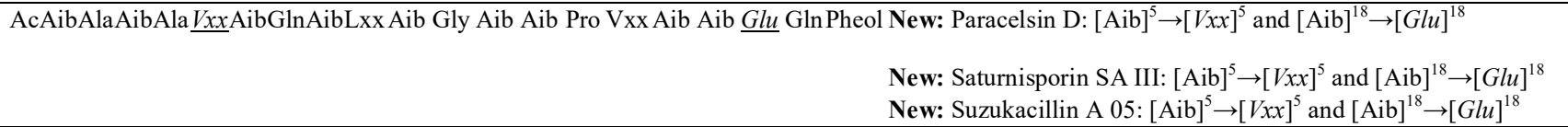 & $\begin{array}{l}\text { Rebuffat et al. } 1993 \\
\text { Krause et al. } 2006 \mathrm{~b}\end{array}$ \\
\hline $\begin{array}{l}\text { Pept-B- } \\
\text { XXXIVa }\end{array}$ & 1937 & 1960 & 991.5 & 1149789 & 39.59 & 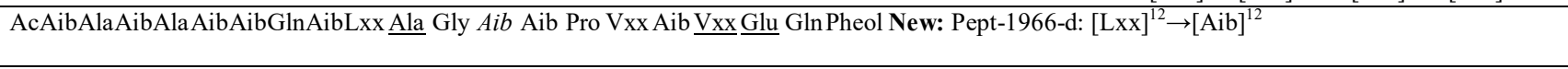 & $\begin{array}{l}\text { Tamandegani et al. } \\
2016\end{array}$ \\
\hline $\begin{array}{l}\text { Pept-B- } \\
\text { XXXIVb }\end{array}$ & 1951 & 1974 & 998.5 & 63789 & 9.13 & IibAlaAibAlaAib $A i b G \operatorname{Gln} A i b$ & $\rightarrow$ Pept-B-XXXI \\
\hline
\end{tabular}


TABLE 10 | Continued

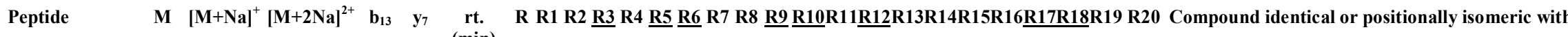

\begin{tabular}{|c|c|c|c|c|c|}
\hline Pept-B-XXXVa 1936 & 1959 & 991 & 1163774 & $\begin{array}{l}\text { AcAibAlaAibAla AibAibGlnAibLxx Aib Gly Aib Aib Pro Vxx Aib Aib Gln Gln Pheol (Positional isomer of Pept-B-XX, XXXIIIa, XLIIb, XLVIa and } \\
\text { LVIII) }\end{array}$ & $\rightarrow$ Pept-B-XX \\
\hline Pept-B-XXXVb 1936 & 1959 & 991 & $1163 \overline{774}$ & AcAibAlaAibAlaAibAlaGlnAibLxx Aib GlyVxx Aib Pro Vxx Aib Aib Gln GlnPheol (Positional isomer of Pept-B-XXXIIIb) & $\rightarrow$ Pept-B-XXXIIIb \\
\hline Pept-B-XXXVI 1964 & 1987 & 1005 & 1191774 & 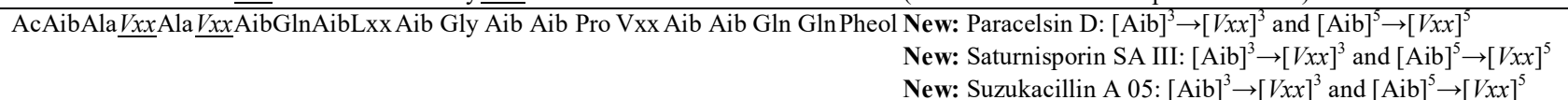 & $\begin{array}{l}\text { Pócsfalvi et al. } 1997 \\
\text { Rebuffat et al. } 1993 \\
\text { Krause et al. 2006b }\end{array}$ \\
\hline & 660 & 015 & & eol New: (Positional isomer of Pept-B-XXV) & $\rightarrow$ Pept-B-XXV \\
\hline
\end{tabular}

Pept-B-

$163 \overline{775} 40.5$

0.13 AcAib

Pept-B-
XXXVIII

$1950 \quad 1973$

998

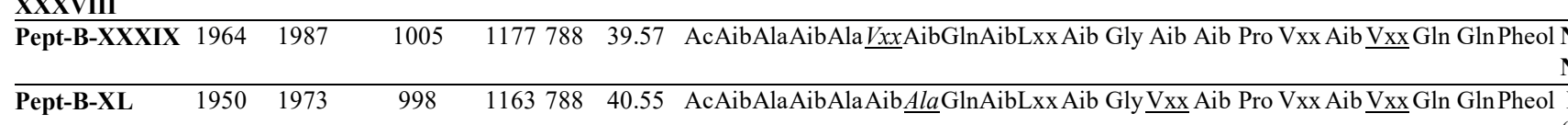

1005

Pept-B New: Suzukacillin A 07: [Aib $]^{5} \rightarrow[\operatorname{Vxx}]^{5}$

$\rightarrow$ Pept-B-XXIV

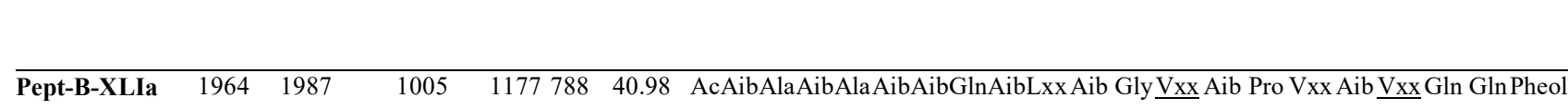
(Positional isomer of Pept-B-XLVIIIa)

New: Trichoderma citrinoviride sequence 6: $[\mathrm{Aib}]^{6} \rightarrow[\text { Ala }]^{6}$

New: Trichoderma citrinoviride sequence $8:[\mathrm{Aib}]^{6} \rightarrow[\text { Ala }]^{6}$ Krause et al. 2006b Maddau et al. 2009

Maddau et al. 2009 Maddau et al. 2009

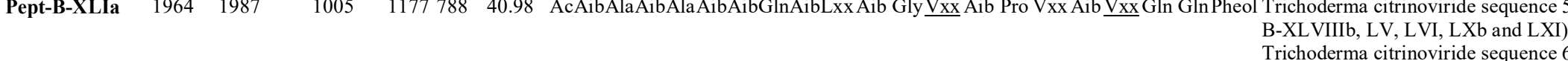
Trichoderma citrinoviride sequence 6

Maddau et al. 2009 Trichoderma citrinoviride sequence 8 Maddau et al. 2009

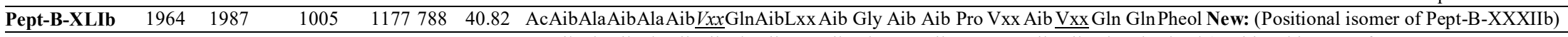

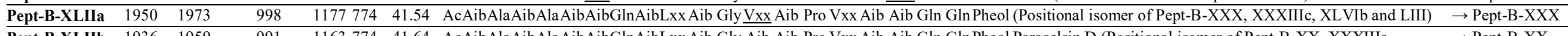

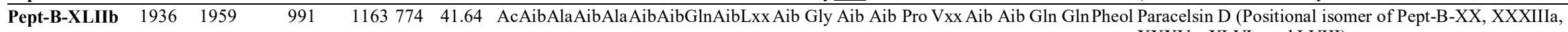
XXXVa, XLVIa and LVIII)

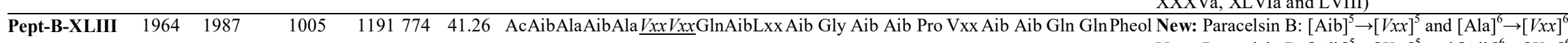
New: Paracelsin D: $[\mathrm{Aib}]^{5} \rightarrow[\mathrm{Vxx}]^{5}$ and $[\mathrm{Aib}]^{6} \rightarrow[V x x]^{6}$ New: Saturnisporin SA I: $[\mathrm{Aib}]^{5} \rightarrow[\mathrm{Vxx}]^{5}$ and $[\mathrm{Ala}]^{6} \rightarrow[\mathrm{Vxx}]^{6}$ New: Saturnisporin SA III: $[\mathrm{Aib}]^{5} \rightarrow[V x x]^{5}$ and $[\mathrm{Aib}]^{6} \rightarrow[V x x]^{6}$ New: Suzukacillin A 02, A 06: $[\mathrm{Aib}]^{5} \rightarrow[V x x]^{5}$ and $[\text { Ala }]^{6} \rightarrow[V x x]^{6}$

New: Suzukacillin A 05: $[\mathrm{Aib}]^{5} \rightarrow[V x x]^{5}$ and $[\mathrm{Aib}]^{6} \rightarrow[V x x]^{6}$ New: Trichocellin TC-A-I, TC-A-III: $[A i b]^{5} \rightarrow[V x x]^{5}$ and $\rightarrow$ Pept-B-XX $[\text { Ala }]^{6} \rightarrow[V x x]^{6}$

Pócsfalvi et al. 1997 Pócsfalvi et al. 1997 Pocsfalvi et al. 1997 Rebuffat et al. 1993 Rebuffat et al. 1993 Krause et al. 2006b

Krause et al. 2006b New: Trichocel

Wada et al. 1994 (Positionar isomer of Pept-B-L)
(Postive

\begin{tabular}{|c|c|c|c|c|c|c|}
\hline$\overline{\text { Pept-B-XLIV }}$ & 1965 & 1988 & 1005.5 & $1191775 \quad 41.65$ & $\begin{array}{c}\text { AcAibAlaAibAla } \underline{V x x} V x x \text { GlnAibLxx Aib Gly Aib Aib Pro Vxx Aib Aib Glu GlnPheol New: Trichocellin TC-B-I: }[A i b]^{5} \rightarrow[V x x]^{5} \text { and }[\text { Ala }]^{6} \rightarrow[V x x]^{6} \\
\text { (Positionar isomer of Pept-B-L) }\end{array}$ & Wada et al. 1994 \\
\hline Pept-B-XLVa & 1950 & 1973 & 998 & 1163788 & 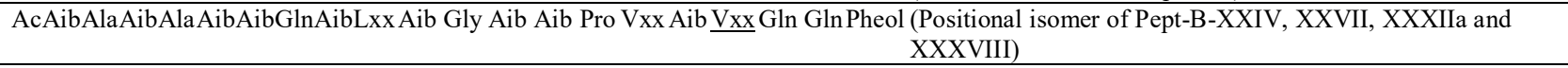 & $\rightarrow$ Pept-B-XXIV \\
\hline
\end{tabular}


TABLE 10 | Continued

Peptide $\quad M \quad[M+N a]^{+}[M+2 N a]^{2+} \quad b_{13} \quad y_{7} \quad$ rt. $\quad R \quad R 1 R 2 \underline{R 3}$ R4 R5 $\underline{\text { R6 }}$ R7 R8 R9 R10R11R12R13R14R15R16R17R18R19 R20 Compound identical or positionally isomeric with (min)

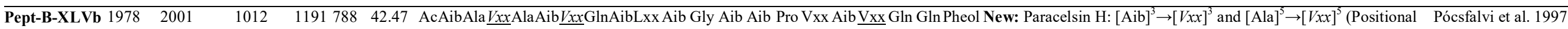
isomer of Pept-B-XLIX)

New: Saturnisporin SA II: $[\mathrm{Aib}]^{3} \rightarrow[V x x]^{3}$ and $[\mathrm{Ala}]^{6} \rightarrow[V x x]^{6}$

Rebuffat et al. 1993

New: Saturnisporin SA IV: $[\mathrm{Aib}]^{3} \rightarrow[V x x]^{3}$ and $[\mathrm{Aib}]^{6} \rightarrow[V x x]^{6}$

New: Suzukacillin A 04, 08: $[\mathrm{Aib}]^{3} \rightarrow[\mathrm{Vxx}]^{3}$ and $[\mathrm{Ala}]^{6} \rightarrow[\mathrm{Vxx}]^{6}$

New: Suzukacillin A 07: $[\mathrm{Aib}]^{3} \rightarrow[V x x]^{3}$ and $[\mathrm{Aib}]^{6} \rightarrow[V x x]^{6}$

New: Trichocellin TC-A-II, A-IV: $[\mathrm{Aib}]^{3} \rightarrow[V x x]^{3}$ and

Rebuffat et al. 1993

Krause et al. 2006b

Krause et al. $2006 \mathrm{~b}$

$[\mathrm{Ala}]^{6} \rightarrow[\operatorname{Vxx}]^{6}$

Wada et al. 1994

Pept-B-

$1936 \quad 1959$

991

116377442.42 AcAibAlaAibAlaAibAibGlnAibLxx Aib Gly Aib Aib Pro Vxx Aib Aib Gln Gln Pheo

LVIII)

$\rightarrow$ Pept-B-XX

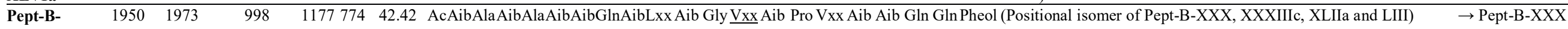

XLVIb

19651988

1005.5

17778

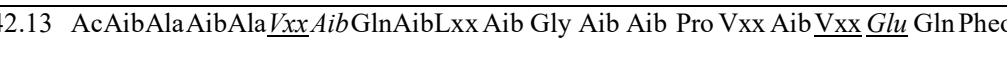

Wada et al. 1994

Pept-B-

New: Saturnisporin SA IV: $[\mathrm{Aib}]^{5} \rightarrow[\mathrm{Vxx}]^{5}$ and $[\mathrm{Gln}]^{18} \rightarrow[\mathrm{Glu}]^{18}$

New: Suzukacillin A 07: $[\mathrm{Aib}]^{5} \rightarrow[\mathrm{Vxx}]^{5}$ and $[\mathrm{Gln}]^{18} \rightarrow[\mathrm{Glu}]^{18}$

Rebuffat et al. 1993 Krause et al. 2006b $\rightarrow$ Pept-B-XL

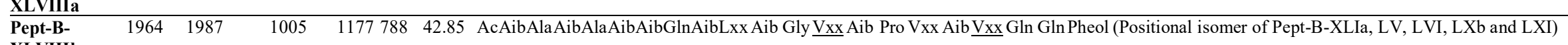

$\rightarrow$ Pept-B-XLIa

XLVIIIb

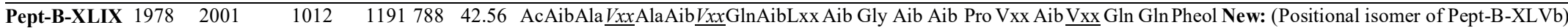

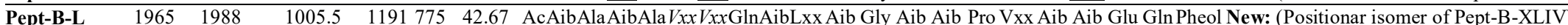

Longibrachin B III., Trilongin CIII.

$\rightarrow$ Pept-B-XLVb

$\rightarrow$ Pept-B-XLIV

Tamandegani et al.

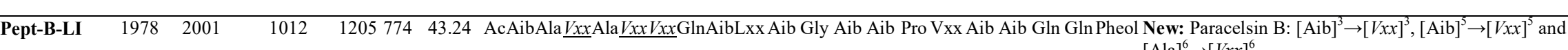
$[\mathrm{Ala}]^{6} \rightarrow[V x x]^{6}$

New: Paracelsin D: $[\mathrm{Aib}]^{3} \rightarrow[V x x]^{3},[\mathrm{Aib}]^{5} \rightarrow[V x x]^{5}$ and

$[\mathrm{Aib}]^{6} \rightarrow[V x x]^{6}$

New: Saturnisporin SA I: $[\mathrm{Aib}]^{3} \rightarrow[V x x]^{3},[\mathrm{Aib}]^{5} \rightarrow[V x x]^{5}$ and

$[\mathrm{Ala}]^{6} \rightarrow[V x x]^{6}$

New: Saturnisporin SA III: $[\mathrm{Aib}]^{3} \rightarrow[V x x]^{3},[\mathrm{Aib}]^{5} \rightarrow[V x x]^{5}$ and

$[\mathrm{Aib}]^{6} \rightarrow[V x x]^{6}$

A 02, A 06: [Aib] $]^{3}-[V x x]^{3},[\mathrm{Aib}]^{5}-[V x x]^{5}$ and Krause et al. 2006b

$[\text { Ala }]^{6} \rightarrow[V x x]^{6}$

New: Suzukacillin A 05: $[\mathrm{Aib}]^{3} \rightarrow[V x x]^{3},[\mathrm{Aib}]^{5} \rightarrow[V x x]^{5}$ and

NAib $]^{6} \rightarrow[V x x]^{6}$

$[\mathrm{Aib}]^{6} \rightarrow[V x x]^{6}$
New: Trichocellin TC-A-I, TC-A-III : $[\mathrm{Aib}]^{3} \rightarrow[V x x]^{3}$,

2016

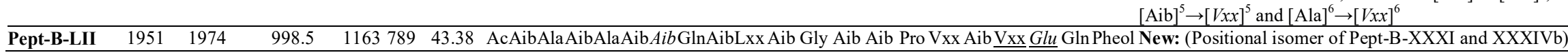

(1)

Pócsfalvi et al. 1997

Rebuffat et al. 1993

Rebuffat et al. 1993

Krause et al. 2006b

Krause et al. 2006b

Wada et al. 1994 $\rightarrow$ Pept-B-XXXI 


\section{TABLE 10 | Continued}

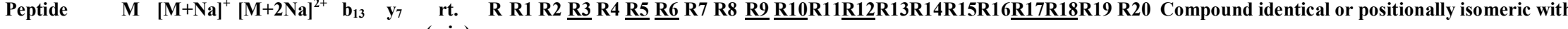 (min)}

\begin{tabular}{|c|c|c|c|c|c|c|c|}
\hline Pept-B-LIII 1950 & 1973 & 998 & 1177774 & 43.99 & AcAibAlaAibAlaAibAibGlnAibLxx Aib Gly $\underline{\text { Vxx }}$ Aib Pro Vxx Aib Aib Gln Gln Pheol ( & $\begin{array}{l}\text { (Positional isomer of Pept-B-XXX, XXXIIIc, XLIIa and XLVIb) } \\
\text { Pept-1952-d } \\
\text { Longibrachin A II., Trilongin BII. }\end{array}$ & $\begin{array}{l}\rightarrow \text { Pept-B-XXX } \\
\text { Tamandegani et al. } \\
2016 \\
\text { Tamandegani et al. } \\
2016\end{array}$ \\
\hline Pept-B-LIV 1978 & 2001 & 1012 & 1191788 & 44.00 & 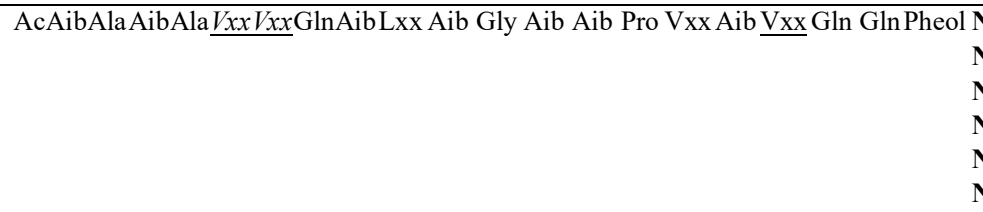 & $\begin{array}{l}\text { New: Paracelsin H: }[\mathrm{Aib}]^{5} \rightarrow[V x x]^{5} \text { and }[\mathrm{Ala}]^{6} \rightarrow[V x x]^{6} \\
\text { New: Saturnisporin SA II: }[\mathrm{Aib}]^{5} \rightarrow[V x x]^{5} \text { and }[\mathrm{Aib}]^{6} \rightarrow[V x x]^{6} \\
\text { New: Saturnisporin SA IV: }[\mathrm{Aib}]^{5} \rightarrow[V x x]^{5} \text { and }[\mathrm{Ala}]^{6} \rightarrow[V x x]^{6} \\
\text { New: Suzukacillin A 04, 08: }[\mathrm{Aib}]^{5} \rightarrow[V x x]^{5} \text { and }[\mathrm{Ala}]^{6} \rightarrow[V x x]^{6} \\
\text { New: Suzukacillin A 07: [Aib }]^{5} \rightarrow[V x x]^{5} \text { and }[\mathrm{Aib} b]^{6} \rightarrow[V x x]^{6} \\
\text { New: Trichocellin TC-A-II, A-IV:[Aib }]^{5} \rightarrow[V x x]^{5} \text { and }[\mathrm{Ala}]^{6} \rightarrow[V x .\end{array}$ & $\begin{array}{l}\text { Pócsfalvi et al. } 1997 \\
\text { Rebuffat et al. } 1993 \\
\text { Rebuffat et al. } 1993 \\
\text { Krause et al. 2006b } \\
\text { Krause et al. 2006b } \\
\text { Wada et al. } 1994\end{array}$ \\
\hline
\end{tabular}

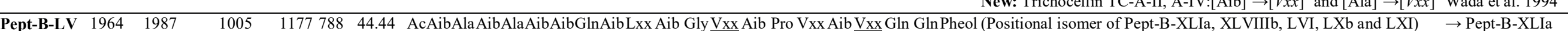

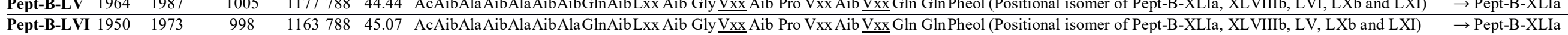

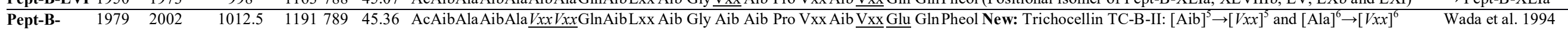

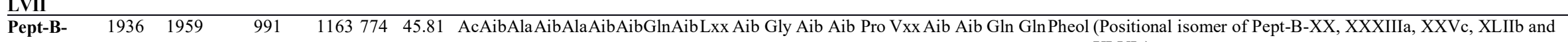
LVIII

Pept-B-LIX $1992 \quad 2015 \quad 1019 \quad 1205788 \quad 45.74$ AcAibAla $\underline{V x x}$ Ala $\underline{V x x V x x}$ GlnAibLxx Aib Gly Aib Aib Pro Vxx Aib Vxx Gln Gln Pheol New: Paracelsin H: $[\text { Aib }]^{3} \rightarrow[V x x]^{3}$, [Aib $]^{5} \rightarrow[V x x]^{5}$ and $[\mathrm{Ala}]^{6} \rightarrow[\mathrm{Vxx}]^{6}$ New: Saturnisporin SA II: $[\mathrm{Aib}]^{3} \rightarrow[V x x]^{3},[\mathrm{Aib}]^{5} \rightarrow[V x x]^{5}$ and $[\mathrm{Ala}]^{6} \rightarrow[V x x]^{6}$

New: Saturnisporin SA IV: $[\mathrm{Aib}]^{3} \rightarrow[\mathrm{Vxx}]^{3},[\mathrm{Aib}]^{5} \rightarrow[\mathrm{Vxx}]^{5}$ and $[\mathrm{Aib}]^{6} \rightarrow[V x x]^{6}$

New: Suzukacillin A 04,08: [Aib $]^{3} \rightarrow[V x x]^{3},[\mathrm{Aib}]^{5} \rightarrow[\mathrm{Vxx}]^{5}$ and $[\mathrm{Ala}]^{6} \rightarrow[V x x]^{6}$

[Ala] $\rightarrow[V x x]^{6}$, $[\mathrm{Aib}]^{6} \rightarrow[V x x]^{6}$

New: Trichocellin TC-A-II, A-IV: $[\mathrm{Aib}]^{3} \rightarrow[V x x]^{3},[\mathrm{Aib}]^{5} \rightarrow[V x x]^{5} \quad$ Wada et al. 1994 and $[\mathrm{Ala}]^{6} \rightarrow[\mathrm{Vxx}]^{6}$ $\rightarrow$ Pept-B-XX 
TABLE 11 I Sequences of the newly identified brevicelsins (group C) from Trichoderma species of clade Longibrachiatum and their similarities to known peptaibols available in the "Comprehensive Peptaibiotics Database"

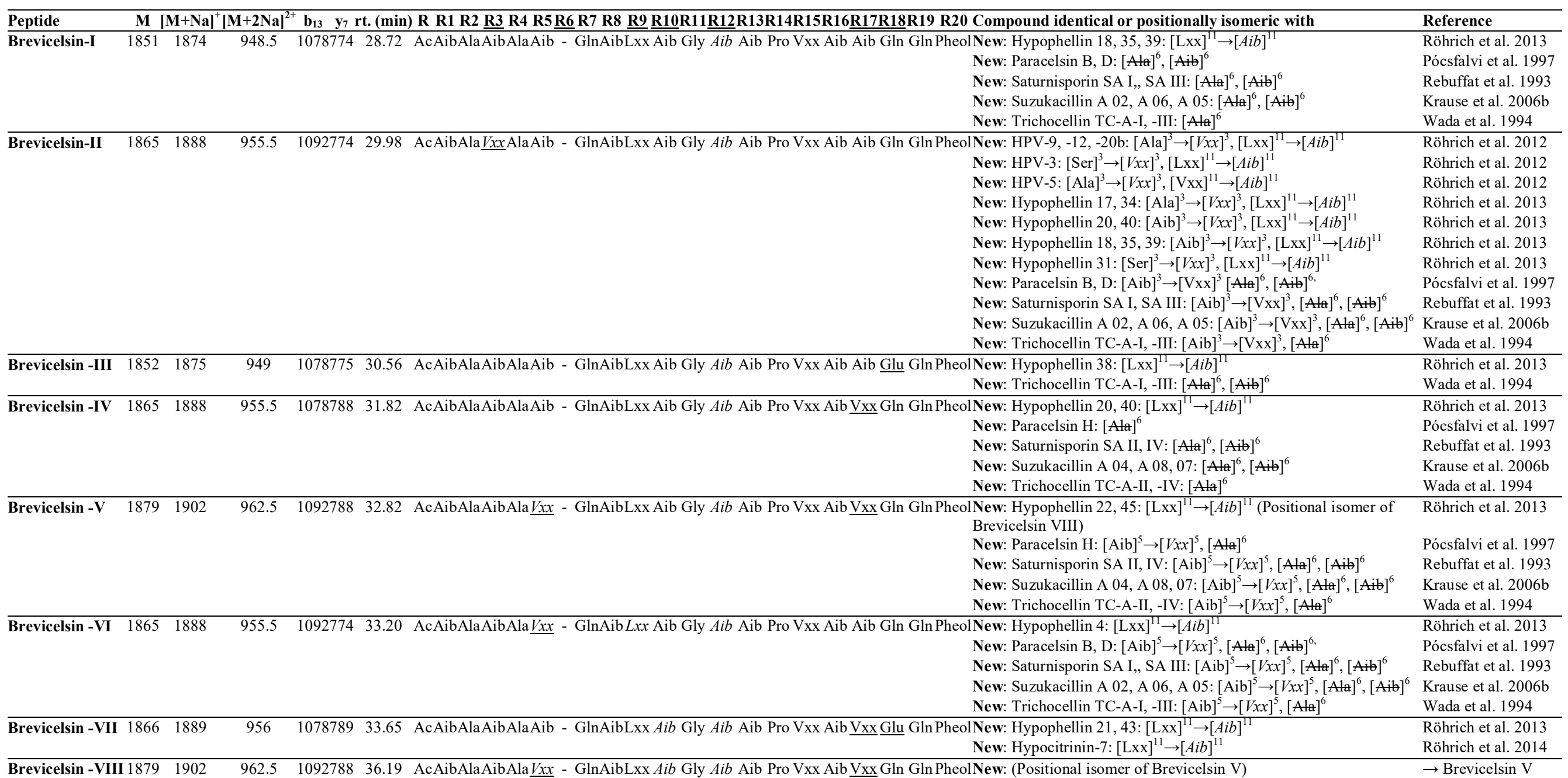

Variable residues in table header and minor sequence variants in sequences are underlined. Amino acid exchanges in new compounds are set in italic. 
Of the 51 sequences from group A, containing exclusively of 20-residue-long peptaibols, 32 have been previously described in the literature, and 19 were new, differing by 1-3 amino acids from known sequences (Table 9). Group B also comprises 20-residue sequences (Table 10). The main difference between group B and group A peptaibols is located at the R12 position, where Aib instead of Lxx is present in most of the group B sequences. Another major difference from group $\mathrm{A}$ is that the $\mathrm{R} 5$ position is not conserved due to a high percentage of Vxx instead of Aib. Sequence analysis identified several conserved regions along with some variable positions (R3, R5, R6, R10, R12, and R17), which have also been reported in a previous study (Pócsfalvi et al. 1997). Vxx was usually found instead of Ala and Aib at certain variable positions like R3, R5 and R6, which has never been observed among similar peptaibols. Although all of these amino acids have helix-forming properties, a substitution by Val would render a more linear and less fluctuating helical conformation owing to its bulkier sidechain. The highly curved backbone conformation is not energetically favored with increasing number of Val in peptaibol sequences. It has been hypothesized that the equilibrium between the bent (closed form) and linear conformations (open amphipathic form) may act as a "conformational switch" of voltage gating in ion channels across bilayers (North et al. 1995). Clearly, such substitutions have an important functional relevance, especially at subterminal positions like R3 and R17. Out of the 77 group B sequences, 34 were identified as new. An entirely new compound, Pept-B-LIX, with a mass of 1992 Da was detected in the crude extracts of three strains (T. konilangbra SZMC 22607, T. flagellatum SZMC 22608 and T. sinensis SZMC 22609). This is an interesting observation because only voglmayrin-16 has the same high mass among the known molecules (Röhrich et al. 2014). Furthermore, only 9 other, completely different peptaibiotic compounds have higher masses according to the literature: aibellin, texenomycin A, B, polysporin D, SCH 643432, septocylindrin A and B, as well as Clonostachys rosea sequences \#2 and \#3 (Kumazawa et al. 1994, Grigoriev et al. 2002, New et al. 1996, Degenkolb et al. 2007, Summers et al. 2007, Rodríguez et al. 2011).

All sequences of group C produced by three strains ( $T$. flagellatum SZMC 22608, $T$. sinensis SZMC 22609 and T. parareesei SZMC 22615) proved to belong to a new group of peptaibols, which was named brevicelsins, as they are similar to, but one amino acid shorter than paracelsins (Brückner and Graf 1983, Pócsfalvi et al. 1997) (Table 11). They are not Nterminally truncated derivatives of their full-length precursors - like it is the case for the 16residue-long brevikindins deriving from 18-residue-long trichokindin-like peptaibols 
(Degenkolb et al. 2016) - but differ from group B sequences by the internal deletion of position 6. This position is critical, since the following Gln plays an important role in the formation of ion channels (Wilson et al. 2011). A full genome sequence is available for $T$. parareesei, analysis of this sequence, however, revealed no extra 19-modules NRPS synthetases but only a 20-modules enzyme (Marik et al. 2019). The 19-residue-long peptaibols could be produced by the same, 20-modules NRPS via the interaction of nonneighboring modules known as internal module skipping. The mechanisms of this phenomenon resulting in additional classes of 10-, 13-, 18-, and 19-residue-long peptaibols were proposed by Degenkolb et al. (2012). R6 is also skipped in T. phellinicola peptaibols (Röhrich et al. 2013), which does, however, contain Lxx in position R12, similar to group A peptaibols and unlike brevicelsins with Aib in this position.

\subsubsection{Qualitative and semi-quantitative peptaibol profiles of the strains}

After investigation of all strains producing peptaibols from group A, "a" and "b" versions of their peptaibol compounds were apparent. Pept-A-XI has a "c" version of the compound, and a few others are represented by only a single sequence (Supplementary Table 15). Compounds such as Pept-A-IV-a and -b were produced constantly in high quantities by all strains. Both Pept-A-IX-a and -b were produced in high quantities by all strains except $T$. aethiopicum SZMC 22602, T. pinnatum SZMC 22603 and T. longibrachiatum SZMC 1775. Similarly, Pept-A-XVI-a and -b were produced by all strains. In this group, seven mainly produced peptaibol varieties appeared on the spectra, Pept-A-IV-a and -b, Pept-A-VI-a and -b, Pept-A-IX-a and -b, Pept-A-XV-a and -b, Pept-A-XVI-a and -b, Pept-A-XIXa as well as Pept-A-XXI-a and -b.

Pept-B-XX and Pept-B-XXVII were produced by all strains examined in all Group B, whereas the other compounds were produced only by certain strains (Supplementary Table 16). Five peptaibol compounds (Pept-B-VII, Pept-B-XVII, Pept-B-XX, Pept-B-XXVII, and Pept-XLV-a and b) were produced at high levels. Certain strains could also produce other compounds, such as Pept-B-XXVIII, Pept-B-XXIX-a and b, Pept-B-XXXIIIa, Pept-A-IVb, Pept-XLIb, Pept-XLIII, Pept-B-XLVa, Pept-B-LI, Pept-B-LIV, and Pept-B-LVIb, at high levels. The most diverse peptaibol profile was observed in T. reesei QM6a (SZMC 22614), which produced 41 different peptaibol compounds, whereas the least diverse profiles were that of T. effusum SZMC 22611 and T. konilangbra SZMC 22607, which produced 11 and 12 sequences, respectively. Some species producing mostly group B peptaibols, T. reesei QM6A (SZMC 22614), T. saturnisporum SZMC 22606 and T. konilangbra SZMC 22607 could also 
produce peptaibols from group A. Interestingly, group A sequences could not be detected from the two mutant strains of T. reesei SZMC 22614 (T. reesei SZMC 22616 and SZMC 22617). The analysis of the T. longibrachiatum SZMC 1775 and the three T. bissettii strains (SZMC 1773, 1776, 12546) revealed similar, but still different, profiles (Supplementary Table 16). The environmental isolates of T. longibrachiatum SZMC 1775 and T. bissettii (SZMC $1773,1776)$ produced more similar profiles, whereas the peptaibol profile of the clinical isolate of T. bissettii (SZMC 12546) was different from those of the three environmental strains. Clinical and environmental strains could not be differentiated based on ITS1, ITS2, act1, call, tefl, hfb4 and rpb2 sequences of 17 investigated strains of $T$. longibrachiatum and T. bissettii (proposed as T. longibrachiatum f. bissettii) (Hatvani et al. 2019). Therefore, the investigation of more $T$. longibrachiatum and $T$. bissettii strains in terms of peptaibol production would be interesting. Brevicelsins from group $\mathrm{C}$ were only produced by three species, T. sinensis, T. flagellatum and, to a lesser extent, T. parareesei. Brevicelsin I and Brevicelsin IV were produced by the examined strains ( $T$. flagellatum SZMC 22608, T. sinensis SZMC 22609 and T. parareesei SZMC 22615) of all three species, but $T$. parareesei produced only these two compounds of group $\mathrm{C}$ peptaibols in addition to the group $\mathrm{B}$ sequences.

We carried out a cluster analysis of the peptaibol diversity profiles in different Trichoderma species of clade Longibrachiatum based on the production levels of different peptaibols by various fungal producers (Supplementary Tables 15 and 16). According to their peptaibol profiles, members of clade Longibrachiatum were divided into two main clusters (Figure 8). The first cluster involves species producing exclusively group A peptaibols. Among them, $T$. novae-zelandiae is characterised with a relatively poor, but sharply distinct, profile of abundantly produced peptaibol compounds from group A, like Pept-A-XXIb, XVIb, XII, Vb, $\mathrm{Ib}$, and IIIc. It may be related to the geographical origin of this species, which is endemic to New Zealand, and to the basal position occupied by it within the clade Longibrachiatum (Samuels et al. 2012b). This species has tuberculate conidia, a trait also found in clade Viride (Jaklitsch et al. 2006), and it may be an ancestral trait of clade Longibrachiatum (Druzhinina et al. 2012). Our results suggest that the production of group A peptaibols may be another ancestral trait of clade Longibrachiatum, while the switch to the production of group B peptaibols might have occurred multiple times and seems therefore to be the result of convergent evolution. This switch from production of group A to group B peptaibols has not been completed fully in certain species: wild-type $T$. reesei as well as $T$. saturnisporum and $T$. 
konilangbra also produce some group A compounds in addition to group B peptaibols. Further species in this cluster include members of the phylogenetic subclades Longibrachiatum/Orientale and Citrinoviride/Pseudokoningii, along with the lone lineages $T$. ghanense and T. capillare (Table 9). This cluster consists of three subclusters, the first one containing the closely related species $T$. aethiopicum and $T$. pinnatum and the second one involving $T$. longibrachiatum and $T$. orientale - all belonging to the phylogenetic subclade Longibrachiatum/Orientale - while the third subcluster corresponds to the subclade Citrinoviride/Pseudokoningii (Table 9, Figure 8). The second main cluster is comprised of species producing mainly group B peptaibols and includes 2 subclusters, with the first containing the phylogenetic subclades Parareesei/Reesei, Saturnisporum and the lone lineages $T$. andinense and T. effusum, while the second harboring the three examined species from subclade Konilangbra/Sinensis (Table 9, Figure 8). All three examined members of this subclade produced the entirely new compound Pept-B-LIX (1992 Da).

Except from $T$. reesei, which was separated from its closest relative $T$. parareesei, the clustering based on peptaibol profiles reflected the close relationships within phylogenetic subclades in most of the cases (e.g., within subclades Longibrachiatum/Orientale, Citrinoviride/Pseudokoningii, or Konilangbra/Sinensis). For example, the species from the Konilangbra/Sinensis subclade are phylogenetically close to each other and are only known from the Paleotropical/Asian areas including Ethiopia ( $T$. flagellatum), Uganda ( $T$. konilangbra) and Taiwan (T. sinensis) (Samuels et al. 2012b). The very close relationship of T. sinensis and T. flagellatum is also reflected by their ability to produce group C peptaibols in addition to group B sequences. The phylogenetic relationships between the subclades are less reflected by the clustering based on peptaibol profiles. Distantly related subclades (e.g., Longibrachiatum/Orientale and Citrinoviride/Pseudokoningii) may share similar profiles, while closely related subclades may exhibit substantially different ones, e.g., members of subclade Citrinoviride/Pseudokoningii produce group A peptaibols, while group B compounds are produced by their close relative $T$. effusum. This could be explained by multiple events of switching from the production of group A to group B during the evolution of clade Longibrachiatum. 


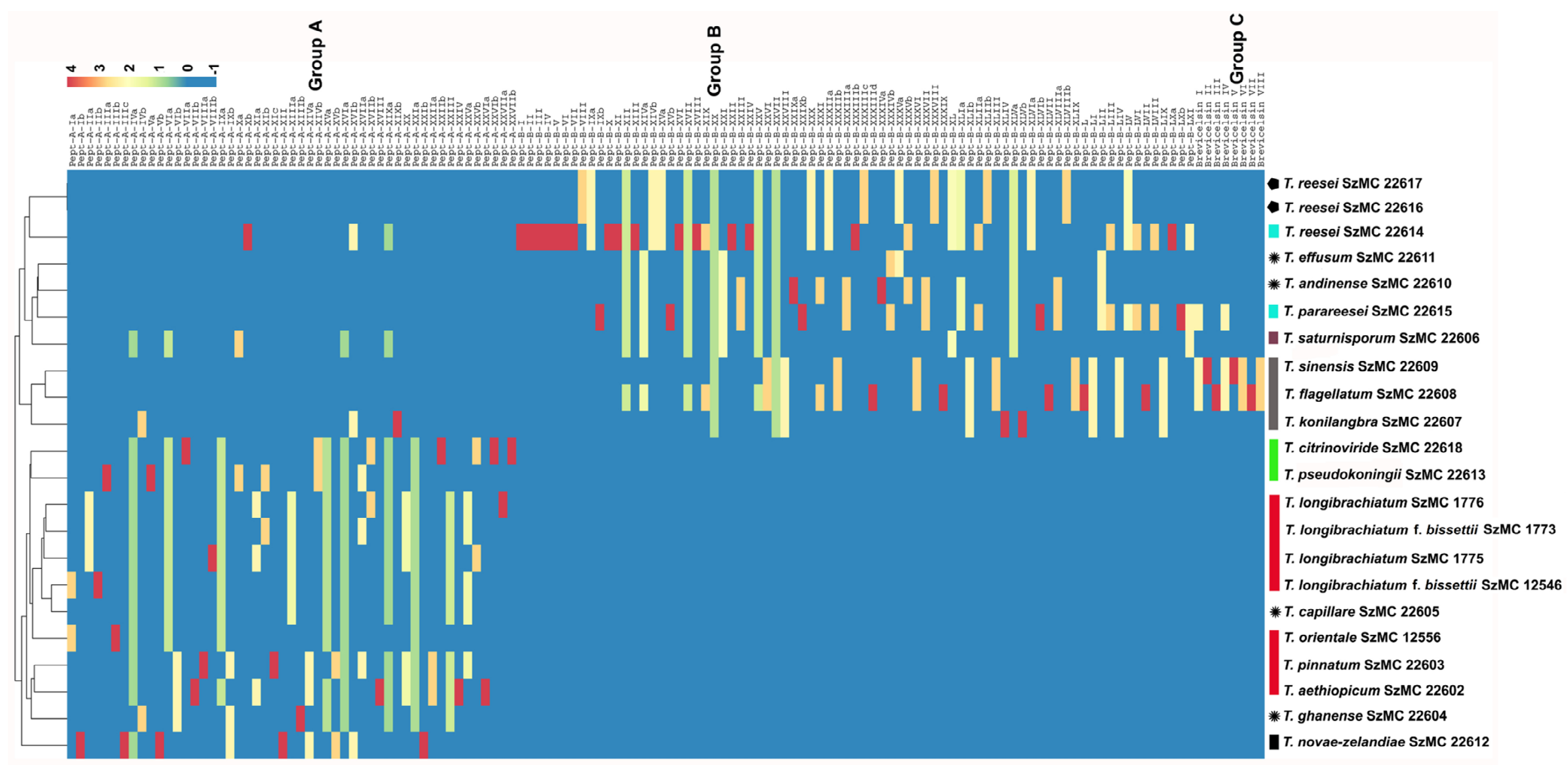

Figure 8 । Heatmap showing the correlation between the production of peptaibols and the phylogenetic relationship between the strains. Monophyletic species are indicated by the bottom bar of the same colour, species attributed to single phylogenetic lineages are marked with a star, while mutant strains are indicated with a filled pentagon. The colour scale denotes production level increasing from zero (deep blue) to high (deep red). 


\subsubsection{Bioactivity of $T$, reesei peptaibols}

T. reesei is a popular, well-characterised species and its strains are widely used for their cellulase production in the biotechnological industry, therefore this species was selected to answer the question whether peptaibols can be used in plant protection. The bioactivity of the peptaibols produced by $T$. reesei QM9414 against plants and several human and phytopathogenic filamentous fungi were investigated.

\subsubsection{Antifungal effect of $T$. reesei peptaibols on filamentous fungi}

The purified peptaibol extracts (98\% purity, containing the mixture of the peptaibols) of $T$. reesei QM9414 (shown in Table 10 and Supplementary Table 16) was tested on human and phytopathogenic filamentous fungi, furthermore, the producer strain itself, as well as its Alael mutant (Table 12). Treatment with 0.4 and $0.2 \mathrm{mg} \mathrm{ml}^{-1}$ purified peptaibol solution resulted in growth inhibition of all strains, whereas a weaker, but still notable inhibition was detected after treatment with the purified extract at a concentration of $0.1 \mathrm{mg} \mathrm{ml}^{-1}$. The peptaibol extract from T. reesei QM9414 exhibited an inhibition profile highly similar to that of ALM. A stronger inhibition was observed in the case of the $\Delta$ lael mutant of $T$. reesei than in the case of the other strains, suggesting that the mutation in the methyl transferase gene - known as a global epigenetic regulator of gene expression - may also affect tolerance to these metabolites. The previous results, in which crude peptaibol extracts were tested on several bacterial, yeast and filamentous fungal strains against peptaibols produced by the species belonging to clade Viride showed similar results. The inhibitory effect of peptaibols to bacteria and filamentous fungi has previously been reviewed (Szekeres et al. 2005, Daniel and Rodrigues Filho 2007). It has also been demonstrated that purified trichokonin VI triggers a change of fungal membrane permeability and disintegration of subcellular structures, has an effect on mitochondrial membrane permeabilisation and intracellular reactive oxygen species (ROS) production, induces phosphatidylserine exposure and eventually triggers metacaspaseindependent apoptosis in F. oxysporum (Shi et al. 2012). 
TABLE 12 | Antifungal activity of the purified peptaibol extract from T. reesei QM9414 to filamentous fungi

\begin{tabular}{|c|c|c|c|}
\hline $\begin{array}{l}\text { Tested filamentous } \\
\text { fungal strain }\end{array}$ & $\begin{array}{l}\text { MIC of purified } \\
\text { peptaibol extract } \\
\left(\left(\mathrm{mg} \mathrm{ml}^{-1}\right)\right.\end{array}$ & $\begin{array}{c}\text { MIC of ALM * } \\
\text { standard }\left(\mathrm{mg} \mathrm{ml}^{-1}\right)\end{array}$ & $\begin{array}{c}\text { MIC of nystatin } \\
\text { standard }\left(\mathrm{mg} \mathrm{ml}^{-1}\right)\end{array}$ \\
\hline $\begin{array}{c}\text { Alternaria alternata } \\
\text { SZMC } 16085\end{array}$ & 0.1 & 0.05 & 0.003125 \\
\hline $\begin{array}{c}\text { Aspergillus fumigatus } \\
\text { SZMC } 23245\end{array}$ & 0.1 & 0.1 & 0.0125 \\
\hline $\begin{array}{c}\text { Fusarium falciforme } \\
\text { SZMC } 11407\end{array}$ & 0.05 & 0.05 & 0.025 \\
\hline $\begin{array}{c}\text { Fusarium keratoplasticum } \\
\text { SZMC } 11414\end{array}$ & 0.1 & 0.1 & 0.05 \\
\hline $\begin{array}{l}\text { Fusarium solani SC } \\
\text { SZMC } 11467\end{array}$ & 0.1 & 0.1 & 0.05 \\
\hline $\begin{array}{c}\text { Phoma cucurbitacearum } \\
\text { SZMC } 16088\end{array}$ & 0.05 & 0.05 & 0.1 \\
\hline $\begin{array}{c}\text { Trichoderma reesei } \\
\text { QM9414 }\end{array}$ & 0.1 & 0.05 & 0.00625 \\
\hline $\begin{array}{l}\text { Trichoderma reesei } \\
\text { QM9414 G24lae1 }\end{array}$ & 0.05 & 0.05 & 0.00625 \\
\hline
\end{tabular}

SC: species complex

*Harzianum A contamination could not be detected in the alametichin standard based on the exact mass of its deprotonated molecular ion $\left([\mathrm{M}-\mathrm{H}]^{-}, m / z=399.1808\right)$.

\subsubsection{Bioactivity of $T$. reesei peptaibols on $A$. thaliana plants}

In order to evaluate the potential of peptaibols as antifungal agents for plant protection, the purified (98\%) microheterogeneous mixture of the peptaibol extract of T. reesei QM9414 was investigated for toxicity in the model plant $A$. thaliana. The extract was diluted to $50,10,5,1$, $0.5,0.3,0.1$, and $0.05 \mathrm{mg} \mathrm{ml}^{-1}$. The plants treated with methanol did not show any difference compared to the absolute control plants, therefore, these plants were used as controls during the subsequent experiments. All of the treated plants were completely inhibited after treatment with the peptaibol extract at concentrations of 50,10 , and $5 \mathrm{mg} \mathrm{ml}^{-1}$, which eventually 
resulted in the death of the plants. Primary root growth was only detected at concentrations $\leq$ $1 \mathrm{mg} \mathrm{ml}^{-1}$, however, inhibited growth could be observed till concentrations of $0.1 \mathrm{mg} \mathrm{ml}^{-1}$ (Figure 9). Treatment with $1 \mathrm{mg} \mathrm{ml}{ }^{-1}$ peptaibol solution resulted in a hook formation of the primary roots. Chlorophyll-a, -b and carotenoid levels were decreased after the treatment with extracts of $\geq 0.3 \mathrm{mg} \mathrm{ml}^{-1}$ (Figure 10). Treatment with a peptaibol solution of $0.1 \mathrm{mg} \mathrm{ml}^{-1}$ resulted in a similar rate of production of photosynthetic pigments, but an increased anthocyanin level in 15-day-old plants. The root growth of these plants was suppressed in 6to 9-day-old plants, although the plants showed normal biomass and could probably eventually survive this minimal toxicity because of the increased levels of anthocyanin (Figure 11).

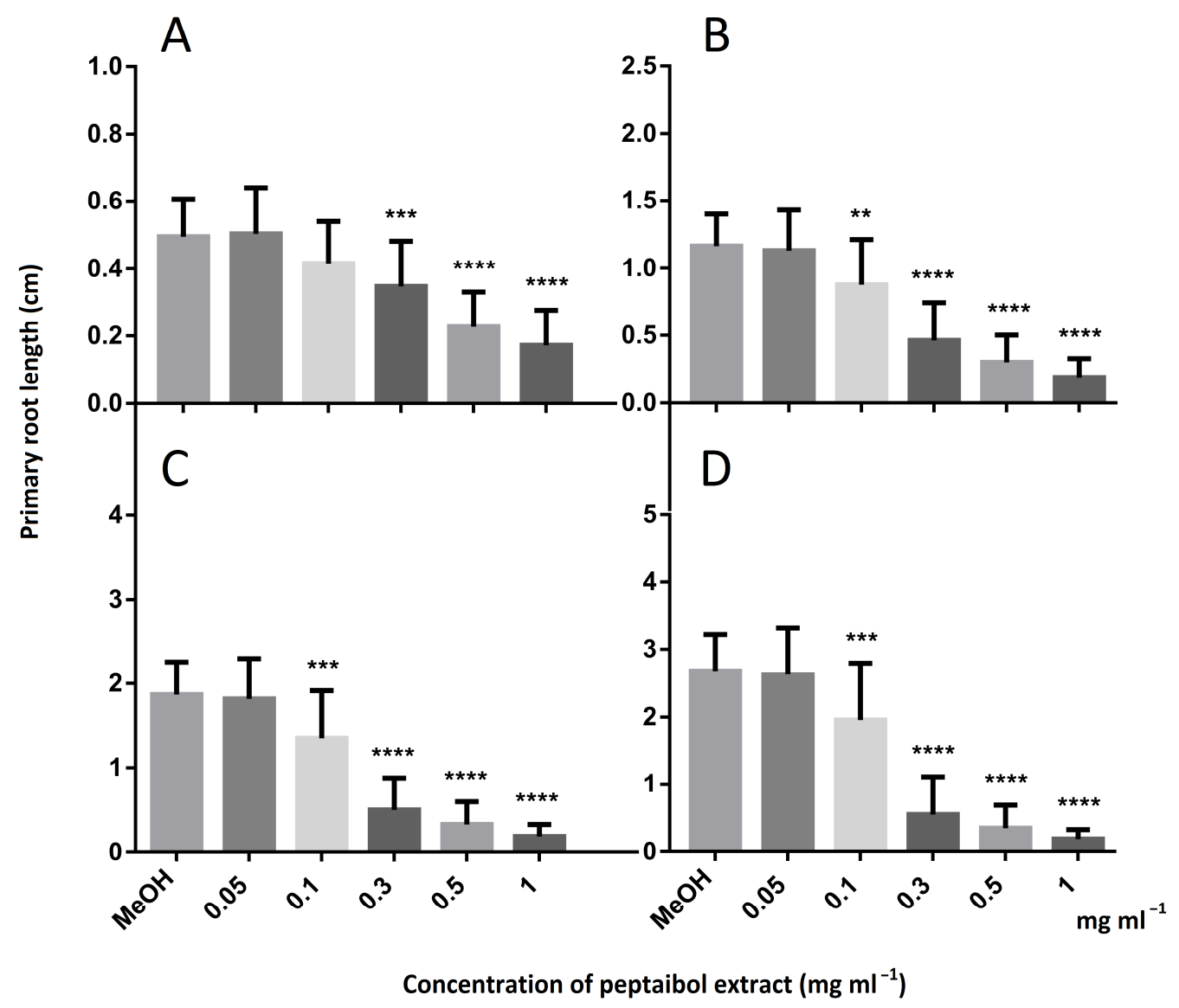

Figure 9 । Primary root growth of 6 (A), 7 (B), 8 (C), and 9 (D) day-old $A$. thaliana plants after treatment with peptaibol extract from T. reesei QM9414. Methanol was used for the control plants as all peptaibol extracts were prepared in this solvent. Significance is assessed based on $P$-values: ${ }^{*} P \leq 0.05,{ }^{* *} P \leq 0.01,{ }^{* * *} P \leq 0.001$ and ${ }^{* * * *} P \leq 0.0001$. 


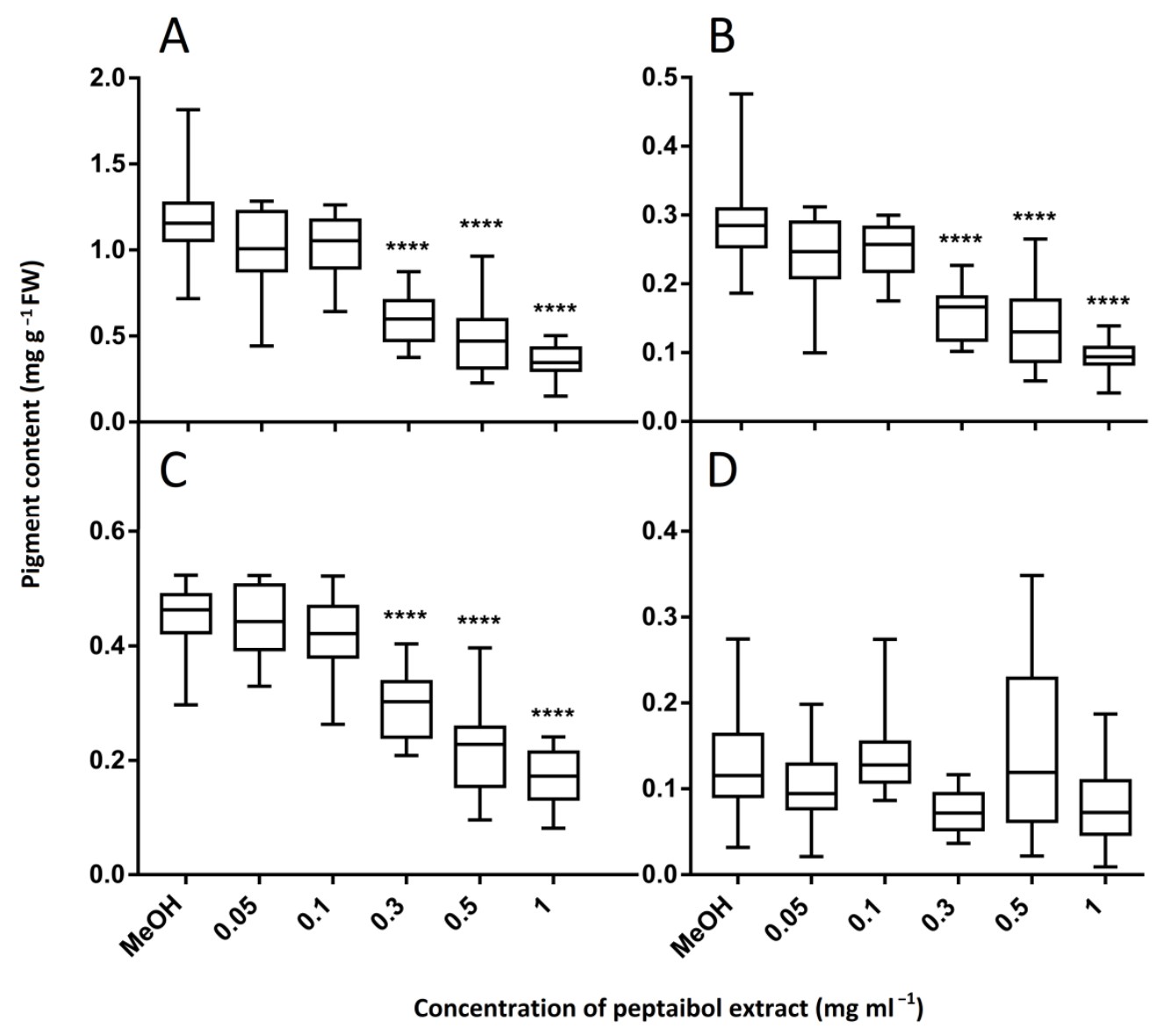

Figure 10 | Pigment content of 15-day-old A. thaliana leaves after treatment with peptaibol extract from T. reesei QM9414: chlorophyll-a (A), chlorophyll-b (B), carotenoids (C) and anthocyanins (D). Methanol was used for the control plants. Significance is assessed based on $P$-values: ${ }^{*} P \leq 0.05,{ }^{* *} P \leq 0.01,{ }^{* * *} P \leq 0.001$ and ${ }^{* * * *} P \leq 0.0001$. 


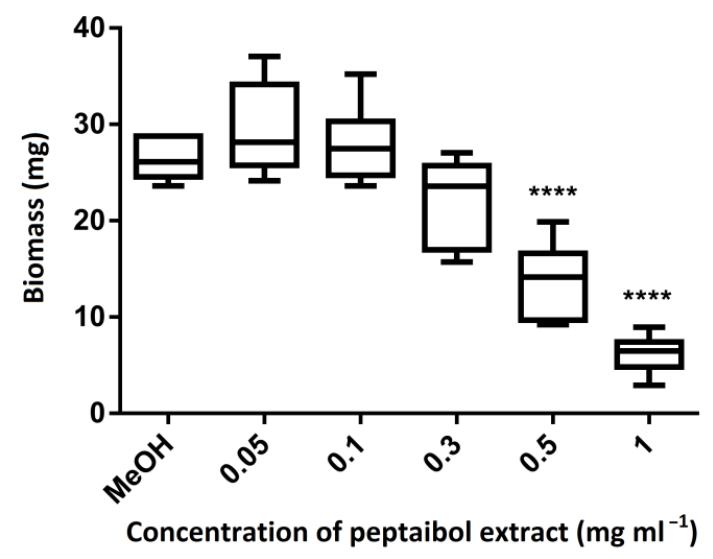

Figure 11 I Biomass of 15-day-old A. thaliana plants after treatment with peptaibol extract from T. reesei QM9414. Methanol was used for the control plants. Significance is assessed based on $P$-values: ${ }^{*} P \leq 0.05,{ }^{* *} P \leq 0.01,{ }^{* * *} P \leq 0.001$ and ${ }^{* * * *} P \leq 0.0001$.

ALM, the most studied peptaibol was shown to induce resistance in plants (Engelberth et al. 2000, Engelberth et al. 2001, Maischak et al. 2010, Li et al. 2016), although it can also cause lesions on Arabidopsis leaves (Rippa et al. 2010). At higher concentration, it induces rRNA cleavage-associated rapid death (Rippa et al. 2007). ALM could permeabilise mainly the apical meristem and epidermis cells of the root tips, but not the basal meristem cells, cortex cells or the root cap of $A$. thaliana (Dotson et al. 2018). If the root was pretreated with cellulase, permeabilisation could not be observed. This study proved cellulose-induced resistance and cell-specific ALM permeabilisation of $A$. thaliana roots. Engelberth et al. (2001) successfully demonstrated the high biological activity of ALM that caused emission of volatile compounds from lima beans (Phaseolus lunatus) placed under low concentration of the peptaibol solution. When it was applied to Bryonia dioica tendrils at the same concentration, it elicited jasmonate-induced tendril coiling. Therefore, peptaibols may be used as potential elicitors of plant defense responses. Recently, antiviral activity of trichorzins was also reported on cowpea plants against Cucumber mosaic virus (Kai et al. 2018). In this recent study, bioactivity tests with the selected, purified peptaibol extract of T. reesei QM9414 demonstrated toxicity to $A$. thaliana plants at higher concentrations. An interesting effect of the peptaibol extract was the induction of hook formation in the root tips. A previous study revealed similar results, where the inoculation of $A$. thaliana with $T$. atroviride resulted in shortened primary root growth of the plants and ended in a hook formation, although the lateral root numbers were increased (Pelagio-Flores et al. 2017). An inhibitory effect on 
primary root growth in $A$. thaliana was also observed after interaction with $T$. longibrachiatum SMF2, and its peptaibols induced auxin production and disruption of the auxin response gradients in root tips (Shi et al. 2016).

It was hypothesized long ago that small secondary metabolites of Trichoderma may act as auxin-like compounds between the optimum concentrations of $10^{-5}$ and $10^{-6} \mathrm{M}$, but have inhibitory effects at higher concentrations (Thimann, 1937, Cleland, 1972, Brenner, 1981). Secondary metabolites of T. koningii (koninginin A) and T. harzianum (6-pentyl- $\alpha$-pyrone) inhibited the growth of etiolated wheat coleoptiles at relatively high concentrations $\left(\geq 10^{-3}\right.$ M), but lower doses $\left(10^{-4}-10^{-3} \mathrm{M}\right)$ had no effect (Cutler et al. 1986, Cutler et al. 1989). In another study, the same compound mentioned as 6-pentyl-2H-pyran-2-on showed inhibitory effects at high concentration, but interestingly a growth induction could also be detected in wheat seedlings after the treatment with low concentrations. Furthermore, tomato plants showed more intensive growth and better root system development after the foliar spray treatment with the same compound at a concentration of $0.166 \mathrm{ml} \mathrm{l}^{-1}$ (Vinale et al. 2008). Another secondary metabolite, harzianolide was tested on rapeseed and tomato seedlings and had a positive effect on growth and defense response of the plants after the treatment with the concentration of $1 \mathrm{mg} \mathrm{l}^{-1}$ (Vinale et al. 2008). The treatment of the seeds at the concentrations of 100 and $10 \mu \mathrm{g} /$ seed resulted in stem length reduction, while at the concentration of 100,10 and $1 \mathrm{ng} / \mathrm{seed}$ the stem length was increased in comparison to the control (Vinale et al. 2009).

\subsubsection{Bioactivity of $T$. reesei peptaibols on mammalian cells}

The endpoint of toxic concentration - the last dilution step of the purified peptaibol solution, which is still toxic - was determined for the peptaibol extract of T. reesei QM9414 on mammalian cells (Table 13). After $20 \mathrm{~min}$ incubation at $37{ }^{\circ} \mathrm{C}$ or $24 \mathrm{~h}$ at room temperature, the sperm motility inhibition end point was detected after treatment with $3 \mu \mathrm{g} \mathrm{ml}^{-1}$ peptaibol solution. The acrosome of the exposed sperm cells reacted at the same concentration, which inhibited motility, indicating that the toxic effect involves the plasma membrane. The inhibition end point of proliferation in PK-15 cells was observed at a concentration of $8 \mu \mathrm{g}$ $\mathrm{ml}^{-1}$ peptaibol solution. Boar sperm cells are frequently used for the detection of toxins, which affect plasma membranes (Castagnoli et al. 2018, Vicente-Carrillo, 2018). Due to the high sensitivity of boar sperm cells to toxins, many studies have concluded that these tests are appropriate for toxin detection (Peltola et al. 2004, Andersson et al. 2009, Andersson et al. 2010). Similar measurements of peptaibol extracts produced by T. longibrachiatum Thb have been reported, and a mixture of trilongins proved to be a stronger inhibitor of motility than 
trilongins alone, or any of the crude extracts (Mikkola et al. 2012). Single ion channels remained in an open state for a longer time when exposed to a combination of the long peptaibols (trilongins BI-BIV) with the short ones (trilongin AI), than for the long peptaibols alone. Furthermore, peptaibols (trichokonin VI) could inhibit HepG2 cancer cells by inducing autophagy and apoptosis through an influx of $\mathrm{Ca}^{2+}$, which triggered the activation of $\mu$-calpain and proceeded to the translocation of Bcl-2-associated X protein (Bax) to mitochondria and the subsequent promotion of apoptosis (Shi et al. 2010). Another peptaibol, emericellipsin A, which is a short lipopeptaibol, exhibited selective cytotoxic activity against HepG2 and HeLa cell lines (Rogozhin et al. 2018), similar to culicinin D, another short linear peptaibol which has been described as a potent anticancer compound (He et al. 2006). In the present study, the partially purified peptaibol extract of $T$. reesei QM9414 proved to inhibit boar spermatozoa and PK-15 cells at $0.1 \mathrm{mg} \mathrm{ml}^{-1}$, which raises the question of a possible in vivo toxicity. Degenkolb et al. (2008a) discussed this issue in detail and suggested that the toxicity of peptaibols may be well below the threshold of human consequence, and it may require direct contact with cell membranes, like in the case of common amphiphilic detergents. This is supported by previous observations demonstrating the very low toxicity of various peptaibols orally administered to rodents and ruminants (Hou et al. 1972, Nayar et al. 1973, Hino et al. 1994).

TABLE 13 I Toxicity of the purified peptaibol extract from T. reesei QM9414 to boar sperm and porcine kidney cells

\section{Sperm motility inhibition}

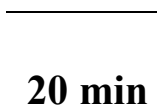

Inhibition of

Acrosome

reaction proliferation of PK-15

cells

\section{$\mathrm{EC}_{50}\left(\mu \mathrm{g} \mathrm{ml}^{-1}\right)$}

\section{Purified peptaibol}

extract

3

3

3

8

$\begin{array}{lllll}\text { Reference (ALM) } & 5 & 0.2 & 0.2 & 8\end{array}$

The values are the median of three measurements, represented by four microscopic fields. The variation between measurements was one dilution step of the 2 -fold dilution series. 


\section{CONCLUSIONS}

Several new compounds of known and novel peptaibol groups, such as koningiopsins, tripleurins and brevicelsins have been identified in this work, broadening the already wide diversity of peptaibol compounds produced by Trichoderma strains. The phylogenetic relationships between the producer species are less reflected by the clustering based on peptaibol profiles, than based on genes, but their peptaibol profiles may also provide an insight into their evolution. The results also provide a better understanding of their interactions with several organisms. Peptaibols were shown to be toxic towards Gram-positive bacteria and filamentous fungi and less effective against Gram-negative bacteria. Yeasts were not affected by peptaibol treatment. These results suggest that the type of cell wall of the host organism may play role in the sensitivity to peptaibols. The peptaibol production of Trichoderma can be affected by the host organisms during infections and the different organisms respond variously to peptaibol treatments. Although, they are toxic to bacteria and fungi, no negative effects could be detected on plants below a certain concentration. This finding can be useful especially in tropical agricultural environments, as peptaibol solutions with biocontrol abilities can replace the use of those Trichoderma strains, which can also grow at human body temperature and cause infections. This can lead to the use of peptaibols as biocontrol agents in plant protection. 


\section{SUMMARY}

Trichoderma species are ecologically and agriculturally beneficial, but certain species can cause damage in the commercial production of mushrooms or may be the causal agents of human infections. Among the bioactive secondary metabolites produced by Trichoderma species, studying the peptaibols is important for the better understanding of the processes that occur during their interactions with phytopathogens throughout their biocontrol activity, or during infections of mushrooms, or even humans. Species of the clade Viride including $T$. koningiopsis and T. gamsii are beneficial organisms of industrial, agricultural, and medicinal fields. T. aggressivum f. europaeum and T. pleuroti belong to clade Harzianum/Virens and can cause green mould diseases in the commercial production of white button mushroom $(A$. bisporus) and oyster mushroom (P. ostreatus), respectively. Clade Longibrachiatum contains species such as $T$. longibrachiatum, $T$. bissettii or $T$. citrinoviride, which can cause infections in immunocompromised humans. Certain species of this clade are beneficial and widely used in the industry, e.g. T. reesei for its cellulase production. This clade is ecologically highly versatile, some of its species can be found worldwide like the opportunistic human pathogens T. longibrachiatum and T. bissettii, whereas others are ecologically restricted, like the biotechnologically important cellulase producer $T$. reesei.

Based on using alamethicin (ALM) as standard, the high-performance liquid chromatography (HPLC) mass spectrometry (MS) instrument was optimized to identify peptaibol compounds. In this work, a total of 215 peptaibol compounds were identified from various Trichoderma strains, out of which 131 sequences proved to be new to science. The majority of the new compounds belong to already described peptaibol subgroups, such as hypomurocins, trikoningins, trichobrachins, paracelsins, suzukacillins, saturnisporins, trichoaureocins, trichocellins, longibrachins, hyporientalins, trichokonins, trilongins, metanicins, trichosporins, gliodeliquescins, hypophellins and T. citrinoviride sequences. Among the new sequences, three completely novel peptaibol subgroups could also be identified and described as koningiopsins, tripleurins and brevicelsins with 11, 24 and 8 sequences, respectively. These novel sequences showed homology to the peptaibol subgroups of trichorzianins, trichokindins, tricholongins, trichostrigocins and the ones mentioned above.

The study of the peptaibiome composition of T. koningiopsis and T. gamsii from clade Viride revealed a total of 30 peptaibol sequences (26 new and 4 known). Certain peptaibol compounds produced by $T$. gamsii were positionally isomeric with the sequence of 
trikoningin KA V known from the literature, and 15 new compounds were homologous with tricholongin B and LB, trichostrigocin TSG-A and TSG-B, trichorzianin TA, TB and Tap sequences. The novel peptaibol group of koningiopsins was described with 11 new sequences, which were produced by $T$. koningiopsis, and showed similarities to trichorzianin TA, TB and Tap sequences. The examination of their antibiotic activity against a broad spectrum of different microorganisms showed that Gram-positive bacteria were strongly inhibited, while Gram-negative bacteria seemed to be less sensitive to the peptaibol treatment. No inhibitory effects of the studied peptaibol extracts could be observed to yeasts, while filamentous fungi showed considerable sensitivity, suggesting that the peptaibol sensitivity of an organism may depend on its cell wall type.

During the study of the peptaibol production of Trichoderma species causing green mould diseases, 20 new and 5 already known hypomurocin-like compounds were identified from $T$. aggressivum $\mathrm{f}$. europaeum. In the case of $T$. pleuroti, the production of a completely new peptaibol group could be detected and named as tripleurins that were found to be related to trichokindins and trichorzins PA. The results also indicate that the peptaibols produced by $T$. aggressivum f. europaeum and T. pleuroti are potential growth inhibitors of mushroom mycelia, therefore their contribution to the antagonistic arsenal of mushroom green mould species can be suggested. Furthermore, the changes detected in the quantity of peptaibol compounds during in vitro confrontation of Trichoderma species with Agaricus and Pleurotus implicate the impact of the host mushroom on Trichoderma peptaibol metabolism.

Structural diversity examination of peptaibol compounds produced by Trichoderma species from clade Longibrachiatum revealed a total of 128 20-residue-long peptaibols from the 17 species examined, including 53 new and 75 recurrent compounds, as well as 8 new 19-residue sequences. These peptaibols could be categorized into groups A, B and C based on their primary structure, where groups A and B consist of 20-residue peptaibols, while group C comprises exclusively of eight new, 19-residue-long sequences. Group C was found to be novel and named as brevicelsins. The peptaibols belonging to group A were positionally isomeric or showed similarity to paracelsin, suzukacillin A, trichocellin-TC, trichoaureocin, longibrachin $\mathrm{A}$ and $\mathrm{B}$, trilongin $\mathrm{B}$ and $\mathrm{C}$, hypophellin, trichobrachin, trichokonin, trichosporin TS-B, metanicin, gliodeliquescin A, or hyporientalin A sequences. The peptaibols belonging to group B were positionally isomeric or showed similarity to paracelsin, suzukacillin A, trichocellin-TC, saturnisporin SA, or T. citrinoviride sequences. Brevicelsins were similar to the 19-residue-long hypophellins and differed from the other peptaibols produced by strains 
of clade Longibrachiatum in the absence of the $6^{\text {th }}$ amino acid residue. They also showed similarities to the 20-residue-long paracelsin, suzukacillin A, trichocellin TC and saturnisporin SA sequences bearing in mind the lack of the $6^{\text {th }}$ position in these sequences. We also carried out a cluster analysis of the peptaibol diversity profiles based on the production levels of different peptaibols by various fungal producers of clade Longibrachiatum. According to their peptaibol profiles, members of clade Longibrachiatum were divided into two main clusters (group A and B). Our results suggest that the production of group A peptaibols may be an ancestral trait of clade Longibrachiatum, while the switch to the production of group B peptaibols might have occurred multiple times and seems therefore to be the result of convergent evolution. This switch has not been completed fully in certain species, which are able to produce some group A compounds in addition to group B peptaibols. However, the phylogenetic relationships between the subclades are less reflected by the clustering based on peptaibol profiles.

The purified (98\%) extract containing the microheterogeneous mixture of peptaibols produced by T. reesei QM9414 was selected for testing its effects on Arabidopsis seedlings. Negative effects on the plants could not be detected below $0.1 \mathrm{mg} \mathrm{ml}^{-1}$ concentration of the purified peptaibol extract from $T$. reesei QM9414, but it could still inhibit phytopathogenic filamentous fungal growth. This observation suggests that purified peptaibol extracts may have potential in plant disease management. Direct treatment with these peptaibols was highly toxic on boar semen and porcine kidney tubular epithelial PK-15 cells at $0.1 \mathrm{mg} \mathrm{ml}^{-1}$, which raises the question of a possible in vivo toxicity. On the other hand, several studies have discussed this issue in detail and suggested that the toxicity of peptaibols may be well below the threshold of human consequence, and it may require direct contact with cell membranes, like in the case of common amphiphilic detergents. T. reesei is a well-characterised, widely used cellulase producer in the biotechnological industry, therefore its peptaibols could be produced as valuable by-products or even the main produces of fermentation.

Altogether, this work highlights the great peptaibiome diversity within the genus Trichoderma and provides new informations about the biological activity of peptaibols against various organisms and opens an avenue to their potential exploration in plant protection. 


\section{9. ÖSSZEFOGLALÓ}

A Trichoderma nemzetségbe tartozó fajok mind ökológiai, mind mezőgazdasági szempontból fontos szerepet töltenek be, néhány Trichoderma faj azonban képes jelentős károkat okozni a gombatermesztésben, továbbá egyes fajok akár humán fertőzések kórokozói is lehetnek. A Trichoderma fajok által termelt másodlagos anyagcseretermékek közül a peptaibolok vizsgálata kiemelkedően fontos lehet annak érdekében, hogy jobban megértsük a termelő fajok biokontroll tulajdonságait, illetve a gombatermesztésben okozott károk, vagy akár a humán fertőzések hátterében zajló folyamatokat. A Trichoderma nemzetség Viride kládjába tartozó fajok, mint például a T. koningiopsis és a T. gamsii, előnyös tulajdonságaik miatt közkedveltek a mezőgazdaságban, iparban és gyógyszeriparban. A Harzianum kládba tartozó T. aggressivum f. europaeum és T. pleuroti fajok képesek zöldpenészes megbetegedéseket okozni termesztett gombákon, mint például a csiperkén ( $A$. bisporus), vagy a laskagombán (P. ostreatus). A Longibrachiatum kládba tartozó T. longibrachiatum, $T$. bissettii és $T$. citrinoviride fajok legyengült immunrendszerü emberekben fertőzéseket okozhatnak. A klád egyes fajai gazdaságilag elönyösek is lehetnek, ilyen például a T. reesei, melyet széles körben használnak kiváló celluláz termelő képessége miatt. A Longibrachiatum klád ökológiai szempontból rendkívül változatos, egyes fajaik világszerte megtalálhatóak, mint például az opportunista humán patogén $T$. longibrachiatum és $T$. bissettii, míg más fajok csak egyes területeken izolálhatóak, mint például a biotechnológiai szempontból jelentős celluláztermelő $T$. reesei.

A nagy teljesítményü folyadékromatográfiás (high-performance liquid chromatography, HPLC) tömegspektrométer (mass spectrometry, MS) készüléket alamethicin (ALM) standard segítségével peptaibol-vegyületek azonosítása céljából optimalizáltuk. Munkám során összesen 215 peptaibol-vegyületet sikerült azonosítani Trichoderma fajokból, melyek közül 131 szekvencia bizonyult újnak. Ezek az új peptidek sok esetben már létező peptaibol-csoportokba tartoznak, melyek a hypomurocinok, a trikoninginek, a trichobrachinok, a paracelsinek, a suzukacillinek, a saturnisporinok, a trichoaureocinek, a trichocellinek, a longibrachinok, a hyporientalinok, a trichokoninok, a trilonginok, a metanicinek, a trichosporinok, a gliodeliquescinek, a hypophellinek és a $T$. citrinoviride szekvenciák. Az új szekvenciák közt sikerült 3 teljesen új peptaibolcsoportot is azonosítanunk, melyek a koningiopsinok 11 új peptaibollal, a tripleurinok 24 új szekvenciával és a brevicelsinek 8 új peptiddel. Ezek az új peptaibolcsoportok a trichorzianinokkal, a 
trichokindinekkel, a tricholonginokkal, a trichostrigocinokkal továbbá a fentebb felsorolt peptaibol-csoportokkal mutattak homológiát.

A Viride kládba tartozó T. koningiopsis and T. gamsii fajok peptaibiomjának feltérképezése során 30 (26 új és 4 ismert) peptaibol-szekvenciát azonosítottunk. A T. gamsii által termelt peptaibolok közül egyes szekvenciák a már ismert trikoningin KA V peptaibol pozícionális izomerjei, azonban 15 új peptidet is sikerült azonosítanunk, melyek a tricholongin B, LB, trichostrigocin TSG-A, TSG-B, trichorzianins TA, TB and Tap szekvenciákkal mutattak homológiát. A T. koningiopsis új, általunk felfedezett, koningiopsin peptaibolcsoportba tartozó 11 új peptidet termelt melyek a trichorzianin TA, TB és Tap szekvenciákkal voltak homológok. A bioaktivitási tesztek során kiderült, hogy a Gram-pozitív baktériumok érzékenyebben reagálnak peptaibol-kezelésre, mint a Gram-negatív baktériumok. Élesztőkkel szemben gátló hatást nem figyeltünk meg, viszont fonalas gombákon jól detektálható növekedésgátlást tapasztaltunk. Ezek alapján elmondható, hogy a megtámadott mikroorganizmusok sejtfalszerkezete befolyással lehet a peptaibolok toxicitására.

A zöldpenészes megbetegedéseket okozó Trichoderma fajok peptaibol-termelésének tanulmányozása során 20 új és 5 ismert hypomurocin-szerü peptaibolt azonosítottunk, melyeket a T. aggressivum f. europaeum termelt. A T. pleuroti egy teljesen új csoportba tartozó általunk felfedezett peptaibolokat, a tripleurinokat termelte, melyek leginkább a trichokindins és trichorzins PA peptaibolokhoz hasonlítottak. Eredményeink alapján elmondhatjuk, hogy a T. aggressivum f. europaeum és $T$. pleuroti által termelt peptaibolok a termesztett gombák micéliumának potenciális növekedésgátlói, tehát ezek is szerepet játszhatanak a zöldpenész tünetegyüttes kialakulásában. Csiperkegomba (Agaricus) és laskagomba (Pleurotus) jelenlétében további mennyiségi változásokat is megfigyeltünk a Trichoderma fajok peptaibol-termelésben, ami arra utal, hogy a gazdaszervezetnek hatása van a Trichoderma fajok peptaibol-metabolizmusára.

A Longibrachiatum kládba tartozó 17 faj által termelt peptaibol-diverzitásának vizsgálata során 128 (53 új és 75 már azonosított) 20 aminosav hosszú, valamint 8 új, általunk felfedezett, 19 aminosav hosszú peptaibol-szekvenciát sikerült azonosítanunk. Ezeket a peptaibolokat az elsődleges szerkezetük alapján 3 csoportba tudtuk besorolni, melyeket $\mathrm{A}, \mathrm{B}$ és C csoportoknak neveztük el. Az A és B csoportok 20 aminosav hosszú szekvenciákat tartalmaznak, míg a C csoportba az új, 19 aminosav hosszú peptaibolok tartoztak. A C csoport 
teljesen új peptaibolokat tartalmazott, melyeket brevicelsineknek neveztünk el. Az A csoportba tartozó szekvenciák pozícionális izomerei, vagy hasonlóságot mutatnak már ismert paracelsin, suzukacillin A, trichocellin-TC, trichoaureocin, longibrachin A, B, trilongin $\mathrm{B}, \mathrm{C}$, hypophellin, trichobrachin, trichokonin, trichosporin TS-B, metanicin, gliodeliquescin A, vagy hyporientalin A szekvenciákkal. A B csoportba tartozó peptaibolok számos paracelsin, suzukacillin A, trichocellin-TC, saturnisporin SA vagy T. citrinoviride szekvenciákkal mutattak hasonlóságot, vagy bizonyos esetekben pozícionális izomerei voltak azoknak. A brevicelsinek a 19 aminosav hosszú hypophellinekhez hasonlítottak leginkább, valamint a többi, Longibrachium kládba tartozó peptaiboloktól a 6. pozíció kiesése miatt tértek el. Szekvencia-hasonlóságot továbbá a 20 aminosav hosszú paracelsin, suzukacillin A, trichocellin TC, saturnisporin SA szekvenciákkal mutatnak, ez esetekben is a felsorolt csoportok szekvenciáiban lévő 6. pozíció hiányát figyelembe véve. A peptaibolok termelési szintje alapján készített peptaibol-profilokkal klaszteranalízist is végeztünk a Longibrachiatum kládba tartozó termelő fajokról. A peptaibolprofilok alapján a klád tagjait két fó klaszterbe tudtuk elkülöníteni (A és B csoport). Eredményeink alapján az A csoportba tartozó peptaibolok termelése a Longibrachiatum klád egy ősi tulajdonsága lehet, míg a $\mathrm{B}$ csoportba tartozó peptaibolok termelésére való váltás többször is megtörtént, mely konvergens evolúció eredménye lehet. Ez a váltás egyes fajok esetében nem történt meg teljes mértékben, ugyanis ezek a fajok képesek a B csoportba tartozó peptaibolok termelése mellett az A csoportba tartozó peptaibolok termelésére is. A peptaibolprofilok alapján történő klaszterezés azonban kevésbé tükrözi a szubkládok közöti filogenetikai kapcsolatokat.

A T. reesei QM9414 által termelt, tisztított, peptaibolok mikroheterogén keverékét tartalmazó (98\%) kivonatot teszteltük Arabidopsis növényeken is. Negatív hatást nem azonosítottunk $0,1 \mathrm{mg} \mathrm{ml}^{-1}$ töménységü oldat alkalmazása esetén, mely koncentráció képes volt számos növénypatogén gomba növekedésének gátlására. Ez a megfigyelés megerősíti, hogy a tisztított peptaibol-kivonatok biokontroll alkalmazásának potenciális értéke lehet a jövőben. Ezen készítmények erősen toxikusnak bizonyultak vaddisznósperma és sertésvese epitéliális sejtvonal (porcine kidney tubular epithelial cell line, PK-15) sejtekre nézve, mely a peptaibolok lehetséges in vivo toxicitásának kérdését teheti fel. Azonban számos tanulmány bizonyította azt, hogy a peptaibolok toxicitása jóval az emberi türéshatár alatt van, a toxicitás csak közvetlenül a sejtmembránnal érintkezve jelentkezik, hasonlóan, mint az általános amfifil vegyületek, mosószerek esetében. A T. reesei egy részletesen feltérképezett, széles 
körben használt, a biotechnológiai ipar által használt celluláztermelő faj, ezért az általa termelt peptaibolok mellék-, de akár fötermékként is könnyen kivonhatók lennének.

Kutatásaim eredményei kiemelik a Trichoderma nemzetség képviselőire jellemző peptaibiomok változatosságát és új információkkal szolgálnak a peptaibolok különböző organizmusokra gyakorolt bioaktivitásairól, valamint új utat nyitnak a növényvédelemben történő alkalmazásuk felé. 


\section{ACKNOWLEDGEMENTS}

Herein I would like to express my gratitude to:

My supervisors, Dr. László Kredics and Dr. András Szekeres for their guiding and help during my research,

The head of my home Department, Prof. Dr. Csaba Vágvölgyi and the head of the Institute of Biology, Prof. Dr. Attila Gácser for providing the workplace for my research,

Dr. Ágnes Szepesi and László Bakacsy from the Department of Plant Biology for their help in the plant experiments,

Dr. Irina S. Druzhinina from TU Wien for her great ideas and help in taxonomy of Trichoderma,

Dr. Maria A. Andersson from Aalto University for the help in the mammalian cell biotests,

Chetna Tyagi, my wife and colleague, who helped me through these years with her experiments, ideas and motivation,

Dávid Rakk, Dóra Balázs, Gábor Endre, Péter Urbán for their help during the peptaibol experiments,

Boglárka Lengyel and Adrienn Magyar from the office of the Department of Microbiology for their help in the administrative work,

Prof. Rainer Schuhmacher, for kindly providing the offline version of the Peptaibiotics Database,

my family for giving me a comfortable background and support,

all my labmates from Lab 308 and all my colleagues at the Department of Microbiology, University of Szeged, who have helped my work in any way. 
The work was supported by:

- the ÚNKP-19-3-SZTE-183 New National Excellence Program of the Ministry for Innovation and Technology

- the Nemzeti Kiválóság Program - Campus Hungary B2/1R/19226 grant

- the European Social Fund in the framework of TÁMOP-4.2.4.A/ 2-11/1-2012-0001 'National Excellence Program',

- the Hungarian Scientific Research Fund by grants NKFI K-105972, and K-116475,

- the bilateral grant 95öu4 from the Austrian-Hungarian Action Fund,

- the GINOP-2.3.2-15-2016-00012 (Széchenyi 2020 Programme)

- the Hungarian Scientific Research Fund by grant K-116475,

- the Széchenyi 2020 Programme (GINOP-2.3.2-15-2016-00052),

- the Széchenyi 2020 Programme (GINOP-2.3.3-15-2016-00006),

- the COST action 16110 (HuPlantControl) 


\section{REFERENCES}

Alm, K., Taponen, J., Dahlbom, M., Tuunainen, E., Koskinen, E. and Andersson, M. (2001). A novel automated fluorometric assay to evaluate sperm viability and fertility in dairy bulls. Theriogenology 56, 677-684. doi: 10.1016/S0093-691X(01)00599-4

Andersson, M. A., Mikkola, R., Rasimus, S., Hoornstra, D., Salin, P., Rahkila, R., et al. (2010). Boar spermatozoa as a biosensor for detecting toxic substances in indoor dust and aerosols. Toxicol. In Vitro 24, 2041-2052. doi: 10.1016/j.tiv.2010.08.011

Andersson, M. A., Mikkola, R., Raulio, M., Kredics, L., Maijala, P., and Salkinoja-Salonen, M. S. (2009). Acrebol, a novel toxic peptaibol produced by an Acremonium exuviarum indoor isolate. J. Appl. Microbiol. 106, 909-923. doi: 10.1111/j.1365-2672.2008.04062.x

Antal, Z., Kredics, L., Pakarinen, J., Dóczi, I., Andersson, M., Salkinoja-Salonen, M., et al. (2005). Comparative study of potential virulence factors in human pathogenic and saprophytic Trichoderma longibrachiatum strains. Acta Microbiol. Immunol. Hung. 52, 341-350. doi: 10.1556/amicr.52.2005.3-4.6

Atanasova, L., Jaklitsch, W. M., Komoń-Zelazowska, M., Kubicek, C. P., and Druzhinina, I. S. (2010). Clonal species Trichoderma parareesei sp. nov. likely resembles the ancestor of the cellulase producer Hypocrea jecorina/T. reesei. Appl. Environ. Microbiol. 76, 7259-7267. doi: 10.1128/AEM.01184-10

Auvin-Guette, C., Rebuffat, S., Vuidepot, I., Massias, M., and Bodo, B. (1993). Structural elucidation of trikoningins KA and KB, peptaibols from Trichoderma koningii. J. Chem. Soc. Perkin Trans. I. 1, 249-255. doi: 10.1039/p19930000249

Becker, D., Kiess, M., and Brückner, H. (1997). Structures of peptaibol antibiotics hypomurocin A and B from the ascomycetous fungus Hypocrea muroiana Hino et Katsumoto. Liebigs Ann. 4, 767-772. doi: 10.1002/jlac.199719970421

Belayneh Mulaw, T., Kubicek, C. P., and Druzhinina, I. S. (2010). The rhizosphere of Coffea arabica in its native highland forests of Ethiopia provides a niche for a distinguished diversity of Trichoderma. Diversity 2, 527-549. doi: 10.3390/d2040527

Bencsik, O., Papp, T., Berta, M., Zana, A., Forgó, P., Dombi, G., et al. (2014). Ophiobolin A from Bipolaris oryzae perturbs motility and membrane integrities of porcine sperm and induces cell death on mammalian somatic cell lines. Toxins 6, 2857-2871. doi: $10.3390 /$ toxins 6092857

Benedetti, E., Bavoso, A., Di Blasio, B., Pavone, V., Pedone, C., Toniolo, C., et al. (1982). Peptaibol antibiotics: a study on the helical structure of the 2-9 sequence of emerimicins III and IV. P. Natl. A. Sci. 79, 7951-7954. doi: 10.1073/pnas.79.24.7951

Benítez, T., Rincón, A. M., Limón, M. C., and Codon, A. C. (2004). Biocontrol mechanisms of Trichoderma strains. Int. Microbiol. 7, 249-260. 
Berg, A., Grigoriev, P. A., Degenkolb, T., Neuhof, T., Härtl, A., Schlegel, B., and Gräfe, U. (2003). Isolation, structure elucidation and biological activities of trichofumins A, B, C and D, new 11 and 13mer peptaibols from Trichoderma sp. HKI 0276. J. Pept. Sci. 9, 810-816. doi: $10.1002 /$ psc.498

Bisby, G. R. (1939). Trichoderma viride Pers. ex Fries, and notes on Hypocrea. Trans. Br. Mycol. Soc. 23, 149-168. doi: 10.1016/S0007-1536(39)80020-1

Bissett, J. (1984). A revision of the genus Trichoderma. I. Section Longibrachiatum sect. nov. Can. J. Bot. 62, 924-931. doi: 10.1139/b84-131

Bissett, J. (1991a). A revision of the genus Trichoderma. II. Infrageneric classification. Can. J. Bot. 69, 2357-2372. doi: 10.1139/b91-297

Bissett, J. (1991b). A revision of the genus Trichoderma. III. Section Pachybasium. Can. J. Bot. 69, 2373-2417. doi: 10.1139/b91-298

Bissett, J. (1991c). A revision of the genus Trichoderma. IV. Additional notes on section Longibrachiatum. Can. J. Bot. 69, 2418-2420. doi: 10.1139/b91-299

Bissett, J., Gams, W., Jaklitsch, W., and Samuels, G. J. (2015). Accepted Trichoderma names in the year 2015. IMA Fungus 6, 263-295. doi: 10.5598/imafungus.2015.06.02.02.

Bissett, J., Szakacs, G., Nolan, C. A., Druzhinina, I., Gradinger, C., and Kubicek, C. P. (2003). New species of Trichoderma from Asia. Can. J. Bot. 81, 570-586. doi: 10.1139/b03051

Brenner, M.L. (1981). Modern methods for plant growth substance analysis. Annu. Rev. Plant Physiol. 32, 511-538. doi: 10.1146/annurev.pp.32.060181.002455

Brunner, K., Zeilinger, S., Ciliento, R., Woo, S. L., Lorito, M., Kubicek, C. P., and Mach, R. L. (2005). Improvement of the fungal biocontrol agent Trichoderma atroviride to enhance both antagonism and induction of plant systemic disease resistance. Appl. Environ. Microbiol. 71, 3959-3965. doi: 10.1128/AEM.71.7.3959-3965.2005

Brückner, H., and Graf, H. (1983). Paracelsin, a peptide antibiotic containing $\alpha-$ aminoisobutyric acid, isolated from Trichoderma ressei Simmons Part A. Experientia 39, 528-530. doi: 10.1007/BF01965190

Brückner, H., Kirschbaum, J., and Jaworski, A. (2002). Sequences of peptaibol antibiotics trichoaureocins from Trichoderma aureoviride. Peptides 362-363

Brückner, H., and Przybylski, M. (1984). Methods for the rapid detection, isolation and sequence determination of "peptaibols" and other aib-containing peptides of fungal origin. I. Gliodeliquescin a from Gliocladium deliquescens. Chromatographia 19, 188-189. doi: 10.1007/BF02687737 
Bushley, K. E., and Turgeon, B. G. (2010). Phylogenomics reveals subfamilies of fungal nonribosomal peptide synthetases and their evolutionary relationships. BMC Evol. Biol. 10, 26. doi: 10.1186/1471-2148-10-26

Castagnoli, E., Marik, T., Mikkola, R., Kredics, L., Andersson, M. A., Salonen, H., et al. (2018a). Indoor Trichoderma strains emitting peptaibols in guttation droplets. J. Appl. Microbiol. 125, 1408-1422. doi: 10.1111/jam.13920

Castagnoli, E., Salo, J., Toivonen, M.S., Marik, T., Mikkola, R., Kredics, L., Vicente-Carrillo, A., et al. (2018b). An evaluation of boar spermatozoa as a biosensor for the detection of sublethal and lethal toxicity. Toxins, 10, 463. doi:10.3390/toxins10110463.

Chaverri, P., Branco-Rocha, F., Jaklitsch, W., Gazis, R., Degenkolb, T., and Samuels, G. J. (2015). Systematics of the Trichoderma harzianum species complex and the re-identification of commercial biocontrol strains. Mycologia 107, 558-590. doi: 10.3852/14-147

Chaverri, P., and Samuels, G. J. (2003). "Hypocrea/Trichoderma (Ascomycota, Hypocreales, Hypocreaceae): species with green ascospores." Centraalbureau voor Schimmelcultures, Utrecht, The Netherlands.

Chen, L., Liu, Y. T., Song, B., Zhang, H. W., Ding, G., Liu, X. Z., et al. (2014). Stereochemical determination of new cytochalasans from the plant endophytic fungus Trichoderma gamsii. Fitoterapia 96, 115-122. doi: 10.1016/j. fitote.2014.04.009

Chen, L., Niu, S. B., Li, L., Ding, G., Yu, M., Zhang, G. S., et al. (2017). Trichoderpyrone, a unique polyketide hybrid with a cyclopentenone-pyrone skeleton from the plant endophytic fungus Trichoderma gamsii. J. Nat. Prod. 80, 1944-1947. doi: 10.1021/acs.jnatprod.7b00190.

Chen, J. L., Sun, S. Z., Miao, C. P., Wu, K., Chen, Y. W., Xu, L. H., et al. (2016). Endophytic Trichoderma gamsii YIM PH30019: a promising biocontrol agent with hyperosmolar, mycoparasitism, and antagonistic activities of induced volatile organic compounds on root-rot pathogenic fungi of Panax notoginseng. J. Ginseng Res. 40, 315-324. doi: 10.1016/j.jgr.2015.09.006.

Chet, I., and Inbar, J. (1994). Biological control of fungal pathogens. Appl. Biochem. Biotechnol. 48, 37-43. doi: 10.1007/BF02825358

Chikanishi, T., Hasumi, K., Harada, T., Kqwqsqki, N., and Endo, A. (1997). Clonostachin, a novel peptaibol that inhibits platelet aggregation. J. Antibiot. 50, 105-110. doi: 10.7164/antibiotics.50.105

Chugh, J. K., and Wallace, B. A. (2001). Peptaibols: models for ion channels. Biochem. Soc. T. 29, 565-570. doi: 10.1042/bst0290565

Cleland, R. (1972). The dosage-response curve for auxin-induced cell elongation: a reevaluation. Planta 104, 1-9. doi: 10.1007/BF00387679 
Condamine, E., Rebuffat, S., Prigent, Y., Ségalas, I., Bodo, B., and Davoust, D. (1998). Three-dimensional structure of the ion-chanel forming peptide trichorzianin TA VII bound to sodium dodecyl sulfate micelles. Biopolymers 46, 75-88. doi: 10.1002/(SICI)10970282(199808)46:2<75::AID-BIP3>3.0.CO;2-U

Contreras-Cornejo, H. A., Macías-Rodríguez, L., del-Val, E., and Larsen, J. (2016). Ecological functions of Trichoderma spp. and their secondary metabolites in the rhizosphere: interactions with plants. FEMS Microbiol. Ecol. 92, fiw036. doi: 10.1093/femsec/fiw036

Cutler, H. G., Cox, R. H., Crumley, F. G., and Cole, P. D. (1986). 6-Pentyl- $\alpha$-pyrone from Trichoderma harzianum: its plant growth inhibitory and antimicrobial properties. Agric. Biol. Chem. 50, 2943-2945. doi: 10.1080/00021369.1986.10867860

Cutler, H. G., Himmelsbach, D. S., Arrendale, R. F., Cole, P. D., and Cox, R. H. (1989). Koninginin A: a novel plant growth regulator from Trichoderma koningii. Agric. Biol. Chem. 53, 2605-2611. doi: 10.1080/00021369.1989.10869746

Cutler, H. G., Himmelsbach, D. S., Yagen, B., Arrendale, R. F., Jacyno, J. M., Cole, P. D., et al. (1991). Koninginin B: a biologically active congener of koninginin A from Trichoderma koningii. J. Agric. Food Chem. 39, 977-980. doi: 10.1021/jf00005a035

Daniel, J. F. D. S., and Rodrigues Filho, R. E. (2007). Peptaibols of Trichoderma. Nat. Prod. Rep. 24, 1128-1141. doi: 10.1039/b618086h

Degenkolb, T., Berg, A., Gams, W., Schlegel, B., and Gräfe, U. (2003). The occurrence of peptaibols and structurally related peptaibiotics in fungi and their mass spectrometric identification via diagnostic fragment ions. J. Pept. Sci. 9, 666-678. doi: 10.1002/psc.497

Degenkolb, T., Dieckmann, R., Nielsen, K. F., Gräfenhan, T., Theis, C., Zafari, D., et al. (2008a). The Trichoderma brevicompactum clade: a separate lineage with new species, new peptaibiotics, and mycotoxins. Mycol. Prog. 7, 177-219. doi: 10.1007/s11557-008-0563-3

Degenkolb, T., von Döhren, H., Nielsen, K. F., Samuels, G. J., and Brückner, H. (2008b). Recent advances and future prospects in peptaibiotics, hydrophobin, and mycotoxin research, and their importance for chemotaxonomy of Trichoderma and Hypocrea. Chem. Biodivers. 5, 671-680. doi: 10.1002/cbdv.200890064

Degenkolb, T., Gräfenhan, T., Nirenberg, H. I., Gams, W., and Brückner, H. (2006a). Trichoderma brevicompactum complex: rich source of novel and recurrent plant-protective polypeptide antibiotics (peptaibiotics). J. Agric. Food Chem. 54, 7047-7061. doi: $10.1021 / \mathrm{jf060788q}$

Degenkolb, T., Gräfenhan, T., Berg, A., Nirenberg, H. I., Gams, W., and Brückner, H. (2006b). Peptaibiomics: screening for polypeptide antibiotics (peptaibiotics) from plantprotective Trichoderma species. Chem. Biodivers. 3, 593-610. doi: 10.1002/cbdv.200690063. 
Degenkolb, T., and Brückner, H. (2008). Peptaibiomics: towards a myriad of bioactive peptides containing $\mathrm{C}^{\alpha}$-dialkylamino acids? Chem. Biodivers. 5, 1817-1843. doi: $10.1002 / \mathrm{cbdv} .200890171$

Degenkolb, T., Fog Nielsen, K., Dieckmann, R., Branco-Rocha, F., Chaverri, P., Samuels, G. J., et al. (2015). Peptaibol, secondary-metabolite, and hydrophobin pattern of commercial biocontrol agents formulated with species of the Trichoderma harzianum complex. Chem. Biodivers. 12, 662-684. doi: 10.1002/cbdv.201400300

Degenkolb, T., Karimi Aghcheh, R., Dieckmann, R., Neuhof, T., Baker, S. E., Druzhinina, I. S., et al. (2012). The production of multiple small peptaibol families by single 14-module peptide synthetases in Trichoderma/Hypocrea. Chem. Biodivers. 9, 499-535. doi: $10.1002 / \mathrm{cbdv} .201100212$

Degenkolb, T., Kirschbaum, J., and Brückner, H. (2007). New sequences, constituents, and producers of peptaibiotics: an updated review. Chem. Biodivers. 4, 1052-1067. doi: 10.1002/cbdv.200790096

Degenkolb, T., Röhrich, C. R., Vilcinscas, A., von Döhren, H., and Brückner, H. (2016). A new family of N-terminally truncated peptaibols from the biocontrol fungus Trichoderma harzianum. J. Pept. Sci. 22, 98.

Dang, L., Li, G., Yang, Z., Luo, S., Zheng, X., and Zhang, K. (2010). Chemical constituents from the endophytic fungus Trichoderma ovalisporum isolated from Panax notoginseng. Ann. Microbiol. 60, 317-320. doi: 10.1007/s13213-010-0043-2

Ding, G., Chen, L., Chen, A., Tian, X., Chen, X., Zhang, H., et al. (2012a). Trichalasins C and D from the plant endophytic fungus Trichoderma gamsii. Fitoterapia 83, 541-544. doi: 10.1016/j.fitote.2011.12.021

Ding, G., Chen, L., Zhou, C., Hong-Mei, J., Liu, Y. T., Chang, X., et al. (2015). Trichoderamides A and B, a pair of stereoisomers from the plant endophytic fungus Trichoderma gamsii. J. Antibiot. 68, 409-413. doi: 10.1038/ja.2015.1

Ding, G., Wang, H., Li, L., Song, B., Chen, H., Zhang, H., et al. (2014). Trichodermone, a spiro-cytochalasan with a tetracyclic nucleus (7/5/6/5) skeleton from the plant endophytic fungus Trichoderma gamsii. J. Nat. Prod. 77, 164-167. doi: 10.1021/np4007487

Ding, G., Wang, H. L., Chen, L., Chen, A. J., Lan, J., Chen, X. D., et al. (2012b). Cytochalasans with different amino-acid origin from the plant endophytic fungus Trichoderma gamsii. J. Antibiot. 65, 143-145. doi: 10.1038/ja.2011.124

Dotson, B. R., Soltan, D., Schmidt, J., Areskoug, M., Rabe, K., Swart, C., et al. (2018). The antibiotic peptaibol alamethicin from Trichoderma permeabilises Arabidopsis root apical meristem and epidermis but is antagonised by cellulase-induced resistance to alamethicin. BMC Plant Biol. 18:165. doi: 10.1186/s12870-018-1370-x 
Druzhinina, I. S., Komoń-Zelazowska, M., Atanasova, L., Seidl, V., and Kubicek, C. P. (2010). Evolution and ecophysiology of the industrial producer Hypocrea jecorina (anamorph Trichoderma reesei) and a new sympatric agamospecies related to it. PLoS ONE 5, e9191. doi: 10.1371/journal.pone.0009191

Druzhinina, I. S., Komoń-Zelazowska, M., Ismaiel, A., Jaklitsch, W., Mullaw, T., Samuels, G. J., et al. (2012). Molecular phylogeny and species delimitation in the section Longibrachiatum of Trichoderma. Fungal Genet. Biol. 49, 358-368. doi: 10.1016/j.fgb.2012.02.004

Druzhinina, I. S., Komoń-Zelazowska, M., Kredics, L., Hatvani, L., Antal, Z., Belayneh, T., et al. (2008). Alternative reproductive strategies of Hypocrea orientalis and genetically close but clonal Trichoderma longibrachiatum, both capable of causing invasive mycoses of humans. Microbiology 154, 3447-3459. doi: 10.1099/mic.0.2008/021196-0

Duclohier, H. (2004). Helical kink and channel behaviour: a comparative study with the peptaibols alamethicin, trichotoxin and antiamoebin. Eur. Biophys. J. 33, 169-174. doi: 10.1007/s00249-003-0383-y

Duclohier, H., Molle, G., and Spach, G. (1989). The influence of the trichorzianin C-terminal residues on the ion channel conductance in lipid bilayers. Biochim. Biophys. Acta. 987, 133136. doi: 10.1016/0005-2736(89)90465-3

Duval, D., Rebuffat, S., Goulard, C., Prigent, Y., Becchi, M., and Bodo, B. (1997). Isolation and sequence analysis of the peptide antibiotics trichorzins PA from Trichoderma harzianum. J. Chem. Soc. Perkin Trans. 1, 2147-2154. doi: 10.1039/A700244K

Engelberth, J., Koch, T., Kühnemann, F., and Boland, W. (2000). Channel-forming peptaibols are potent elicitors of plant secondary metabolism and tendril coiling. Angew. Chem., Int. Ed. 39, 1860-1862. doi: 10.1002/(SICI)1521-3773(20000515)39:10<1860::AIDANIE1860>3.0.CO;2-F

Engelberth, J., Koch, T., Schüler, G., Bachmann, N., Rechtenbach, J., and Boland, W. (2001). Ion channel-forming alamethicin is a potent elicitor of volatile biosynthesis and tendril coiling. Cross talk between jasmonate and salicylate signaling in lima bean. Plant Physiol. 125, 369-377. doi: 10.1104/pp.125.1.369

Forbrig, E., Staffa, J. K., Salewski, J., Mroginski, M. A., Hildebrandt, P., and Kozuch, J. (2018). Monitoring the orientational changes of alamethicin during incorporation into bilayer lipid membranes. Langmuir 34, 2373-2385. doi: 10.1021/acs.langmuir.7b04265

Futaki, S., and Asami, K. (2007). Ligand-induced extramembrane conformation switch controlling alamethicin assembly and the channel current. Chem. Biodivers. 4, 1313-1322. doi: $10.1002 / \mathrm{cbdv} .200790112$

Geraldine, A. M., Lopes, F. A. C., Carvalho, D. D. C., Barbosa, E. T., Rodrigues, A. R., Brandão, R. S., et al. (2013). Cell wall-degrading enzymes and parasitism of sclerotia are key 
factors on field biocontrol of white mold by Trichoderma spp. Biol. Control. 67, 308-316. doi: 10.1016/j.biocontrol.2013.09.013

Goulard, C., Hlimi, S., Rebuffat, S., and Bodo, B. (1995). Trichorzins HA and MA, antibiotic peptides from Trichoderma harzianum. J. Antibiot. 48, 1248-1253. doi: 10.7164/antibiotics.48.1248

Grigoriev, P.A., Berg, A., Schlegel, B., Heinze, S., and Gräfe, U. (2002). Formation of anionselective membrane pores by texenomycin A, a basic lipopeptaibol antibiotic. J. Antibiot. 55, 826-828. doi: 10.7164/antibiotics.55.826

Hajji, M. E., Rebuffat, S., Lecommandeur, D., and Bodo, B. (1987) Isolation and sequence determination of trichorzianines A antifungal peptides from Trichoderma harzianum. Int. J. Pept. Protein Res. 29, 207-215. doi: 10.1111/j.1399-3011.1987.tb02247.x

Harman, G. E., and Kubicek, C. P. (eds) (1998). "Trichoderma and Gliocladium. Volume 2: Enzymes, biological control and commercial applications." Taylor \& Francis, London, UK.

Harman, G. E., Howell, C. R., Viterbo, A., Chet, I., and Lorito, M. (2004). Trichoderma species - opportunistic, avirulent plant symbionts. Nat. Rev. Microbiol. 2, 43-56. doi: $10.1038 /$ nrmicro797

Hatvani, L., Antal, Z., Manczinger, L., Szekeres, A., Druzhinina, I. S., Kubicek, C. P., et al. (2007). Green mold diseases of Agaricus and Pleurotus spp. are caused by related but phylogenetically different Trichoderma species. Phytopathology, 97, 532-537. doi: 10.1094/PHYTO-97-4-0532

Hatvani, L., Homa, M., Chenthamara, K., Cai, F., Kocsubé, S., Atanasova, L., et al. (2019). Agricultural systems as potential sources of emerging human mycoses caused by Trichoderma: a successful, common phylotype of Trichoderma longibrachiatum in the frontline. FEMS Microbiol. Lett. 366, fnz246. doi: 10.1093/femsle/fnz246

Hatvani, L., Kocsubé, S., Manczinger, L., Antal, Z., Szekeres, A., Druzhinina, I. S., et al. (2008). "The green mould disease global threat to the cultivation of oyster mushroom (Pleurotus ostreatus): a review." in Science and cultivation of edible and medicinal fungi: Mushroom Science XVII, Proceeding of the 17th Congress of the International Society for Mushroom Science, 485-495

Hatvani, L., Manczinger, L., Vágvölgyi, C., and Kredics, L. (2013). "Trichoderma as a human pathogen," in Trichoderma - Biology and Applications, eds: Mukherjee, P. K., Horwitz, B. A., Singh, U. S., Mukherjee, M., and Schmoll M. CAB International, Wallingford, UK, 292-313. doi: $10.1079 / 9781780642475.0292$

He, H., Janso, J. E., Yang, H. Y., Bernan, V. S., Lin, S. L., and Yu, K. (2006). Culicinin D, an antitumor peptaibol produced by the fungus Culicinomyces clavisporus, strain LL-12I252. J. Nat. Prod. 69, 736-741. doi: 10.1021/np058133r 
Hermosa, M. R., Emma, K. E. C. K., Chamorro, I., Rubio, B., Luis, S. A. N. Z., Vizcaíno, J. A., et al. (2004). Genetic diversity shown in Trichoderma biocontrol isolates. Mycol. Res. 108, 897-906. doi: 10.1017/S0953756204000358

Hermosa, R., Viterbo, A., Chet, I., and Monte, E. (2012). Plant-beneficial effects of Trichoderma and of its genes. Microbiology 158, 17-25. doi: 10.1099/mic.0.052274-0

Hino, T., Saitoh, H., Miwa, T., Kanda, M., and Kumazawa, S. (1994). Effect of aibellin, a peptide antibiotic, on propionate production in the rumen of goats. J. Dairy Sci. 77, 34263431. doi: 10.3168/jds.S0022-0302(94)77285-4

Hoornstra, D., Andersson, M. A., Mikkola, R. and Salkinoja-Salonen, M. S. (2003). A new method for in vitro detection of microbially produced mitochondrial toxins. Toxicol. In Vitro 17, 745-751. doi: 10.1016/S0887-2333(03)00097-3

Horváth, E., Brunner, S., Bela, K., Papdi, C., Szabados, L., Tari, I., et al. (2015). Exogenous salicylic acid-triggered changes in the glutathione transferases and peroxidases are key factors in the successful salt stress acclimation of Arabidopsis thaliana. Funct. Plant Biol. 42, 11291140. doi: 10.1071/FP15119

Horváth, J., Násztor, Z., Bartha, F., Bogár, F., and Leitgeb, B. (2016). Characterizing the structural and folding properties of long-sequence hypomurocin B peptides and their analogs. Pept. Sci. 106, 645-657. doi: 10.1002/bip.22870

Hou, C. T., Ciegler, A., and Hesseltine, C. W. (1972). New mycotoxin, trichotoxin A, from Trichoderma viride isolated from southern leaf blight-infected corn. Appl. Microbiol. 23, 183-185.

Howell, C. R. (2003). Mechanisms employed by Trichoderma species in the biological control of plant diseases: the history and evolution of current concepts. Plant dis. 87, 4-10. doi: 10.1094/PDIS.2003.87.1.4

Huang, Q., Tezuka, Y., Hatanaka, Y., Kikuchi, T., Nishi, A., and Tubaki, K. (1995). Studies on metabolites of mycoparasitic fungi. IV. Minor peptaibols of Trichoderma koningii. Chem. Pharm. Bull. 43, 1663-1667. doi: 10.1248/cpb.43.1663

Huang, Q., Tezuka, Y., Hatanaka, Y., Kikuchi, T., Nishi, A., and Tubaki, K. (1996). Studies on metabolites of mycoparasitic fungi. V. Ion-spray ionization mass spectrometric analysis of trichokonin-II, a peptaibol mixture obtained from the culture broth of Trichoderma koningii. Chem. Pharm. Bull. 44, 590-593. doi: 10.1248/cpb.44.590

Huang, Q., Tezuka, Y., Kikuchi, T., and Momose, Y. (1994). Trichokonin VI, a new $\mathrm{Ca}^{2+}$ channel agonist in bullfrog cardiac myocytes. Eur. J. Pharmacol. 271, R5-R6. doi: 10.1016/0014-2999(94)90290-9

Hülsmann, H., Heinze, S., Ritzau, M., Schlegel, B., and Gräfe, U. (1998). Isolation and structure of peptaibolin, a new peptaibol from Sepedonium strains. J. Antibiot. 51, 1055-1058. doi: 10.7164/antibiotics.51.1055 
Iida, A., Okuda, M., Uesato, S., Takaishi, Y., Shingu, T., Morita, M., et al. (1990). Fungal metabolites. Part 3. Structural elucidation of antibiotic peptides, trichosporin-B-IIIb, -IIIc, $\mathrm{IVb},-\mathrm{IVc},-\mathrm{IVd}$, -VIa and -VIb from Trichoderma polysporum. Application of fast-atom bombardment mass spectrometry/mass spectrometry to peptides containing a unique Aib-Pro peptide bond. J. Chem. Soc. Perkin Trans. 1, 3249-3255. doi: 10.1039/P19900003249

Iida, A., Sanekata, M., Fujita, T., Tanaka, H., Enoki, A., Fuse, G., et al. (1994). Fungal metabolites. XVI. Structures of new peptaibols, trichokindins I-VII, from the fungus Trichoderma harzianum. Chem. Pharm. Bull. 42, 1070-1075. doi: 10.1248/cpb.42.1070

Jaklitsch, W. M. (2009). European species of Hypocrea part I. The green-spored species. Stud. Mycol. 63, 1-91. doi: 10.3114/sim.2009.63.01

Jaklitsch, W. M. (2011). European species of Hypocrea part II: species with hyaline ascospores. Fungal divers. 48, 1-250. doi: 10.1007/s13225-011-0088-y

Jaklitsch, W. M., and Voglmayr, H. (2013). New combinations in Trichoderma (Hypocreaceae, Hypocreales). Mycotaxon, 126, 143. doi: 10.5248/126.143

Jaklitsch, W. M., and Voglmayr, H. (2015). Biodiversity of Trichoderma (Hypocreaceae) in Southern Europe and Macaronesia. Stud. Mycol. 80, 1-87. doi: 10.1016/j.simyco.2014.11.001

Jaklitsch, W. M., Poldmaa, K., and Samuels, G. J. (2008). Reconsideration of Protocrea (Hypocreales, Hypocreaceae). Mycologia 100, 962-984. doi: 10.3852/08-101

Jaklitsch, W. M., Samuels, G. J., Dodd, S. L., Lu, B. S., and Druzhinina, I. S. (2006). Hypocrea rufa/Trichoderma viride: a reassessment, and description of five closely related species with and without warted conidia. Stud. Mycol. 56, 135-177. doi: 10.3114/sim.2006.56.04

Jaworski, A., and Brückner, H. (2001). Sequences of polypeptide antibiotics stilboflavins, natural peptaibol libraries of the mold Stilbella flavipes. J. Pept. Sci. 7, 433-447. doi: $10.1002 /$ psc. 335

Jaworski, A., Kirschbaum, J., and Brückner, H. (1999). Structures of trichovirins II, peptaibol antibiotics from the mold Trichoderma viride NRRL 5243. J. Pept. Sci. 5, 341-351. doi: 10.1002/(SICI)1099-1387(199908)5:8<341::AID-PSC204>3.0.CO;2-0

Jen, W. C., Jones, G. A., Brewer, D., Parkinson, V. O., and Taylor, A. (1987). The antibacterial activity of alamethicins and zervamicins. J. Appl. Microbiol. 63, 293-298. doi: 10.1111/j.1365-2672.1987.tb02705.x

Kai, K., Mine, K., Akiyama, K., Ohki, S., and Hayashi, H. (2018). Anti-plant viral activity of peptaibols, trichorzins HA II, HA V, and HA VI, isolated from Trichoderma harzianum HK61. J. Pest. Sci. 43, D18-D39. doi: 10.1584/jpestics.D18-039

Kim, C. S., Yu, S. H., Nakagiri, A., Shirouzu, T., Sotome, K., Kim, S. C., and Maekawa, N. (2012). Re-evaluation of Hypocrea pseudogelatinosa and H. pseudostraminea isolated from 
shiitake mushroom (Lentinula edodes) cultivation in Korea and Japan. Plant Pathology J. 28, 341-356. doi: 10.5423/PPJ.OA.05.2012.0068

Kim, C. S., Shirouzu, T., Nakagiri, A., Sotome, K., and Maekawa, N. (2013). Trichoderma eijii and T. pseudolacteum, two new species from Japan. Mycol. Prog. 12, 739-753. doi: 10.1007/s11557-012-0886-y

Kimonyo, A., and Brückner, H. (2013). Sequences of metanicins, 20-residue peptaibols from the ascomycetous fungus CBS 597.80. Chem. Biodivers. 10, 813-826. doi: $10.1002 / \mathrm{cbdv} .201300064$

Kirschbaum, J., Krause, C., Winzheimer, R. K., and Brückner, H. (2003). Sequences of alamethicins F30 and F50 reconsidered and reconciled. J. Peptide. 9, 799-809. doi: $10.1002 /$ psc. 535

Koide N., Asami K., and Fujita T. (1997). Ion-channels formed by hypelcins, antibiotic peptides, in planar bilayer lipid membranes. Biochim. Biophys. Acta. 1326, 47-53. doi: 10.1016/S0005-2736(97)00005-9

Komon-Zelazowska, M., Bissett, J., Zafari, D., Hatvani, L., Manczinger, L., Woo, S., et al. (2007). Genetically closely related but phenotypically divergent Trichoderma species cause green mold disease in oyster mushroom farms worldwide. Appl. Environ. Microbiol., 73, 7415-7426. doi: 10.1128/AEM.01059-07

Körmöczi, P., Leitgeb, B., Cseh, T., Hatvani, L., Manczinger, L., Vágvölgyi, C., et al. (2009). An image analysis-based method for the evaluation of the aggressivity of Trichoderma strains towards Pleurotus ostreatus, Acta Microbiol. Immunol. Hung. 56, 188-189.

Kottb, M., Gigolashvili, T., Großkinsky, D. K., and Piechulla, B. (2015). Trichoderma volatiles effecting Arabidopsis: from inhibition to protection against phytopathogenic fungi. Front. Microbiol. 6, 995. doi: 10.3389/fmicb.2015.00995

Krause, C., Kirschbaum, J., and Brückner, H. (2006a). Peptaibiomics: an advanced, rapid and selective analysis of peptaibiotics/peptaibols by SPE/LC-ES-MS. Amino Acids 30, 435-443. doi: 10.1007/s00726-005-0275-9

Krause, C., Kirschbaum, J., and Brückner, H. (2007). Peptaibiomics: microheterogeneity, dynamics, and sequences of trichobrachins, peptaibiotics from Trichoderma parceramosum Bissett (T. longibrachiatum Rifai). Chem. Biodivers. 4, 1083-1102. doi: 10.1002/cbdv.200790098

Krause, C., Kirschbaum, J., Jung, G., and Brückner, H. (2006b). Sequence diversity of the peptaibol antibiotic suzukacillin-A from the mold Trichoderma viride. J. Pept. Sci. 12, 321327. doi: $10.1002 /$ psc. 728

Kredics, L., Antal, Z., Dóczi, I., Manczinger, L., Kevei, F., and Nagy, E. (2003). Clinical importance of the genus Trichoderma. Acta Microbiol. Immunol. Hung. 50, 105-117. doi: 10.1556/AMicr.50.2003.2-3.1 
Kredics, L., Garcia Jimenez, L., Naeimi, S., Czifra, D., Urbán, P., Manczinger, L., et al. (2010). "A challenge to mushroom growers: the green mould disease of cultivated champignons." in Current research, technology and education topics in applied microbiology and microbial biotechnology, Microbiology Book Series, ed: Méndes-Vilas, A. Formatex Research Center, Dadajoz, Spain, pp. 295-305.

Kredics, L., Hatvani, L., Naeimi, S., Körmöczi, P., Manczinger, L., Vágvölgyi, C. and Druzhinina, I. (2014). "Biodiversity of the genus Hypocrea/Trichoderma in different habitats." in Biotechnology and biology of Trichoderma, eds: Gupta V. K., Schmoll M., Herrera-Estrella A., Upadhyay R.S., Druzhinina I., and Tuohy M.G. Elsevier, Amsterdam, The Netherlands, 3-24. doi: 10.1016/B978-0-444-59576-8.00001-1

Kredics, L., Szekeres, A., Czifra, D., Vágvölgyi, C., and Leitgeb, B. (2013). Recent results in alamethicin research. Chem. Biodivers. 10, 744-771. doi: 10.1002/cbdv.201200390

Kubicek, C. P., Herrera-Estrella, A., Seidl-Seiboth, V., Martinez, D. A., Druzhinina, I. S., Thon, M., et al. (2011). Comparative genome sequence analysis underscores mycoparasitism as the ancestral life style of Trichoderma. Genome Biol. 12, 40. doi: 10.1186/gb-2011-12-4$\mathrm{r} 40$

Kubicek, C. P., Komoń-Zelazowska, M., and Druzhinina, I. S. (2008). Fungal genus Hypocrea/Trichoderma: from barcodes to biodiversity. J. Zhejiang Univ. Sc. B. 9, 753. doi: 10.1631/jzus.B0860015

Kubicek, C. P., Mikus, M., Schuster, A., Schmoll, M., and Seiboth, B. (2009). Metabolic engineering strategies for the improvement of cellulase production by Hypocrea jecorina. Biotechnol. Biofuels 2, 19. doi: 10.1186/1754-6834-2-19

Kubicek, C. P., Steindorff, A. S., Chenthamara, K., Manganiello, G., Henrissat, B., Zhang, J., et al. (2019). Evolution and comparative genomics of the most common Trichoderma species. BMC genomics, 20, 485. doi: 10.1186/s12864-019-5680-7

Küçük, Ç., and Kivanç, M. (2004). Isolation of Trichoderma spp. and determination of their antifungal, biochemical and physiological features. Turk. J. Biol. 27, 247-253.

Kuhls, K., Lieckfeldt, E., Börner, T., and Guého, E. (1999). Molecular reidentification of human pathogenic Trichoderma isolates as Trichoderma longibrachiatum and Trichoderma citrinoviride. Med. Mycol. 37, 25-33. doi: 10.1080/02681219980000041

Kuhls, K., Lieckfeldt, E., Samuels, G. J., Kovacs, W., Meyer, W., Petrini, O., et al. (1996). Molecular evidence that the asexual industrial fungus Trichoderma reesei is a clonal derivative of the ascomycete Hypocrea jecorina. Proc. Natl. Acad. Sci. 93, 7755-7760. doi: 10.1073/pnas.93.15.7755

Kuhls, K., Lieckfeldt, E., Samuels, G. J., Meyer, W., Kubicek, C. P., and Börner, T. (1997). Revision of Trichoderma sect. Longibrachiatum including related teleomorphs based on 
analysis of ribosomal DNA internal transcribed spacer sequences. Mycologia 89, 442-460. doi: 10.1080/00275514.1997.12026803

Kullnig-Gradinger, C. M., Szakacs, G., and Kubicek, C. P. (2002). Phylogeny and evolution of the genus Trichoderma: A multigene approach. Mycol. Res. 106, 757-767. doi: $10.1017 / \mathrm{S} 0953756202006172$

Kumazawa, S., Kanda, M., Aoyama, H., Utagawa, M., Kondo, J., Sakamoto, S., et al. (1994). Structural elucidation of aibellin, a new peptide antibiotic with efficiency enhancing activity on rumen fermentation. J. Antibiot. 47, 1136-1144. doi: 10.7164/antibiotics.47.1136

Kushwaha, M., and Verma, A. K. (2014). Antagonistic activity of Trichoderma spp, (a biocontrol agent) against isolated and identified plant pathogens. IJCBS, 1, 1-6.

Lad, P. J., and White, A. A. (1979). Effect of alamethicin, gramicidin S and melittin uppn the particulate guanylate cyclase from rat lung. BBA-Enzymology. 570, 198-209. doi: 10.1016/0005-2744(79)90214-6

Landreau, A., Pouchus, Y. F., Sallenave-Namont, C., Biard, J. F., Boumard, M. C., du Pont, T. R. et al. (2002). Combined use of LC/MS and a biological test for rapid identification of marine mycotoxins produced by Trichoderma koningii. J. Microbiol. Meth. 48, 181-194. doi: 10.1016/S0167-7012(01)00322-0

Leclerc, G., Rebuffat, S., Goulard, C., and Bodo, B. (1998). Directed biosynthesis of peptaibol antibiotics in two Trichoderma strains. J. Antibiot. 51, 170-177. doi: 10.7164/antibiotics.51.170

Li, T., Cofer, T., Engelberth, M., and Engelberth, J. (2016). Defense priming and jasmonates: a role for free fatty acids in insect elicitor-induced long distance signaling. Plants 5, 5. doi: $10.3390 /$ plants 5010005

Lichtenthaler, H. K. (1987). Chlorophylls and carotenoids: pigments of photosynthetic biomembranes. Methods Enzymol. 148, 350-382. doi: 10.1016/0076-6879(87)48036-1

Lieckfeldt, E., Samuels, G. J., Nirenberg, H. I., and Petrini, O. (1999). A morphological and molecular perspective of Trichoderma viride: Is it one or two species? Appl. Environ. Microbiol. 65, 2418-2428. doi: 10.1128/AEM.65.6.2418-2428.1999

Lopes, F. A. C., Steindorff, A. S., Geraldine, A. M., Brandão, R. S., Monteiro, V. N., Júnior, M. L., et al. (2012). Biochemical and metabolic profiles of Trichoderma strains isolated from common bean crops in the Brazilian Cerrado, and potential antagonism against Sclerotinia sclerotiorum. Fungal Biol-UK. 116, 815-824. doi: 10.1016/j.funbio.2012.04.015

Lorito, M., Farkas, V., Rebuffat, S., Bodo, B., and Kubicek, C. P. (1996a). Cell wall synthesis is a major target of mycoparasitic antagonism by Trichoderma harzianum. J. Bacteriol. 178, 6382-6385. doi: 10.1128/jb.178.21.6382-6385.1996 
Lorito, M., Woo, S.L., D’Ambrosio, M., Harman, G.E., Hayes, C.K., Kubicek, C.P., and Scala, F. (1996b). Synergistic interaction between cell wall degrading enzymes and membrane affecting compounds. Mol. Plant Microbe Interact. 9, 206-213. doi: 10.1094/MPMI-9-0206.

Maddau, L., Cabras, A., Franceschini, A., Linaldeddu, B. T., Crobu, S., Roggio, T., et al. (2009). Occurrence and characterization of peptaibols from Trichoderma citrinoviride, an endophytic fungus of cork oak, using electrospray ionization quadrupole time-of-flight mass spectrometry. Microbiology 155, 3371-3381. doi: 10.1099/mic.0.030916-0

Maischak, H., Zimmermann, M. R., Felle, H. H., Boland, W., and Mithöfer, A. (2010). Alamethicin-induced electrical long distance signaling in plants. Plant. Signal. Behav. 5, 988990. doi: $10.4161 / \mathrm{psb} .5 .8 .12223$

Mak, D. O., and Webb, W. W. (1995). Two classes of alamethicin transmembrane channels: molecular models from single-channel properties. Biophys. J. 69, 2323-2336. doi: 10.1016/S0006-3495(95)80102-5

Marahiel, M. A. (1997). Protein templates for the biosynthesis of peptide antibiotics. Chem. Biol. 4, 561-567. doi: 10.1016/S1074-5521(97)90242-8

Marahiel, M. A., Stachelhaus, T., and Mootz, H. D. (1997). Modular peptide synthetases involved in nonribosomal peptide synthesis. Chem. Rev. 97, 2651-2674. doi: $10.1021 / \mathrm{cr} 960029 \mathrm{e}$

Marik, T., Urbán, P., Tyagi, C., Szekeres, A., Leitgeb, B., Vágvölgyi, M., et al. (2017). Diversity profile and dynamics of peptaibols produced by green mould Trichoderma species in interactions with their hosts Agaricus bisporus and Pleurotus ostreatus. Chem. Biodivers. 14, e1700033. doi: 10.1002/cbdv.201700033

Marik, T., Tyagi, C., Balázs, D., Urbán, P., Szepesi, Á., Bakacsy, L., et al. (2019). Structural diversity and bioactivities of peptaibol compounds from the Longibrachiatum clade of the filamentous fungal genus Trichoderma. Front. Microbiol. 10, 1434. doi: 10.3389/fmicb.2019.01434

Marik, T., Tyagi, C., Racić, G., Rakk, D., Szekeres, A., Vágvölgyi, C., et al. (2018). New 19residue peptaibols from Trichoderma clade Viride. Microorganisms 6, 85. doi: 10.3390/microorganisms6030085

Martin, D. R., and Williams, R. J. (1976). Chemical nature and sequence of alamethicin. Biochem. J. 153, 181. doi: 10.1042/bj1530181

Mathew, M. K., and Balaram, P. (1983). A helix dipole model for alamethicin and related transmembrane channels. FEBS Lett. 157, 1-5. doi: 10.1016/0014-5793(83)81105-3

May, J. J., Kessler, N., Marahiel, M. A., and Stubbs, M. T. (2002). Crystal structure of DhbE, an archetype for aryl acid activating domains of modular nonribosomal peptide synthetases. Proc. Natl. Acad. Sci. U.S.A. 99, 12120-12125. doi: 10.1073/pnas. 182156699 
McMullin, D. R., Renaud, J. B., Barasubiye, T., Sumarah, M. W., and Miller, J. D. (2017). Metabolites of Trichodermaspecies isolated from damp building materials. Can. J. Microbiol. 63, 621-632. doi: 10.1139/cjm-2017-0083

Melling, J., and McMullen, A. J. (1975). "Separation, purification and characterisation of alamethicins produced from Trichoderma viride." in ISC-IAMS Proceedings, Science Council of Japan 5, 446-452.

Metsalu, T., and Vilo, J. (2015). ClustVis: a web tool for visualizing clustering of multivariate data using Principal Component Analysis and heatmap. Nucleic Acids Res. 43, 566-570. doi: 10.1093/nar/gkv468

Meyer, C. E., and Reusser, F. (1967). A polypeptide antibacterial agent isolated from Trichoderma viride. Experientia 23, 85-86. doi: 10.1007/BF02135929

Mikkola, R., Andersson, M. A., Kredics, L., Grigoriev, P. A., Sundell, N., and SalkinojaSalonen, M. S. (2012). 20-Residue and 11-residue peptaibols from the fungus Trichoderma longibrachiatum are synergistic in forming $\mathrm{Na}^{+} / \mathrm{K}^{+}$-permeable channels and adverse action towards mammalian cells. FEBS J. 279, 4172-4190. doi: 10.1111/febs.12010

Migheli, Q., González-Candelas, L., Dealessi, L., Camponogara, A., and Ramón-Vidal, D. (1998). Transformants of Trichoderma longibrachiatum overexpressing the $\beta-1,4-$ endoglucanase gene egl1 show enhanced biocontrol of Pythium ultimum on cucumber. Phytopathology 88, 673-677. doi: 10.1094/PHYTO.1998.88.7.673

Molle, G., Duclohier, H., Julien, S., and Spach, G. (1991). Synthetic analogues of alamethicin: Effect of C-terminal residue substitutions and chain length on the ion channel lifetimes. Biochim. Biophys. Acta. 1064, 365-369. doi: 10.1016/0005-2736(91)90324-2

Nagaraj, R., and Balaram, P. (1981). Alamethicin, a transmembrane channel. Acc. Chem. Res. 14, 356-362. doi: 10.1021/ar00071a005

Nagaraj, G., Uma, M. V., Shivayogi, M. S., and Balaram, H. (2001). Antimalarial activities of peptide antibiotics isolated from fungi. Antimicrob. Agents Ch. 45, 145-149. doi: 10.1128/AAC.45.1.145-149.2001

Nayar, P. R., Kumar, A., and Thirumalachar, M. J. (1973). Antiamoebin as feed additive for increased lactation in dairy animals. Hindustan Antibiot. Bull. 16, 93-96.

Neuhof, T., Dieckmann, R., Druzhinina, I. S., Kubicek, C. P., and von Döhren, H. (2007). Intact-cell MALDI-TOF mass spectrometry analysis of peptaibol formation by the genus Trichoderma/Hypocrea: can molecular phylogeny of species predict peptaibol structures? Microbiology 153, 3417-3437. doi: 10.1099/mic.0.2007/006692-0

Neumann, N. K., Stoppacher, N., Zeilinger, S., Degenkolb, T., Brückner, H., and Schuhmacher, R. (2015). The peptaibiotics database-a comprehensive online resource. Chem. Biodivers. 12, 743-751. doi: 10.1002/cbdv.201400393 
New, A. P., Eckers, C., Haskins, N. J., Neville, W. A., Elson, S., Hueso-Rodríguez, J. A., and Rivera-Sagredo, A. (1996). Structures of polysporins AD, four new peptaibols isolated from Trichoderma polysporum. Tetrahedron Lett. 37, 3039-3042. doi: 10.1016/00404039(96)00463-7

Nielsen, K. F., Gräfenhan, T., Zafari, D., and Thrane, U. J. (2005). Trichothecene production by Trichoderma brevicompactum. Agric. Food Chem. 53, 8190-8196. doi: 10.1021/jf051279b

North, C. L., Barranger-Mathys, M., and Cafiso, D. S. (1995). Membrane orientation of the N-terminal segment of alamethicin determined by solid-state 15N NMR. Biophys. J. 69, 2392-2397. doi: 10.1016/S0006-3495(95)80108-6

Olabiyi, T. I., and Ruocco, M. (2013). In-vitro competition bioassay experiment on the effect of Trichoderma species and some crop pathogenic fungi. J. Biol. Agric. Healthcare 3, 115120.

Overton, B. E., Stewart, E. L., Geiser, D. M., and Jaklitsch, W. M. (2006a). Systematics of Hypocrea citrina and related taxa. Stud. Mycol. 56, 1-38. doi: 10.3114/sim.2006.56.01

Overton, B. E., Stewart, E. L., and Geiser, D. M. (2006b). Taxonomy and phylogenetic relationships of nine species of Hypocrea with anamorphs assignable to Trichoderma section Hypocreanum. Stud. Mycol. 56, 39-65. doi: 10.3114/sim.2006.56.02

Park, M. S., Bae, K. S., and Yu, S. H. (2006). Two new species of Trichoderma associated with green mold of oyster mushroom cultivation in Korea. Mycobiology 34, 111-113. doi: 10.4489/MYCO.2006.34.3.111

Payne, J. W., Jakes, R., and Hartley, B. S. (1970). The primary structure of alamethicin. Biochem. J. 117, 757-766. doi: 10.1042/bj1170757

Peltola, J., Ritieni, A., Mikkola, R., Grigoriev, P. A., Pócsfalvi, G., Andersson, M. A., et al. (2004). Biological effects of Trichoderma harzianum peptaibols on mammalian cells. Appl. Environ. Microbiol. 70, 4996-5004. doi: 10.1128/AEM.70.8.4996-5004.2004

Pelagio-Flores, R., Esparza-Reynoso, S., Garnica-Vergara, A., López-Bucio, J., and HerreraEstrella, A. (2017). Trichoderma-induced acidification is an early trigger for changes in Arabidopsis root growth and determines fungal phytostimulation. Front. Plant Sci. 8, 822. doi: $10.3389 /$ fpls.2017.00822

Pereira, J. L., Queiroz, R. M., Charneau, S. O., Felix, C. R., Ricart, C. A., da Silva, F. L., et al. (2014). Analysis of Phaseolus vulgaris response to its association with Trichoderma harzianum (ALL-42) in the presence or absence of the phytopathogenic fungi Rhizoctonia solani and Fusarium solani. PLoS One 9, e98234. doi: 10.1371/journal.pone.0098234

Pócsfalvi, G., Ritieni, A., Ferranti, P., Randazzo, G., Vékey, K., and Malorni, A. (1997). Microheterogeneity characterization of a paracelsin mixture from Trichoderma reesei using high-energy collision-induced dissociation tandem mass spectrometry. Rapid Commun. Mass 
Spectrom. 11， 922-930. doi: 10.1002/(SICI)1097-0231(199705)11:8<922::AIDRCM927>3.0.CO;2-N

Pócsfalvi, G., Scala, F., Lorito, M., Ritieni, A., Randazzo, G., Ferranti, P., et al. (1998). Microheterogeneity characterization of a trichorzianine-A mixture from Trichoderma harzianum. J. Mass Spectrom. 33, 154-163. doi: 10.1002/(SICI)10969888(199802)33:2<154::AID-JMS620>3.0.CO;2-0

Qualhato, T. F., Lopes, F. A. C., Steindorff, A. S., Brandao, R. S., Jesuino, R. S. A., and Ulhoa, C. J. (2013). Mycoparasitism studies of Trichoderma species against three phytopathogenic fungi: evaluation of antagonism and hydrolytic enzyme production. Biotechnol. Lett. 35, 1461-1468. doi: 10.1007/s10529-013-1225-3

Rebuffat, S., Conraux, L., Massias, M., Auvin-Guette, C., and Bodo, B. (1993). Sequence and solution conformation of the 20-residue peptaibols, saturnisporins SA II and SA IV. Int. J. Pept. Protein Res. 41, 74-84. doi: 10.1111/j.1399-3011.1993.tb00117.x

Rebuffat, S., Goulard, C., Bodo, B., and Roquebert, M. F. (1999). The peptaibol antibiotics from Trichoderma soil fungi; structural diversity and membrane properties. Recent Res. Devel. Org. Biorg. Chem. 3, 65-91.

Rebuffat, S., Goulard, C., Hlimi, S., and Bodo, B. (2000). Two unprecedented natural Aibpeptides with the (Xaa-Yaa-Aib-Pro) motif and an unusual C-terminus: structures, membranemodifying and antibacterial properties of pseudokonins KL III and KL VI from the fungus Trichoderma pseudokoningii. J. Pept. Sci. 6, 519-533. doi: 10.1002/10991387(200010)6:10<519::AID-PSC273>3.0.CO;2-6

Rebuffat, S., Hajji, M., Hennig, P., Davoust, D., and Bodo, B. (1989). Isolation, sequence, and conformation of seven trichorzianines from Trichoderma harzianum. Chem. Biol. Drug Des. 34, 200-210. doi: 10.1111/j.1399-3011.1989.tb00231.x

Rebuffat, S., Prigent, Y., Auvin-Guette, C., and Bodo, B. (1991). Tricholongins BI and BII, 19-residue peptaibols from Trichoderma longibrachiatum. FEBS J. 201, 661-674. doi: 10.1111/j.1432-1033.1991.tb16327.x

Reese, E. T., Levinson, H. S., Downing, M. H., and White, W. L. (1950). Quartermaster culture collection. Farlowia 4, 45-86.

Reino, J. L., Guerrero, R. F., Hernández-Galán, R., and Collado, I. G. (2008). Secondary metabolites from species of the biocontrol agent Trichoderma. Phytochem. Rev. 7, 89-123. doi: 10.1007/s11101-006-9032-2.

Richter, S., Cormican, M. G., Pfaller, M. A., Lee, C. K., Gingrich, R., Rinaldi, M. G., and Sutton, D. A. (1999). Fatal disseminated Trichoderma longibrachiatum infection in an adult bone marrow transplant patient: species identification and review of the literature. J. Clin. Microbial. 37, 1154-1160. doi: 10.1128/JCM.37.4.1154-1160.1999

Rifai, M. A. (1969). A revision of the genus Trichoderma. Mycol. Pap. 116, 1-56. 
Rippa, S., Adenier, H., Derbaly, M., and Béven, L. (2007). The peptaibol alamethicin induces an rRNA-cleavage-associated death in Arabidopsis thaliana. Chem. Biodivers. 4, 1360-1373. doi: $10.1002 / \mathrm{cbdv} .200790116$

Rippa, S., Eid, M., Formaggio, F., Toniolo, C., and Béven, L. (2010). Hypersensitive-like response to the pore-former peptaibol alamethicin in Arabidopsis thaliana. Chem. Bio. Chem. 11, 2042-2049. doi: 10.1002/cbic.201000262

Ritieni, A., Fogliano, V., Nanno, D., Randazzo, G., Altomare, C., Perrone, G., et al. (1995). Paracelsin E, a new peptaibol from Trichoderma saturnisporum. J. Nat. Prod. 58, 1745-1748. doi: $10.1021 / \mathrm{np} 50125 \mathrm{a} 017$

Rodríguez, M.A., Cabrera, G., Gozzo, F.C., Eberlin, M.N., and Godeas, A. (2011). Clonostachys rosea BAFC3874 as a Sclerotinia sclerotiorum antagonist: mechanisms involved and potential as a biocontrol agent. J. Appl. Microbiol. 110, 1177-1186. doi: 10.1111/j.1365-2672.2011.04970.x

Rogozhin, E. A., Sadykova, V. S., Baranova, A. A., Vasilchenko, A. S., Lushpa, V. A., Mineev, K. S., et al. (2018). A novel lipopeptaibol emericellipsin A with antimicrobial and antitumor activity produced by the extremophilic fungus Emericellopsis alkalina. Molecules 23, 2785. doi: 10.3390/molecules23112785

Rojo, F. G., Reynoso, M. M., Ferez, M., Chulze, S. N., and Torres, A. M. (2007). Biological control by Trichoderma species of Fusarium solani causing peanut brown root rot under field conditions. Crop Prot. 26, 549-555. doi: 10.1016/j.cropro.2006.05.006

Röhrich, C. R., Iversen, A., Jaklitsch, W. M., Voglmayr, H., Berg, A., Dörfelt, H., et al. (2012). Hypopulvins, novel peptaibiotics from the polyporicolous fungus Hypocrea pulvinata, are produced during infection of its natural hosts. Fungal Biol. 116, 1219-1231. doi: 10.1016/j.funbio.2012.10.003

Röhrich, C. R., Iversen, A., Jaklitsch, W. M., Voglmayr, H., Vilcinskas, A., Nielsen, K. F., et al. (2013). Screening the biosphere: The fungicolous fungus Trichoderma phellinicola, a prolific source of hypophellins, new 17-, 18-, 19-, and 20-residue peptaibiotics. Chem. Biodivers. 10, 787-812. doi: 10.1002/cbdv.201200339

Röhrich, C. R., Jaklitsch, W. M., Voglmayr, H., Iversen, A., Vilcinskas, A., Nielsen, K. F., et al. (2014). Front line defenders of the ecological niche! Screening the structural diversity of peptaibiotics from saprotrophic and fungicolous Trichoderma/Hypocrea species. Fungal Divers. 69, 117-146. doi: 10.1007/s13225-013-0276-z

Sallenave, C., Pouchus, Y. F., Bardouil, M., Lassus, P., Roquebert, M. F., and Verbist, J. F. (1999). Bioaccumulation of mycotoxins by shellfish: contamination of mussels by metabolites of a Trichoderma koningii strain isolated in the marine environment. Toxicon 37, 77-83. doi: 10.1016/S0041-0101(98)00135-4 
Samuels, G. J., Dodd, S. L., Gams, W., Castlebury, L. A., and Petrini, O. (2002). Trichoderma species associated with the green mold epidemic of commercially grown Agaricus bisporus. Mycologia 94, 146-170. doi: 10.1080/15572536.2003.11833257

Samuels, G. J., Dodd, S. L., Lu, B. S., Petrini, O., Schroers, H. J., and Druzhinina I. S. (2006). The Trichoderma koningii aggregate species. Stud. Mycol. 56, 67-133. doi: 10.3114/sim.2006.56.03

Samuels, G. J., and Ismaiel, A. (2011). Hypocrea peltata: a mycological Dr Jekyll and Mr Hyde? Mycologia, 103, 616-630. doi: 10.3852/10-227

Samuels, G. J., Ismaiel, A., de Souza, J., and Chaverri, P. (2012a). Trichoderma stromaticum and its overseas relatives. Mycol. Prog. 11, 215-254. doi: 10.1007/s11557-011-0743-4

Samuels, G. J., Ismaiel, A., Mulaw, T. B., Szakacs, G., Druzhinina, I. S., Kubicek, C. P., et al. (2012b). The Longibrachiatum clade of Trichoderma: a revision with new species. Fungal Divers. 55, 77-108. doi: 10.1007/s13225-012-0152-2

Samuels, G. J., Petrini, O., Kuhls, K., Lieckfeldt, E., and Kubicek, C. P. (1998). The Hypocrea schweinitzii complex and Trichoderma sect. Longibrachiatum. Stud. Mycol. 41, 154.

Sandoval-Denis, M., Sutton, D. A., Cano-Lira, J. F., Gené, J., Fothergill, A. W., Wiederhold, N. P., and Guarro, J. (2014). Phylogeny of the clinically relevant species of the emerging fungus Trichoderma and their antifungal susceptibilities. J. Clin. Microbial. 52, 2112-2125. doi: 10.1128/JCM.00429-14

Schuster, A., and Schmoll, M. (2010). Biology and biotechnology of Trichoderma. Appl. Microbiol. Biotechnol. 87, 787-799. doi: 10.1007/s00253-010-2632-1

Schirmböck, M., Lorito, M., Wang, Y. L., Hayes, C. K., Arisan-Atac, I., Scala, F., et al. (1994). Parallel formation and synergism of hydrolytic enzymes and peptaibol antibiotics, molecular mechanisms involved in the antagonistic action of Trichoderma harzianum against phytopathogenic fungi. Appl. Environ. Microbiol. 60, 4364-4370.

Seiboth, B., Karimi, R. A., Phatale, P. A., Linke, R., Hartl, L., Sauer, D. G., et al. (2012). The putative protein methyltransferase LAE1 controls cellulase gene expression in Trichoderma reesei. Mol. Microbiol. 84, 1150-1164. doi: 10.1111/j.1365-2958.2012.08083.x

Shahid, M., Srivastava, M., Singh, A., Kumar, V., Rastogi, S., Pathak, N., et al. (2014). Comparative study of biological agents, Trichoderma harzianum (ThAzad) and Trichoderma viride (01PP) for controlling wilt disease in pigeon pea. J. Microb. Biochem. Technol. 6, 110 115. doi: $10.4172 / 1948-5948.1000130$

Shi, W. L., Chen, X. L., Wang, L. X., Gong, Z. T., Li, S., Li, C. L., et al. (2016). Cellular and molecular insight into the inhibition of primary root growth of Arabidopsis induced by peptaibols, a class of linear peptide antibiotics mainly produced by Trichoderma spp. J. Exp. Bot. 67, 2191-2205. doi: 10.1093/jxb/erw023 
Shi, M., Chen, L., Wang, X. W., Zhang, T., Zhao, P. B., Song, X. Y., et al. (2012). Antimicrobial peptaibols from Trichoderma pseudokoningii induce programmed cell death in plant fungal pathogens. Microbiology 158, 166-175. doi: 10.1099/mic.0.052670-0

Shi, M., Wang, H. N., Xie, S. T., Luo, Y., Sun, C. Y., Chen, X. L., et al. (2010). Antimicrobial peptaibols, novel suppressors of tumor cells, targeted calcium-mediated apoptosis and autophagy in human hepatocellular carcinoma cells. Mol. Cancer 9, 26. doi: $10.1186 / 1476-4598-9-26$

Seidl, V., Seibel, C., Kubicek, C. P., and Schmoll, M. (2009). Sexual development in the industrial workhorse Trichoderma reesei. Proc. Natl. Acad. Sci. U.S.A. 106, 13909-13914. doi: 10.1073/pnas.0904936106

Sivasithamparam, K., and Ghisalberti, E. L. (1998). "Secondary Metabolism in Trichoderma and Gliocladium." in Trichoderma and Gliocladium: basic biology, taxonomy and genetics, eds: Kubicek, C. P., and Harman, G. E. Taylor \& Francis, London, UK, 139-191.

Song, X. Y., Shen, Q. T., Xie, S. T., Chen, X. L., Sun, C. Y., and Zhang, Y. Z. (2006). Broadspectrum antimicrobial activity and high stability of Trichokonins from Trichoderma koningii $\mathrm{SMF}_{2}$ against phytopathogens. FEMS Microbiol. Lett. 260, 119-125. doi: 10.1111/j.15746968.2006.00316.x

Stoppacher, N., Neumann, N. K., Burgstaller, L., Zeilinger, S., Degenkolb, T., Brückner, H., et al. (2013). The comprehensive peptaibiotics database. Chem. Biodivers. 10, 734-743. doi: $10.1002 / \mathrm{cbdv} .201200427$

Sulakhe, P. V., and Höehn, E. K. (1984). Interaction of EGTA with a hydrophobic region inhibits particulate adenylate cyclase from rat cerebral cortex: a study of an EGTA-inhibitable enzyme by using alamethicin. Int. J. Biochem. 16, 1029-1035. doi: 10.1016/0020$711 \mathrm{X}(84) 90083-1$

Summers, M.Y., Kong, F., Feng, X., Siegel, M.M., Janso, J.E., Graziani, E.I., et al. (2007). Septocylindrins A and B: peptaibols produced by the terrestrial fungus Septocylindrium sp. LL-Z1518. J. Nat. Prod. 70, 391-396. doi: 10.1021/np060571q

Szekeres, A., Leitgeb, B., Kredics, L., Antal, Z., Hatvani, L., Manczinger, L., et al. (2005). Peptaibols and related peptaibiotics of Trichoderma. Acta Microbiol. Immunol. Hung. 52, 137-168. doi: 10.1556/AMicr.52.2005.2.2

Szekeres, A., Leitgeb, B., Kredics, L., Manczinger, L., and Vágvölgyi, C. (2006). A novel, image analysis-based method for the evaluation of in vitro antagonism. J. Microbiol. Methods 65, 619-622. doi: 10.1016/j.mimet.2005.09.014

Tamandegani, P. R., Marik, T., Zafari, D., Balázs, D., Vágvölgyi, C., Szekeres, A., and Kredics, L. (2020). Changes in peptaibol production of Trichoderma species during in vitro antagonistic interactions with fungal plant pathogens. Biomolecules 10, 730. doi: 10.3390/biom10050730 
Tamandegani, P. R., Zafari, D., Marik, T., Szekeres, A., Vágvölgyi, C., and Kredics, L. (2016). Peptaibol profiles of Iranian Trichoderma isolates. Acta Biol. Hung. 67, 431-441. doi: 10.1556/018.67.2016.4.9

Thimann, K. V. (1937). On the nature of inhibitions caused by auxin. Am. J. Bot. 24, 407412. doi: 10.1002/j.1537-2197.1937.tb09119.x

Toniolo, C., and Brückner H. (eds.) (2009). "Peptaibiotics: Fungal Peptides Containing $\alpha-$ Dialkyl $\alpha$-Amino Acids." Wiley-VCH, Weinheim. Germany

Touati, I., Ruiz, N., Thomas, O., Druzhinina, I. S., Atanasova, L., Tabbene, O., et al. (2018). Hyporientalin A, an anti-Candida peptaibol from a marine Trichoderma orientale. World J. Microbiol. Biotechnol. 34, 98. doi: 10.1007/s11274-018-2482-z

Tyagi, C., Marik, T., Szekeres, A., Vágvölgyi, C., Kredics, L., and Ötvös, F. (2019a). Tripleurin XIIc: Peptide folding dynamics in aqueous and hydrophobic environment mimic using accelerated molecular dynamics. Molecules 24, 358. doi: 10.3390/molecules24020358

Tyagi, C., Marik, T., Vágvölgyi, C., Kredics, L., and Ötvös, F. (2019b). Accelerated Molecular Dynamics Applied to the Peptaibol Folding Problem. Int. J. Mol. Sci. 20, 4268. doi: $10.3390 /$ ijms 20174268

Urbán, P., Miao, Y., Fekete, C., Hatvani, L., Büchner, R., Vágvölgyi, C., et al. (2016). "Complete genome sequence of the green mould pathogen Trichoderma pleuroti" in 18th Danube-Kris-Mures-Tisa (DKMT) Euroregional Conference on Environment and Health, Book of Abstracts, ed. Škrbić, B. University of Novi Sad, Novi Sad, Serbia, 51-52.

Van Bohemen, A. I., Zalouk-Vergnoux, A., Poirier, L., Phuong, N. N., Inguimbert, N., Salah, K. B. H., et al. (2016). Development and validation of LC-MS methods for peptaibol quantification in fungal extracts according to their lengths. J. Chromatogr. B. Biomed. Sci. Appl. 1009, 25-33. doi: 10.1016/j.jchromb.2015.11.039

Verma, M., Brar, S. K., Tyagi, R. D., Surampalli, R. Y., and Valéro, J. R. (2007). Antagonistic fungi, Trichoderma spp.: panoply of biological control. Biochem. Eng. J. 37, 120. doi: $10.1016 /$ j.bej.2007.05.012

Vicente-Carrillo, A. (2018). The usefulness of sperm kinematics in drug-induced toxicity assessment. Bas. Clin. Pharmacol. Toxicol. 123, 3-7. doi: 10.1111/bcpt.12994

Vinale, F., Flematti, G., Sivasithamparam, K., Lorito, M., Marra, R., Skelton, B. W., et al. (2009). Harzianic acid, an antifungal and plant growth promoting metabolite from Trichoderma harzianum. J. Nat. Prod. 72, 2032-2035. doi: 10.1021/np900548p

Vinale, F., Sivasithamparam, K., Ghisalberti, E. L., Marra, R., Barbetti, M. J., Li, H., et al. (2008). A novel role for Trichoderma secondary metabolites in the interactions with plants. Physiol. Mol. Plant Pathol. 72, 80-86. doi: 10.1016/j.pmpp.2008.05.005 
Vinale, F., Sivasithamparam, K., Ghisalberti, E. L., Woo, S. L., Nigro, M., Marra, R., et al. (2014). Trichoderma secondary metabolites active on plants and fungal pathogens. The Open Mycol. J. 8, 127-139. doi: 10.2174/1874437001408010127

Wada, S. I., Nishimura, T., Iida, A., Toyama, N., and Fujita, T. (1994). Primary structures of antibiotic peptides, trichocellins-A and-B from Trichoderma viride. Tetrahedron Lett. 35, 3095-3098. doi: 10.1016/S0040-4039(00)76838-9

Waghunde, R. R., Shelake, R. M., and Sabalpara, A. N. (2016). Trichoderma: A significant fungus for agriculture and environment. Afr. J. Agric. Res. 11, 1952-1965. doi: 10.5897/AJAR2015.10584

Walsh, T. J., and Groll, A. H. (1999). Emerging fungal pathogens: evolving challenges to immunocompromised patients for the twenty-first century. Transplant Infect. Dis. 1, 247-261. doi:10.1034/j.1399-3062.1999.010404.x

Wei, X., Yang, F., and Straney, D. C. (2005). Multiple non-ribosomal peptide synthetase genes determine peptaibol synthesis in Trichoderma virens. Can. J. Microbiol. 51, 423-429. doi: 10.1139/w05-006

Wiest, A., Grzegorski, D., Xu, B. W., Goulard, C., Rebuffat, S., Ebbole, D. J., et al. (2002). Identification of peptaibols from Trichoderma virens and cloning of a peptaibol synthetase. $J$. Biol. Chem. 277, 20862-20868. doi: 10.1074/jbc.M201654200

Wilson, M. A., Wei, C., Bjelkmar, P., Wallace, B. A., and Pohorille, A. (2011). Molecular dynamics simulation of the antiamoebin ion channel: linking structure and conductance. Biophys. J. 100, 2394-2402. doi: 10.1016/j.bpj.2011.03.054

Woo, S. L., Di Benedetto, P., Senatore, M., Abadi, K., Gigante, S., Soriente, I., et al. (2004). Identification and characterization of Trichoderma species aggressive to Pleurotus in Italy. $J$. Zhejiang Univ. Agric. Life Sci. 30, 469-470. doi: 10089209-200408-30-4-469-470-a

Woolley, G. A. (2007). Channel-forming activity of alamethicin: effects of covalent tethering. Chem. Biodivers. 4, 1323-1337. doi: 10.1002/cbdv.200790113

Yun, B. S., Yoo, I. D., Kim, Y. H., Kim, Y. S., Lee, S. J., Kim, K. S., and Yeo, W. H. (2000). Peptaivirins A and B, two new antiviral peptaibols against TMV infection. Tetrahedron Lett. 41, 1429-1431. doi: 10.1016/S0040-4039(99)02308-4

Zhang, S., Gan, Y., Xu, B., and Xue, Y. (2014). The parasitic and lethal effects of Trichoderma longibrachiatum against Heterodera avenae. Biol. Control 72, 1-8. doi: 10.1016/j.biocontrol.2014.01.009

Zhang, S., Gan, Y., and Xu, B. (2015). Biocontrol potential of a native species of Trichoderma longibrachiatum against Meloidogyne incognita. Appl. Soil Ecol. 94, 21-29. doi: 10.1016/j.apsoil.2015.04.010 
Zhang, Y. B., and Zhuang, W. Y. (2018). New species of Trichoderma in the Harzianum, Longibrachiatum and Viride clades. Phytotaxa 379, 131-142. doi: 10.11646/phytotaxa.379.2.1 


\section{SUPPLEMENTARY MATERIAL}

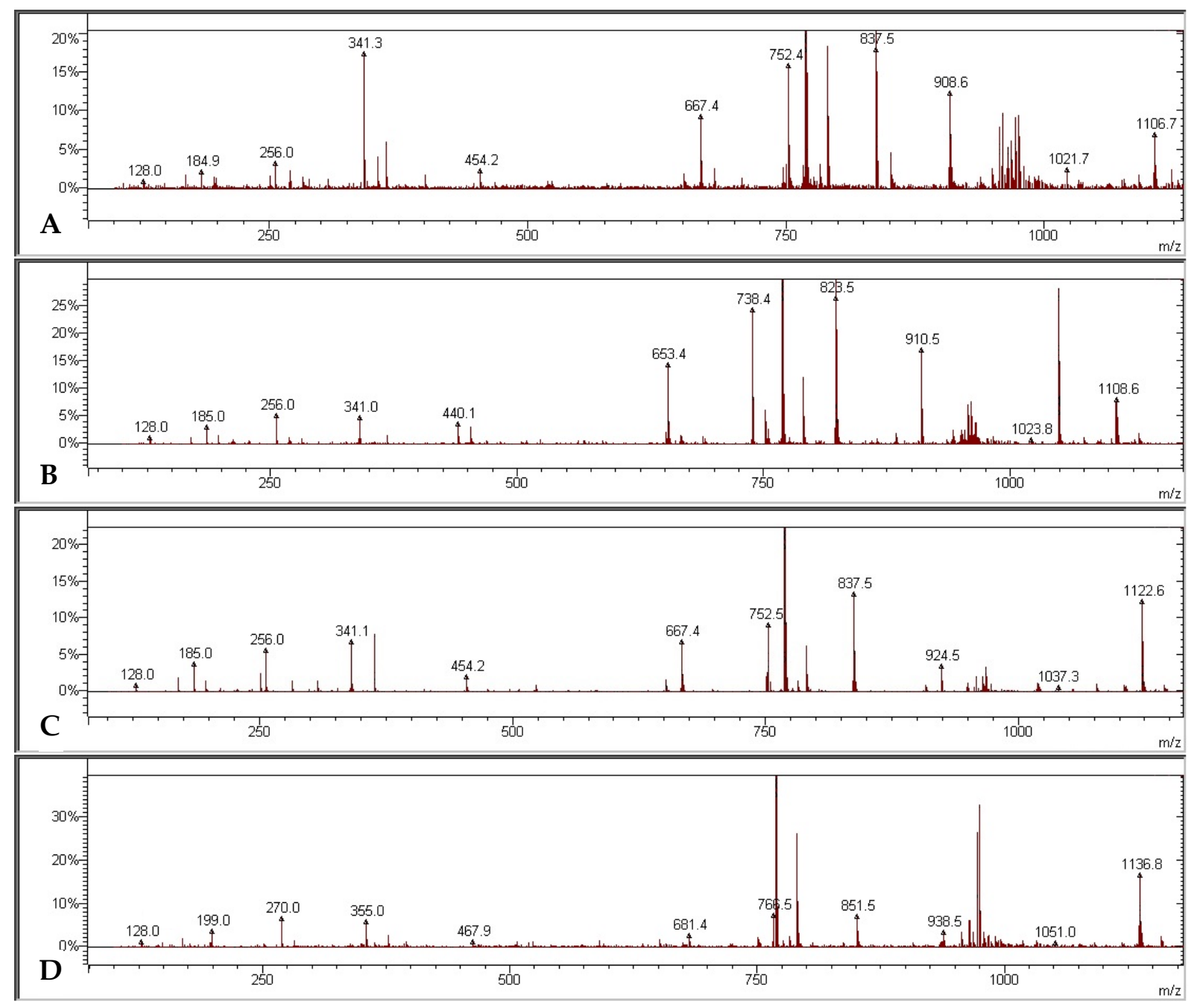

Figure 1 | Typical $b$ ion series of described peptaibols ranged from $b_{12}$ at $m / z 1106$ (A), $m / z$ 1108 (B), $m / z 1122$ (C), $m / z 1136$ (D) resulting from the full scan measurements of crude peptaibol extracts prepared from T. gamsii SZMC 1656 performed on Varian-MS system 


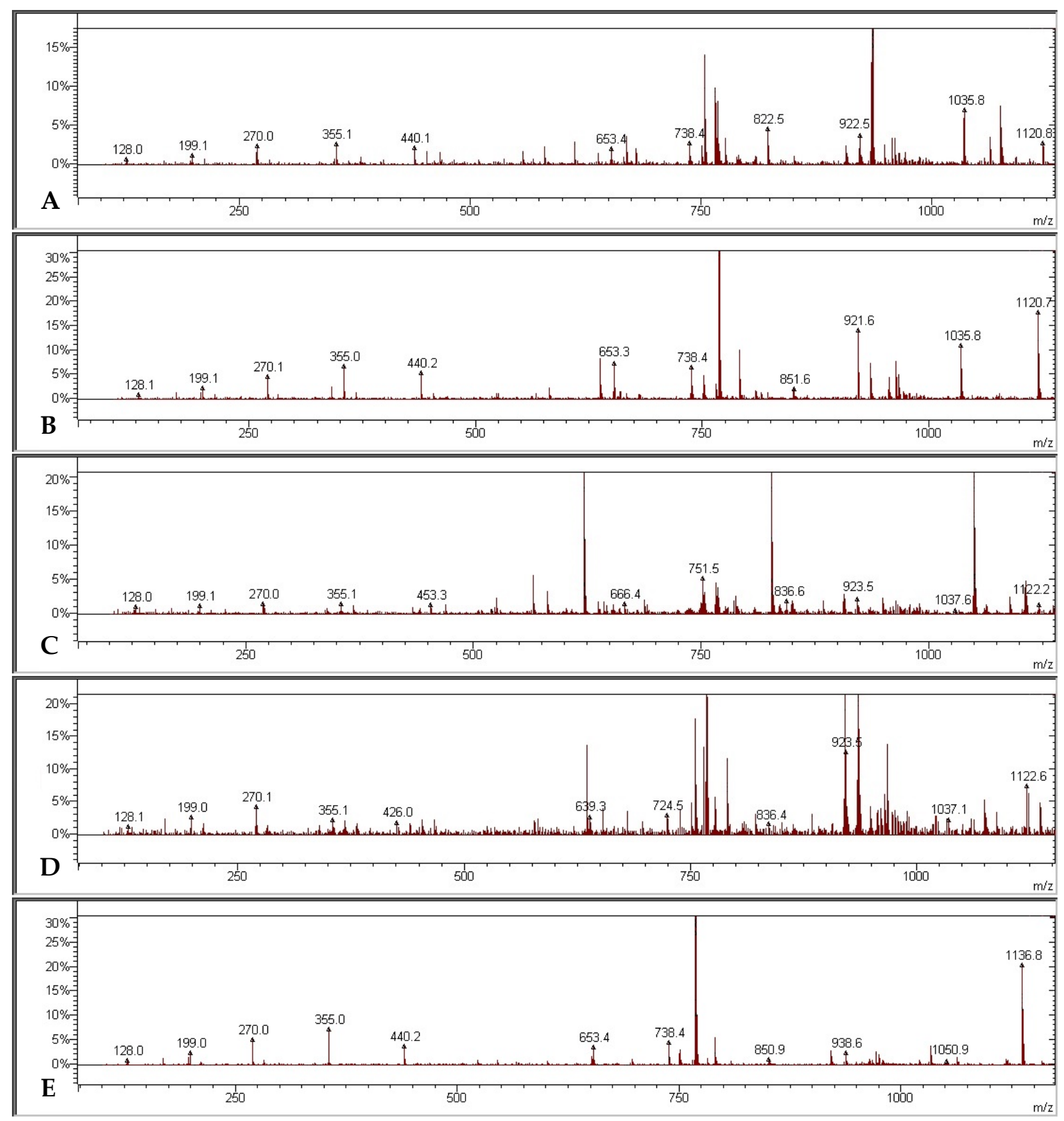

Figure 2 | Typical $b$ ion series of described peptaibols ranging from $b_{12}$ at $m / z 1120$ (Koningiopsin IIb, IIIb - A), m/z 1120 (Koningiopsins VIa, VIb - B), m/z 1122 (Koningiopsins Ia, Ib- C), m/z 1122 (Koningiopsins IIIa - D), m/z 1136 (Koningiopsins IIa, $\mathrm{IV}, \mathrm{Va}, \mathrm{Vb}$ - E) resulting from the full scan measurements of crude peptaibol extracts prepared from T. koningiopsis SZMC 12500 performed on Varian-MS system 

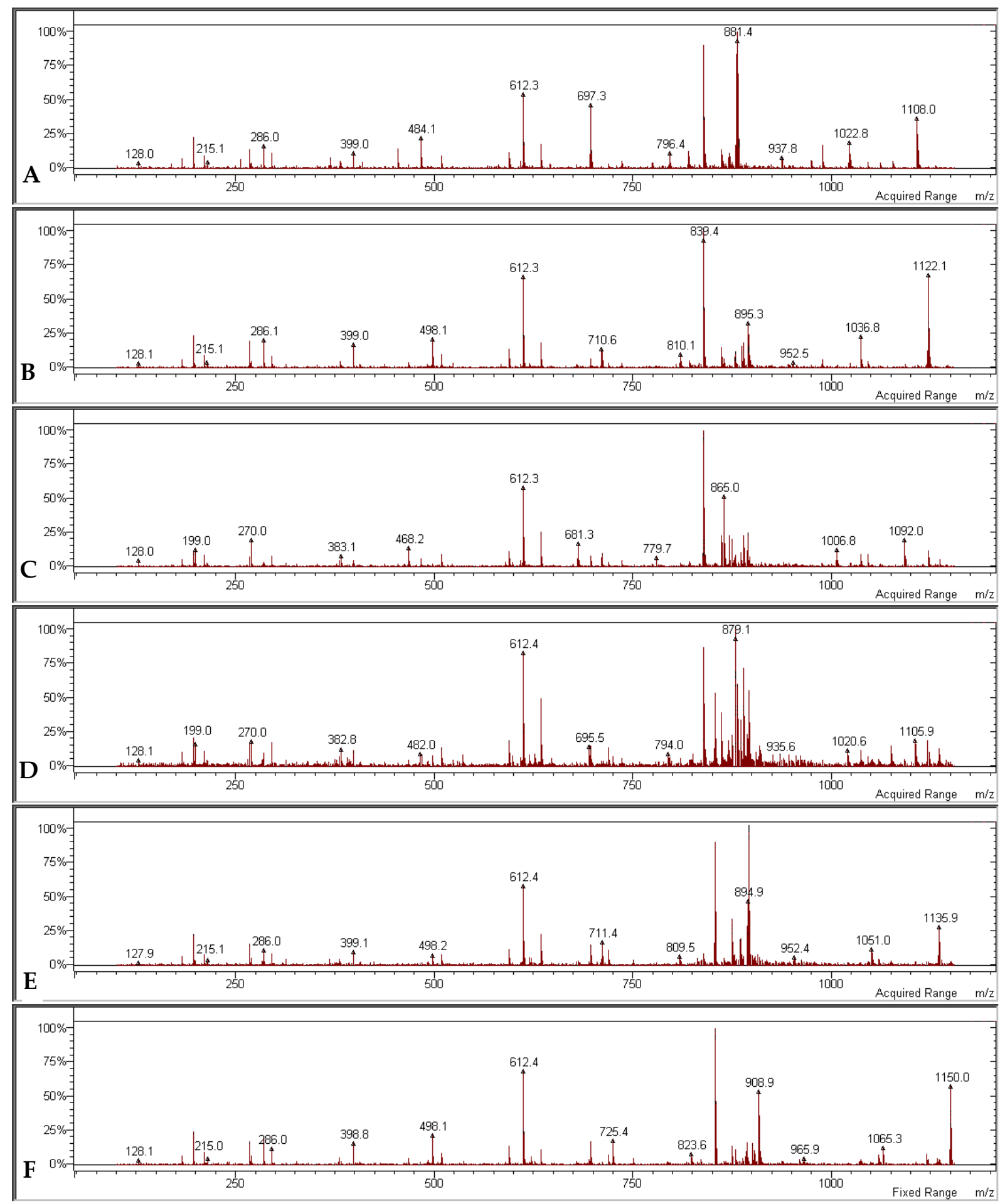

Figure 3 I Typical b ion series of six selected compounds: Hypomurocin B1 (A), Pept-1733a-1 (B), Hypomurocin B 3a (C), Pept-1717-a-1 (D), Pept-1747-a-2 (E) and Pept-1761-a-3 (F) resulting from the full scan measurements of crude peptaibol extracts prepared from $T$. aggressivum f. europaeum CBS 433.95 (SZMC 1811) performed on Varian-MS system 

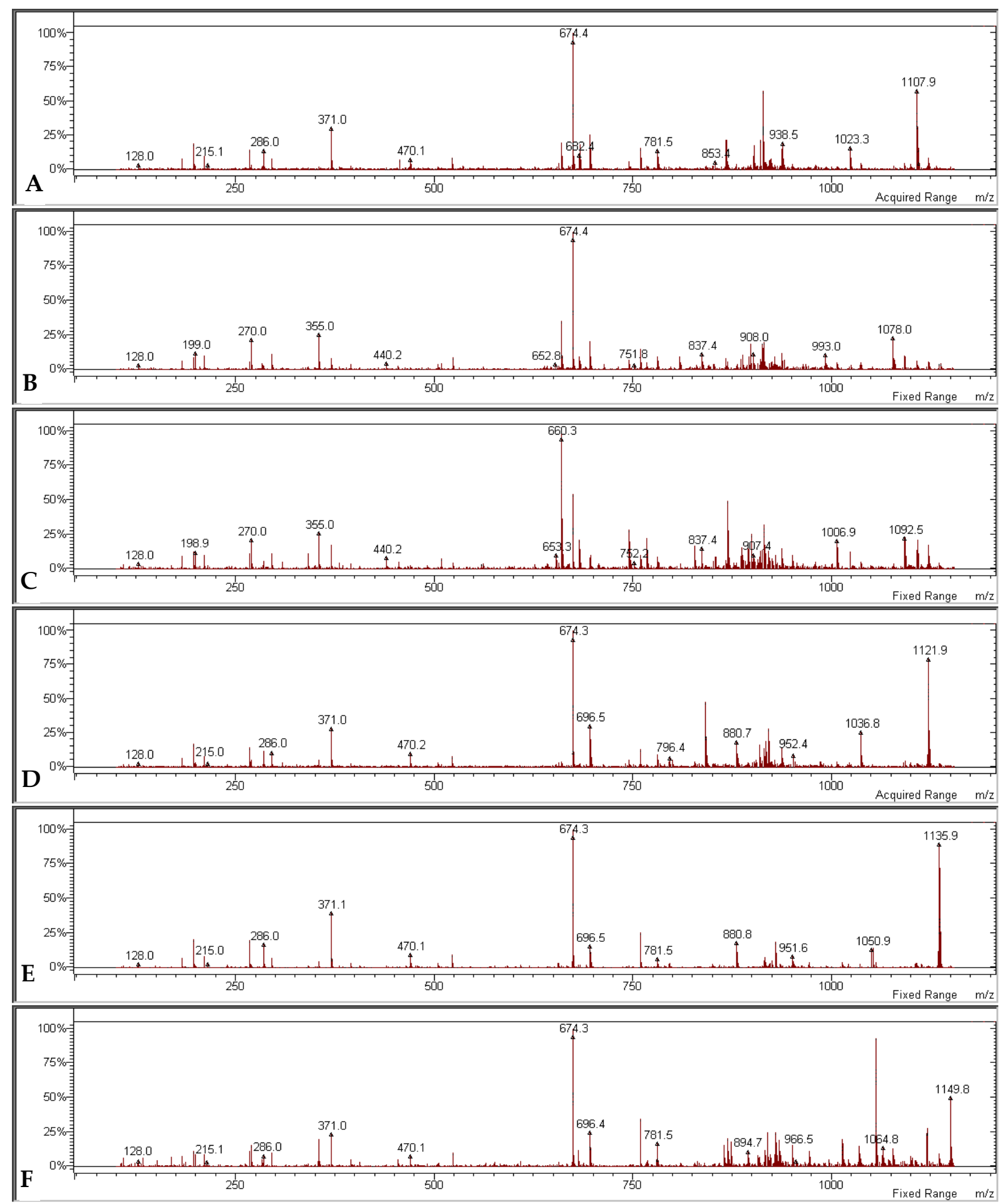

Figure 4 । Typical b ion series of six selected compounds: Tripleurin IIIa (A), Tripleurin IV (B), Tripleurin VII (C), Tripleurin VIIIa (D), Tripleurin XIIc (E) and Tripleurin XIV (F) resulting from the full scan measurements of crude peptaibol extracts prepared from $T$. pleuroti TPhu1 (SZMC 12454) performed on Varian-MS system 

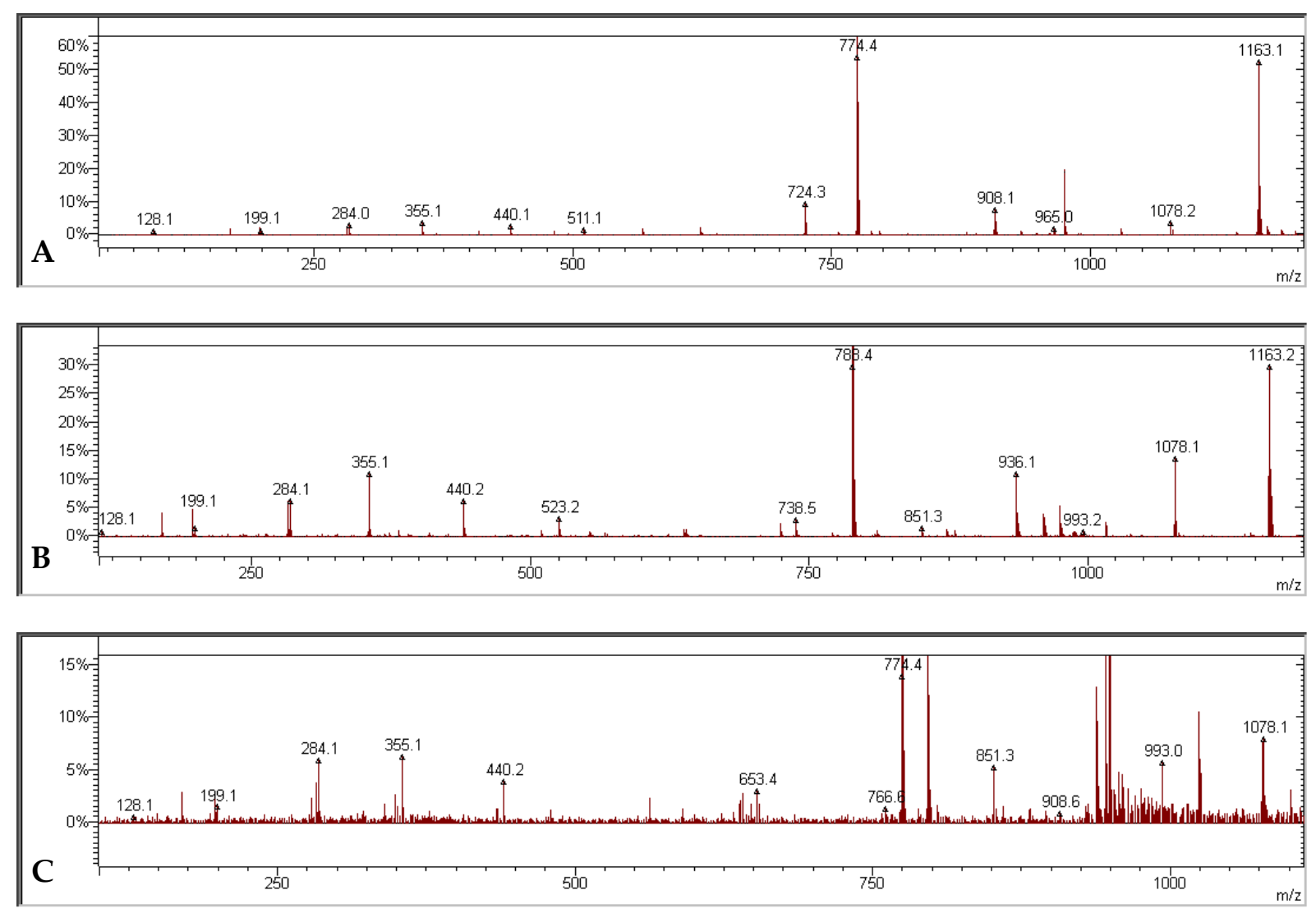

Figure 5 I Typical b-type ion series of three selected compounds: Pept-A-IVa (A), Pept-BXXVII (B) from $b_{13}$ at $m / z 1163$ and Brevicelsin I (C) ranged from $b_{13}$ at $m / z 1078$ resulting from the full scan measurements of crude peptaibol extracts performed on Varian MS system and prepared from T. orientale SZMC 12556, T. saturnisporum SZMC 22606 and $T$. flagellatum SZMC 22608, respectively. 

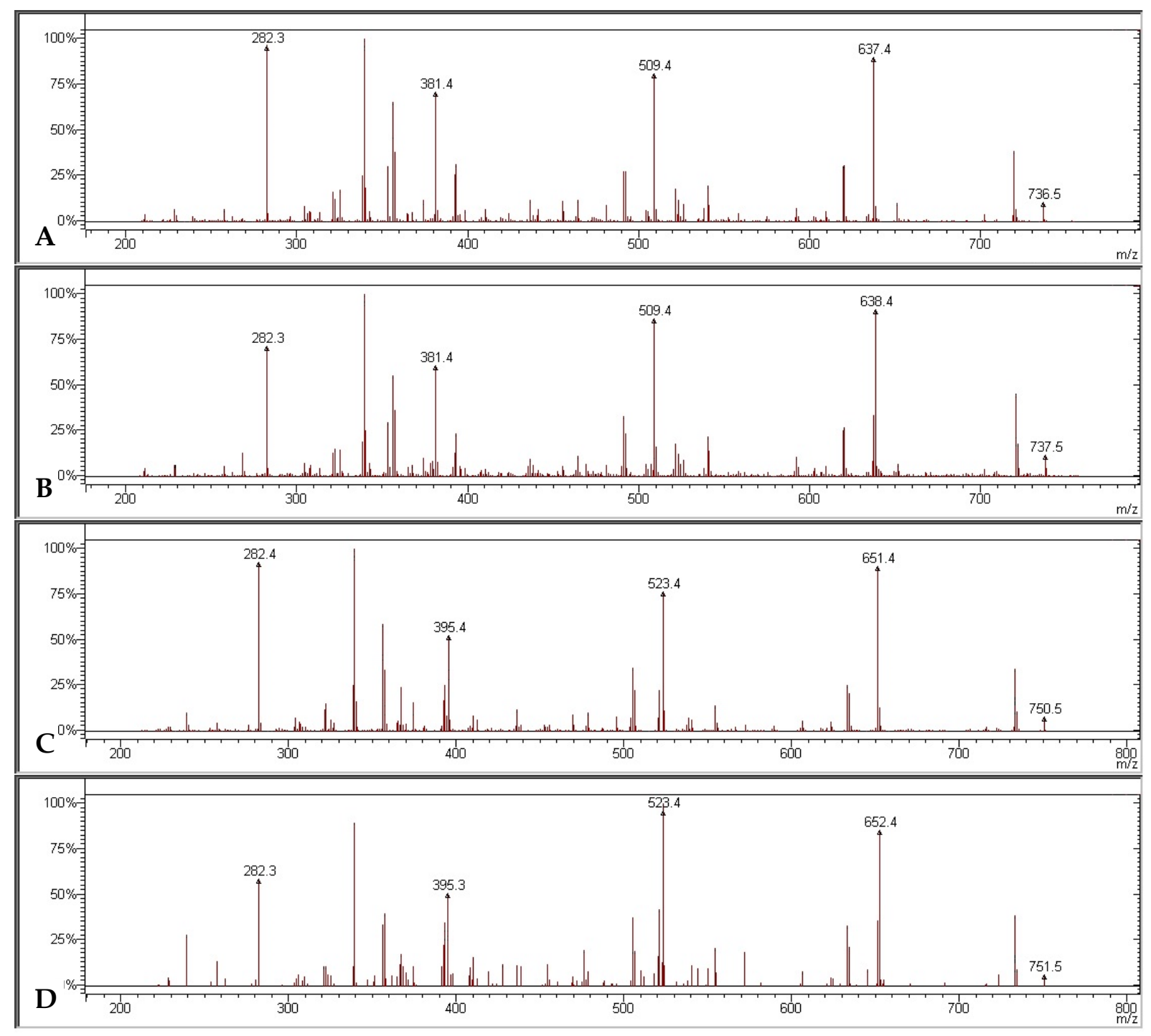

Figure 6 | Typical $\mathrm{MS}^{2}$ spectra of y-ions 754.5 (A), 755.5 (B), 768.5 (C) and 769.5 (D) resulting from the full scan measurements of crude peptaibol extracts of $T$. gamsii SZMC 1656 and T. koningiopsis SZMC 12500 performed on Varian-MS system. The MS ${ }^{2}$ patterns originating from the same $\mathrm{m} / z$ values were identical. 

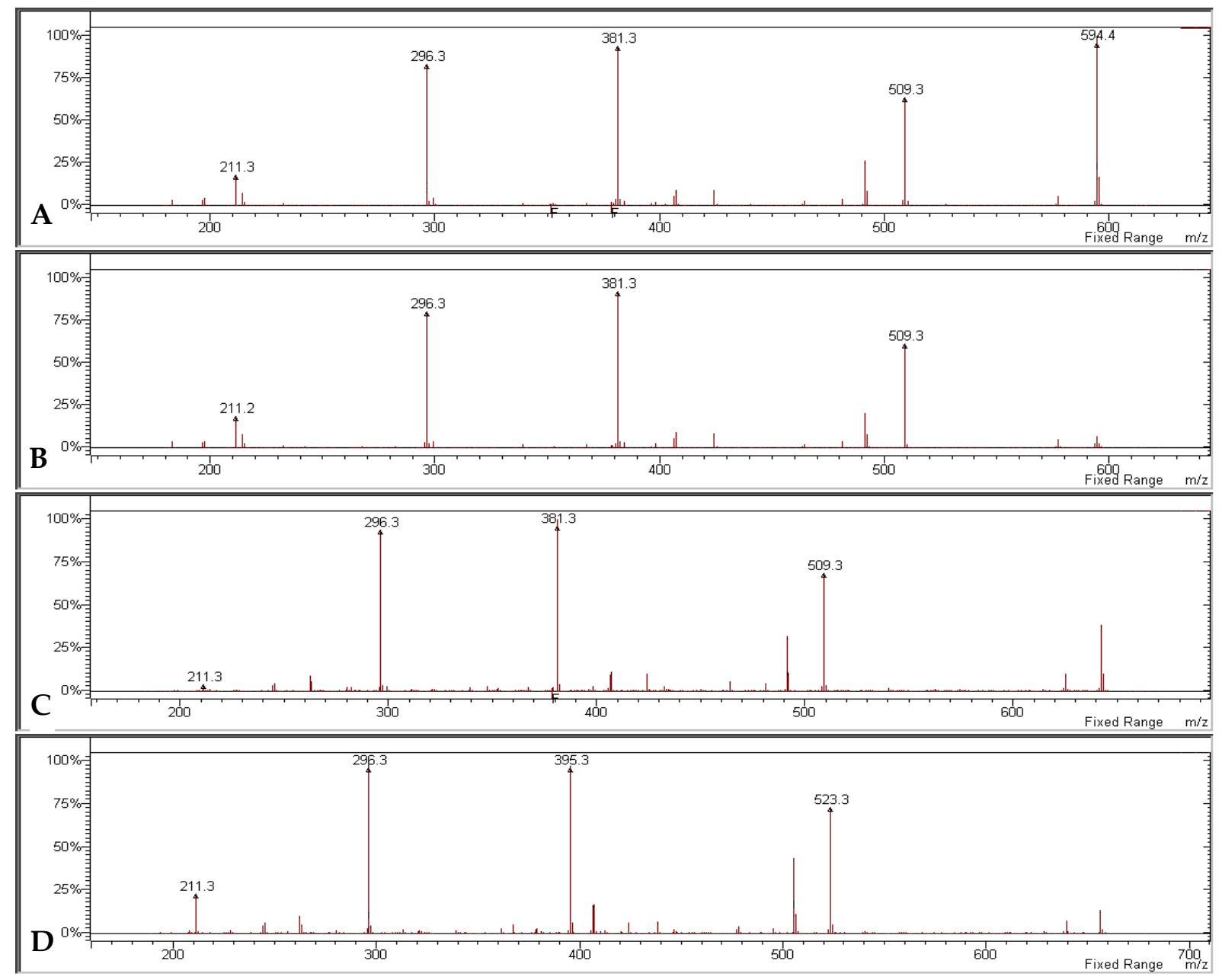

Figure 7 I Typical $\mathrm{MS}^{2}$ spectra of y-ions 612.5 (A), 626.5 (B), 660.5 (C) and 674.5 (D) resulting from the full scan measurements of crude peptaibol extracts of A, B: T. aggressivum f. europaeum CBS 433.95 (SZMC 1811) and C, D: T. pleuroti TPhul (SZMC 12454) performed on Varian-MS system. The $\mathrm{MS}^{2}$ patterns originating from the same $\mathrm{m} / \mathrm{z}$ values were identical. 

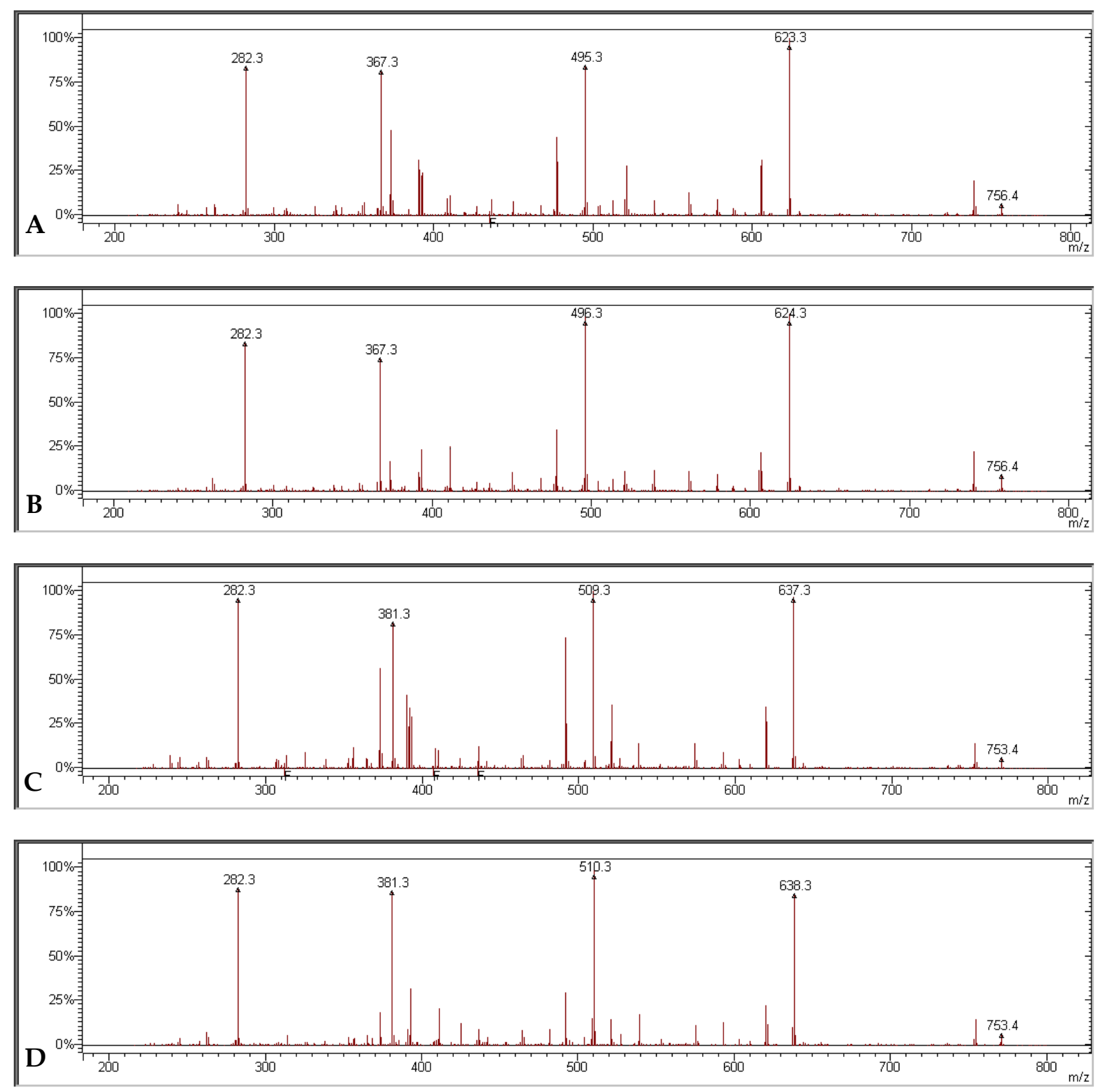

Figure 8 | Typical MS ${ }^{2}$ spectra of y-type ions $m / z 774.4$ (A), $m / z 775.4$ (B), $m / z 788.4$ (C) and $m / z 789.4$ (D) resulting from the full scan measurements of crude peptaibol extracts of the strains belonging to Longibrachiatum clade. Analyses were performed on Varian MS system. $\mathrm{MS}^{2}$ spectra obtained from precursor ions of the same $\mathrm{m} / \mathrm{z}$ ratio were identical. 
A

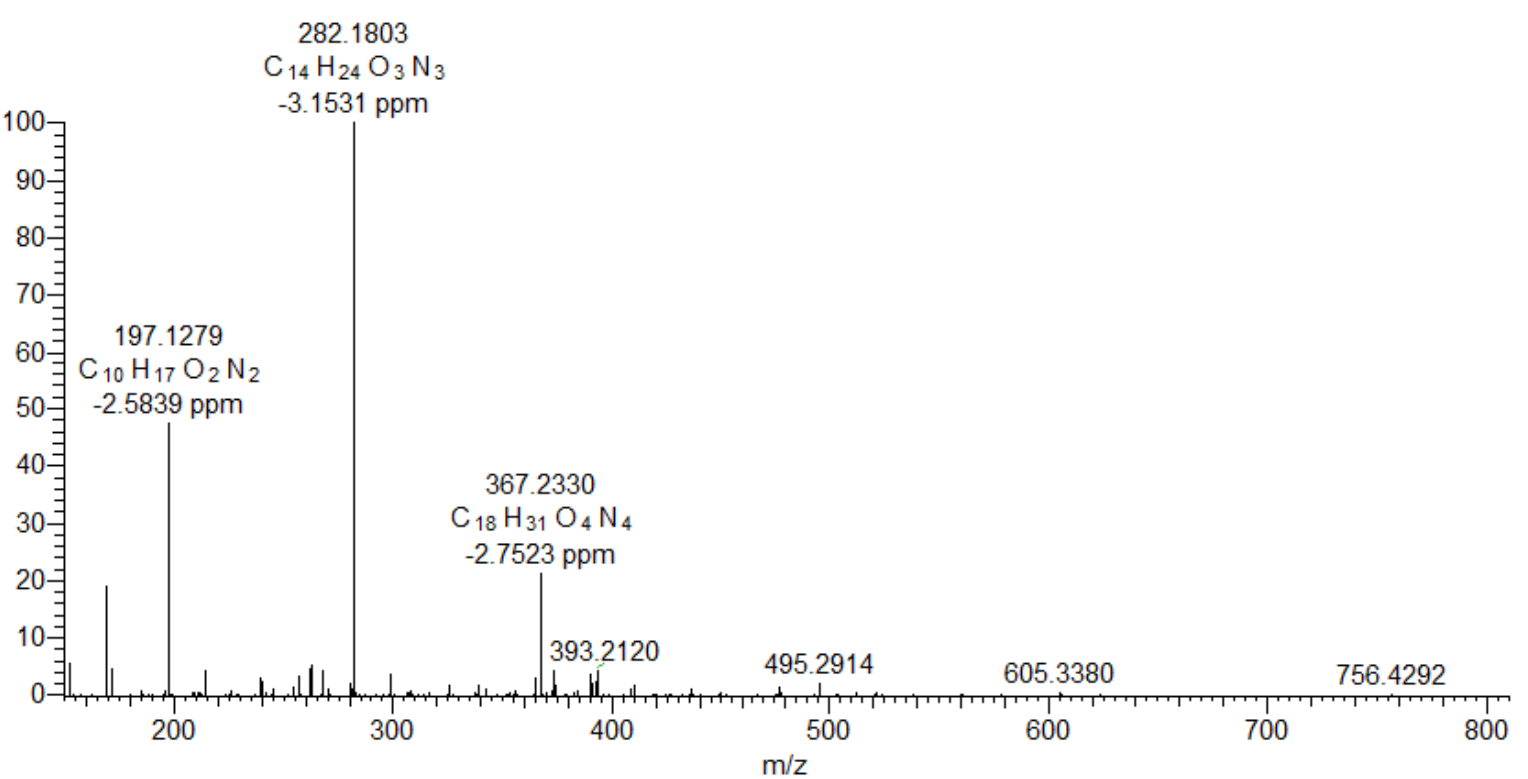

B

282.1804
$\mathrm{C}_{14} \mathrm{H}_{24} \mathrm{O}_{3} \mathrm{~N}_{3}$

$1000_{\exists} \quad-3.0450 \mathrm{ppm}$

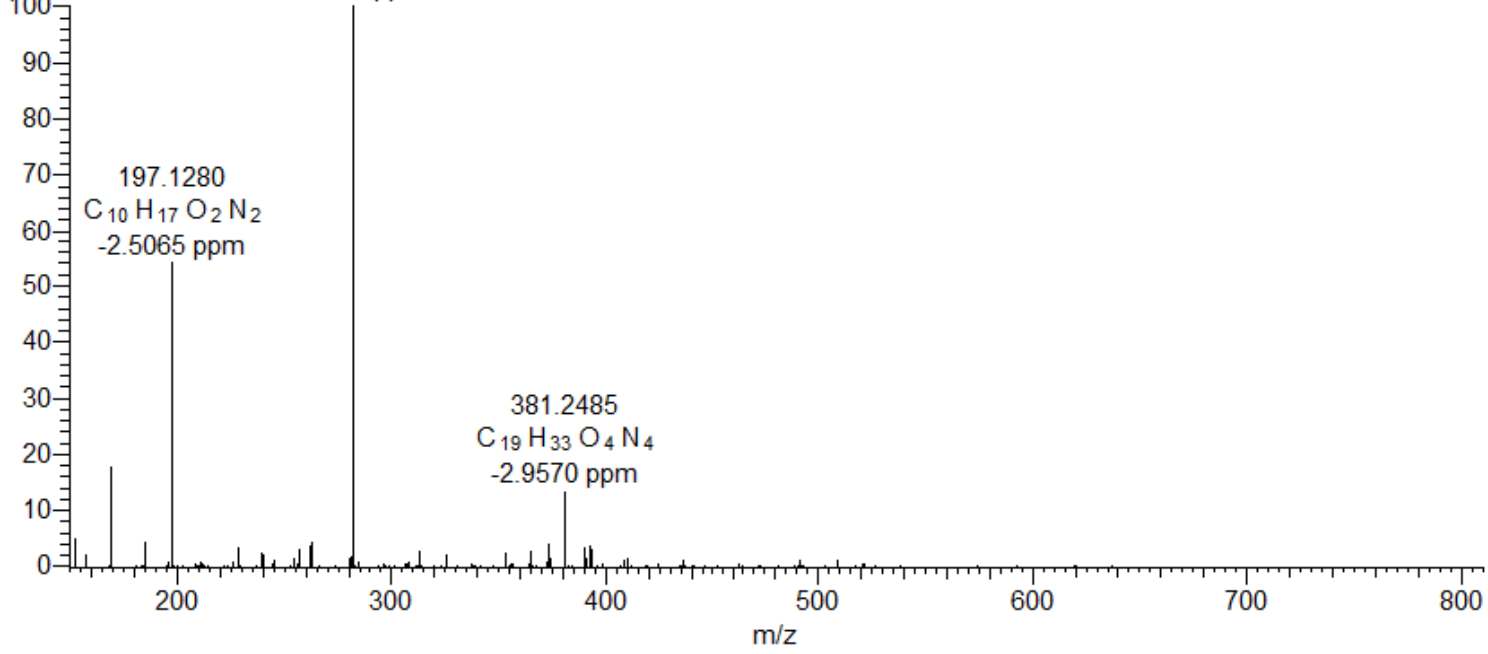

Figure 9 | Typical MS ${ }^{2}$ spectra of y-type ions $m / z 774.4$ (A) and $m / z 788.4$ (B) resulting from the full scan measurements of crude peptaibol extracts of the strains belonging to Longibrachiatum clade. Analyses were performed on Orbitrap-MS system. $\mathrm{MS}^{2}$ spectra obtained from precursor ions of the same $\mathrm{m} / \mathrm{z}$ ratio were identical. 


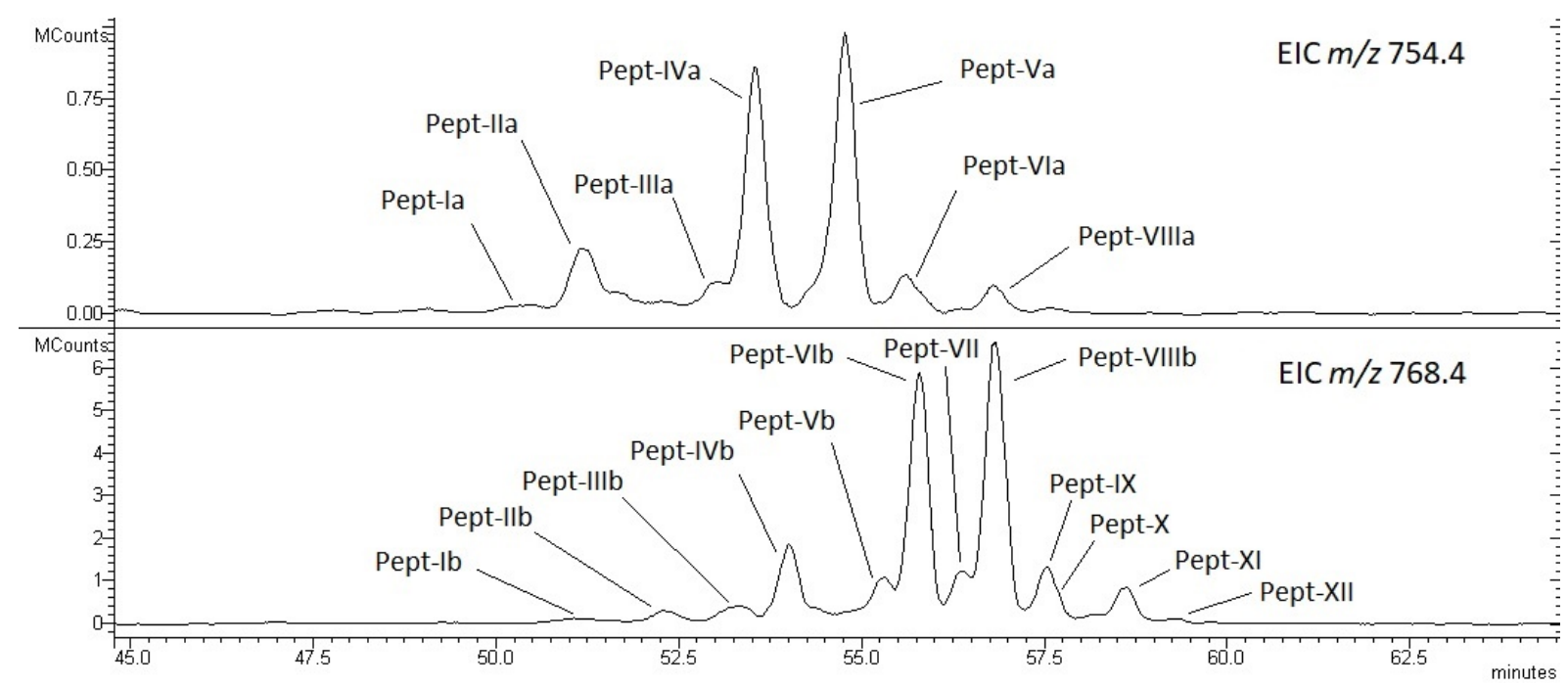

Figure 10 | EIC resulting from full scan measurements of crude extracts from T. gamsii SZMC 1656. The coeluted components within some peaks were identified based on Varian$\mathrm{MS}^{2}$ examinations.

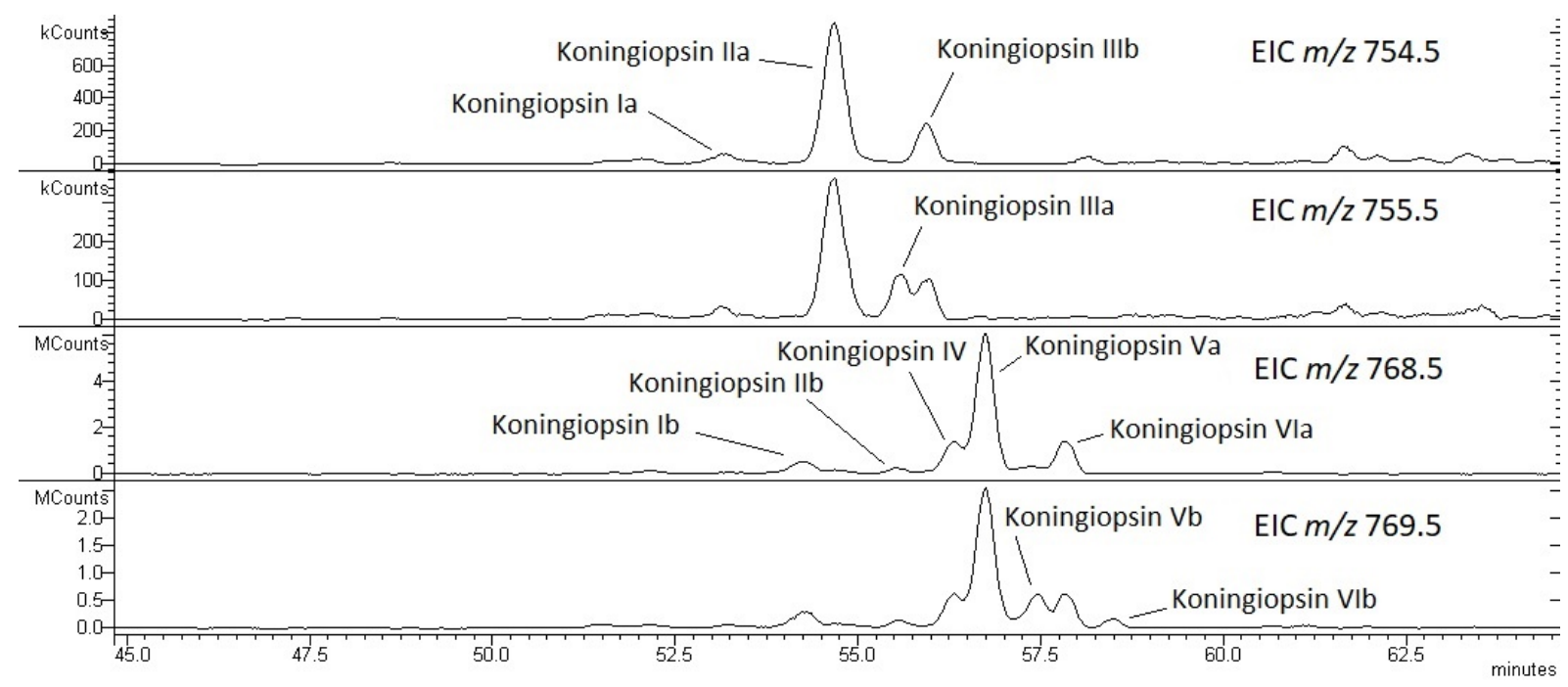

Figure 11 I EIC resulting from full scan measurements of crude extracts prepared from $T$. koningiopsis SZMC 12500 


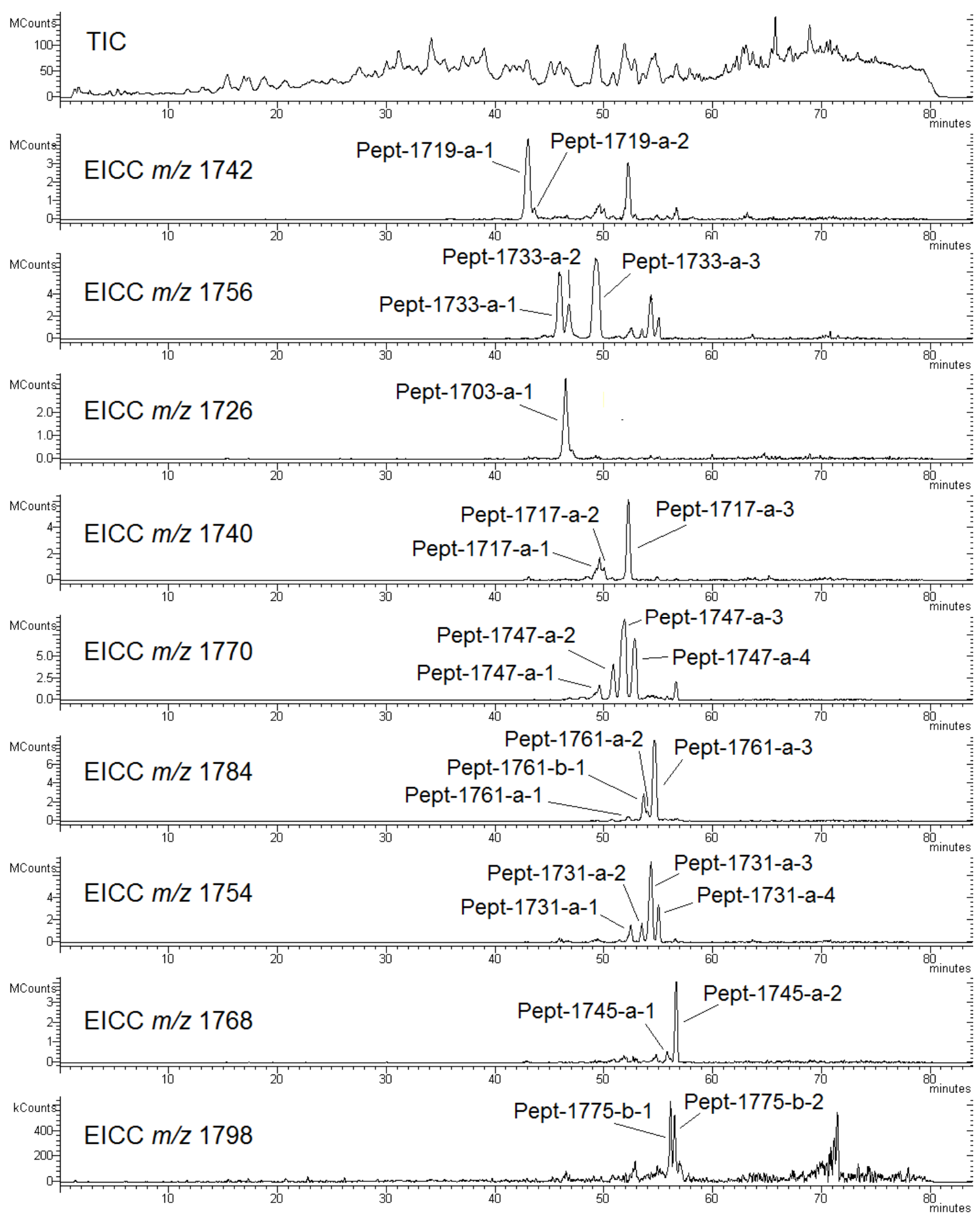

Figure 12 | TICs and EICs resulting from full scan measurements of peptaibol molecules prepared from T. aggressivum f. europaeum CBS 433.95 (SZMC 1811) performed on VarianMS system. 


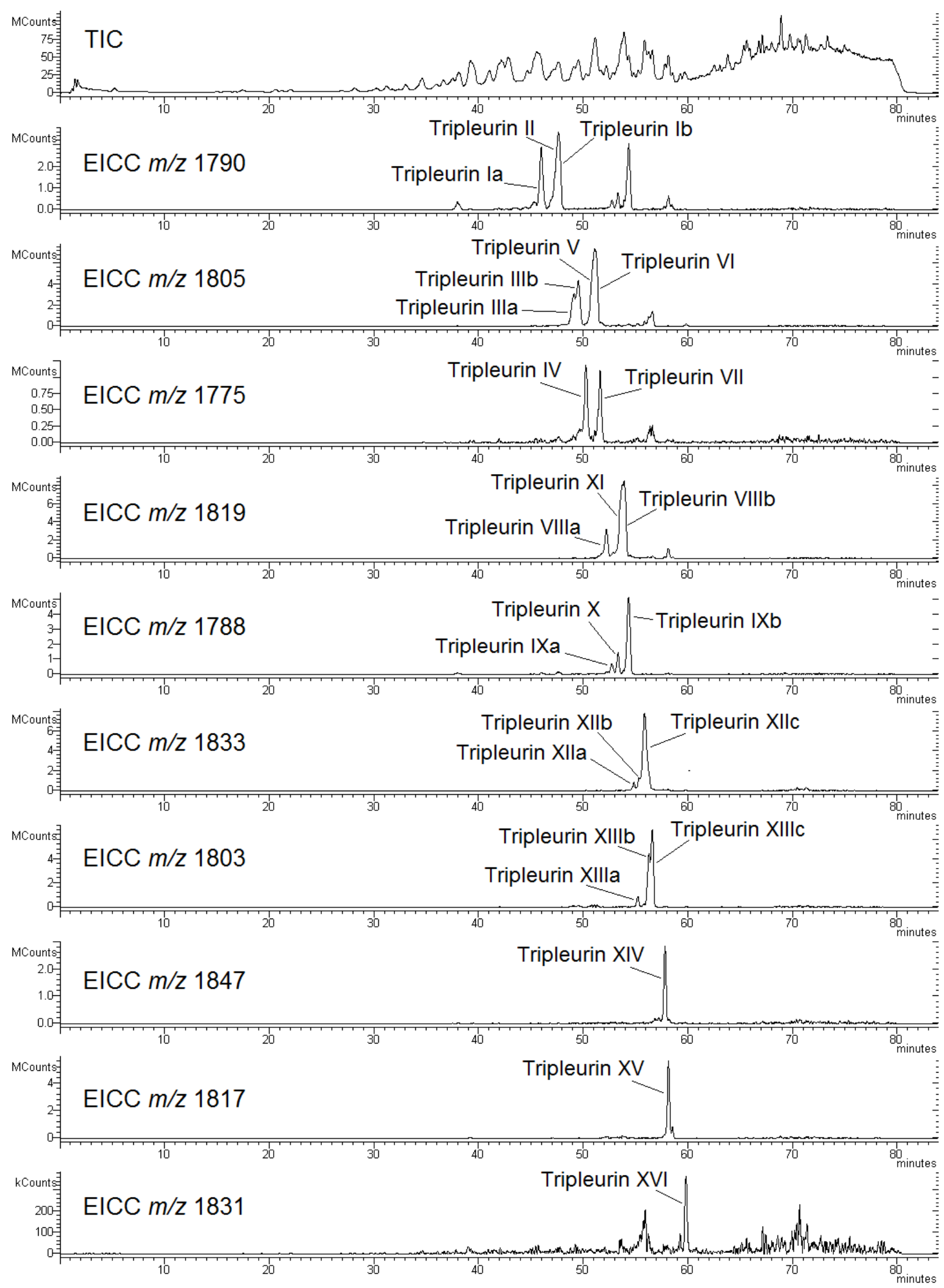

Figure 13 | TIC and EIC resulting from full scan measurements of peptaibol molecules prepared from $T$. pleuroti TPhu1 (SZMC 12454) performed on Varian-MS system. The coeluted components within some peaks were identified based on Varian-MS ${ }^{2}$ examinations. 


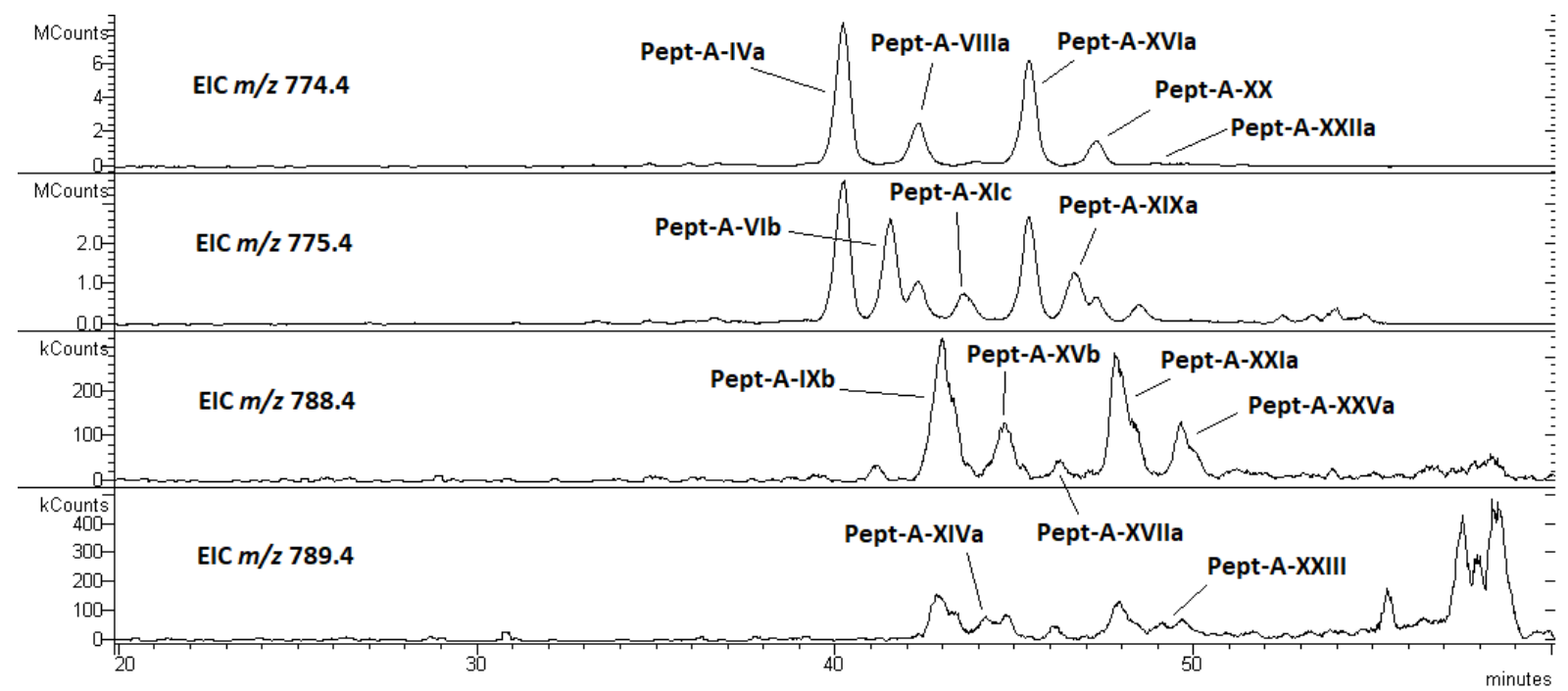

Figure 14 | EIC resulting from full scan measurements of crude extracts from $T$. pinnatum SZMC 22603 performed on Varian-MS system. The coeluting components within some peaks were identified based on $\mathrm{MS}^{2}$ experiments.

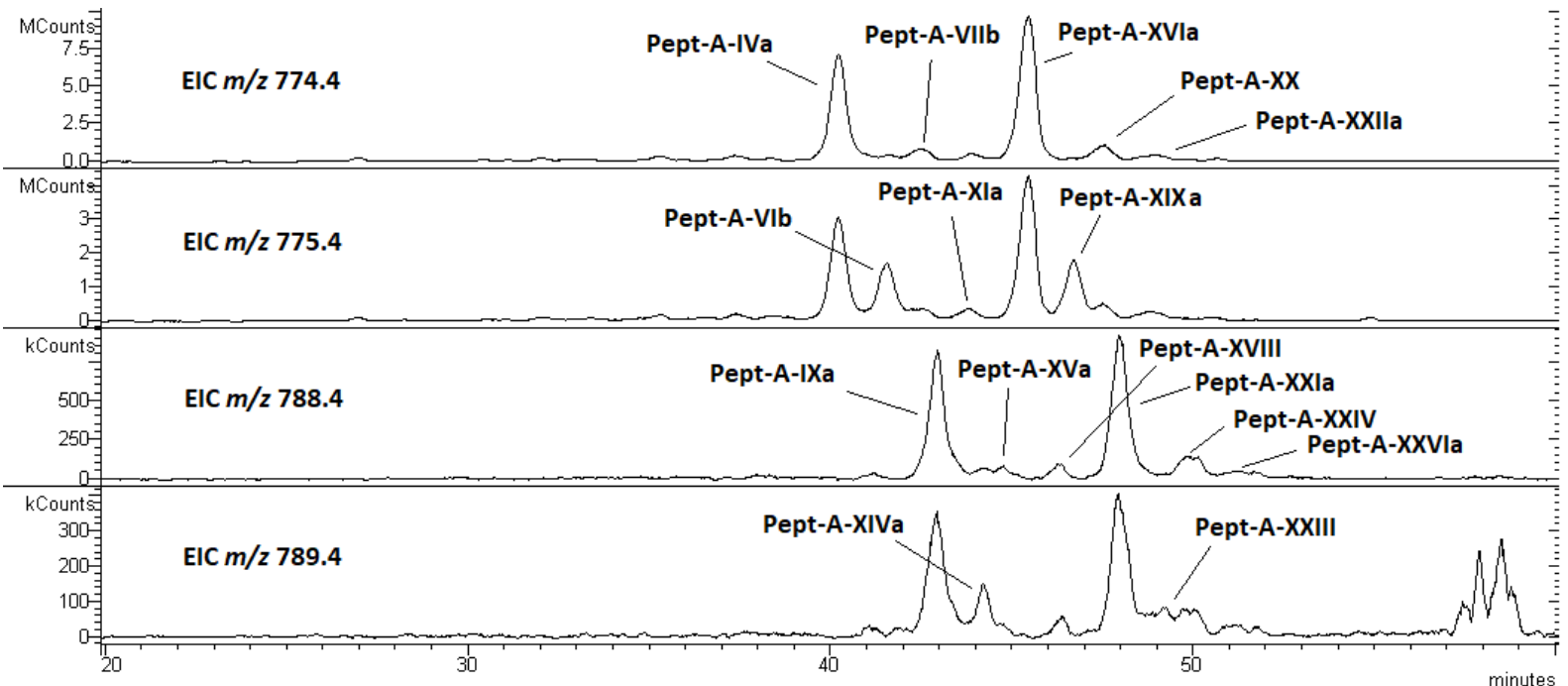

Figure 15 I EIC resulting from full scan measurements of crude extracts from $T$. aethiopicum SZMC 22602 performed on Varian-MS system. The coeluting components within some peaks were identified based on $\mathrm{MS}^{2}$ experiments. 


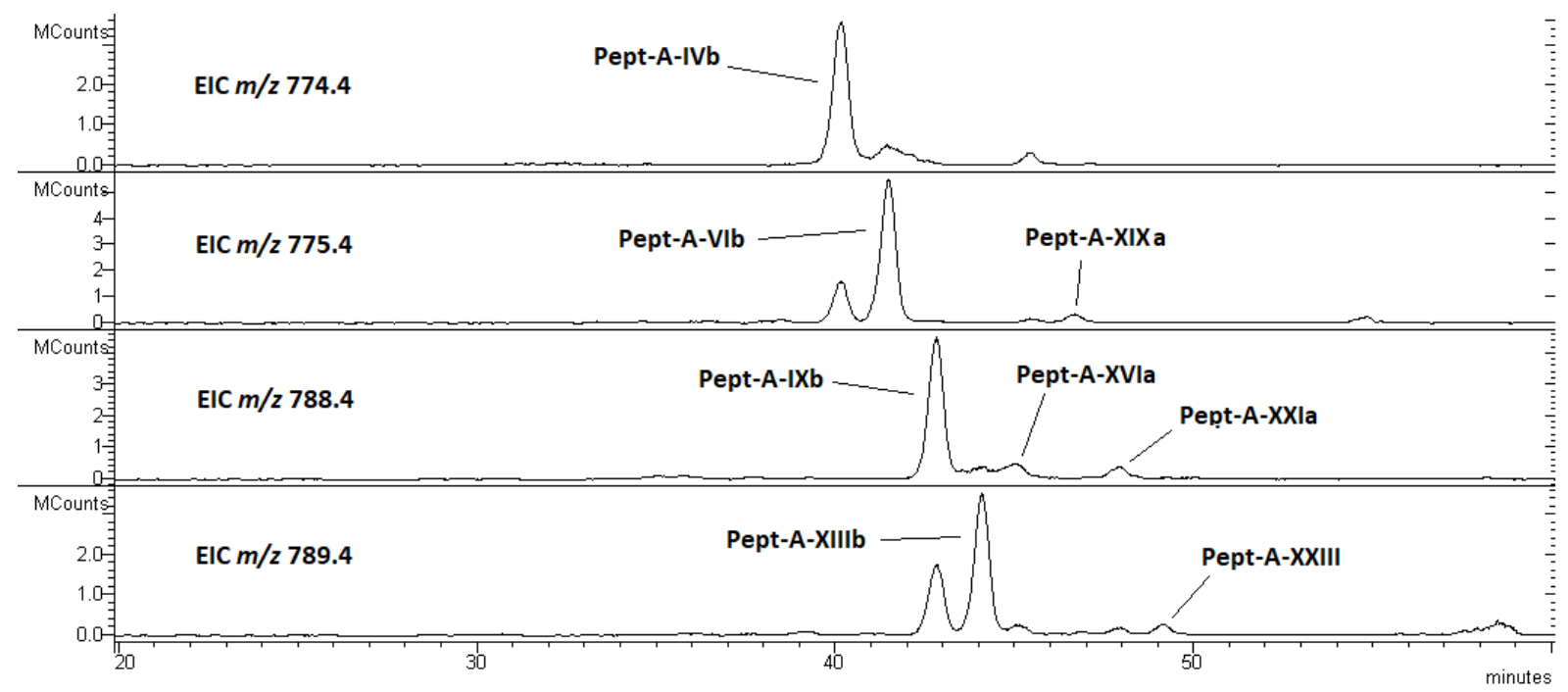

Figure 16 | EIC resulting from full scan measurements of crude extracts from $T$. ghanense SZMC 22604 performed on Varian-MS system. The coeluting components within some peaks were identified based on $\mathrm{MS}^{2}$ experiments.

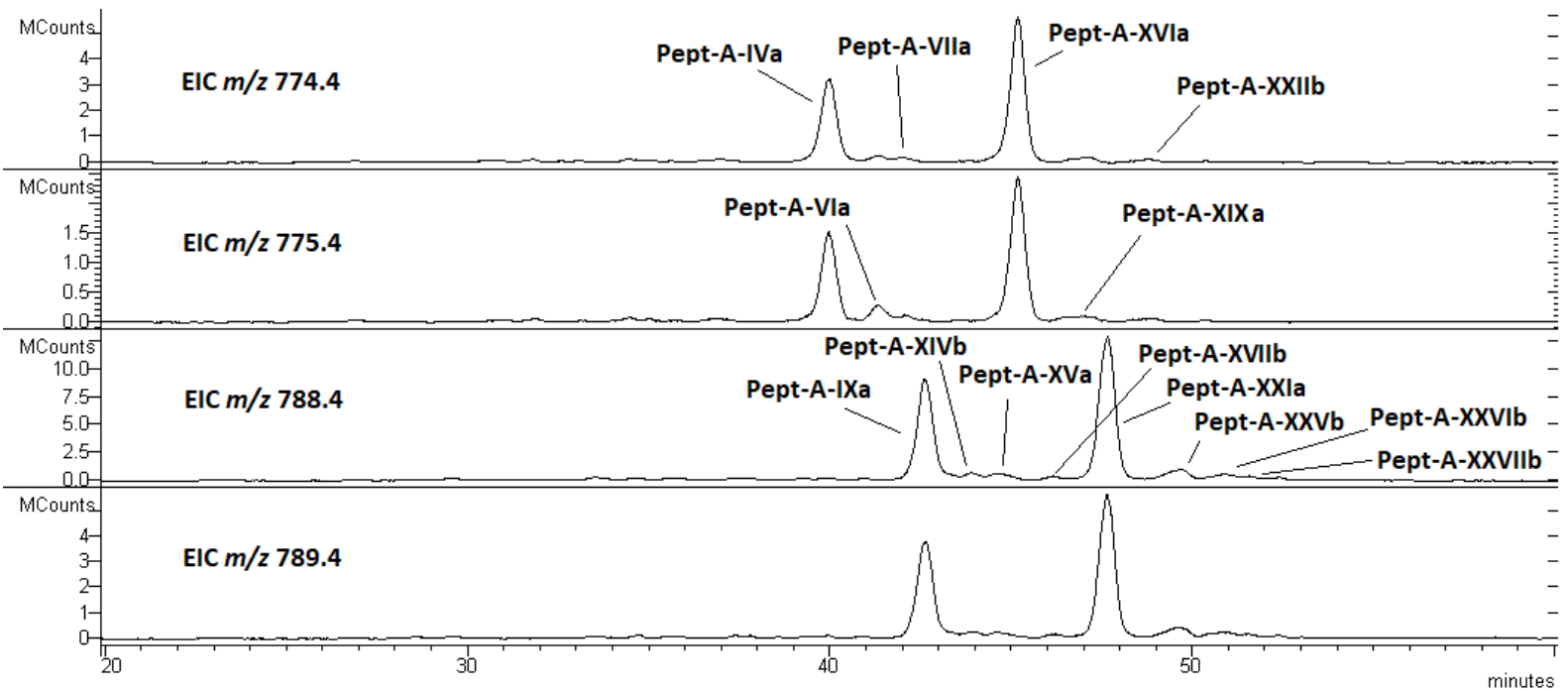

Figure 17 I EIC resulting from full scan measurements of crude extracts from $T$. citrinoviride SZMC 22618 performed on Varian-MS system. The coeluting components within some peaks were identified based on $\mathrm{MS}^{2}$ experiments. 


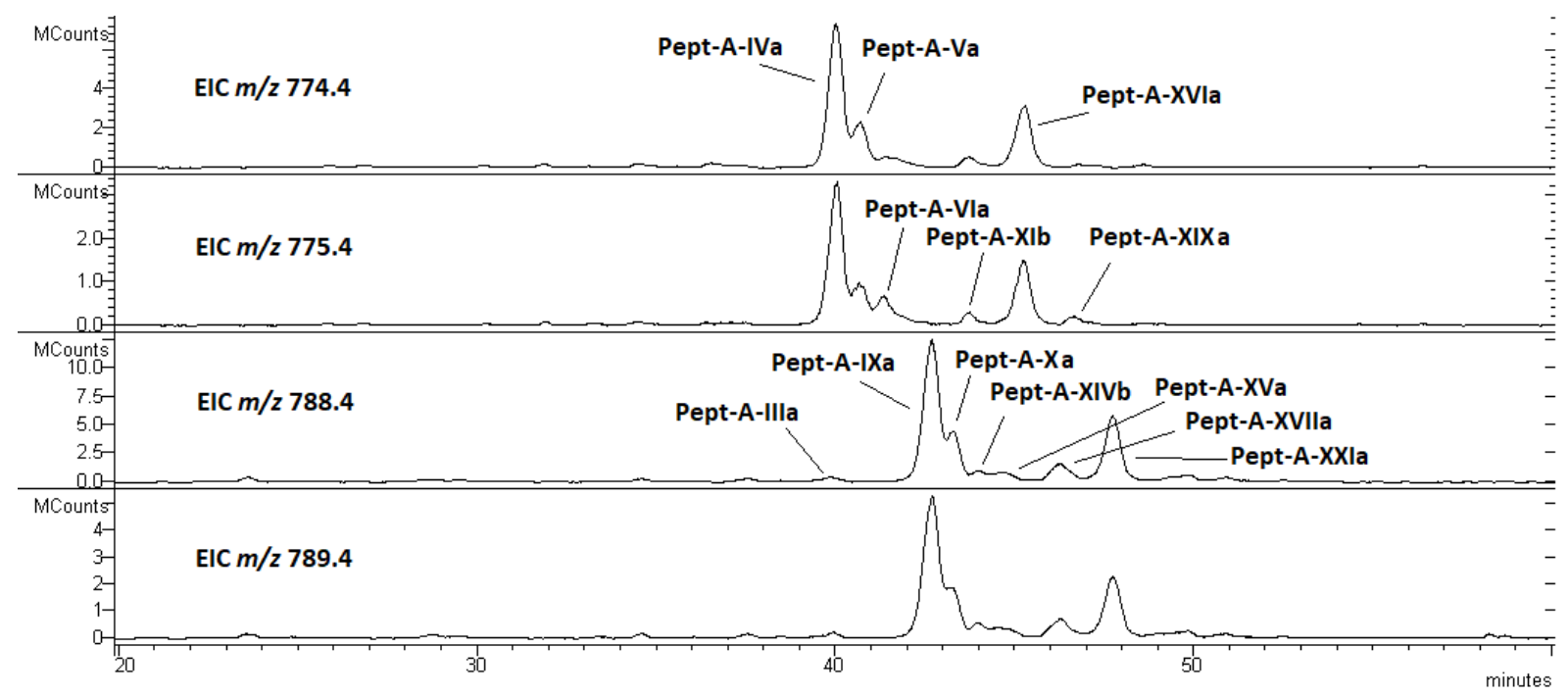

Figure 18 | EIC resulting from full scan measurements of crude extracts from $T$. pseudokoningii SZMC 22613 performed on Varian-MS system. The coeluting components within some peaks were identified based on $\mathrm{MS}^{2}$ experiments.

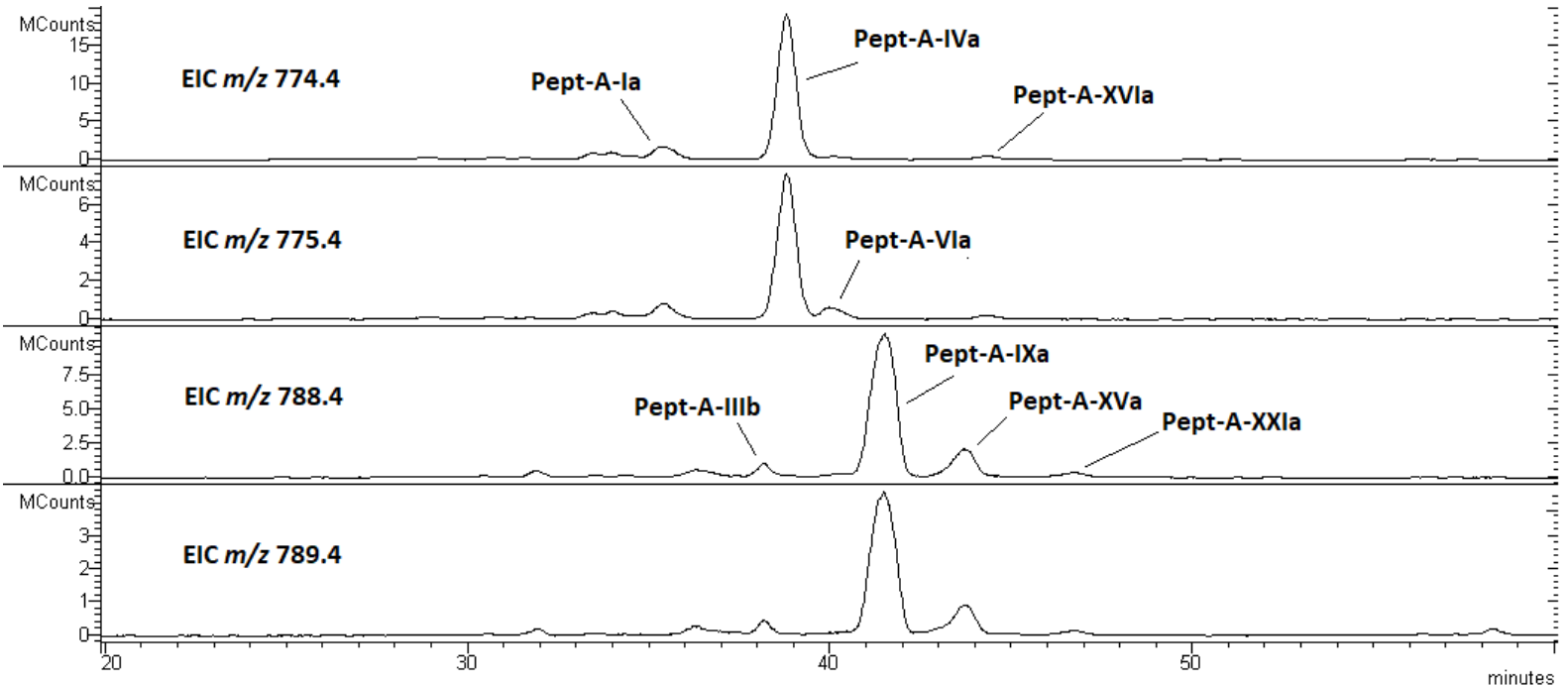

Figure 19 I EIC resulting from full scan measurements of crude extracts from $T$. orientale SZMC 12556 performed on Varian-MS system. The coeluting components within some peaks were identified based on $\mathrm{MS}^{2}$ experiments. 


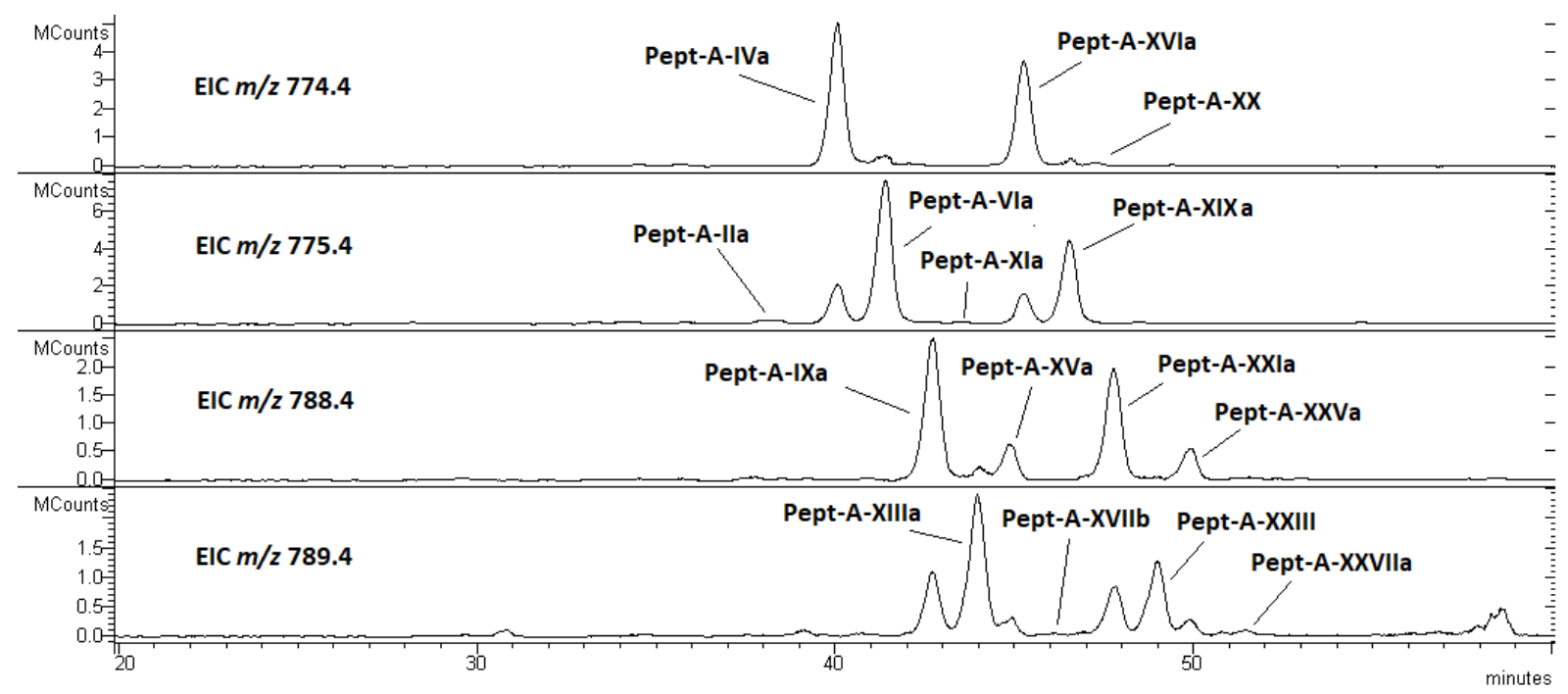

Figure 20 | EIC resulting from full scan measurements of crude extracts from T. bissettii SZMC 1776 performed on Varian-MS system. The coeluting components within some peaks were identified based on $\mathrm{MS}^{2}$ experiments.

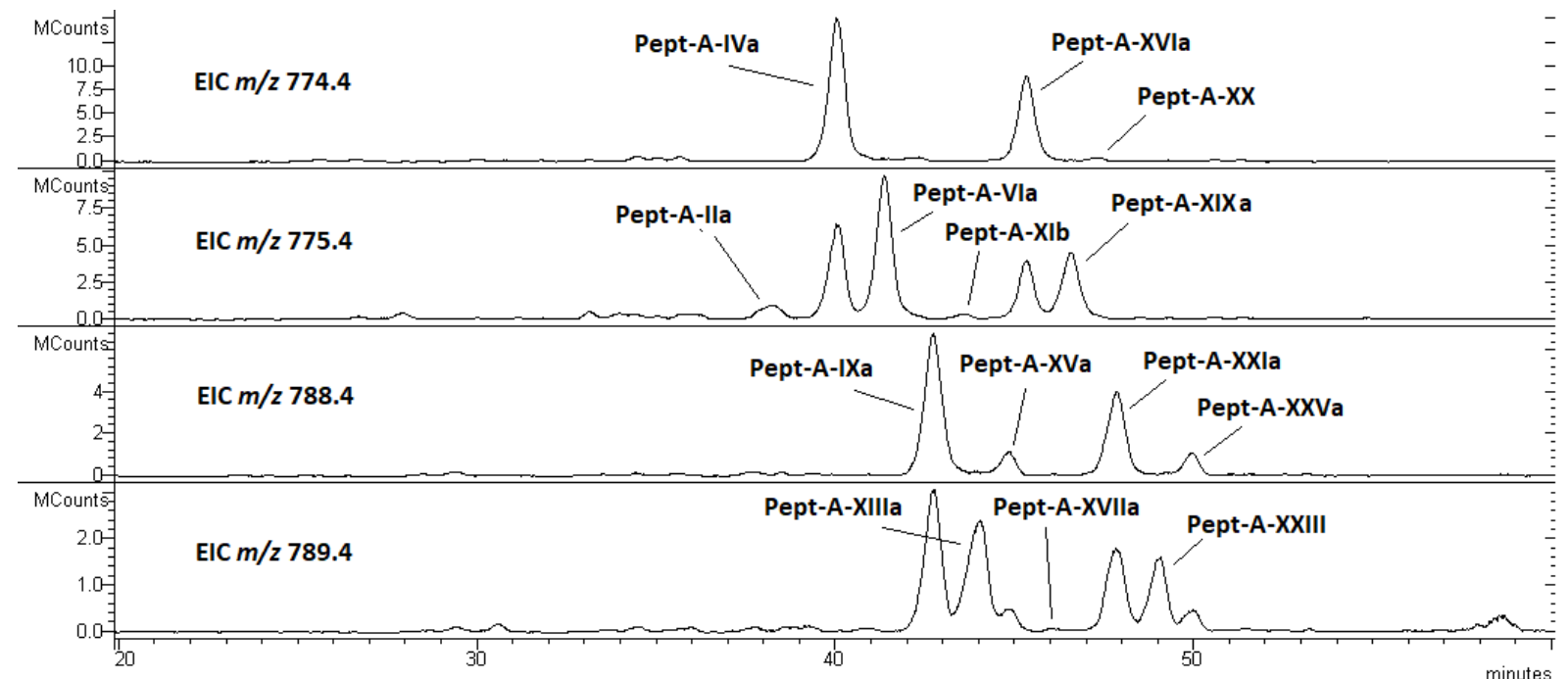

Figure 21 I EIC resulting from full scan measurements of crude extracts from $T$. bissettii SZMC 1773 performed on Varian-MS system. The coeluting components within some peaks were identified based on $\mathrm{MS}^{2}$ experiments. 


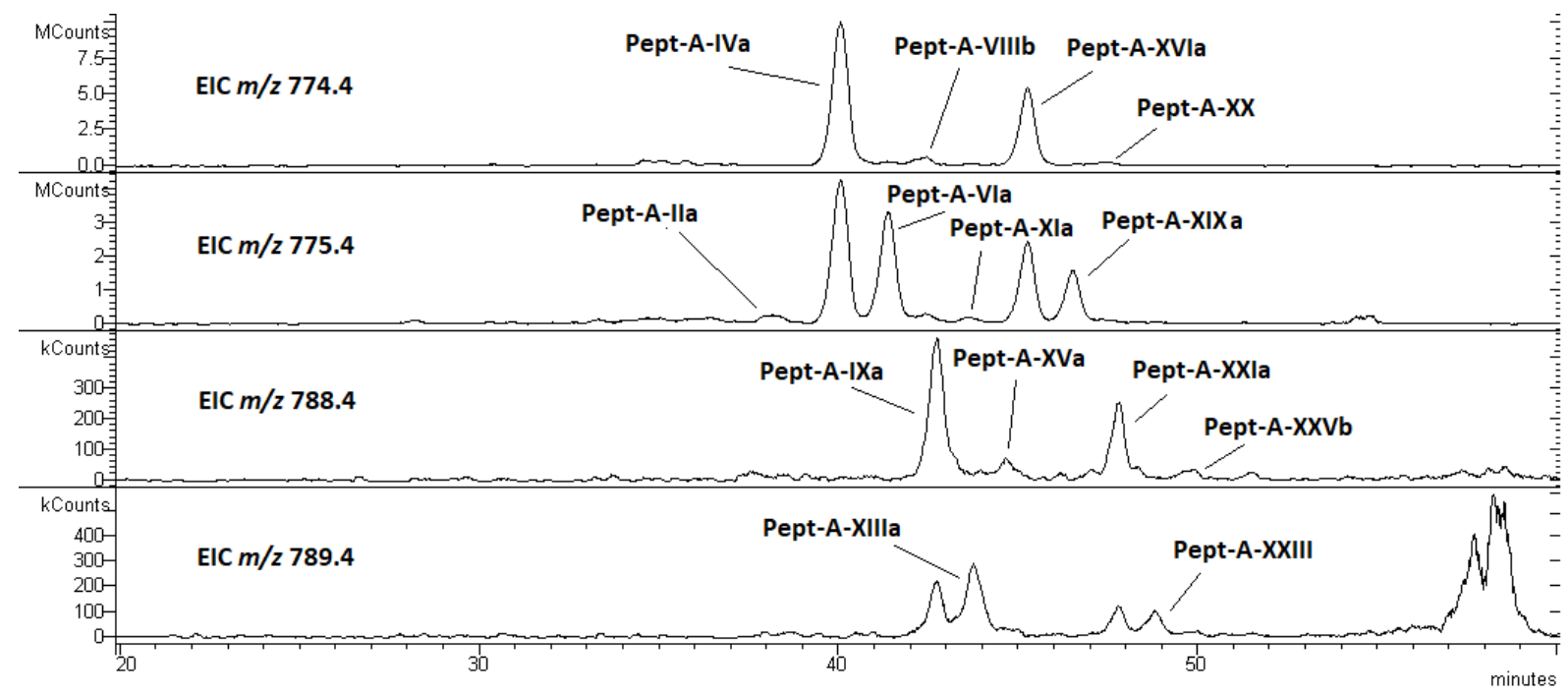

Figure 22 | EIC resulting from full scan measurements of crude extracts from $T$. longibrachiatum SZMC 1775 performed on Varian-MS system. The coeluting components within some peaks were identified based on $\mathrm{MS}^{2}$ experiments.

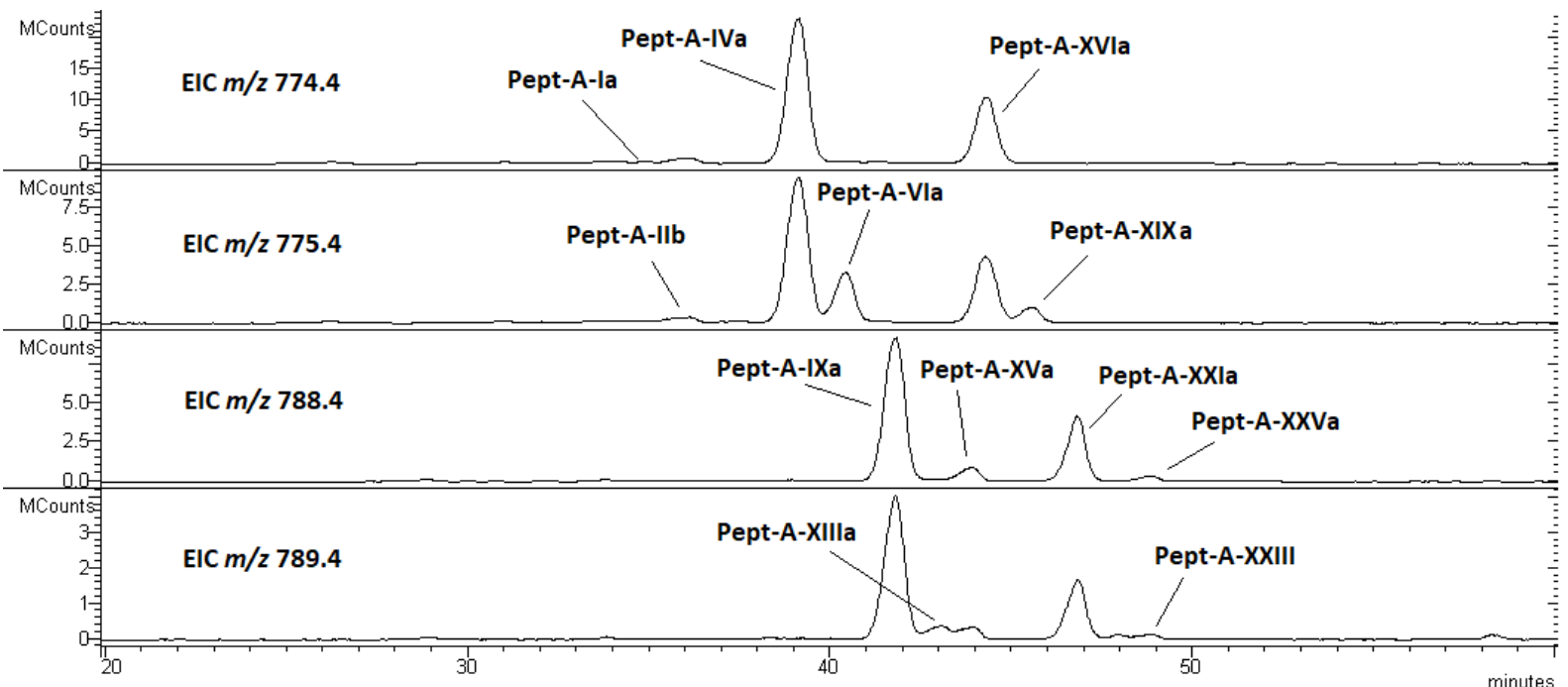

Figure 23 I EIC resulting from full scan measurements of crude extracts from $T$. bissettii SZMC 12546 performed on Varian-MS system. The coeluting components within some peaks were identified based on $\mathrm{MS}^{2}$ experiments. 


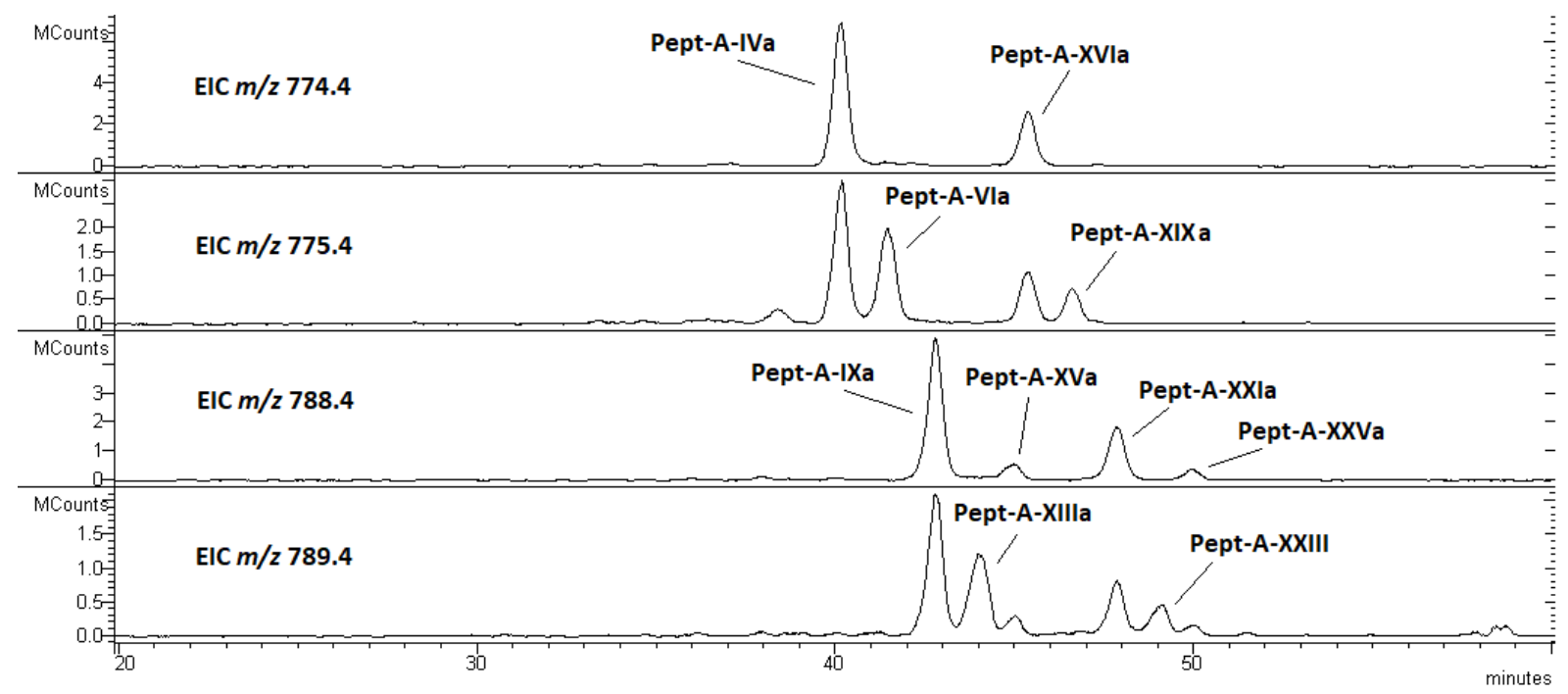

Figure 24 I EIC resulting from full scan measurements of crude extracts from $T$. capillare SZMC 22605 performed on Varian-MS system. The coeluting components within some peaks were identified based on $\mathrm{MS}^{2}$ experiments.

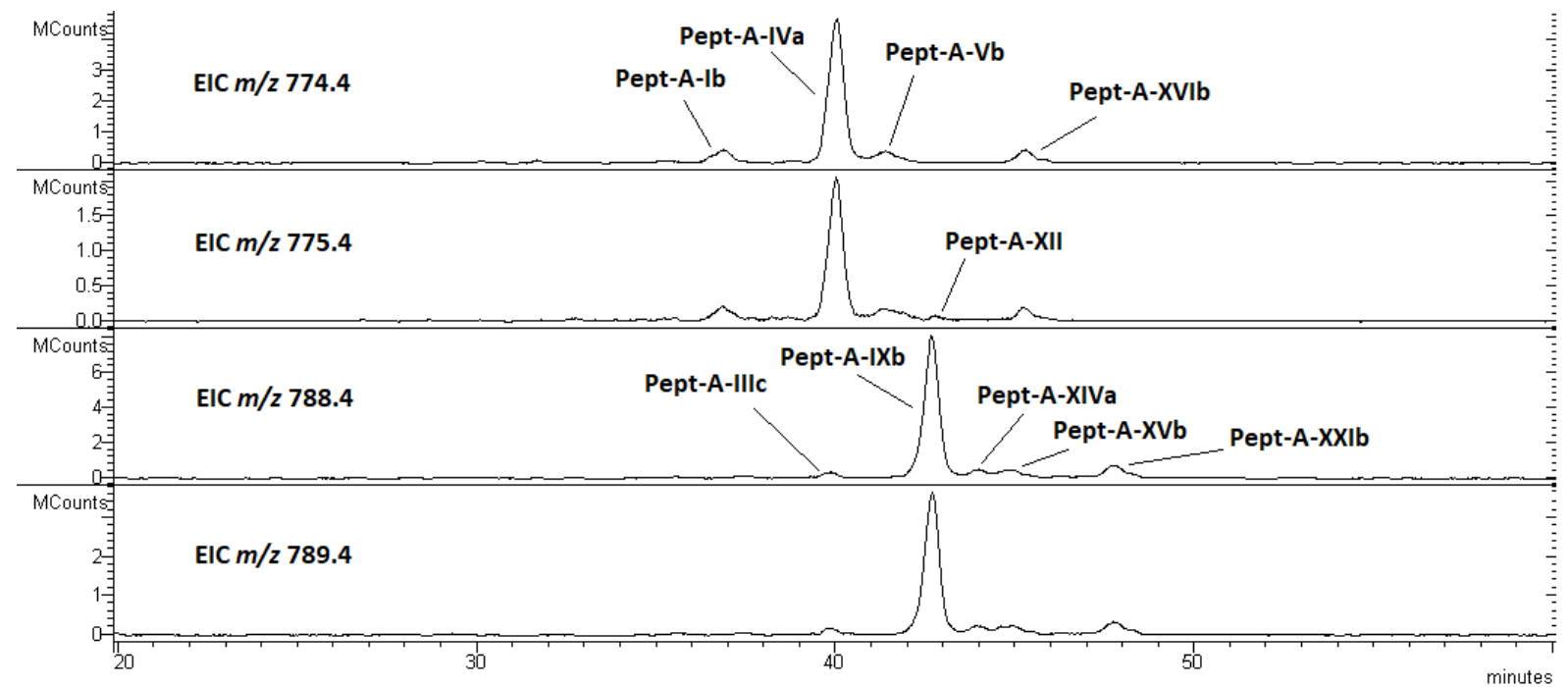

Figure 25 I EIC resulting from full scan measurements of crude extracts from $T$. novaezelandiae SZMC 22612 performed on Varian-MS system. The coeluting components within some peaks were identified based on $\mathrm{MS}^{2}$ experiments. 


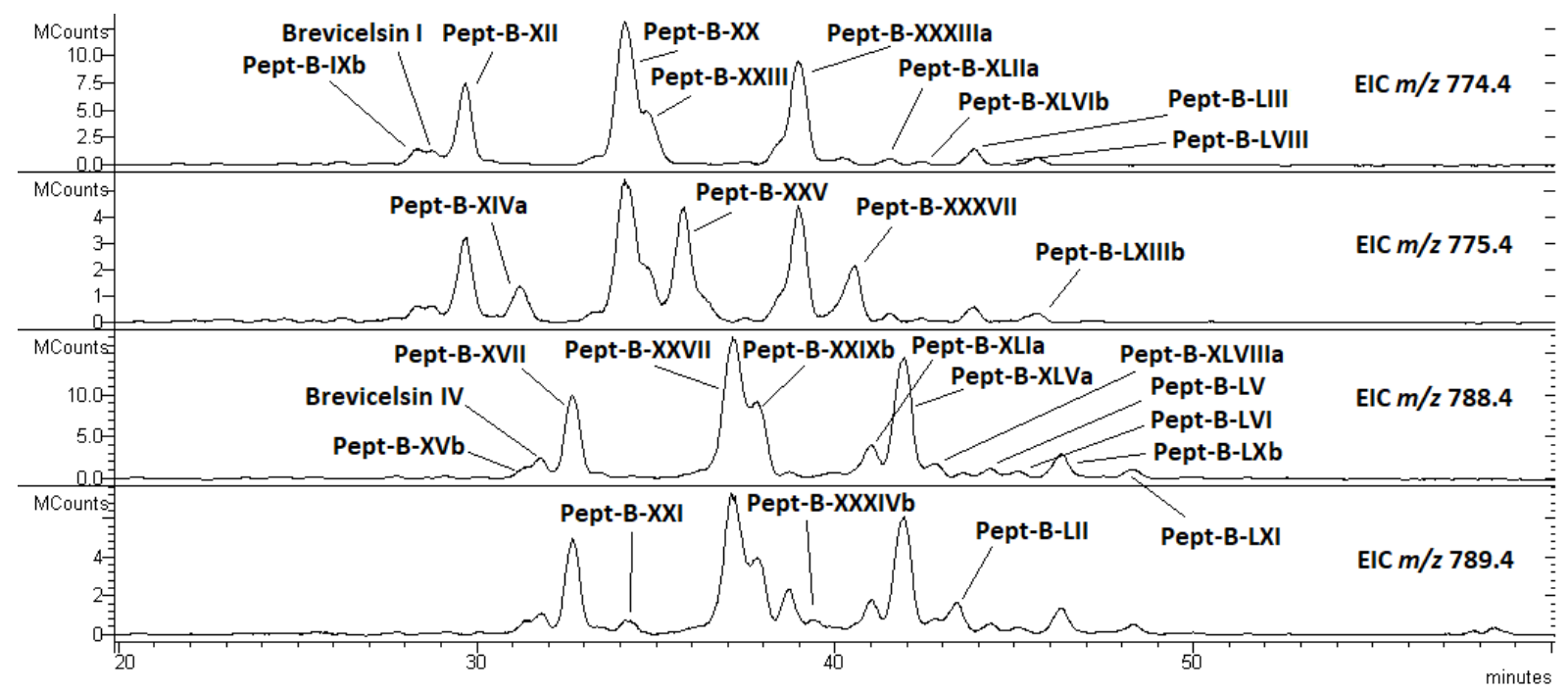

Figure 26 | EIC resulting from full scan measurements of crude extracts from $T$. parareesei SZMC 22615 performed on Varian-MS system. The coeluting components within some peaks were identified based on $\mathrm{MS}^{2}$ experiments.

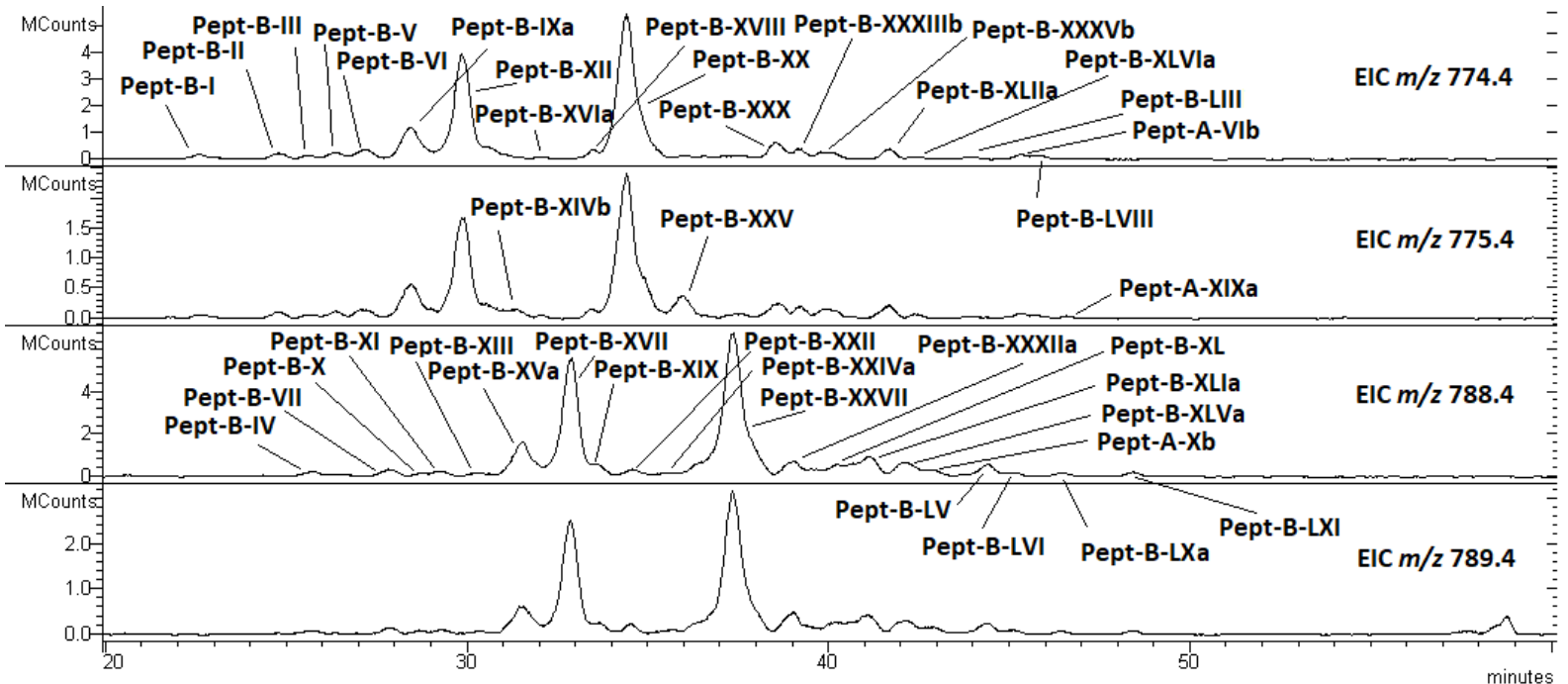

Figure 27 I EIC resulting from full scan measurements of crude extracts from $T$. reesei SZMC 22614 performed on Varian-MS system. The coeluting components within some peaks were identified based on $\mathrm{MS}^{2}$ experiments. 


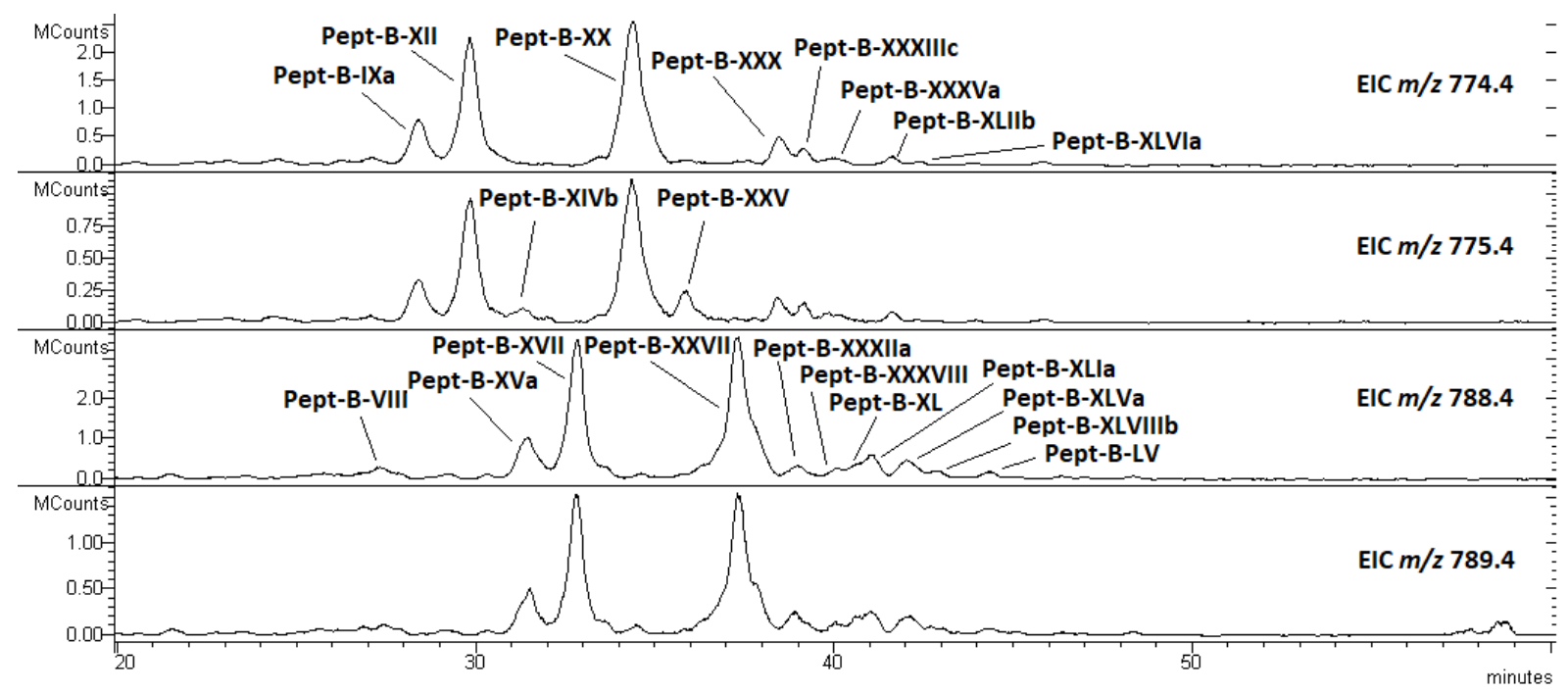

Figure 28 I EIC resulting from full scan measurements of crude extracts from $T$. reesei SZMC 22616 performed on Varian-MS system. The coeluting components within some peaks were identified based on $\mathrm{MS}^{2}$ experiments.

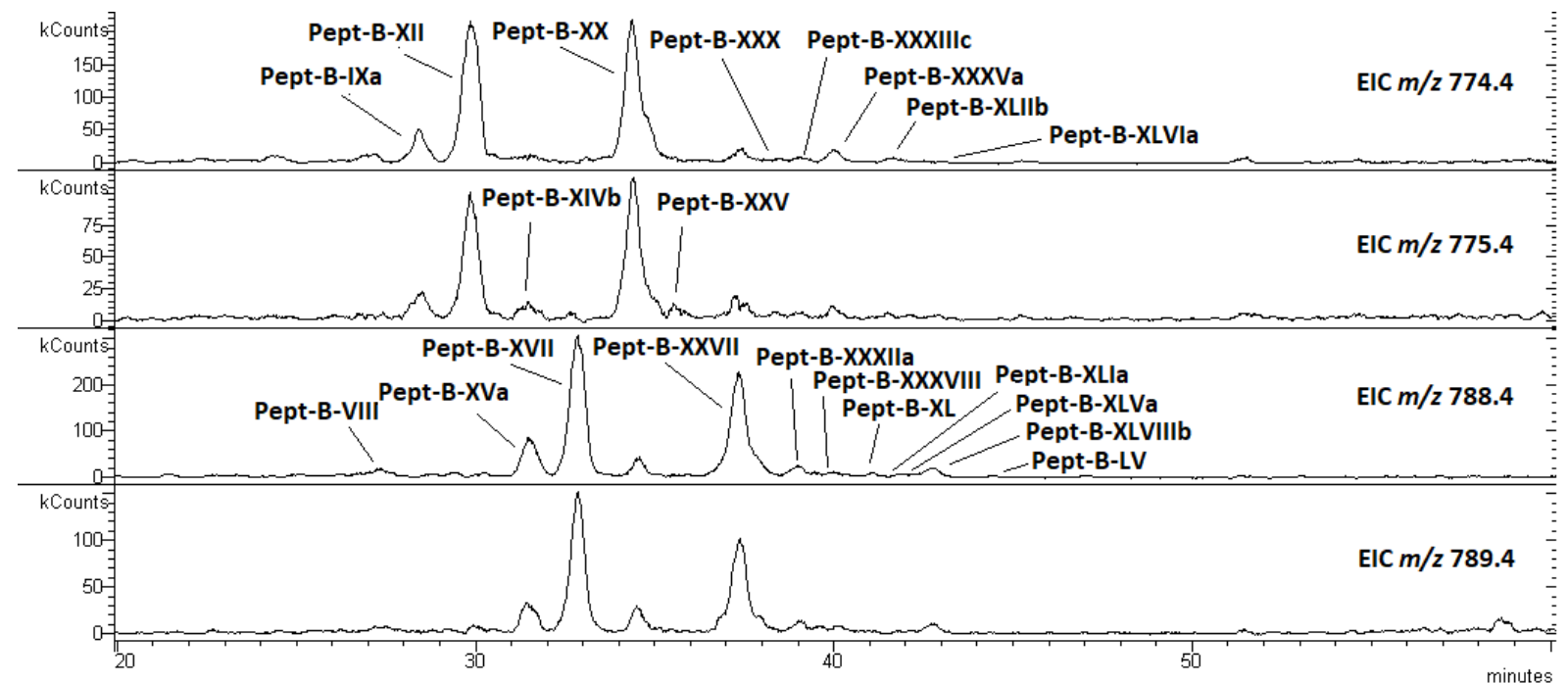

Figure 29 I EIC resulting from full scan measurements of crude extracts from $T$. reesei SZMC 22617 performed on Varian-MS system. The coeluting components within some peaks were identified based on $\mathrm{MS}^{2}$ experiments. 


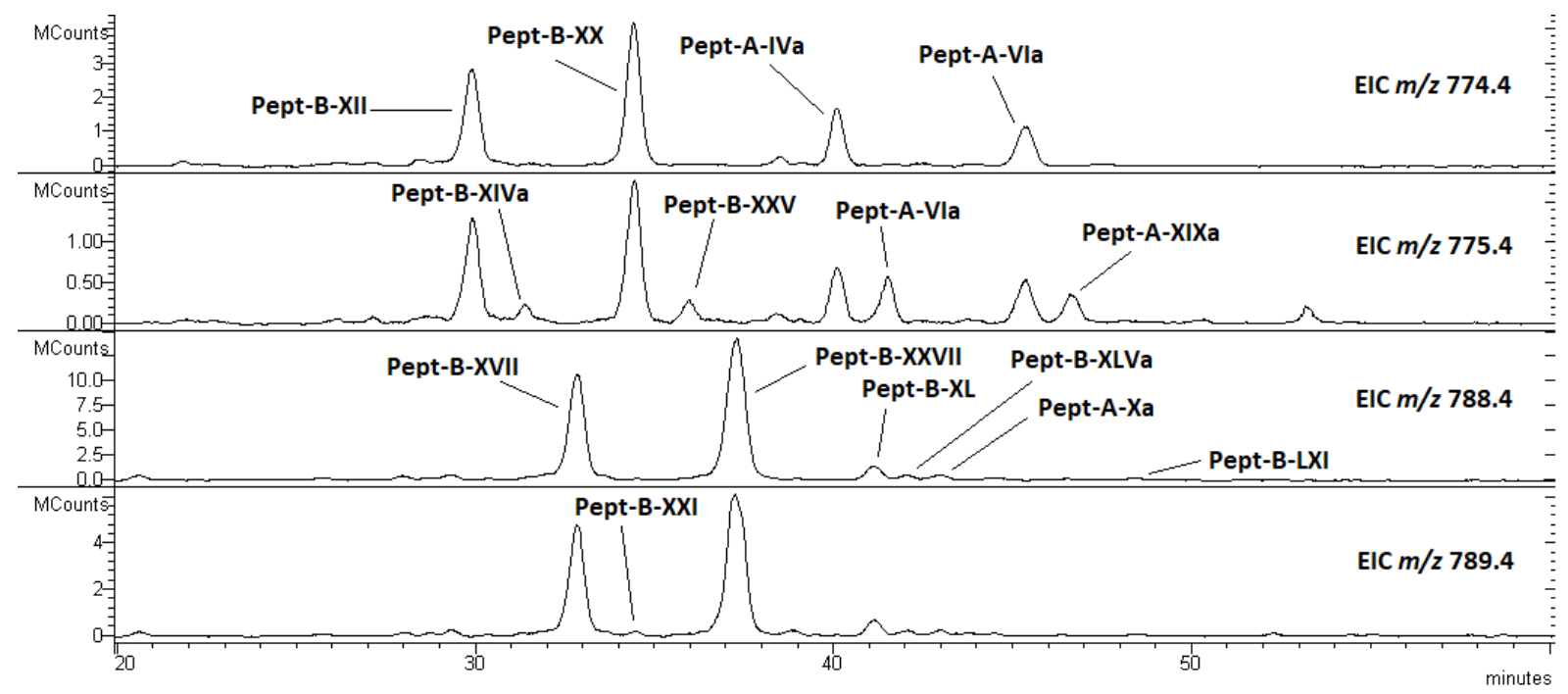

Figure 30 | EIC resulting from full scan measurements of crude extracts from $T$. saturnisporum SZMC 22606 performed on Varian-MS system. The coeluting components within some peaks were identified based on $\mathrm{MS}^{2}$ experiments.

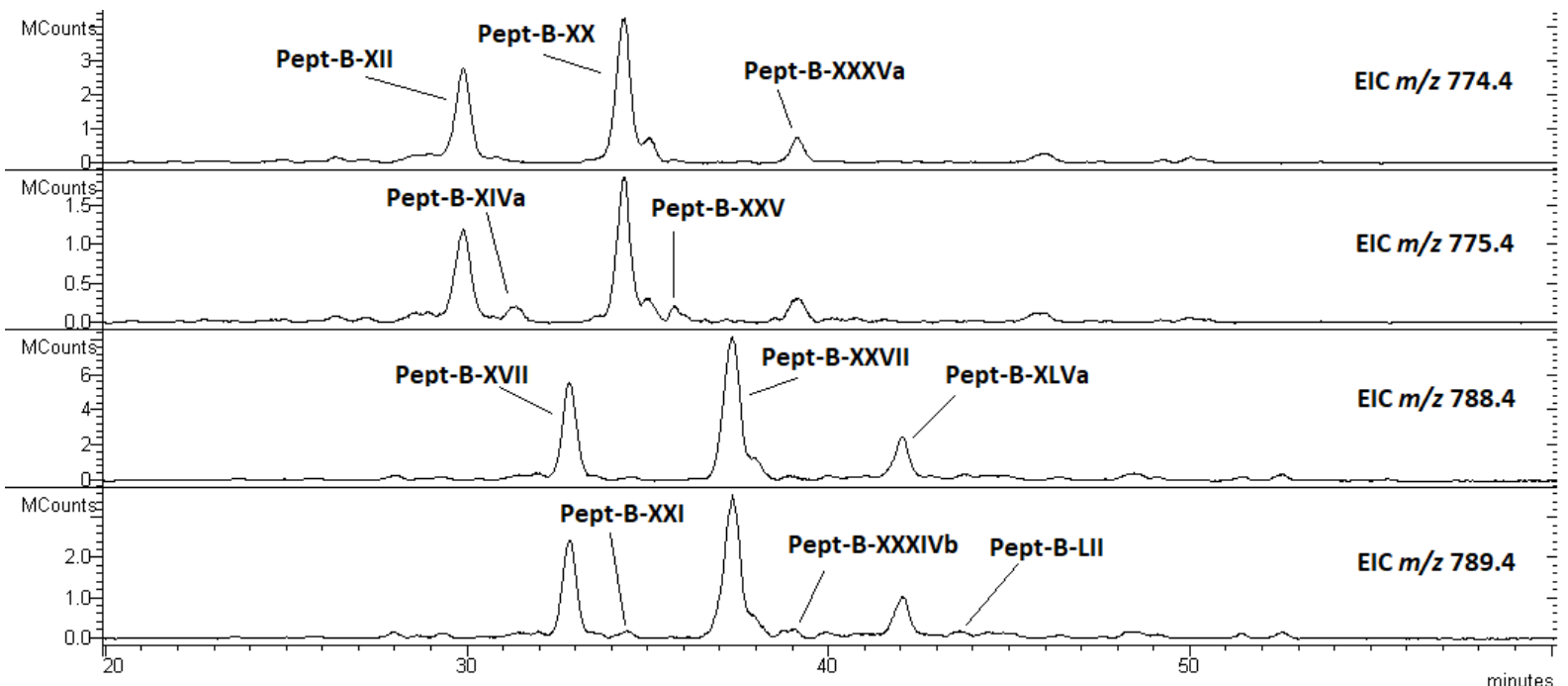

Figure 31 I EIC resulting from full scan measurements of crude extracts from T. effusum SZMC 22611 performed on Varian-MS system. The coeluting components within some peaks were identified based on $\mathrm{MS}^{2}$ experiments. 


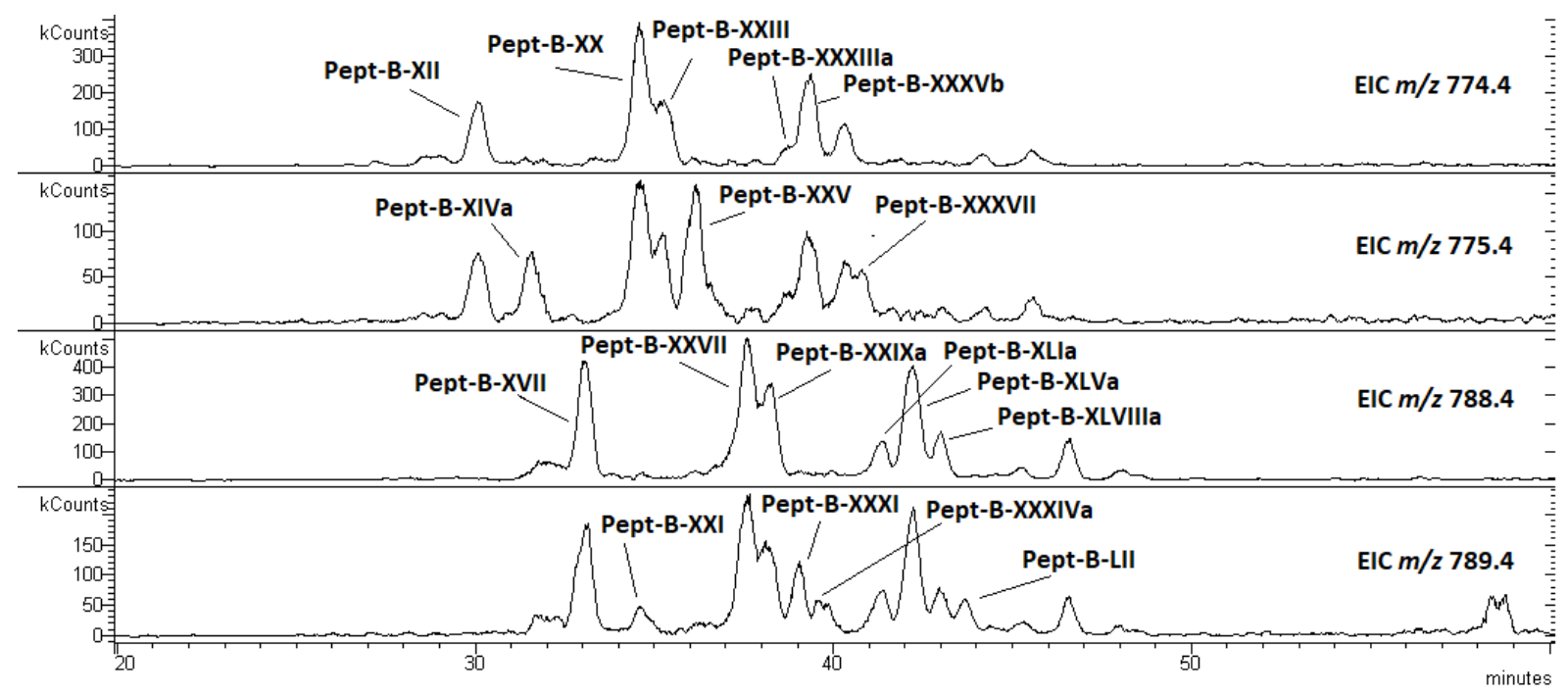

Figure 32 । EIC resulting from full scan measurements of crude extracts from $T$. andinense SZMC 22610 performed on Varian-MS system. The coeluting components within some peaks were identified based on $\mathrm{MS}^{2}$ experiments.

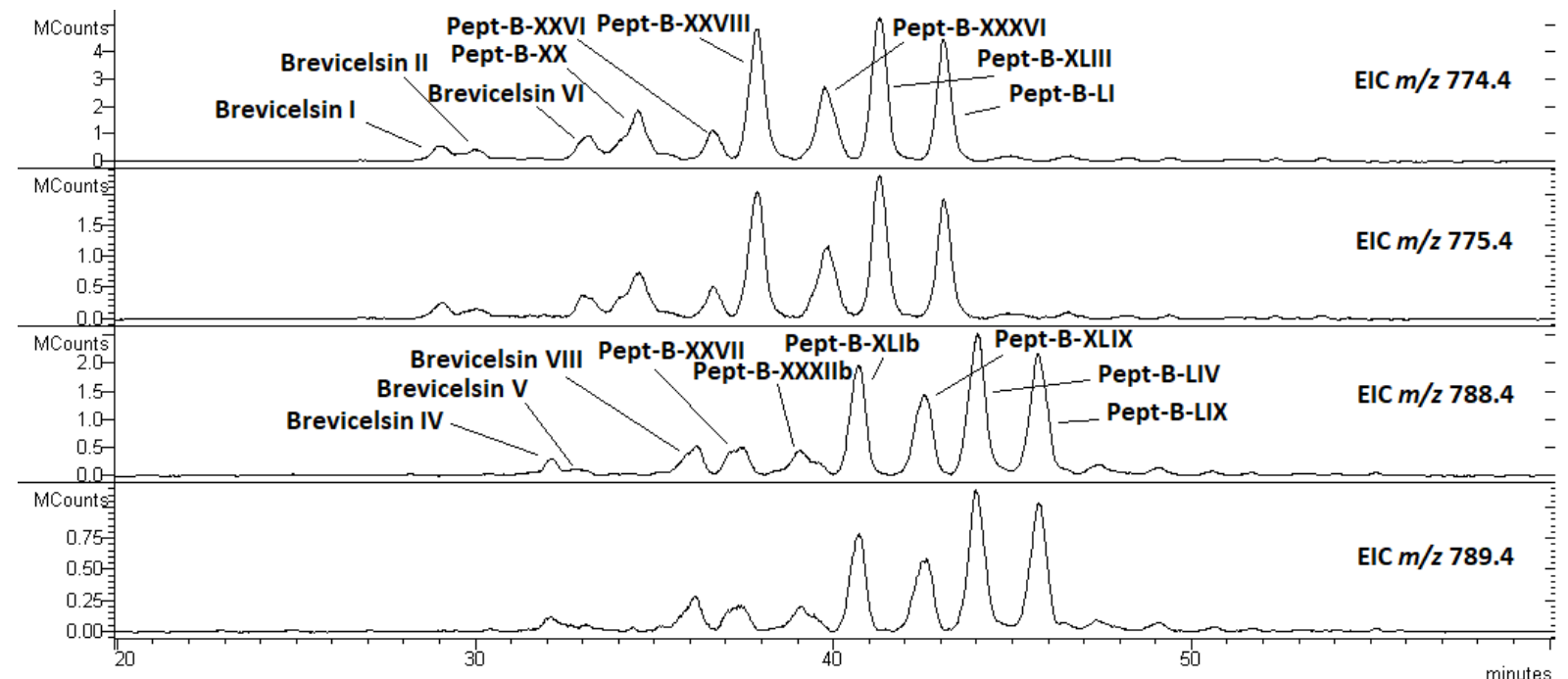

Figure 33 I EIC resulting from full scan measurements of crude extracts from $T$. sinense SZMC 22609 performed on Varian-MS system. The coeluting components within some peaks were identified based on $\mathrm{MS}^{2}$ experiments. 


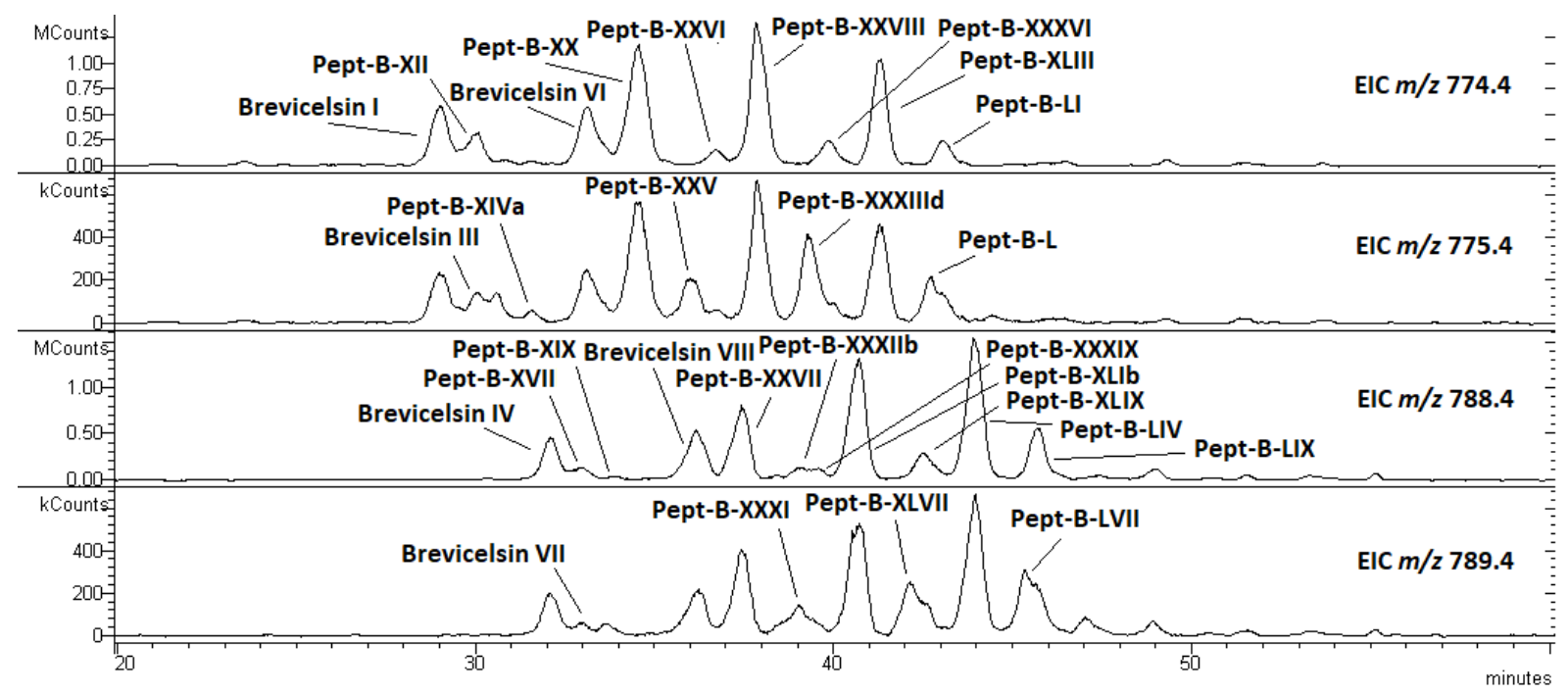

Figure 34 । EIC resulting from full scan measurements of crude extracts from $T$. flagellatum SZMC 22608 performed on Varian-MS system. The coeluting components within some peaks were identified based on $\mathrm{MS}^{2}$ experiments.

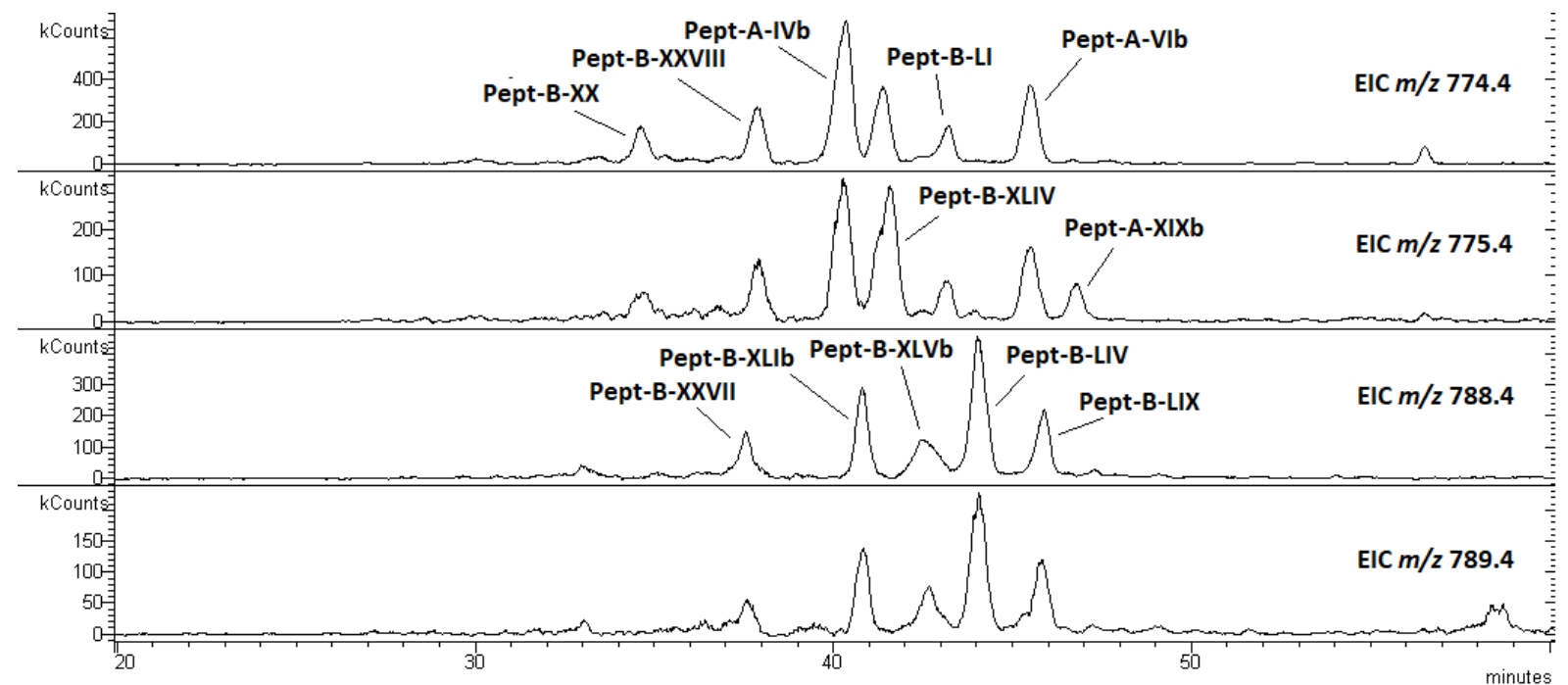

Figure 35 I EIC resulting from full scan measurements of crude extracts from $T$. konilangbra SZMC 22607 performed on Varian-MS system. The coeluting components within some peaks were identified based on $\mathrm{MS}^{2}$ experiments. 
Table 1 I Diagnostic fragment ions of peptaibols of clade Longibrachiatum peptaibol compounds of group A detected with full scan Orbitrap-MS measurement

\begin{tabular}{|c|c|c|c|c|c|c|c|c|c|c|c|c|c|c|c|c|}
\hline Peptide & M & {$[\mathbf{M}+\mathbf{H}]^{+}$} & $\mathbf{b}_{1}$ & $\mathbf{b}_{2}$ & $\mathbf{b}_{3}$ & $\mathbf{b}_{4}$ & $b_{5}$ & $b_{6}$ & $\mathbf{b}_{7}$ & $\mathbf{b}_{8}$ & $\mathbf{b}_{9}$ & $b_{10}$ & $\mathbf{b}_{11}$ & $b_{12}$ & $b_{13}$ & $\mathbf{y}_{7}$ \\
\hline Pept-A-Ia & 1922.0989 & 1923.1048 & 128.0704 & 199.1071 & 284.1598 & 355.1985 & 440.2528 & 511.2871 & n.d. & 724.3967 & 823.4642 & 894.5065 & 951.5278 & 1064.6081 & 1149.6611 & 774.4469 \\
\hline Pept-A-Ib & 1922.0989 & 1923.1048 & 128.0704 & 199.1071 & 284.1598 & 355.1985 & 440.2528 & 525.3029 & n.d. & 738.4129 & 837.4860 & 908.5167 & 965.5449 & 1064.6081 & 1149.6611 & 774.4469 \\
\hline Pept-A-IIa & 1923.0829 & 1924.0999 & 128.0704 & 199.1071 & 284.1598 & 355.1985 & 440.2528 & 511.2871 & n.d. & 724.3967 & 823.4642 & 908.5167 & 965.5449 & 1064.6081 & 1149.6611 & 775.4322 \\
\hline Pept-A-IIb & 1923.0829 & 1924.0999 & 128.0704 & 199.1071 & 284.1598 & 355.1985 & 440.2528 & 511.2871 & n.d. & 724.3967 & 823.4642 & 894.5065 & 951.5278 & 1064.6081 & 1149.6611 & 775.4322 \\
\hline Pept-A-IIIa & 1936.1146 & 1937.1206 & 128.0704 & 199.1071 & 284.1598 & 355.1985 & 440.2528 & 511.2871 & n.d. & 724.3967 & 823.4642 & 908.5167 & 965.5449 & 1064.6081 & 1149.6611 & 788.4616 \\
\hline Pept-A-IIIb & 1936.1146 & 1937.1206 & 128.0704 & 199.1071 & 284.1598 & 355.1985 & 440.2528 & 511.2871 & n.d. & 724.3967 & 823.4642 & 894.5065 & 951.5278 & 1064.6081 & 1149.6611 & 788.4616 \\
\hline Pept-A-IIIc & 1936.1146 & 1937.1206 & 128.0704 & 199.1071 & 284.1598 & 355.1985 & 440.2528 & 525.3029 & n.d. & 738.4129 & 837.4860 & 908.5167 & 965.5449 & 1064.6081 & 1149.6611 & 788.4616 \\
\hline Pept-A-IVa & 1936.1146 & 1937.1206 & 128.0704 & 199.1071 & 284.1598 & 355.1985 & 440.2528 & 511.2871 & n.d. & 724.3967 & 823.4642 & 908.5167 & 965.5449 & 1078.6224 & 1163.6769 & 774.4469 \\
\hline Pept-A-IVb & 1936.1146 & 1937.1206 & 128.0704 & 199.1071 & 284.1598 & 355.1985 & 440.2528 & 511.2871 & n.d. & 724.3967 & 837.4860 & 908.5167 & 965.5449 & 1078.6224 & 1163.6769 & 774.4469 \\
\hline Pept-A-Va & 1950.1302 & 1951.1368 & 128.0704 & 199.1071 & 284.1598 & 355.1985 & 440.2528 & 525.3029 & n.d. & 738.4129 & 837.4860 & 922.5319 & 979.5613 & 1092.6402 & 1177.6921 & 774.4469 \\
\hline Pept-A-Vb & 1950.1302 & 1951.1368 & 128.0704 & 199.1071 & 284.1598 & 355.1985 & 440.2528 & 511.2871 & n.d. & 724.3967 & 837.4860 & 922.5319 & 979.5613 & 1092.6402 & 1177.6921 & 774.4469 \\
\hline Pept-A-VIa & 1937.0986 & 1938.0984 & 128.0704 & 199.1071 & 284.1598 & 355.1985 & 440.2528 & 511.2871 & n.d. & 724.3967 & 823.4642 & 908.5167 & 965.5449 & 1078.6224 & 1163.6769 & 775.4322 \\
\hline Pept-A-VIb & 1937.0986 & 1938.0984 & 128.0704 & 199.1071 & 284.1598 & 355.1985 & 440.2528 & 511.2871 & n.d. & 724.3967 & 837.4860 & 908.5167 & 965.5449 & 1078.6224 & 1163.6769 & 775.4322 \\
\hline Pept-A-VIIa & 1936.1146 & 1937.1206 & 128.0704 & 199.1071 & 284.1598 & 355.1985 & 440.2528 & 511.2871 & n.d. & 724.3967 & 823.4642 & 908.5167 & 965.5449 & 1078.6224 & 1163.6769 & 774.4469 \\
\hline Pept-A-VIIb & 1936.1146 & 1937.1206 & 128.0704 & 199.1071 & 298.1597 & 369.2134 & 454.2668 & 525.3029 & n.d. & 738.4129 & 837.4860 & 908.5167 & 965.5449 & 1078.6224 & 1163.6769 & 774.4469 \\
\hline Pept-A-VIIIa & 1950.1302 & 1951.1368 & 128.0704 & 199.1071 & 298.1597 & 369.2134 & 454.2668 & 525.3029 & n.d. & 738.4129 & 851.4953 & 922.5319 & 979.5613 & 1092.6402 & 1177.6921 & 774.4469 \\
\hline Pept-A-VIIIb & 1950.1302 & 1951.1368 & 128.0704 & 199.1071 & 298.1597 & 369.2134 & 454.2668 & 525.3029 & n.d. & 738.4129 & 837.4860 & 922.5319 & 979.5613 & 1092.6402 & 1177.6921 & 774.4469 \\
\hline Pept-A-IXa & 1950.1302 & 1951.1368 & 128.0704 & 199.1071 & 284.1598 & 355.1985 & 440.2528 & 511.2871 & n.d. & 724.3967 & 823.4642 & 908.5167 & 965.5449 & 1078.6224 & 1163.6769 & 788.4616 \\
\hline Pept-A-IXb & 1950.1302 & 1951.1368 & 128.0704 & 199.1071 & 284.1598 & 355.1985 & 440.2528 & 511.2871 & n.d. & 724.3967 & 837.4860 & 908.5167 & 965.5449 & 1078.6224 & 1163.6769 & 788.4616 \\
\hline Pept-A-Xa & 1964.1459 & 1965.1522 & 128.0704 & 199.1071 & 284.1598 & 355.1985 & 440.2528 & 525.3029 & n.d. & 738.4129 & 837.4860 & 922.5319 & 979.5613 & 1092.6402 & 1177.6921 & 788.4616 \\
\hline Pept-A-Xb & 1964.1459 & 1965.1522 & 128.0704 & 199.1071 & 284.1598 & 355.1985 & 440.2528 & 511.2871 & n.d. & 724.3967 & 837.4860 & 922.5319 & 979.5613 & 1092.6402 & 1177.6921 & 788.4616 \\
\hline Pept-A-XIa & 1951.1143 & 1952.1302 & 128.0704 & 199.1071 & 298.1597 & 369.2134 & 454.2668 & 525.3029 & n.d. & 738.4129 & 837.4860 & 922.5319 & 979.5613 & 1092.6402 & 1177.6921 & 775.4322 \\
\hline Pept-A-XIb & 1951.1143 & 1952.1302 & 128.0704 & 199.1071 & 284.1598 & 355.1985 & 440.2528 & 525.3029 & n.d. & 738.4129 & 837.4860 & 922.5319 & 979.5613 & 1092.6402 & 1177.6921 & 775.4322 \\
\hline Pept-A-XIc & 1951.1143 & 1952.1302 & 128.0704 & 199.1071 & 298.1597 & 369.2134 & 454.2668 & 525.3029 & n.d. & 738.4129 & 851.4953 & 922.5319 & 979.5613 & 1092.6402 & 1177.6921 & 775.4322 \\
\hline Pept-A-XII & 1937.0986 & 1938.0984 & 128.0704 & 199.1071 & 284.1598 & 355.1985 & 440.2528 & 511.2871 & n.d. & 724.3967 & 837.4860 & 908.5167 & 965.5449 & 1078.6224 & 1163.6769 & 775.4322 \\
\hline Pept-A-XIIIa & 1951.1143 & 1952.1302 & 128.0704 & 199.1071 & 284.1598 & 355.1985 & 440.2528 & 511.2871 & n.d. & 724.3967 & 823.4642 & 908.5167 & 965.5449 & 1078.6224 & 1163.6769 & 789.4509 \\
\hline
\end{tabular}


Table 1 I continued

\begin{tabular}{|c|c|c|c|c|c|c|c|c|c|c|c|c|c|c|c|c|}
\hline Peptide & $\mathbf{M}$ & {$[\mathbf{M}+\mathbf{H}]^{+}$} & $\mathbf{b}_{1}$ & $\mathbf{b}_{2}$ & $\mathbf{b}_{3}$ & $\mathbf{b}_{4}$ & $b_{5}$ & $b_{6}$ & $\mathbf{b}_{7}$ & $\mathbf{b}_{8}$ & $\mathbf{b}_{9}$ & $\mathbf{b}_{10}$ & $b_{11}$ & $b_{12}$ & $b_{13}$ & $\mathbf{y}_{7}$ \\
\hline Pept-A-XIIIb & 1951.1143 & 1952.1302 & 128.0704 & 199.1071 & 284.1598 & 355.1985 & 440.2528 & 511.2871 & n.d. & 724.3967 & 837.4860 & 908.5167 & 965.5449 & 1078.6224 & 1163.6769 & 789.4509 \\
\hline Pept-A-XIVa & 1965.1299 & 1966.1444 & 128.0704 & 199.1071 & 284.1598 & 355.1985 & 440.2528 & 525.3029 & n.d. & 738.4129 & 851.4953 & 922.5319 & 979.5613 & 1092.6402 & 1177.6921 & 789.4509 \\
\hline Pept-A- XIVb & 1964.1459 & 1965.1522 & 128.0704 & 199.1071 & 284.1598 & 355.1985 & 440.2528 & 525.3029 & n.d. & 738.4129 & 837.4860 & 922.5319 & 979.5613 & 1092.6402 & 1177.6921 & 788.4616 \\
\hline Pept-A-XVa & 1950.1302 & 1951.1368 & 128.0704 & 199.1071 & 284.1598 & 355.1985 & 440.2528 & 511.2871 & n.d. & 724.3967 & 823.4642 & 908.5167 & 965.5449 & 1078.6224 & 1163.6769 & 788.4616 \\
\hline Pept-A-XVb & 1964.1459 & 1965.1522 & 128.0704 & 199.1071 & 284.1598 & 355.1985 & 440.2528 & 525.3029 & n.d. & 738.4129 & 851.4953 & 922.5319 & 979.5613 & 1092.6402 & 1177.6921 & 788.4616 \\
\hline Pept-A-XVIa & 1950.1302 & 1951.1368 & 128.0704 & 199.1071 & 284.1598 & 355.1985 & 440.2528 & 525.3029 & n.d. & 738.4129 & 837.4860 & 922.5319 & 979.5613 & 1092.6402 & 1177.6921 & 774.4469 \\
\hline Pept-A-XVIb & 1950.1302 & 1951.1368 & 128.0704 & 199.1071 & 284.1598 & 355.1985 & 440.2528 & 525.3029 & n.d. & 738.4129 & 851.4953 & 922.5319 & 979.5613 & 1092.6402 & 1177.6921 & 774.4469 \\
\hline Pept-A-XVIIa & 1964.1459 & 1965.1522 & 128.0704 & 199.1071 & 284.1598 & 355.1985 & 440.2528 & 525.3029 & n.d. & 738.4129 & 837.4860 & 922.5319 & 979.5613 & 1092.6402 & 1177.6921 & 788.4616 \\
\hline Pept-A-XVIIb & 1950.1302 & 1951.1368 & 128.0704 & 199.1071 & 284.1598 & 355.1985 & 440.2528 & 511.2871 & n.d. & 724.3967 & 823.4642 & 908.5167 & 965.5449 & 1078.6224 & 1163.6769 & 788.4616 \\
\hline Pept-A-XVIII & 1978.1615 & 1979.1713 & 128.0704 & 199.1071 & 298.1597 & 369.2134 & 454.2668 & 539.3186 & n.d. & 752.4301 & 851.4953 & 936.5563 & 993.5684 & 1106.6547 & 1191.7080 & 788.4616 \\
\hline Pept-A-XIXa & 1951.1143 & 1952.1302 & 128.0704 & 199.1071 & 284.1598 & 355.1985 & 440.2528 & 525.3029 & n.d. & 738.4129 & 837.4860 & 922.5319 & 979.5613 & 1092.6402 & 1177.6921 & 775.4322 \\
\hline Pept-A-XIXb & 1951.1143 & 1952.1302 & 128.0704 & 199.1071 & 284.1598 & 355.1985 & 440.2528 & 525.3029 & n.d. & 738.4129 & 851.4953 & 922.5319 & 979.5613 & 1092.6402 & 1177.6921 & 775.4322 \\
\hline Pept-A-XX & 1964.1459 & 1965.1522 & 128.0704 & 199.1071 & 298.1597 & 369.2134 & 454.2668 & 539.3186 & n.d. & 752.4301 & 851.4953 & 936.5563 & 993.5867 & 1106.6547 & 1191.7080 & 774.4469 \\
\hline Pept-A-XXIa & 1964.1459 & 1965.1522 & 128.0704 & 199.1071 & 284.1598 & 355.1985 & 440.2528 & 525.3029 & n.d. & 738.4129 & 837.4860 & 922.5319 & 979.5613 & 1092.6402 & 1177.6921 & 788.4616 \\
\hline Pept-A-XXIb & 1964.1459 & 1965.1522 & 128.0704 & 199.1071 & 284.1598 & 355.1985 & 440.2528 & 525.3029 & n.d. & 738.4129 & 851.4953 & 922.5319 & 979.5613 & 1092.6402 & 1177.6921 & 788.4616 \\
\hline Pept-A-XXIIa & 1964.1459 & 1965.1522 & 128.0704 & 199.1071 & 298.1597 & 369.2134 & 454.2668 & 539.3186 & n.d. & 752.4301 & 851.4953 & 936.5563 & 993.5684 & 1106.6547 & 1191.7080 & 774.4469 \\
\hline Pept-A-XXIIb & 1964.1459 & 1965.1522 & 128.0704 & 199.1071 & 284.1598 & 355.1985 & 440.2528 & 525.3029 & n.d. & 738.4129 & 851.4953 & 936.5563 & 993.5684 & 1106.6547 & 1191.7080 & 774.4469 \\
\hline Pept-A-XXIII & 1965.1299 & 1966.1444 & 128.0704 & 199.1071 & 284.1598 & 355.1985 & 440.2528 & 525.3029 & n.d. & 738.4129 & 837.4860 & 922.5319 & 979.5613 & 1092.6402 & 1177.6921 & 789.4509 \\
\hline Pept-A-XXIV & 1978.1615 & 1979.1713 & 128.0706 & 199.1072 & 298.1597 & 369.2134 & 454.2668 & 539.3186 & n.d. & 752.4301 & 851.4953 & 936.5563 & 993.5684 & 1106.6547 & 1191.7080 & 788.4616 \\
\hline Pept-A-XXVa & 1964.1459 & 1965.1522 & 128.0704 & 199.1071 & 284.1598 & 355.1985 & 440.2528 & 525.3029 & n.d. & 738.4129 & 837.4860 & 922.5319 & 979.5613 & 1092.6402 & 1177.6921 & 788.4616 \\
\hline Pept-A-XXVb & 1978.1615 & 1979.1713 & 128.0704 & 199.1071 & 284.1598 & 355.1985 & 440.2528 & 525.3029 & n.d. & 738.4129 & 851.4953 & 936.5563 & 993.5684 & 1106.6547 & 1191.7080 & 788.4616 \\
\hline Pept-A-XXVIa & 1978.1615 & 1979.1713 & 128.0704 & 199.1071 & 298.1597 & 369.2134 & 454.2668 & 539.3186 & n.d. & 752.4301 & 851.4953 & 936.5563 & 993.5684 & 1106.6547 & 1191.7080 & 788.4616 \\
\hline $\begin{array}{l}\text { Pept-A- } \\
\text { XXVIb }\end{array}$ & 1978.1615 & 1979.1713 & 128.0704 & 199.1071 & 284.1598 & 355.1985 & 440.2528 & 525.3029 & n.d. & 738.4129 & 851.4953 & 936.5563 & 993.5684 & 1106.6547 & 1191.7080 & 788.4616 \\
\hline $\begin{array}{l}\text { Pept-A- } \\
\text { XXVIIa }\end{array}$ & 1965.1299 & 1966.1444 & 128.0704 & 199.1071 & 284.1598 & 355.1985 & 440.2528 & 525.3029 & n.d. & 738.4129 & 837.4860 & 922.5319 & 979.5613 & 1092.6402 & 1177.6921 & 789.4509 \\
\hline $\begin{array}{l}\text { Pept-A- } \\
\text { XXVIIb }\end{array}$ & 1978.1615 & 1979.1713 & 128.0704 & 199.1071 & 284.1598 & 355.1985 & 440.2528 & 525.3029 & n.d. & 738.4129 & 851.4953 & 936.5563 & 993.5684 & 1106.6547 & 1191.7080 & 788.4616 \\
\hline
\end{tabular}

n.d.: not detected 
Table 2 I Diagnostic fragment ions of peptaibols of clade Longibrachiatum peptaibols of group B detected with full scan Orbitrap-MS measurement

\begin{tabular}{|c|c|c|c|c|c|c|c|c|c|c|c|c|c|c|c|c|}
\hline Peptide & $\mathbf{M}$ & {$[\mathbf{M}+\mathbf{H}]^{+}$} & $b_{1}$ & $\mathbf{b}_{2}$ & $\mathbf{b}_{3}$ & $\mathbf{b}_{4}$ & $b_{5}$ & $b_{6}$ & $\mathbf{b}_{7}$ & $\mathbf{b}_{8}$ & $\mathbf{b}_{9}$ & $b_{10}$ & $b_{11}$ & $b_{12}$ & $\mathbf{b}_{13}$ & $\mathbf{y}_{7}$ \\
\hline Pept-B-I & 1908.0833 & 1909.0897 & 128.0704 & 199.1071 & 270.1443 & 341.1819 & 426.2344 & 497.2745 & n.d. & 710.3871 & 823.4642 & 908.5167 & 965.5449 & 1050.5927 & 1135.6458 & 774.4469 \\
\hline Pept-B-II & 1908.0833 & 1909.0897 & 128.0704 & 199.1071 & 270.1443 & 341.1819 & 426.2344 & 497.2745 & n.d. & 710.3871 & 823.4642 & 908.5167 & 965.5449 & 1050.5927 & 1135.6458 & 774.4469 \\
\hline Pept-B-III & 1908.0833 & 1909.0897 & 128.0704 & 199.1071 & 270.1443 & 341.1819 & 426.2344 & 497.2745 & n.d. & 710.3871 & 823.4642 & 908.5167 & 965.5449 & 1050.5927 & 1135.6458 & 774.4469 \\
\hline Pept-B-IV & 1922.0989 & 1923.1048 & 128.0704 & 199.1071 & 270.1443 & 341.1819 & 426.2344 & 497.2745 & n.d. & 710.3871 & 823.4642 & 908.5167 & 965.5449 & 1050.5927 & 1135.6458 & 788.4616 \\
\hline Pept-B-V & 1908.0833 & 1909.0897 & 128.0704 & 199.1071 & 270.1443 & 341.1819 & 426.2344 & 497.2745 & n.d. & 710.4143 & 823.4719 & 908.5167 & 965.5449 & 1050.5927 & 1135.6458 & 774.4469 \\
\hline Pept-B-VI & 1922.0989 & 1923.1048 & 128.0704 & 199.1071 & 284.1598 & 355.1985 & 440.2505 & 511.2871 & n.d. & 724.3967 & 837.4860 & 922.5308 & 979.5613 & 1064.6081 & 1149.6611 & 774.4469 \\
\hline Pept-B-VII & 1922.0989 & 1923.1048 & 128.0704 & 199.1071 & 270.1443 & 341.1819 & 426.2344 & 497.2745 & n.d. & 710.3871 & 823.4642 & 908.5167 & 965.5449 & 1050.5927 & 1135.6458 & 788.4616 \\
\hline Pept-B-VIII & 1936.1146 & 1937.1206 & 128.0704 & 199.1071 & 284.1598 & 355.1985 & 440.2528 & 511.2871 & n.d. & 724.3967 & 837.4860 & 922.5319 & 979.5613 & 1064.6081 & 1149.6611 & 788.4616 \\
\hline Pept-B-IXa & 1908.0833 & 1909.0897 & 128.0704 & 199.1071 & 284.1598 & 355.1985 & 440.2528 & 511.2871 & n.d. & 724.3967 & 823.4642 & 908.5167 & 965.5449 & 1050.5927 & 1135.6458 & 774.4469 \\
\hline Pept-B-IXb & 1909.0986 & 1909.0897 & 128.0704 & 199.1071 & 284.1598 & 355.1985 & 440.2528 & 511.2871 & n.d. & 724.3967 & 837.4860 & 922.5319 & 979.5613 & 1050.5927 & 1135.6458 & 774.4469 \\
\hline Pept-B-X & 1922.0989 & 1923.1048 & 128.0704 & 199.1071 & 284.1598 & 355.1985 & 440.2528 & 511.2871 & n.d. & 724.3967 & 823.4642 & 908.5167 & 965.5449 & 1050.5927 & 1135.6458 & 788.4616 \\
\hline Pept-B-XI & 1922.0989 & 1923.1048 & 128.0704 & 199.1071 & 284.1598 & 355.1985 & 440.2528 & 511.2871 & n.d. & 724.3967 & 823.4642 & 908.5167 & 965.5449 & 1050.5927 & 1135.6458 & 788.4616 \\
\hline Pept-B-XII & 1922.0989 & 1923.1048 & 128.0704 & 199.1071 & 284.1598 & 355.1985 & 440.2528 & 511.2871 & n.d. & 724.3967 & 837.4860 & 922.5319 & 979.5613 & 1064.6081 & 1149.6611 & 774.4469 \\
\hline Pept-B-XIII & 1922.0989 & 1923.1048 & 128.0704 & 199.1071 & 284.1598 & 355.1985 & 440.2528 & 511.2871 & n.d. & 724.3967 & 823.4642 & 908.5167 & 965.5449 & 1050.5927 & 1135.6458 & 788.4616 \\
\hline Pept-B-XIVa & 1923.0829 & 1924.0999 & 128.0704 & 199.1071 & 284.1598 & 355.1985 & 440.2528 & 511.2871 & n.d. & 724.3967 & 837.4860 & 922.5319 & 979.5613 & 1064.6081 & 1149.6611 & 775.4322 \\
\hline Pept-B-XIVb & 1923.0829 & 1924.0999 & 128.0704 & 199.1071 & 284.1598 & 355.1985 & 440.2528 & 525.3029 & n.d. & 738.4078 & 837.4860 & 922.5319 & 979.5613 & 1064.6081 & 1149.6611 & 775.4322 \\
\hline Pept-B-XVa & 1922.0989 & 1923.1048 & 128.0704 & 199.1071 & 284.1598 & 355.1985 & 440.2528 & 511.2871 & n.d. & 724.3967 & 823.4642 & 908.5167 & 965.5449 & 1050.5927 & 1135.6458 & 788.4616 \\
\hline Pept-B-XVb & 1922.0989 & 1923.1048 & 128.0704 & 199.1071 & 284.1598 & 355.1985 & 440.2528 & 511.2871 & n.d. & 724.3967 & 837.4860 & 922.5319 & 979.5613 & 1050.5927 & 1135.6458 & 788.4616 \\
\hline Pept-B-XVI & 1922.0989 & 1923.1048 & 128.0704 & 199.1071 & 284.1598 & 355.1985 & 440.2528 & 525.3029 & n.d. & 738.4129 & 837.4860 & 922.5319 & 979.5613 & 1064.6081 & 1149.6611 & 774.4469 \\
\hline Pept-B-XVII & 1936.1146 & 1937.1206 & 128.0704 & 199.1071 & 284.1598 & 355.1985 & 440.2528 & 511.2871 & n.d. & 724.3967 & 837.4860 & 922.5319 & 979.5613 & 1064.6081 & 1149.6611 & 788.4616 \\
\hline Pept-B-XVIII & 1923.1067 & 1924.0999 & 128.0704 & 199.1071 & 284.1598 & 355.1985 & 440.2528 & 511.2871 & n.d. & 724.3967 & 837.4860 & 922.5319 & 979.5613 & 1064.6081 & 1149.6611 & 774.4469 \\
\hline Pept-B-XIX & 1936.1146 & 1937.1206 & 128.0704 & 199.1071 & 284.1598 & 355.1985 & 440.2528 & 511.2871 & n.d. & 724.3967 & 837.4860 & 922.5319 & 979.5613 & 1064.6081 & 1149.6611 & 788.4616 \\
\hline Pept-B-XX & 1936.1146 & 1937.1206 & 128.0704 & 199.1071 & 284.1598 & 355.1985 & 440.2528 & 525.3029 & n.d. & 738.4129 & 851.4953 & 936.5465 & 993.5684 & 1078.6224 & 1163.6769 & 774.4469 \\
\hline Pept-B-XXI & 1937.0986 & 1938.0984 & 128.0704 & 199.1071 & 284.1598 & 355.1985 & 440.2528 & 511.2871 & n.d. & 724.3967 & 837.4860 & 922.5319 & 979.5613 & 1064.6081 & 1149.6611 & 789.4509 \\
\hline Pept-B-XXII & 1936.1146 & 1937.1206 & 128.0704 & 199.1071 & 284.1598 & 355.1985 & 440.2528 & 511.2871 & n.d. & 724.3967 & 837.4860 & 922.5319 & 979.5613 & 1064.6081 & 1149.6611 & 788.4616 \\
\hline Pept-B-XXIII & 1922.0989 & 1923.1048 & 128.0704 & 199.1071 & 284.1598 & 355.1985 & 440.2528 & 511.2871 & n.d. & 724.3967 & 837.4860 & 922.5319 & 979.5613 & 1064.6081 & 1149.6611 & 774.4469 \\
\hline
\end{tabular}


Table 2 | continued

\begin{tabular}{|c|c|c|c|c|c|c|c|c|c|c|c|c|c|c|c|c|}
\hline Peptide & $\mathbf{M}$ & {$[\mathbf{M}+\mathbf{H}]^{+}$} & $\mathbf{b}_{1}$ & $\mathbf{b}_{2}$ & $\mathbf{b}_{3}$ & $\mathbf{b}_{4}$ & $\mathbf{b}_{5}$ & $b_{6}$ & $\mathbf{b}_{7}$ & $\mathbf{b}_{8}$ & $\mathbf{b}_{9}$ & $\mathbf{b}_{10}$ & $b_{11}$ & $b_{12}$ & $\mathbf{b}_{13}$ & $\mathbf{y}_{7}$ \\
\hline Pept-B-XXIV & 1950.1302 & 1951.1368 & 128.0704 & 199.1071 & 284.1598 & 355.1985 & 440.2528 & 525.3029 & n.d. & 738.4129 & 851.5267 & 936.5563 & 993.5684 & 1078.6224 & 1163.6755 & 788.4616 \\
\hline Pept-B-XXV & 1937.0986 & 1938.0984 & 128.0704 & 199.1071 & 284.1598 & 355.1985 & 440.2528 & 525.3029 & n.d. & 738.4129 & 851.4953 & 936.5563 & 993.5684 & 1078.6224 & 1163.6769 & 775.4322 \\
\hline Pept-B-XXVI & 1950.1302 & 1951.1368 & 128.0704 & 199.1071 & 298.1756 & 369.2134 & 454.2668 & 539.3186 & n.d. & 752.4368 & 865.5170 & 950.5699 & 1007.5874 & 1092.6402 & 1177.6921 & 774.4469 \\
\hline Pept-B-XXVII & 1950.1302 & 1951.1368 & 128.0704 & 199.1071 & 284.1598 & 355.1985 & 440.2528 & 525.3029 & n.d. & 738.4129 & 851.4953 & 936.5563 & 993.5684 & 1078.6224 & 1163.6769 & 788.4616 \\
\hline Pept-B-XXVIII & 1950.1302 & 1951.1368 & 128.0704 & 199.1071 & 284.1598 & 355.1985 & 454.2668 & 539.3186 & n.d. & 752.4301 & 865.5170 & 950.5699 & 1007.5874 & 1092.6402 & 1177.6921 & 774.4469 \\
\hline Pept-B-XXIXa & 1936.1146 & 1937.1206 & 128.0704 & 199.1071 & 284.1598 & 355.1985 & 440.2528 & 525.3029 & n.d. & 738.4129 & 851.4953 & 922.5319 & 979.5613 & 1064.6081 & 1149.6611 & 788.4616 \\
\hline Pept-B-XXIXb & 1936.1146 & 1937.1206 & 128.0704 & 199.1071 & 284.1598 & 355.1985 & 440.2528 & 511.2871 & n.d. & 724.3967 & 837.4860 & 922.5319 & 979.5613 & 1064.6081 & 1149.6611 & 788.4616 \\
\hline Pept-B-XXX & 1950.1302 & 1951.1368 & 128.0704 & 199.1071 & 284.1598 & 355.1985 & 440.2528 & 525.3029 & n.d. & 738.4129 & 851.4953 & 936.5563 & 993.5684 & 1092.6402 & 1177.6921 & 774.4469 \\
\hline Pept-B-XXXI & 1951.1143 & 1952.1302 & 128.0704 & 199.1071 & 284.1598 & 355.1985 & 440.2528 & 525.3029 & n.d. & 738.4129 & 851.4953 & 936.5563 & 993.5684 & 1078.6224 & 1163.6769 & 789.4509 \\
\hline Pept-B-XXXIIa & 1950.1302 & 1951.1368 & 128.0704 & 199.1071 & 284.1598 & 355.1985 & 440.2528 & 525.3029 & n.d. & 738.4129 & 851.4953 & 936.5563 & 993.5684 & 1078.6224 & 1163.6769 & 788.4616 \\
\hline Pept-B-XXXIIb & 1964.1459 & 1965.1522 & 128.0704 & 199.1071 & 284.1598 & 355.1985 & 440.2528 & 539.3186 & n.d. & 752.4301 & 865.5170 & 950.5699 & 1007.5874 & 1092.6402 & 1177.6921 & 788.4616 \\
\hline Pept-B-XXXIIIa & 1936.1146 & 1937.1206 & 128.0704 & 199.1071 & 284.1598 & 355.1985 & 440.2528 & 525.3029 & n.d. & 738.4129 & 851.4953 & 936.5563 & 993.5684 & 1078.6224 & 1163.6769 & 774.4469 \\
\hline Pept-B-XXXIIIb & 1936.1146 & 1937.1206 & 128.0704 & 199.1071 & 284.1598 & 355.1985 & 440.2528 & 511.2871 & n.d. & 724.3967 & 837.4860 & 922.5319 & 979.5613 & 1078.6224 & 1163.6769 & 774.4469 \\
\hline Pept-B-XXXIIIc & 1950.1302 & 1951.1368 & 128.0704 & 199.1071 & 284.1598 & 355.1985 & 440.2528 & 525.3029 & n.d. & 738.4129 & 851.4953 & 936.5563 & 993.5684 & 1092.6402 & 1177.6921 & 774.4469 \\
\hline Pept-B-XXXIIId & 1951.1143 & 1952.1302 & 128.0704 & 199.1071 & 284.1598 & 355.1985 & 454.2668 & 539.3186 & n.d. & 752.4301 & 865.5170 & 950.5699 & 1007.5874 & 1092.6402 & 1177.6921 & 775.4322 \\
\hline Pept-B-XXXIVa & 1937.0986 & 1938.0984 & 128.0704 & 199.1071 & 284.1598 & 355.1985 & 440.2528 & 525.3029 & n.d. & 738.4129 & 851.4953 & 922.5319 & 979.5613 & 1064.6081 & 1149.6611 & 789.4509 \\
\hline Pept-B-XXXIVb & 1951.1143 & 1952.1302 & 128.0704 & 199.1071 & 284.1598 & 355.1985 & 440.2528 & 525.3029 & n.d. & 738.4129 & 851.4953 & 936.5563 & 993.5684 & 1078.6224 & 1163.6769 & 789.4509 \\
\hline Pept-B-XXXVa & 1936.1146 & 1937.1206 & 128.0704 & 199.1071 & 284.1598 & 355.1985 & 440.2528 & 525.3029 & n.d. & 738.4129 & 851.4953 & 936.5563 & 993.5684 & 1078.6224 & 1163.6769 & 774.4469 \\
\hline Pept-B-XXXVb & 1936.1146 & 1937.1206 & 128.0704 & 199.1071 & 284.1598 & 355.1985 & 440.2528 & 511.2871 & n.d. & 724.3967 & 837.4860 & 922.5319 & 979.5613 & 1078.6224 & 1163.6769 & 774.4469 \\
\hline Pept-B-XXXVI & 1964.1459 & 1965.1522 & 128.0704 & 199.1071 & 298.1756 & 369.2134 & 468.2668 & 553.3335 & n.d. & 766.4425 & 879.5344 & 964.5869 & 1021.6084 & 1106.7307 & 1191.7080 & 774.4469 \\
\hline Pept-B-XXXVII & 1937.0986 & 1938.0984 & 128.0704 & 199.1071 & 284.1598 & 355.1985 & 440.2528 & 525.3029 & n.d. & 738.4129 & 851.4953 & 936.5563 & 993.5684 & 1078.6224 & 1163.6769 & 775.4322 \\
\hline Pept-B-XXXVIII & 1950.1302 & 1951.1368 & 128.0704 & 199.1071 & 284.1598 & 355.1985 & 440.2528 & 525.3029 & n.d. & 738.4129 & 851.4953 & 936.5563 & 993.5684 & 1078.6224 & 1163.6769 & 788.4616 \\
\hline Pept-B-XXXIX & 1964.1459 & 1965.1522 & 128.0704 & 199.1071 & 284.1598 & 355.1985 & 454.2668 & 539.3186 & n.d. & 752.4301 & 865.5170 & 950.5699 & 1007.5874 & 1092.6402 & 1177.6921 & 788.4616 \\
\hline Pept-B-XL & 1950.1302 & 1951.1368 & 128.0704 & 199.1071 & 284.1598 & 355.1985 & 440.2528 & 511.2871 & n.d. & 724.3967 & 837.4860 & 922.5319 & 979.5613 & 1078.6224 & 1163.6769 & 788.4616 \\
\hline Pept-B- XLIa & 1964.1459 & 1965.1522 & 128.0704 & 199.1071 & 284.1598 & 355.1985 & 440.2528 & 525.3029 & n.d. & 738.4129 & 851.4953 & 936.5563 & 993.5684 & 1092.6402 & 1177.6921 & 788.4616 \\
\hline Pept-B- XLIb & 1964.1459 & 1965.1522 & 128.0704 & 199.1071 & 284.1598 & 355.1985 & 440.2528 & 539.3186 & n.d. & 752.4301 & 865.5170 & 950.5699 & 1007.5874 & 1092.6402 & 1177.6921 & 788.4616 \\
\hline
\end{tabular}


Table 2 | continued

\begin{tabular}{|c|c|c|c|c|c|c|c|c|c|c|c|c|c|c|c|c|}
\hline Peptide & M & {$[\mathbf{M}+\mathbf{H}]^{+}$} & $\mathbf{b}_{1}$ & $\mathbf{b}_{2}$ & $\mathbf{b}_{3}$ & $\mathbf{b}_{4}$ & $b_{5}$ & $b_{6}$ & $\mathbf{b}_{7}$ & $\mathbf{b}_{8}$ & $b_{9}$ & $\mathbf{b}_{10}$ & $b_{11}$ & $b_{12}$ & $\mathbf{b}_{13}$ & $\mathbf{y}_{7}$ \\
\hline Pept-B- XLIIa & 1950.1302 & 1951.1368 & 128.0704 & 199.1071 & 284.1598 & 355.1985 & 440.2528 & 525.3029 & n.d. & 738.4129 & 851.4953 & 936.5563 & 993.5684 & 1092.6402 & 1177.6921 & 774.4469 \\
\hline Pept-B- XLIIb & 1936.1146 & 1937.1206 & 128.0704 & 199.1071 & 284.1598 & 355.1985 & 440.2528 & 525.3029 & n.d. & 738.4129 & 851.4953 & 936.5563 & 993.5684 & 1078.6224 & 1163.6769 & 774.4469 \\
\hline Pept-B- XLIII & 1964.1459 & 1965.1522 & 128.0704 & 199.1071 & 284.1598 & 355.1985 & 454.2668 & 553.3335 & n.d. & 766.4425 & 879.5344 & 964.5869 & 1021.6084 & 1106.7307 & 1191.7080 & 774.4469 \\
\hline Pept-B- XLIV & 1965.1299 & 1966.1444 & 128.0704 & 199.1071 & 284.1598 & 355.1985 & 454.2668 & 553.3337 & n.d. & 766.4421 & 879.5344 & 964.5869 & 1021.6047 & 1106.6547 & 1191.7080 & 775.4322 \\
\hline Pept-B- XLVa & 1950.1302 & 1951.1368 & 128.0704 & 199.1071 & 284.1598 & 355.1985 & 440.2528 & 525.3029 & n.d. & 738.4129 & 851.4953 & 936.5563 & 993.5684 & 1078.6224 & 1163.6769 & 788.4616 \\
\hline Pept-B- XLVb & 1978.1615 & 1979.1713 & 128.0704 & 199.1071 & 284.1598 & 369.2134 & 454.2668 & 553.3335 & n.d. & 766.4425 & 879.5344 & 964.5869 & 1021.6084 & 1106.6547 & 1191.7080 & 788.4616 \\
\hline Pept-B-XLVIa & 1936.1146 & 1937.1206 & 128.0704 & 199.1071 & 284.1598 & 355.1985 & 440.2528 & 525.3029 & n.d. & 738.4129 & 851.4953 & 936.5563 & 993.5684 & 1078.6224 & 1163.6769 & 774.4469 \\
\hline Pept-B-XLVIb & 1950.1302 & 1951.1368 & 128.0704 & 199.1071 & 284.1598 & 355.1985 & 440.2528 & 525.3029 & n.d. & 738.4129 & 851.4953 & 936.5563 & 993.5684 & 1092.6402 & 1177.6921 & 774.4469 \\
\hline Pept-B-XLVII & 1964.1459 & 1965.1522 & 128.0704 & 199.1071 & 284.1598 & 355.1985 & 454.2668 & 539.3186 & n.d. & 752.4301 & 865.5170 & 950.5699 & 1007.5874 & 1092.6402 & 1177.6921 & 789.4509 \\
\hline Pept-B- XLVIIIa & 1950.1302 & 1951.1368 & 128.0704 & 199.1071 & 284.1598 & 355.1985 & 440.2528 & 511.2871 & n.d. & 724.3967 & 837.4860 & 922.5319 & 979.5613 & 1078.6224 & 1163.6769 & 788.4616 \\
\hline Pept-B- XLVIIIb & 1964.1459 & 1965.1522 & 128.0704 & 199.1071 & 284.1598 & 355.1985 & 440.2528 & 525.3029 & n.d. & 738.4129 & 851.4953 & 936.5563 & 993.5684 & 1092.6402 & 1177.6921 & 788.4616 \\
\hline Pept-B-XLIX & 1978.1615 & 1979.1713 & 128.0704 & 199.1071 & 298.1756 & 369.2134 & 454.2668 & 553.3335 & n.d. & 766.4425 & 879.5344 & 964.5869 & 1021.6084 & 1106.6547 & 1191.7080 & 788.4616 \\
\hline Pept-B-L & 1965.1299 & 1966.1444 & 128.0704 & 199.1071 & 284.1598 & 355.1985 & 454.2668 & 553.3335 & n.d. & 766.4425 & 879.5344 & 964.5869 & 1021.6084 & 1106.6547 & 1191.7080 & 775.4322 \\
\hline Pept-B-LI & 1978.1615 & 1979.1713 & 128.0704 & 199.1071 & 284.1598 & 369.2134 & 468.2816 & 567.3482 & n.d. & 780.4582 & 893.5424 & 978.6031 & 1035.6162 & 1120.6686 & 1205.7234 & 774.4469 \\
\hline Pept-B-LII & 1951.1143 & 1952.1302 & 128.0704 & 199.1071 & 284.1598 & 355.1985 & 440.2528 & 525.3029 & n.d. & 738.4129 & 851.4953 & 936.5563 & 993.5684 & 1078.6224 & 1163.6769 & 789.4509 \\
\hline Pept-B-LIII & 1950.1302 & 1951.1368 & 128.0704 & 199.1071 & 284.1598 & 355.1985 & 440.2528 & 525.3029 & n.d. & 738.4129 & 851.4953 & 936.5563 & 993.5684 & 1092.6402 & 1177.6921 & 774.4469 \\
\hline Pept-B-LIV & 1978.1615 & 1979.1713 & 128.0704 & 199.1071 & 284.1598 & 355.1985 & 454.2668 & 553.3335 & n.d. & 766.4425 & 879.5344 & 964.5869 & 1021.6084 & 1106.6547 & 1191.7080 & 788.4616 \\
\hline Pept-B-LV & 1964.1459 & 1965.1522 & 128.0704 & 199.1071 & 284.1598 & 355.1985 & 440.2528 & 525.3029 & n.d. & 738.4129 & 851.4953 & 936.5563 & 993.5684 & 1092.6402 & 1177.6921 & 788.4616 \\
\hline Pept-B-LVI & 1950.1302 & 1951.1368 & 128.0704 & 199.1071 & 284.1598 & 355.1985 & 440.2528 & 511.2871 & n.d. & 724.3967 & 837.4860 & 922.5319 & 979.5613 & 1078.6224 & 1163.6769 & 788.4616 \\
\hline Pept-B-LVII & 1979.1456 & 1980.1604 & 128.0704 & 199.1071 & 284.1598 & 355.1985 & 454.2668 & 553.3335 & n.d. & 766.4425 & 879.5344 & 964.5869 & 1021.6084 & 1106.6547 & 1191.7080 & 789.4509 \\
\hline Pept-B-LVIII & 1936.1146 & 1937.1206 & 128.0704 & 199.1071 & 284.1598 & 355.1985 & 440.2528 & 525.3029 & n.d. & 738.4129 & 851.4953 & 936.5563 & 993.5684 & 1078.6224 & 1163.6769 & 774.4469 \\
\hline Pept-B-LIX & 1992.1772 & 1993.1845 & 128.0704 & 199.1071 & 298.1756 & 369.2134 & 468.2816 & 567.3482 & n.d. & 780.4582 & 893.5424 & 978.6031 & 1035.6162 & 1120.6686 & 1205.7234 & 788.4616 \\
\hline Pept-B-LXa & 1964.1459 & 1965.1522 & 128.0704 & 199.1071 & 284.1598 & 355.1985 & 440.2528 & 525.3029 & n.d. & 738.4129 & 837.4860 & 922.5319 & 979.5613 & 1092.6402 & 1177.6921 & 788.4616 \\
\hline Pept-B-LXb & 1964.1459 & 1965.1522 & 128.0704 & 199.1071 & 284.1598 & 355.1985 & 440.2528 & 525.3029 & n.d. & 738.4129 & 851.4953 & 936.5563 & 993.5684 & 1092.6402 & 1177.6921 & 788.4616 \\
\hline Pept-B-LXI & 1964.1459 & 1965.1522 & 128.0704 & 199.1071 & 284.1598 & 355.1985 & 440.2528 & 525.3029 & n.d. & 738.4129 & 851.4953 & 936.5563 & 993.5684 & 1092.6402 & 1177.6921 & 788.4616 \\
\hline
\end{tabular}


Table 3 I Diagnostic fragment ions of peptaibols of brevicelsins (group C) from clade Longibrachiatum detected with the full scan Orbitrap-MS measurement

\begin{tabular}{|c|c|c|c|c|c|c|c|c|c|c|c|c|c|c|c|c|}
\hline Peptide & $\mathbf{M}$ & {$[\mathbf{M}+\mathbf{H}]^{+}$} & $\mathbf{b}_{1}$ & $\mathbf{b}_{2}$ & $\mathbf{b}_{3}$ & $\mathbf{b}_{4}$ & $b_{5}$ & $\mathbf{b}_{6}$ & $\mathbf{b}_{7}$ & $\mathbf{b}_{8}$ & $\mathbf{b}_{9}$ & $b_{10}$ & $b_{11}$ & $b_{12}$ & $b_{13}$ & $\mathbf{y}_{7}$ \\
\hline Brevicelsin I & 1851.0618 & 1852.0668 & 128.0704 & 199.1071 & 284.1598 & 355.1985 & 440.2528 & - & n.d. & 653.3604 & 766.4414 & 851.4953 & 908.5167 & 993.5684 & 1078.6224 & 774.4469 \\
\hline Brevicelsin II & 1865.0775 & 1866.0851 & 128.0704 & 199.1071 & 298.1756 & $369 . .2134$ & 454.2668 & - & n.d. & 667.4159 & 780.4582 & 865.5097 & 922.5319 & 1007.5874 & 1092.6402 & 774.4469 \\
\hline Brevicelsin III & 1852.0458 & 1853.0613 & 128.0704 & 199.1071 & 284.1598 & 355.1985 & 440.2528 & - & n.d. & 653.3604 & 766.4425 & 851.4953 & 908.5167 & 993.5684 & 1078.6224 & 775.4322 \\
\hline Brevicelsin IV & 1865.0775 & 1866.0851 & 128.0704 & 199.1071 & 284.1598 & 355.1985 & 440.2528 & - & n.d. & 653.3604 & 766.4425 & 851.4953 & 908.5167 & 993.5684 & 1078.6224 & 788.4616 \\
\hline Brevicelsin V & 1879.0931 & 1880.1007 & 128.0704 & 199.1071 & 284.1598 & 355.1985 & 454.2668 & - & n.d. & 667.3751 & 780.4582 & 865.5170 & 922.5319 & 1007.5874 & 1092.6402 & 788.4616 \\
\hline Brevicelsin VI & 1865.0775 & 1866.0851 & 128.0704 & 199.1071 & 284.1598 & 355.1985 & 454.2668 & - & n.d. & 667.3751 & 780.4582 & 865.5170 & 922.5319 & 1007.5874 & 1092.6402 & 774.4469 \\
\hline Brevicelsin VII & 1866.0615 & 1867.0745 & 128.0704 & 199.1071 & 284.1598 & 355.1985 & 440.2528 & - & n.d. & 653.3604 & 766.4425 & 851.4953 & 908.5167 & 993.5684 & 1078.6224 & 789.4509 \\
\hline Brevicelsin VIII & 1879.0931 & 1880.1007 & 128.0704 & 199.1071 & 284.1598 & 355.1985 & 454.2668 & - & n.d. & 667.3751 & 780.4582 & 865.5170 & 922.5319 & 1007.5874 & 1092.6402 & 788.4616 \\
\hline
\end{tabular}

n.d.: not detected 
Table 4 | Diagnostic fragment ions of acylium ion $\left(\mathrm{y}_{7}\right)$ detected with Orbitrap-MS ${ }^{2}$ measurements of peptaibol compounds from group A

\begin{tabular}{|c|c|c|c|c|c|c|c|}
\hline Peptide & $\mathbf{y}_{7}$ & $\begin{array}{c}\mathbf{y}_{7}- \\
\mathbf{H}_{2} \mathbf{O} *\end{array}$ & $\begin{array}{c}\mathbf{y}_{7}-\mathbf{A A} \\
(\mathbf{1 9})\end{array}$ & $\begin{array}{l}\mathbf{y}_{7}-\mathbf{A A} \\
(19-18)\end{array}$ & $\begin{array}{l}\mathbf{y}_{7}-\mathbf{A A} \\
(19-17)\end{array}$ & $\begin{array}{l}y_{7}-A A \\
(19-16)\end{array}$ & $\begin{array}{l}\mathbf{y}_{7}-\mathbf{A A} \\
(19-15)\end{array}$ \\
\hline Pept-A-Ia & 774.4469 & 756.4 & 623.3480 & 495.2911 & 367.2330 & 282.1803 & 197.1279 \\
\hline Pept-A-Ib & 774.4469 & 756.4 & 623.3480 & 495.2911 & 367.2330 & 282.1803 & 197.1279 \\
\hline Pept-A-IIa & 775.4322 & 757.4 & 624.3356 & 496.2768 & 367.2330 & 282.1803 & 197.1279 \\
\hline Pept-A-IIb & 775.4322 & 757.4 & 624.3356 & 496.2768 & 367.2330 & 282.1803 & 197.1279 \\
\hline Pept-A-IIIa & 788.4616 & 770.3 & 637.3637 & 509.3106 & 381.2485 & 282.1804 & 197.1280 \\
\hline Pept-A-IIIb & 788.4616 & 770.3 & 637.3637 & 509.3106 & 381.2485 & 282.1804 & 197.1280 \\
\hline Pept-A-IIIc & 788.4616 & 770.3 & 637.3637 & 509.3106 & 381.2485 & 282.1804 & 197.1280 \\
\hline Pept-A-IVa & 774.4469 & 756.4 & 623.3480 & 495.2911 & 367.2330 & 282.1803 & 197.1279 \\
\hline Pept-A-IVb & 774.4469 & 756.4 & 623.3480 & 495.2911 & 367.2330 & 282.1803 & 197.1279 \\
\hline Pept-A-Va & 774.4469 & 756.4 & 623.3480 & 495.2911 & 367.2330 & 282.1803 & 197.1279 \\
\hline Pept-A-Vb & 774.4469 & 756.4 & 623.3480 & 495.2911 & 367.2330 & 282.1803 & 197.1279 \\
\hline Pept-A-VIa & 775.4322 & 757.4 & 624.3356 & 496.2768 & 367.2330 & 282.1803 & 197.1279 \\
\hline Pept-A-VIb & 775.4322 & 757.4 & 624.3356 & 496.2768 & 367.2330 & 282.1803 & 197.1279 \\
\hline Pept-A-VIIa & 774.4469 & 756.4 & 623.3480 & 495.2911 & 367.2330 & 282.1803 & 197.1279 \\
\hline Pept-A-VIIb & 774.4469 & 756.4 & 623.3480 & 495.2911 & 367.2330 & 282.1803 & 197.1279 \\
\hline Pept-A-VIIIa & 774.4469 & 756.4 & 623.3480 & 495.2911 & 367.2330 & 282.1803 & 197.1279 \\
\hline Pept-A-VIIIb & 774.4469 & 756.4 & 623.3480 & 495.2911 & 367.2330 & 282.1803 & 197.1279 \\
\hline Pept-A-IXa & 788.4616 & 770.3 & 637.3637 & 509.3106 & 381.2485 & 282.1804 & 197.1280 \\
\hline Pept-A-IXb & 788.4616 & 770.3 & 637.3637 & 509.3106 & 381.2485 & 282.1804 & 197.1280 \\
\hline Pept-A-Xa & 788.4616 & 770.3 & 637.3637 & 509.3106 & 381.2485 & 282.1804 & 197.1280 \\
\hline Pept-A-Xb & 788.4616 & 770.3 & 637.3637 & 509.3106 & 381.2485 & 282.1804 & 197.1280 \\
\hline Pept-A-XIa & 775.4322 & 757.4 & 624.3356 & 496.2768 & 367.2330 & 282.1803 & 197.1279 \\
\hline Pept-A-XIb & 775.4322 & 757.4 & 624.3356 & 496.2768 & 367.2330 & 282.1803 & 197.1279 \\
\hline Pept-A-XIc & 775.4322 & 757.4 & 624.3356 & 496.2768 & 367.2330 & 282.1803 & 197.1279 \\
\hline Pept-A-XII & 775.4322 & 757.4 & 624.3356 & 496.2768 & 367.2330 & 282.1803 & 197.1279 \\
\hline Pept-A-XIIIa & 789.4509 & 771.3 & 638.3518 & 510.2926 & 381.2485 & 282.1804 & 197.1280 \\
\hline Pept-A-XIIIb & 789.4509 & 771.3 & 638.3518 & 510.2926 & 381.2485 & 282.1804 & 197.1280 \\
\hline Pept-A-XIVa & 789.4509 & 771.3 & 638.3518 & 510.2926 & 381.2485 & 282.1804 & 197.1280 \\
\hline Pept-A- XIVb & 788.4616 & 770.3 & 637.3637 & 509.3106 & 381.2485 & 282.1804 & 197.1280 \\
\hline Pept-A-XVa & 788.4616 & 770.3 & 637.3637 & 509.3106 & 381.2485 & 282.1804 & 197.1280 \\
\hline Pept-A-XVb & 788.4616 & 770.3 & 637.3637 & 509.3106 & 381.2485 & 282.1804 & 197.1280 \\
\hline Pept-A-XVIa & 774.4469 & 756.4 & 623.3480 & 495.2911 & 367.2330 & 282.1803 & 197.1279 \\
\hline Pept-A-XVIb & 774.4469 & 756.4 & 623.3480 & 495.2911 & 367.2330 & 282.1803 & 197.1279 \\
\hline Pept-A-XVIIa & 788.4616 & 770.3 & 637.3637 & 509.3106 & 381.2485 & 282.1804 & 197.1280 \\
\hline Pept-A-XVIIb & 788.4616 & 770.3 & 637.3637 & 509.3106 & 381.2485 & 282.1804 & 197.1280 \\
\hline Pept-A-XVIII & 788.4616 & 770.3 & 637.3637 & 509.3106 & 381.2485 & 282.1804 & 197.1280 \\
\hline Pept-A-XIXa & 775.4322 & 757.4 & 624.3356 & 496.2768 & 367.2330 & 282.1803 & 197.1279 \\
\hline Pept-A-XIXb & 775.4322 & 757.4 & 624.3356 & 496.2768 & 367.2330 & 282.1803 & 197.1279 \\
\hline Pept-A-XX & 774.4469 & 756.4 & 623.3480 & 495.2911 & 367.2330 & 282.1803 & 197.1279 \\
\hline Pept-A-XXIa & 788.4616 & 770.3 & 637.3637 & 509.3106 & 381.2485 & 282.1804 & 197.1280 \\
\hline Pept-A-XXIb & 788.4616 & 770.3 & 637.3637 & 509.3106 & 381.2485 & 282.1804 & 197.1280 \\
\hline
\end{tabular}

* determined on Varian-MS system 
Table 4 | continued

\begin{tabular}{l|ccccccc} 
Peptide & $\mathbf{y}_{\mathbf{7}}$ & $\begin{array}{c}\mathbf{y}_{\mathbf{7}}- \\
\mathbf{H}_{\mathbf{2}} \mathbf{O} *\end{array}$ & $\begin{array}{c}\mathbf{y}_{\mathbf{7}}-\mathbf{A A} \\
\mathbf{( 1 9 )}\end{array}$ & $\begin{array}{c}\mathbf{y}_{\mathbf{7}}-\mathbf{A A} \\
\mathbf{( 1 9 - 1 8 )}\end{array}$ & $\begin{array}{c}\mathbf{y}_{\mathbf{7}}-\mathbf{A A} \\
(\mathbf{1 9 - 1 7})\end{array}$ & $\begin{array}{c}\mathbf{y}_{\mathbf{7}}-\mathbf{A A} \\
\mathbf{( 1 9 - 1 6 )}\end{array}$ & $\begin{array}{c}\mathbf{y}_{\mathbf{7}}-\mathbf{A A} \\
\mathbf{( 1 9 - 1 5 )}\end{array}$ \\
\hline Pept-A-XXIIa & 774.4469 & 756.4 & 623.3480 & 495.2911 & 367.2330 & 282.1803 & 197.1279 \\
Pept-A-XXIIb & 774.4469 & 756.4 & 623.3480 & 495.2911 & 367.2330 & 282.1803 & 197.1279 \\
Pept-A-XXIII & 789.4509 & 771.3 & 638.3518 & 510.2926 & 381.2485 & 282.1804 & 197.1280 \\
Pept-A-XXIV & 788.4616 & 770.3 & 637.3637 & 509.3106 & 381.2485 & 282.1804 & 197.1280 \\
Pept-A-XXVa & 788.4616 & 770.3 & 637.3637 & 509.3106 & 381.2485 & 282.1804 & 197.1280 \\
Pept-A-XXVb & 788.4616 & 770.3 & 637.3637 & 509.3106 & 381.2485 & 282.1804 & 197.1280 \\
Pept-A-XXVIa & 788.4616 & 770.3 & 637.3637 & 509.3106 & 381.2485 & 282.1804 & 197.1280 \\
Pept-A-XXVIb & 788.4616 & 770.3 & 637.3637 & 509.3106 & 381.2485 & 282.1804 & 197.1280 \\
Pept-A-XXVIIa & 789.4509 & 771.3 & 638.3518 & 510.2926 & 381.2485 & 282.1804 & 197.1280 \\
Pept-A-XXVIIb & 788.4616 & 770.3 & 637.3637 & 509.3106 & 381.2485 & 282.1804 & 197.1280 \\
\hline
\end{tabular}

* determined on Varian-MS system

Table 5 I Diagnostic fragment ions of acylium ion $\left(\mathrm{y}_{7}\right)$ detected with Orbitrap-MS ${ }^{2}$ measurements of peptaibol compounds from group B

\begin{tabular}{l|ccccccc} 
Peptide & $\mathbf{y}_{\mathbf{7}}$ & $\begin{array}{c}\mathbf{y}_{\mathbf{7}}- \\
\mathbf{H}_{\mathbf{2}} \mathbf{O}\end{array}$ & $\begin{array}{c}\mathbf{y}_{\mathbf{7}} \mathbf{- A A} \\
\mathbf{( 1 9 )}\end{array}$ & $\begin{array}{c}\mathbf{y}_{\mathbf{7}} \mathbf{- A A} \\
\mathbf{( 1 9 - 1 8 )}\end{array}$ & $\begin{array}{c}\mathbf{y}_{\mathbf{7}}-\mathbf{A A} \\
(\mathbf{1 9 - 1 7 )}\end{array}$ & $\begin{array}{c}\mathbf{y}_{\mathbf{7}}-\mathbf{A A} \\
\mathbf{( 1 9 - 1 6 )}\end{array}$ & $\begin{array}{c}\mathbf{y}_{\mathbf{7}} \mathbf{- A A} \\
(\mathbf{1 9 - 1 5})\end{array}$ \\
\hline Pept-B-I & 774.4469 & 756.4 & 623.3480 & 495.2911 & 367.2330 & 282.1803 & 197.1279 \\
Pept-B-II & 774.4469 & 756.4 & 623.3480 & 495.2911 & 367.2330 & 282.1803 & 197.1279 \\
Pept-B-III & 774.4469 & 756.4 & 623.3480 & 495.2911 & 367.2330 & 282.1803 & 197.1279 \\
Pept-B-IV & 788.4616 & 770.3 & 637.3637 & 509.3106 & 381.2485 & 282.1804 & 197.1280 \\
Pept-B-V & 774.4469 & 756.4 & 623.3480 & 495.2911 & 367.2330 & 282.1803 & 197.1279 \\
Pept-B-VI & 774.4469 & 756.4 & 623.3480 & 495.2911 & 367.2330 & 282.1803 & 197.1279 \\
Pept-B-VII & 788.4616 & 770.3 & 637.3637 & 509.3106 & 381.2485 & 282.1804 & 197.1280 \\
Pept-B-VIII & 788.4616 & 770.3 & 637.3637 & 509.3106 & 381.2485 & 282.1804 & 197.1280 \\
Pept-B-IXa & 774.4469 & 756.4 & 623.3480 & 495.2911 & 367.2330 & 282.1803 & 197.1279 \\
Pept-B-IXb & 774.4469 & 756.4 & 623.3480 & 495.2911 & 367.2330 & 282.1803 & 197.1279 \\
Pept-B-X & 788.4616 & 770.3 & 637.3637 & 509.3106 & 381.2485 & 282.1804 & 197.1280 \\
Pept-B-XI & 788.4616 & 770.3 & 637.3637 & 509.3106 & 381.2485 & 282.1804 & 197.1280 \\
Pept-B-XII & 774.4469 & 756.4 & 623.3480 & 495.2911 & 367.2330 & 282.1803 & 197.1279 \\
Pept-B-XIII & 788.4616 & 770.3 & 637.3637 & 509.3106 & 381.2485 & 282.1804 & 197.1280 \\
Pept-B-XIVa & 775.4322 & 757.4 & 624.3356 & 496.2768 & 367.2330 & 282.1803 & 197.1279 \\
Pept-B-XIVb & 775.4322 & 757.4 & 624.3356 & 496.2768 & 367.2330 & 282.1803 & 197.1279 \\
Pept-B-XVa & 788.4616 & 770.3 & 637.3637 & 509.3106 & 381.2485 & 282.1804 & 197.1280 \\
Pept-B-XVb & 788.4616 & 770.3 & 637.3637 & 509.3106 & 381.2485 & 282.1804 & 197.1280 \\
Pept-B-XVI & 774.4469 & 756.4 & 623.3480 & 495.2911 & 367.2330 & 282.1803 & 197.1279 \\
Pept-B-XVII & 788.4616 & 770.3 & 637.3637 & 509.3106 & 381.2485 & 282.1804 & 197.1280 \\
Pept-B-XVIII & 774.4469 & 756.4 & 623.3480 & 495.2911 & 367.2330 & 282.1803 & 197.1279 \\
Pept-B-XIX & 788.4616 & 770.3 & 637.3637 & 509.3106 & 381.2485 & 282.1804 & 197.1280 \\
Pept-B-XX & 774.4469 & 756.4 & 623.3480 & 495.2911 & 367.2330 & 282.1803 & 197.1279
\end{tabular}

* determined on Varian-MS system 
Table $5 \mid$ continued

\begin{tabular}{|c|c|c|c|c|c|c|c|}
\hline Peptide & $\mathbf{y}_{7}$ & $\begin{array}{c}\mathbf{y}_{7}- \\
\mathbf{H}_{2} \mathbf{O} *\end{array}$ & $\begin{array}{c}\mathbf{y}_{7}-\mathbf{A A} \mathbf{A} \\
(\mathbf{1 9})\end{array}$ & $\begin{array}{c}\mathbf{y}_{7}-\mathbf{A A} \\
(19-18)\end{array}$ & $\begin{array}{l}\mathbf{y}_{7}-\mathbf{A A} \\
(19-17)\end{array}$ & $\begin{array}{l}\mathbf{y}_{7}-\mathbf{A A} \\
(19-16)\end{array}$ & $\begin{array}{c}\mathbf{y}_{7}-\mathbf{A A} \\
(19-15)\end{array}$ \\
\hline Pept-B-XXI & 789.4 & 771.3 & 638.3518 & 510.2926 & 381.2485 & 282.1804 & 197.1280 \\
\hline Pept-B-XXII & 788.4616 & 770.3 & 637.3637 & 509.3106 & 381.2485 & 282.1804 & 197.1280 \\
\hline Pept-B-XXIII & 774.4469 & 756.4 & 623.3480 & 495.2911 & 367.2330 & 282.1803 & 197.1279 \\
\hline Pept-B-XXIV & 788.4616 & 770.3 & 637.3637 & 509.3106 & 381.2485 & 282.1804 & 197.1280 \\
\hline Pept-B-XXV & 775.4322 & 757.4 & 624.3356 & 496.2768 & 367.2330 & 282.1803 & 197.1279 \\
\hline Pept-B-XXVI & 774.4469 & 756.4 & 623.3480 & 495.2911 & 367.2330 & 282.1803 & 197.1279 \\
\hline Pept-B-XXVII & 788.4616 & 770.3 & 637.3637 & 509.3106 & 381.2485 & 282.1804 & 197.1280 \\
\hline Pept-B-XXVIII & 774.4469 & 756.4 & 623.3480 & 495.2911 & 367.2330 & 282.1803 & 197.1279 \\
\hline Pept-B-XXIXa & 788.4616 & 770.3 & 637.3637 & 509.3106 & 381.2485 & 282.1804 & 197.1280 \\
\hline Pept-B-XXIXb & 788.4616 & 770.3 & 637.3637 & 509.3106 & 381.2485 & 282.1804 & 197.1280 \\
\hline Pept-B-XXX & 774.4469 & 756.4 & 623.3480 & 495.2911 & 367.2330 & 282.1803 & 197.1279 \\
\hline Pept-B-XXXI & 789.4509 & 771.3 & 638.3518 & 510.2926 & 381.2485 & 282.1804 & 197.1280 \\
\hline Pept-B-XXXIIa & 788.4616 & 770.3 & 637.3637 & 509.3106 & 381.2485 & 282.1804 & 197.1280 \\
\hline Pept-B-XXXIIb & 788.4616 & 770.3 & 637.3637 & 509.3106 & 381.2485 & 282.1804 & 197.1280 \\
\hline Pept-B-XXXIIIa & 774.4469 & 756.4 & 623.3480 & 495.2911 & 367.2330 & 282.1803 & 197.1279 \\
\hline Pept-B-XXXIIIb & 774.4469 & 756.4 & & & & & \\
\hline Pept-B-XXXIIIc & 774.4469 & 756.4 & 623.3480 & 495.2911 & 367.2330 & 282.1803 & 197.1279 \\
\hline Pept-B-XXXIIId & 775.4322 & 757.4 & & 496.2768 & & 282.1803 & 197.1279 \\
\hline Pept-B-XXXIVa & 789.4509 & 771.3 & 638.3518 & 510.2926 & 381.2485 & 282.1804 & 197.1280 \\
\hline Pept-B-XXXIVb & 789.4509 & 771.3 & 638.3518 & 510.2926 & 381.2485 & 282.1804 & 197.1280 \\
\hline Pept-B-XXXVa & 774.4469 & 756.4 & 623.3480 & 495.2911 & 367.2330 & 282.1803 & 197.1279 \\
\hline Pept-B-XXXVb & 774.4469 & 756.4 & 623.3480 & 495.2911 & 367.2330 & 282.1803 & 197.1279 \\
\hline Pept-B-XXXVI & 774.4469 & 756.4 & 623.3480 & 495.2911 & 367.2330 & 282.1803 & 197.1279 \\
\hline Pept-B-XXXVII & 775.4322 & 757.4 & 624.3356 & 496.2768 & 367.2330 & 282.1803 & 197.1279 \\
\hline Pept-B-XXXVIII & 788.4616 & 770.3 & 637.3637 & 509.3106 & 381.2485 & 282.1804 & 197.1280 \\
\hline Pept-B-XXXIX & 788.4616 & 770.3 & 637.3637 & 509.3106 & 381.2485 & 282.1804 & 197.1280 \\
\hline Pept-B-XL & 788.4616 & 770.3 & 637.3637 & 509.3106 & 381.2485 & 282.1804 & 197.1280 \\
\hline Pept-B- XLIa & 788.4616 & 770.3 & 637.3637 & 509.3106 & 381.2485 & 282.1804 & 197.1280 \\
\hline Pept-B- XLIb & 788.4616 & 770.3 & 637.3637 & 509.3106 & 381.2485 & 282.1804 & 197.1280 \\
\hline Pept-B- XLIIa & 774.4469 & 756.4 & 623.3480 & 495.2911 & 367.2330 & 282.1803 & 197.1279 \\
\hline Pept-B- XLIIb & 774.4469 & 756.4 & 623.3480 & 495.2911 & 367.2330 & 282.1803 & 197.1279 \\
\hline Pept-B- XLIII & 774.4469 & 756.4 & 623.3480 & 495.2911 & 367.2330 & 282.1803 & 197.1279 \\
\hline Pept-B- XLIV & 775.4322 & 757.4 & 624.3356 & 496.2768 & 367.2330 & 282.1803 & 197.1279 \\
\hline Pept-B- XLVa & 788.4616 & 770.3 & 637.3637 & 509.3106 & 381.2485 & 282.1804 & 197.1280 \\
\hline Pept-B- XLVb & 788.4616 & 770.3 & 637.3637 & 509.3106 & 381.2485 & 282.1804 & 197.1280 \\
\hline Pept-B-XLVIa & 774.4469 & 756.4 & 623.3480 & 495.2911 & 367.2330 & 282.1803 & 197.1279 \\
\hline Pept-B-XLVIb & 774.4469 & 756.4 & 623.3480 & 495.2911 & 367.2330 & 282.1803 & 197.1279 \\
\hline Pept-B-XLVII & 789.4509 & 771.3 & 638.3518 & 510.2926 & 381.2485 & 282.1804 & 197.1280 \\
\hline
\end{tabular}

* determined on Varian-MS system 
Table 5 | continued

\begin{tabular}{l|ccccccc} 
Peptide & $\mathbf{y}_{\mathbf{7}}$ & $\begin{array}{c}\mathbf{y}_{\mathbf{7}}- \\
\mathbf{H}_{\mathbf{2}} *\end{array}$ & $\begin{array}{c}\mathbf{y}_{\mathbf{7}} \mathbf{- A A} \\
\mathbf{( 1 9 )}\end{array}$ & $\begin{array}{c}\mathbf{y}_{\mathbf{7}}-\mathbf{A A} \\
\mathbf{( 1 9 - 1 8 )}\end{array}$ & $\begin{array}{c}\mathbf{y}_{\mathbf{7}}-\mathbf{A A} \\
\mathbf{( 1 9 - 1 7 )}\end{array}$ & $\begin{array}{c}\mathbf{y}_{\mathbf{7}}-\mathbf{A A} \\
(\mathbf{1 9 - 1 6})\end{array}$ & $\begin{array}{c}\mathbf{y}_{\mathbf{7}}-\mathbf{A A} \\
\mathbf{( 1 9 - 1 5 )}\end{array}$ \\
\hline Pept-B-XLVIIIa & 788.4616 & 770.3 & 637.3637 & 509.3106 & 381.2485 & 282.1804 & 197.1280 \\
Pept-B-XLVIIIb & 788.4616 & 770.3 & 637.3637 & 509.3106 & 381.2485 & 282.1804 & 197.1280 \\
Pept-B-XLIX & 788.4616 & 770.3 & 637.3637 & 509.3106 & 381.2485 & 282.1804 & 197.1280 \\
Pept-B-L & 775.4322 & 757.4 & 624.3356 & 496.2768 & 367.2330 & 282.1803 & 197.1279 \\
Pept-B-LI & 774.4469 & 756.4 & 623.3480 & 495.2911 & 367.2330 & 282.1803 & 197.1279 \\
Pept-B-LII & 789.4509 & 771.3 & 638.3518 & 510.2926 & 381.2485 & 282.1804 & 197.1280 \\
Pept-B-LIII & 774.4469 & 756.4 & 623.3480 & 495.2911 & 367.2330 & 282.1803 & 197.1279 \\
Pept-B-LIV & 788.4616 & 770.3 & 637.3637 & 509.3106 & 381.2485 & 282.1804 & 197.1280 \\
Pept-B-LV & 788.4616 & 770.3 & 637.3637 & 509.3106 & 381.2485 & 282.1804 & 197.1280 \\
Pept-B-LVI & 788.4616 & 770.3 & 637.3637 & 509.3106 & 381.2485 & 282.1804 & 197.1280 \\
Pept-B-LVII & 789.4509 & 771.3 & 638.3518 & 510.2926 & 381.2485 & 282.1804 & 197.1280 \\
Pept-B-LVIII & 774.4469 & 756.4 & 623.3480 & 495.2911 & 367.2330 & 282.1803 & 197.1279 \\
Pept-B-LIX & 788.4616 & 770.3 & 637.3637 & 509.3106 & 381.2485 & 282.1804 & 197.1280 \\
Pept-B-LXa & 788.4616 & 770.3 & 637.3637 & 509.3106 & 381.2485 & 282.1804 & 197.1280 \\
Pept-B-LXb & 788.4616 & 770.3 & 637.3637 & 509.3106 & 381.2485 & 282.1804 & 197.1280 \\
Pept-B-LXI & 788.4616 & 770.3 & 637.3637 & 509.3106 & 381.2485 & 282.1804 & 197.1280 \\
\hline
\end{tabular}

* determined on Varian-MS system

Table 6 | Diagnostic fragment ions of acylium ion $\left(\mathrm{y}_{7}\right)$ detected with Orbitrap-MS ${ }^{2}$ measurements of brevicelsins (group C)

\begin{tabular}{l|ccccccc} 
Peptide & $\mathbf{y}_{\mathbf{7}}$ & $\begin{array}{c}\mathbf{y}_{\mathbf{7}}- \\
\mathbf{H}_{\mathbf{2}} \mathbf{O}\end{array}$ & $\begin{array}{c}\mathbf{y}_{\mathbf{7}}-\mathbf{A A} \\
\mathbf{( 1 9 )}\end{array}$ & $\begin{array}{c}\mathbf{y}_{\mathbf{7}}-\mathbf{A A} \\
\mathbf{( 1 9 - 1 8 )}\end{array}$ & $\begin{array}{c}\mathbf{y}_{\mathbf{7}}-\mathbf{A A} \\
\mathbf{( 1 9 - 1 7 )}\end{array}$ & $\begin{array}{c}\mathbf{y}_{\mathbf{7}}-\mathbf{A A} \\
\mathbf{( 1 9 - 1 6 )}\end{array}$ & $\begin{array}{c}\mathbf{y}_{\mathbf{7}}-\mathbf{A A} \\
(\mathbf{1 9 - 1 5})\end{array}$ \\
\hline Brevicelsin I & 774.4469 & 756.4 & 623.3480 & 495.2911 & 367.2330 & 282.1803 & 197.1279 \\
Brevicelsin II & 774.4469 & 756.4 & 623.3480 & 495.2911 & 367.2330 & 282.1803 & 197.1279 \\
Brevicelsin III & 775.4322 & 757.4 & 624.3356 & 496.2768 & 367.2330 & 282.1803 & 197.1279 \\
Brevicelsin IV & 788.4616 & 770.3 & 637.3637 & 509.3106 & 381.2485 & 282.1804 & 197.1280 \\
Brevicelsin V & 788.4616 & 770.3 & 637.3637 & 509.3106 & 381.2485 & 282.1804 & 197.1280 \\
Brevicelsin VI & 774.4469 & 756.4 & 623.3480 & 495.2911 & 367.2330 & 282.1803 & 197.1279 \\
Brevicelsin VII & 789.4509 & 771.3 & 638.3518 & 510.2926 & 381.2485 & 282.1804 & 197.1280 \\
Brevicelsin VIII & 788.4616 & 770.3 & 637.3637 & 509.3106 & 381.2485 & 282.1804 & 197.1280 \\
\hline
\end{tabular}

* determined on Varian-MS system 
Table 7 I Diagnostic fragment ions of peptaibols detected with the full scan Varian-MS measurement of peptaibol extracts from plate cultures of $T$. gamsii SZMC 1656

\begin{tabular}{|c|c|c|c|c|c|c|c|c|c|c|c|c|c|c|c|c|c|}
\hline Peptide & $\begin{array}{c}\text { Area } \\
\text { size }\end{array}$ & $\mathbf{M}$ & {$[\mathrm{M}+\mathbf{N a}]^{+}$} & {$[\mathrm{M}+2 \mathrm{Na}]^{2+}$} & $\mathbf{b}_{1}$ & $\mathbf{b}_{2}$ & $\mathbf{b}_{3}$ & $\mathbf{b}_{4}$ & $\mathbf{b}_{5}$ & $\mathbf{b}_{6}$ & $\mathbf{b}_{7}$ & $\mathbf{b}_{8}$ & $\mathbf{b}_{9}$ & $\mathbf{b}_{10}$ & $\mathbf{b}_{11}$ & $\mathbf{b}_{12}$ & $\mathbf{y}_{7}$ \\
\hline Pept-Ia & $0.28 \%$ & 1861.1 & 1884.1 & 953.55 & 128.0 & 185.0 & 256.0 & 341.0 & 440.1 & n.d. & 653.4 & 738.4 & 823.5 & 910.5 & 1023.8 & 1108.6 & 754.5 \\
\hline Pept-Ib & $1.51 \%$ & 1876.2 & 1899.2 & 961.1 & 128.0 & 185.0 & 256.0 & 341.0 & 440.1 & n.d. & 653.4 & 738.4 & 823.5 & 910.5 & 1023.8 & 1108.6 & 768.5 \\
\hline Pept-IIa & $1.66 \%$ & 1876.1 & 1899.1 & 961.05 & 128.0 & 185.0 & 256.0 & 341.1 & 454.2 & n.d. & 667.4 & 752.5 & 837.5 & 924.5 & 1037.3 & 1122.6 & 754.5 \\
\hline Pept-IIb & $1.99 \%$ & 1875.2 & 1898.2 & 960.6 & 128.0 & 185.0 & 256.0 & 341.0 & 440.1 & n.d. & 653.4 & 738.4 & 823.5 & 910.5 & 1023.8 & 1108.6 & 768.5 \\
\hline Pept-IIIa & $0.56 \%$ & 1876.2 & 1899.2 & 961.1 & 128.0 & 185.0 & 256.0 & 341.1 & 454.2 & n.d. & 667.4 & 752.5 & 837.5 & 924.5 & 1037.3 & 1122.6 & 754.5 \\
\hline Pept-IIIb & $2.96 \%$ & 1875.3 & 1898.3 & 960.65 & 128.0 & 185.0 & 256.0 & 341.0 & 440.1 & n.d. & 653.4 & 738.4 & 823.5 & 910.5 & 1023.8 & 1108.6 & 768.5 \\
\hline Pept-IVa & $3.70 \%$ & 1875.2 & 1898.2 & 960.6 & 128.0 & 185.0 & 256.0 & 341.1 & 454.2 & n.d. & 667.4 & 752.5 & 837.5 & 924.5 & 1037.3 & 1122.6 & 754.5 \\
\hline Pept-IVb & $9.21 \%$ & 1875.2 & 1898.2 & 960.6 & 128.0 & 185.0 & 256.0 & 341.0 & 440.1 & n.d. & 653.4 & 738.4 & 823.5 & 910.5 & 1023.8 & 1108.6 & 768.5 \\
\hline Pept-Va & $4.49 \%$ & 1876.2 & 1899.2 & 961.1 & 128.0 & 185.0 & 256.0 & 341.1 & 454.2 & n.d. & 667.4 & 752.5 & 837.5 & 924.5 & 1037.3 & 1122.6 & 754.5 \\
\hline Pept-Vb & $5.41 \%$ & 1890.2 & 1913.2 & 968.1 & 128.0 & 185.0 & 256.0 & 341.1 & 454.2 & n.d. & 667.4 & 752.5 & 837.5 & 924.5 & 1037.3 & 1122.6 & 768.5 \\
\hline Pept-VIa & $0.84 \%$ & 1876.2 & 1899.2 & 961.1 & 128.0 & 185.0 & 256.0 & 341.1 & 454.2 & n.d. & 667.4 & 752.5 & 837.5 & 924.5 & 1037.3 & 1122.6 & 754.5 \\
\hline Pept-VIb & $23.32 \%$ & 1890.2 & 1913.2 & 968.1 & 128.0 & 185.0 & 256.0 & 341.1 & 454.2 & n.d. & 667.4 & 752.5 & 837.5 & 924.5 & 1037.3 & 1122.6 & 768.5 \\
\hline Pept-VII & $4.16 \%$ & 1889.3 & 1912.3 & 967.65 & 128.0 & 185.0 & 256.0 & 341.1 & 454.2 & n.d. & 667.4 & 752.5 & 837.5 & 924.5 & 1037.3 & 1122.6 & 768.5 \\
\hline Pept-VIIIa & $0.49 \%$ & 1874.2 & 1897.2 & 960.1 & 128.0 & 185.0 & 256.0 & 341.1 & 454.2 & n.d. & 667.4 & 752.5 & 837.5 & 924.5 & 1037.3 & 1122.6 & 754.5 \\
\hline Pept-VIIIb & $27.99 \%$ & 1890.2 & 1913.2 & 968.1 & 128.0 & 185.0 & 256.0 & 341.1 & 454.2 & n.d. & 667.4 & 752.5 & 837.5 & 924.5 & 1037.3 & 1122.6 & 768.5 \\
\hline Pept-IX & & 1874.5 & 1897.5 & 960.25 & 128.0 & 184.9 & 256.0 & 341.3 & 454.2 & n.d. & 667.4 & 752.4 & 837.5 & 908.6 & 1021.7 & 1106.7 & \\
\hline Pept-X & & 1904.2 & 1927.2 & 975.1 & 128.0 & 199.0 & 270.0 & 355.0 & 467.9 & n.d. & 681.4 & 766.5 & 851.5 & 938.5 & 1051.0 & 1136.8 & \\
\hline Pept-XI & $4.82 \%$ & 1903.3 & 1926.3 & 974.65 & 128.0 & 199.0 & 270.0 & 355.0 & 467.9 & n.d. & 681.4 & 766.5 & 851.5 & 938.5 & 1051.0 & 1136.8 & 768.5 \\
\hline Pept-XII & $0.69 \%$ & 1904.2 & 1927.2 & 975.1 & 128.0 & 199.0 & 270.0 & 355.0 & 467.9 & n.d. & 681.4 & 766.5 & 851.5 & 938.5 & 1051.0 & 1136.8 & 768.5 \\
\hline
\end{tabular}

n.d.: not detected, *value belonging to both peptides (result of the same peak of y7 ion) 
Table 8 I Diagnostic fragment ions of peptaibols detected with the full scan Varian-MS measurement of peptaibol extracts from plate cultures of $T$. koningiopsis SZMC 12500

\begin{tabular}{|c|c|c|c|c|c|c|c|c|c|c|c|c|c|c|c|c|c|}
\hline Peptide & $\begin{array}{c}\text { Area } \\
\text { size }\end{array}$ & $\mathbf{M}$ & {$[\mathbf{M}+\mathbf{N a}]^{+}$} & {$[\mathrm{M}+2 \mathrm{Na}]^{2+}$} & $\mathbf{b}_{1}$ & $\mathbf{b}_{2}$ & $\mathbf{b}_{3}$ & $\mathbf{b}_{4}$ & $\mathbf{b}_{5}$ & $\mathbf{b}_{6}$ & $\mathbf{b}_{7}$ & $\mathbf{b}_{8}$ & $\mathbf{b}_{9}$ & $\mathbf{b}_{10}$ & $\mathbf{b}_{11}$ & $\mathbf{b}_{12}$ & $\mathbf{y}_{7}$ \\
\hline Koningiopsin Ia & $0.91 \%$ & 1875.5 & 1898.5 & 960.75 & 128.0 & 199.1 & 270.0 & 355.1 & 453.3 & n.d. & 666.4 & 751.5 & 836.6 & 923.5 & 1037.6 & 1122.2 & 754.5 \\
\hline Koningiopsin Ib & $5.96 \%$ & 1889.5 & 1912.5 & 967.75 & 128.0 & 199.1 & 270.0 & 355.1 & 453.3 & n.d. & 666.4 & 751.5 & 836.6 & 923.5 & 1037.6 & 1122.2 & 768.5 \\
\hline Koningiopsin IIa & $8.13 \%$ & 1890.5 & 1913.5 & 968.25 & 128.0 & 199.0 & 270.0 & 355.0 & 440.2 & n.d. & 653.4 & 738.4 & 850.9 & 938.6 & 1050.9 & 1136.8 & 754.5 \\
\hline Koningiopsin IIb & $2.88 \%$ & 1889.6 & 1912.6 & 967.8 & 128.1 & 199.1 & 270.0 & 355.1 & 440.1 & n.d. & 653.4 & 738.4 & 822.5 & 922.5 & 1035.8 & 1120.8 & 768.5 \\
\hline Koningiopsin IIIa & $0.97 \%$ & 1891.6 & 1914.6 & 968.8 & 128.1 & 199.0 & 270.1 & 355.1 & 426.0 & n.d. & 639.3 & 724.5 & 836.4 & 923.5 & 1037.1 & 1122.6 & 755.5 \\
\hline Koningiopsin IIIb & $2.03 \%$ & 1873.6 & 1896.6 & 959.8 & 128.1 & 199.1 & 270.0 & 355.1 & 440.1 & n.d. & 653.4 & 738.4 & 822.5 & 922.5 & 1035.8 & 1120.8 & 754.5 \\
\hline Koningiopsin IV & $12.27 \%$ & 1903.6 & 1926.6 & 974.8 & 128.0 & 199.0 & 270.0 & 355.0 & 440.2 & n.d. & 653.4 & 738.4 & 850.9 & 938.6 & 1050.9 & 1136.8 & 768.5 \\
\hline Koningiopsin $\mathrm{Va}$ & $47.94 \%$ & 1903.6 & 1926.6 & 974.8 & 128.0 & 199.0 & 270.0 & 355.0 & 440.2 & n.d. & 653.4 & 738.4 & 850.9 & 938.6 & 1050.9 & 1136.8 & 768.5 \\
\hline Koningiopsin $\mathrm{Vb}$ & $5.95 \%$ & 1905.6 & 1928.6 & 975.8 & 128.0 & 199.0 & 270.0 & 355.0 & 440.2 & n.d. & 653.4 & 738.4 & 850.9 & 938.6 & 1050.9 & 1136.8 & 769.5 \\
\hline Koningiopsin VIa & $11.54 \%$ & 1888.6 & 1911.6 & 967.3 & 128.1 & 199.1 & 270.1 & 355.0 & 440.2 & n.d. & 653.3 & 738.4 & 851.6 & 921.6 & 1035.8 & 1120.7 & 768.5 \\
\hline Koningiopsin VIb & $1.41 \%$ & 1888.7 & 1911.7 & 967.35 & 128.1 & 199.1 & 270.1 & 355.0 & 440.2 & n.d. & 653.3 & 738.4 & 851.6 & 921.6 & 1035.8 & 1120.7 & 769.5 \\
\hline
\end{tabular}

n.d.: not detected 
Table 9 | Diagnostic fragment ions of acylium ion $\left(\mathrm{y}_{7}\right)$ detected with Varian-MS ${ }^{2}$ measurements of peptaibol extracts from plate cultures of T. gamsii SZMC 1656

\begin{tabular}{|c|c|c|c|c|c|c|}
\hline Peptide & $\mathbf{y}_{7}$ & $\begin{array}{c}\mathbf{y}_{7-}^{-} \\
\mathbf{H}_{2} \mathbf{O}\end{array}$ & $\mathbf{y}_{7}-\mathbf{A A}(\mathbf{A})$ & $\mathbf{y}_{7}-\mathbf{A A}(19-$ & $\mathbf{y}_{7}-\mathbf{A A}(19-$ & $\begin{array}{c}\mathbf{y}_{7}-\mathbf{A A}(19- \\
16)\end{array}$ \\
\hline Pept-Ia & 754.5 & 736.5 & 637.4 & 509.4 & 381.4 & 282.3 \\
\hline Pept-Ib & 768.5 & 750.5 & 651.4 & 523.4 & 395.4 & 282.4 \\
\hline Pept-IIa & 754.5 & 736.5 & 637.4 & 509.4 & 381.4 & 282.3 \\
\hline Pept-IIb & 768.5 & 750.5 & 651.4 & 523.4 & 395.4 & 282.4 \\
\hline Pept-IIIa & 754.5 & 736.5 & 637.4 & 509.4 & 381.4 & 282.3 \\
\hline Pept-IIIb & 768.5 & 750.5 & 651.4 & 523.4 & 395.4 & 282.4 \\
\hline Pept-IVa & 754.5 & 736.5 & 637.4 & 509.4 & 381.4 & 282.3 \\
\hline Pept-IVb & 768.5 & 750.5 & 651.4 & 523.4 & 395.4 & 282.4 \\
\hline Pept-Va & 754.5 & 736.5 & 637.4 & 509.4 & 381.4 & 282.3 \\
\hline Pept-Vb & 768.5 & 750.5 & 651.4 & 523.4 & 395.4 & 282.4 \\
\hline Pept-VIa & 754.5 & 736.5 & 637.4 & 509.4 & 381.4 & 282.3 \\
\hline Pept-VIb & 768.5 & 750.5 & 651.4 & 523.4 & 395.4 & 282.4 \\
\hline Pept-VII & 768.5 & 750.5 & 651.4 & 523.4 & 395.4 & 282.4 \\
\hline Pept-VIIIa & 754.5 & 736.5 & 637.4 & 509.4 & 381.4 & 282.3 \\
\hline Pept-VIIIb & 768.5 & 750.5 & 651.4 & 523.4 & 395.4 & 282.4 \\
\hline $\begin{array}{l}\text { Pept-IX } \\
\text { Pept-X }\end{array}$ & 768.5 & 750.5 & 651.4 & 523.4 & 395.4 & 282.4 \\
\hline Pept-XI & 768.5 & 750.5 & 651.4 & 523.4 & 395.4 & 282.4 \\
\hline Pept-XII & 768.5 & 750.5 & 651.4 & 523.4 & 395.4 & 282.4 \\
\hline
\end{tabular}

Table 10 | Diagnostic fragment ions of acylium ion $\left(\mathrm{y}_{7}\right)$ detected with Varian-MS ${ }^{2}$ measurements of peptaibol extracts from plate cultures of T. koningiopsis SZMC 12500

\begin{tabular}{|c|c|c|c|c|c|c|}
\hline Peptide & $\mathbf{y}_{7}$ & $\begin{array}{c}\mathbf{y}_{7}- \\
\mathbf{H}_{2} \mathbf{O}\end{array}$ & $\mathbf{y}_{7}-\mathbf{A A}(19)$ & $\mathbf{y}_{7}-\mathbf{A A}(19-$ & $\begin{array}{c}\mathbf{y}_{7}-\mathbf{A A}(19- \\
\mathbf{1 7})\end{array}$ & $\begin{array}{c}y_{7}-\mathbf{A A}(19- \\
16)\end{array}$ \\
\hline Koningiopsin Ia & 754.5 & 736.5 & 637.4 & 509.4 & 381.4 & 282.3 \\
\hline Koningiopsin Ib & 768.5 & 750.5 & 651.4 & 523.4 & 395.4 & 282.4 \\
\hline Koningiopsin IIa & 754.5 & 736.5 & 637.4 & 509.4 & 381.4 & 282.3 \\
\hline Koningiopsin IIb & 768.5 & 750.5 & 651.4 & 523.4 & 395.4 & 282.4 \\
\hline Koningiopsin IIIa & 755.5 & 737.5 & 638.4 & 509.4 & 381.4 & 282.3 \\
\hline Koningiopsin IIIb & 754.5 & 736.5 & 637.4 & 509.4 & 381.4 & 282.3 \\
\hline Koningiopsin IV & 768.5 & 750.5 & 651.4 & 523.4 & 395.4 & 282.4 \\
\hline Koningiopsin $\mathrm{Va}$ & 768.5 & 750.5 & 651.4 & 523.4 & 395.4 & 282.4 \\
\hline Koningiopsin $\mathrm{Vb}$ & 769.5 & 751.5 & 652.4 & 523.4 & 395.3 & 282.3 \\
\hline Koningiopsin VIa & 768.5 & 750.5 & 651.4 & 523.4 & 395.4 & 282.4 \\
\hline Koningiopsin VIb & 769.5 & 751.5 & 652.4 & 523.4 & 395.3 & 282.3 \\
\hline
\end{tabular}


Table 11 I Diagnostic fragment ions of peptaibols detected with the full scan Varian-MS measurement in plate cultures of T. aggressivum f. europaeum CBS 433.95 (SZMC 1811)

\begin{tabular}{|c|c|c|c|c|c|c|c|c|c|c|c|c|c|c|c|c|c|c|c|c|}
\hline $\begin{array}{l}\text { Name of } \\
\text { compound }\end{array}$ & $\begin{array}{c}\text { Area } \\
\text { size }\end{array}$ & $\mathbf{M}$ & {$[\mathbf{M}+\mathbf{H}]^{+}$} & {$[\mathrm{M}+\mathrm{Na}]^{+}$} & {$[\mathbf{M}+2 \mathrm{H}]^{2+}$} & {$[\mathrm{M}+\mathrm{Na}+\mathbf{H}]^{2+}$} & {$[\mathrm{M}+2 \mathrm{Na}]^{2+}$} & $\mathbf{b}_{1}$ & $\mathbf{b}_{2}$ & $\mathbf{b}_{3}$ & $\mathbf{b}_{4}$ & $\mathbf{b}_{5}$ & $\mathbf{b}_{6}$ & $\mathbf{b}_{7}$ & $\mathbf{b}_{8}$ & $\mathbf{b}_{9}$ & $\mathbf{b}_{10}$ & $b_{11}$ & $\mathbf{b}_{12}$ & $\mathbf{y}_{6}$ \\
\hline Pept-1719-a-1 & $5.6 \%$ & 1719 & 1720.4 & 1742.4 & 860.7 & 871.7 & 8882.7 & 128 & 215 & 286 & 399 & "484 & "n.d. & "697 & 7966 & 881 & 938 & 1023 & "1108.5 & 612.4 \\
\hline Pept-1719-a-2 & $0.6 \%$ & 1719 & 1720.4 & 1742.4 & 860.7 & 871.7 & 882.7 & 128 & 215 & 286 & 399 & 484 & n.d. & 697 & 796 & 881 & 938 & 1023 & 1107.7 & 612.4 \\
\hline Pept-1733-a-1 & $7.6 \%$ & 1733 & 1734.4 & 1756.4 & 867.7 & 878.7 & 889.7 & 128 & 215 & 286 & 399 & 498 & n.d. & 711 & 810 & 895 & 952 & 1037 & 1122.1 & 612.4 \\
\hline Pept-1703-a-1 & $4.0 \%$ & 1703 & 1704.4 & 1726.3 & 852.7 & 863.7 & 874.7 & 128 & 199 & 270 & 383 & 468 & n.d. & 681 & 780 & 865 & 922 & 1007 & 1092 & 612.3 \\
\hline Pept-1733-a-2 & $4.0 \%$ & 1733 & 1734.4 & 1756.4 & 867.7 & 878.7 & 889.7 & 128 & 215 & 286 & 399 & 484 & n.d. & 711 & 810 & 895 & 952 & 1037 & 1121.9 & 612.4 \\
\hline Pept-1717-a-1 & $0.4 \%$ & 1717 & 1718.4 & 1740.4 & 859.7 & 870.7 & 881.7 & 128 & 199 & 270 & 383 & 482 & n.d. & 695 & 794 & 879 & 936 & 1021 & 1105.9 & 612.4 \\
\hline Pept-1733-a-3 & $12.5 \%$ & 1733 & 1734.4 & 1756.4 & 867.7 & 878.7 & 889.7 & 128 & 215 & 286 & 399 & 484 & n.d. & 697 & 796 & 881 & 938 & 1037 & 1122.1 & 612.4 \\
\hline Pept-1717-a-2 & $2.9 \%$ & 1717 & 1718.4 & 1740.4 & 859.7 & 870.7 & 881.7 & 128 & 199 & 270 & 383 & 482 & n.d. & 695 & 794 & 879 & 936 & 1021 & 1106 & 612.4 \\
\hline Pept-1747-a-1 & $2.4 \%$ & 1747 & 1748.4 & 1770.4 & 874.7 & 885.7 & 896.7 & 128 & 215 & 286 & 399 & 498 & n.d. & 711 & 810 & 895 & 952 & 1051 & 1135.9 & 612.4 \\
\hline Pept-1747-a-2 & $4.2 \%$ & 1747 & 1748.4 & 1770.4 & 874.7 & 885.7 & 896.7 & 128 & 215 & 286 & 399 & 498 & n.d. & 711 & 810 & 895 & 952 & 1051 & 1135.9 & 612.4 \\
\hline Pept-1747-a-3 & $13.5 \%$ & 1747 & 1748.4 & 1770.4 & 874.7 & 885.7 & 896.7 & 128 & 215 & 286 & 399 & 498 & n.d. & 711 & 810 & 895 & 952 & 1051 & 1136 & 612.4 \\
\hline Pept-1761-a-1 & $0.6 \%$ & 1762 & 1763.4 & 1785.4 & 881.7 & 892.7 & 904.2 & 128 & 215 & 286 & 399 & 498 & n.d. & 725 & 824 & 909 & 966 & 1065 & 1150.1 & 612.4 \\
\hline Pept-1717-a-3 & $5.6 \%$ & 1717 & 1718.4 & 1740.4 & 859.7 & 870.7 & 881.7 & 128 & 199 & 270 & 383 & 468 & n.d. & 681 & 780 & 865 & 922 & 1021 & 1105.9 & 612.4 \\
\hline Pept-1731-a-1 & $1.4 \%$ & 1731 & 1732.4 & 1754.4 & 866.7 & 877.7 & 888.7 & 128 & 199 & 270 & 383 & 468 & n.d. & 695 & 794 & 879 & 936 & 1035 & 1119.9 & 612.4 \\
\hline Pept-1747-a-4 & $8.1 \%$ & 1747 & 1748.4 & 1770.4 & 874.7 & 885.7 & 896.7 & 128 & 215 & 286 & 399 & 484 & n.d. & 711 & 810 & 895 & 952 & 1051 & 1136.6 & 612.4 \\
\hline Pept-1731-a-2 & $1.3 \%$ & 1731 & 1732.4 & 1754.4 & 866.7 & 877.7 & 888.7 & 128 & 199 & 270 & 383 & 482 & n.d. & 695 & 794 & 879 & 936 & 1035 & 1120.9 & 612.4 \\
\hline Pept-1761-b-1 & $2.2 \%$ & 1761 & 1762.4 & 1784.4 & 881.7 & 892.7 & 903.7 & 128 & 215 & 286 & 399 & 498 & n.d. & 711 & 810 & 895 & 952 & 1051 & 1136 & 626.4 \\
\hline Pept-1761-a-2 & $1.0 \%$ & 1761 & 1762.4 & 1784.4 & 881.7 & 892.7 & 903.7 & 128 & 215 & 286 & 399 & 498 & n.d. & 725 & 824 & 909 & 966 & 1065 & 1149.9 & 612.4 \\
\hline Pept-1731-a-3 & $6.9 \%$ & 1731 & 1732.4 & 1754.4 & 866.7 & 877.7 & 888.7 & 128 & 199 & 270 & 383 & 482 & n.d. & 695 & 794 & 879 & 936 & 1035 & 1120.2 & 612.4 \\
\hline Pept-1761-a-3 & $8.7 \%$ & 1761 & 1762.4 & 1784.4 & 881.7 & 892.7 & 903.7 & 128 & 215 & 286 & 399 & 498 & n.d. & 725 & 824 & 909 & 966 & 1065 & 1150 & 612.4 \\
\hline Pept-1731-a-4 & $2.5 \%$ & 1731 & 1732.4 & 1754.4 & 866.7 & 877.7 & 888.7 & 128 & 199 & 270 & 383 & 468 & n.d. & 695 & 794 & 879 & 936 & 1035 & 1119.8 & 612.4 \\
\hline Pept-1745-a-1 & $0.5 \%$ & 1745 & 1746.4 & 1768.4 & 873.7 & 884.7 & 895.7 & 128 & 199 & 270 & 383 & 482 & n.d. & 709 & 808 & 893 & 950 & 1049 & 1134.3 & 612.4 \\
\hline Pept-1775-b-1 & $0.4 \%$ & 1775 & 1776.4 & 1798.4 & 888.7 & 899.7 & 910.7 & 128 & 215 & 286 & 399 & 498 & n.d. & 725 & 824 & 909 & 966 & 1065 & 1149.6 & 626.4 \\
\hline Pept-1775-b-2 & $0.3 \%$ & 1775 & 1776.4 & 1798.4 & 888.7 & 899.7 & 910.7 & 128 & 215 & 286 & 399 & 498 & n.d. & 725 & 824 & 909 & 966 & 1065 & 1149.7 & 626.4 \\
\hline Pept-1745-a-2 & $2.8 \%$ & 1745 & 1746.4 & 1768.4 & 873.7 & 884.7 & 895.7 & 128 & 199 & 270 & 383 & 482 & n.d. & 709 & 808 & 893 & 950 & 1049 & 1133.9 & 612.4 \\
\hline
\end{tabular}

n.d.: not detected 
Table 12 | Diagnostic fragment ions of acylium ion $\left(\mathrm{y}_{6}\right)$ detected with Varian-MS ${ }^{2}$ measurements in plate cultures of T. aggressivum f. europaeum CBS 433.95 (SZMC 1811)

\begin{tabular}{|c|c|c|c|c|c|c|c|}
\hline Name of compound & $\mathbf{M}$ & $\mathbf{y}_{6}$ & $\mathbf{y}_{6}-\mathrm{H}_{2} \mathrm{O}$ & $\mathbf{y}_{6}-\mathbf{A A}(18)$ & $\mathbf{y}_{6}$-AA (18-17) & $\mathrm{y}_{6}$-AA (18-16) & $\mathbf{y}_{6}-\mathbf{A A}(18-15)$ \\
\hline Pept-1719-a-1 & 1719 & 612.4 & $\begin{array}{c}594.4 \\
\end{array}$ & 509.4 & 381.4 & 296.4 & 211.4 \\
\hline Pept-1719-a-2 & 1719 & 612.4 & 594.4 & 509.4 & 381.4 & 296.4 & 211.4 \\
\hline Pept-1733-a-1 & 1733 & 612.4 & 594.4 & 509.4 & 381.4 & 296.4 & 211.4 \\
\hline Pept-1703-a-1 & 1703 & 612.3 & 594.4 & 509.4 & 381.4 & 296.4 & 211.4 \\
\hline Pept-1733-a-2 & 1733 & 612.4 & 594.4 & 509.4 & 381.4 & 296.4 & 211.4 \\
\hline Pept-1717-a-1 & 1717 & 612.4 & 594.4 & 509.4 & 381.4 & 296.4 & 211.4 \\
\hline Pept-1733-a-3 & 1733 & 612.4 & 594.4 & 509.4 & 381.4 & 296.4 & 211.4 \\
\hline Pept-1717-a-2 & 1717 & 612.4 & 594.4 & 509.4 & 381.4 & 296.4 & 211.4 \\
\hline Pept-1747-a-1 & 1747 & 612.4 & 594.4 & 509.4 & 381.4 & 296.4 & 211.4 \\
\hline Pept-1747-a-2 & 1747 & 612.4 & 594.4 & 509.4 & 381.4 & 296.4 & 211.4 \\
\hline Pept-1747-a-3 & 1747 & 612.4 & 594.4 & 509.4 & 381.4 & 296.4 & 211.4 \\
\hline Pept-1761-a-1 & 1762 & 612.4 & 594.4 & 509.4 & 381.4 & 296.4 & 211.4 \\
\hline Pept-1717-a-3 & 1717 & 612.4 & 594.4 & 509.4 & 381.4 & 296.4 & 211.4 \\
\hline Pept-1731-a-1 & 1731 & 612.4 & 594.4 & 509.4 & 381.4 & 296.4 & 211.4 \\
\hline Pept-1747-a-4 & 1747 & 612.4 & 594.4 & 509.4 & 381.4 & 296.4 & 211.4 \\
\hline Pept-1731-a-2 & 1731 & 612.4 & 594.4 & 509.4 & 381.4 & 296.4 & 211.4 \\
\hline Pept-1761-b-1 & 1761 & 626.4 & 608.4 & 509.4 & 381.4 & 296.4 & 211.4 \\
\hline Pept-1761-a-2 & 1761 & 612.4 & 594.4 & 509.4 & 381.4 & 296.4 & 211.4 \\
\hline Pept-1731-a-3 & 1731 & 612.4 & 594.4 & 509.4 & 381.4 & 296.4 & 211.4 \\
\hline Pept-1761-a-3 & 1761 & 612.4 & 594.4 & 509.4 & 381.4 & 296.4 & 211.4 \\
\hline Pept-1731-a-4 & 1731 & 612.4 & 594.4 & 509.4 & 381.4 & 296.4 & 211.4 \\
\hline Pept-1745-a-1 & 1745 & 612.4 & 594.4 & 509.4 & 381.4 & 296.4 & 211.4 \\
\hline Pept-1775-b-1 & 1775 & 626.4 & 608.4 & 509.4 & 381.4 & 296.4 & 211.4 \\
\hline Pept-1775-b-2 & 1775 & 626.4 & 608.4 & 509.4 & 381.4 & 296.4 & 211.4 \\
\hline Pept-1745-a-2 & 1745 & 612.4 & 594.4 & 509.4 & 381.4 & 296.4 & 211.4 \\
\hline
\end{tabular}


Table 13 I Diagnostic fragment ions of peptaibols detected with the full scan Varian-MS measurement in plate cultures of T. pleuroti TPhu1 (SZMC 12454)

\begin{tabular}{|c|c|c|c|c|c|c|c|c|c|c|c|c|c|c|c|c|c|c|c|c|}
\hline $\begin{array}{l}\text { Name of } \\
\text { compound }\end{array}$ & $\begin{array}{c}\text { Area } \\
\text { size }\end{array}$ & $\mathbf{M}$ & {$[\mathbf{M}+\mathbf{H}]^{+}$} & {$[\mathbf{M}+\mathbf{N a}]^{+}$} & {$[\mathbf{M}+2 \mathrm{H}]^{2+}$} & {$[\mathbf{M}+\mathbf{N a}+\mathbf{H}]^{2+}$} & {$[\mathrm{M}+2 \mathrm{Na}]^{2+}$} & $\mathbf{b}_{1}$ & $\mathbf{b}_{2}$ & $\mathbf{b}_{3}$ & $\mathbf{b}_{4}$ & $\mathbf{b}_{5}$ & $\mathbf{b}_{6}$ & $\mathbf{b}_{7}$ & $\mathbf{b}_{8}$ & $\mathbf{b}_{9}$ & $\mathbf{b}_{10}$ & $b_{11}$ & $\mathbf{b}_{12}$ & $\mathbf{y}_{6}$ \\
\hline Tripleurin Ia & $0.6 \%$ & 1767 & 1768.0 & 1790.0 & 884.5 & 895.5 & 906.5 & 128 & 215 & 286 & 371 & 456 & n.d. & 669 & 768 & 853 & 924 & 1023 & 1107.9 & 660.3 \\
\hline Tripleurin II & $2.8 \%$ & 1767 & 1768.0 & 1790.0 & 884.5 & 895.5 & 906.5 & 128 & 215 & 286 & 371 & 456 & n.d. & 669 & 768 & 853 & 924 & 1009 & 1094.5 & 674.3 \\
\hline Tripleurin Ib & $6.5 \%$ & 1767 & 1768.0 & 1790.0 & 884.5 & 895.5 & 906.5 & 128 & 215 & 286 & 371 & 456 & n.d. & 669 & 768 & 853 & 924 & 1023 & 1107.8 & 660.3 \\
\hline Tripleurin IIIa & $4.6 \%$ & 1782 & 1783.0 & 1805.0 & 891.5 & 902.5 & 914.0 & 128 & 215 & 286 & 371 & 470 & n.d. & 683 & 782 & 867 & 938 & 1023 & 1107.9 & 674.4 \\
\hline Tripleurin IIIb & $6.3 \%$ & 1782 & 1783.0 & 1805.0 & 891.5 & 902.5 & 914.0 & 128 & 215 & 286 & 371 & 470 & n.d. & 683 & 782 & 867 & 938 & 1023 & 1108 & 674.4 \\
\hline Tripleurin IV & $1.4 \%$ & 1752 & 1753.4 & 1775.4 & 876.5 & 887.5 & 899.2 & 128 & 199 & 270 & 355 & 440 & n.d. & 653 & 752 & 837 & 908 & 993 & 1077.9 & 674.4 \\
\hline Tripleurin V & $7.0 \%$ & 1782 & 1783.0 & 1805.0 & 891.5 & 902.5 & 914.0 & 128 & 215 & 286 & 371 & 456 & n.d. & 669 & 768 & 867 & 938 & 1037 & 1122.5 & 660.3 \\
\hline Tripleurin VI & $7.9 \%$ & 1782 & 1783.0 & 1805.0 & 891.5 & 902.5 & 914.0 & 128 & 215 & 286 & 371 & 470 & n.d. & 669 & 768 & 853 & 924 & 1023 & 1107.9 & 674.3 \\
\hline Tripleurin VII & $1.2 \%$ & 1752 & 1753.4 & 1775.4 & 876.5 & 887.5 & 899.2 & 128 & 199 & 270 & 355 & 440 & n.d. & 653 & 752 & 837 & 908 & 1007 & 1092.5 & 660.4 \\
\hline $\begin{array}{l}\text { Tripleurin } \\
\text { VIIIa }\end{array}$ & $4.0 \%$ & 1796 & 1797.0 & 1819.0 & 898.5 & 909.5 & 921.0 & 128 & 215 & 286 & 371 & 470 & n.d. & 697 & 796 & 881 & 952 & 1037 & 1121.8 & 674.3 \\
\hline Tripleurin IXa & $0.8 \%$ & 1765 & 1766.0 & 1788.0 & 883.5 & 894.5 & 905.5 & 128 & 199 & 270 & 355 & 454 & n.d. & 667 & 766 & 865 & 936 & 1021 & 1106.6 & 660.4 \\
\hline Tripleurin X & $1.2 \%$ & 1765 & 1766.0 & 1788.0 & 883.5 & 894.5 & 905.5 & 128 & 199 & 270 & 355 & 454 & n.d. & 667 & 766 & 851 & 922 & 1007 & 1091.8 & 674.4 \\
\hline Tripleurin XI & $7.4 \%$ & 1796 & 1797.0 & 1819.0 & 898.5 & 909.5 & 921.0 & 128 & 215 & 286 & 371 & 456 & n.d. & 683 & 782 & 881 & 952 & 1051 & 1135.8 & 660.3 \\
\hline $\begin{array}{l}\text { Tripleurin } \\
\text { VIIIb }\end{array}$ & $10.0 \%$ & 1796 & 1797.0 & 1819.0 & 898.5 & 909.5 & 921.0 & 128 & 215 & 286 & 371 & 470 & n.d. & 683 & 782 & 867 & 938 & 1037 & 1122.2 & 674.3 \\
\hline Tripleurin IXb & $5.9 \%$ & 1765 & 1766.0 & 1788.0 & 883.5 & 894.5 & 905.5 & 128 & 199 & 270 & 355 & 454 & n.d. & 667 & 766 & 865 & 936 & 1021 & 1105.8 & 660.4 \\
\hline Tripleurin XIIa & $0.9 \%$ & 1810 & 1811.0 & 1833.0 & 905.5 & 916.5 & 928.0 & 128 & 215 & 286 & 371 & 470 & n.d. & 697 & 782 & 881 & 952 & 1051 & 1135.8 & 674.4 \\
\hline Tripleurin XIIb & $1.3 \%$ & 1810 & 1811.0 & 1833.0 & 905.5 & 916.5 & 928.0 & 128 & 215 & 286 & 371 & 470 & n.d. & 697 & 782 & 881 & 952 & 1051 & 1135.9 & 674.4 \\
\hline Tripleurin XIIc & $12.0 \%$ & 1810 & 1811.0 & 1833.0 & 905.5 & 916.5 & 928.0 & 128 & 215 & 286 & 371 & 470 & n.d. & 697 & 782 & 881 & 952 & 1051 & 1135.9 & 674.3 \\
\hline $\begin{array}{l}\text { Tripleurin } \\
\text { XIIIa }\end{array}$ & $0.8 \%$ & 1780 & 1781.0 & 1803.0 & 890.5 & 901.5 & 913.0 & 128 & 199 & 270 & 355 & 454 & n.d. & 695 & 780 & 865 & 936 & 1021 & 1106 & 674.3 \\
\hline $\begin{array}{l}\text { Tripleurin } \\
\text { XIIIb }\end{array}$ & $3.1 \%$ & 1780 & 1781.0 & 1803.0 & 890.5 & 901.5 & 913.0 & 128 & 199 & 270 & 355 & 454 & n.d. & 695 & 780 & 851 & 922 & 1021 & 1106.4 & 674.4 \\
\hline $\begin{array}{l}\text { Tripleurin } \\
\text { XIIIc }\end{array}$ & $7.4 \%$ & 1780 & 1781.0 & 1803.0 & 890.5 & 901.5 & 913.0 & 128 & 199 & 270 & 355 & 454 & n.d. & 695 & 780 & 851 & 922 & 1021 & 1105.9 & 674.4 \\
\hline Tripleurin XIV & $2.2 \%$ & 1824 & 1825.0 & 1847.0 & 912.5 & 923.5 & 935.0 & 128 & 215 & 286 & 371 & 470 & n.d. & 697 & 782 & 895 & 966 & 1065 & 1149.8 & 674.3 \\
\hline Tripleurin XV & $4.6 \%$ & 1794 & 1795.0 & 1817.0 & 897.5 & 908.5 & 920.0 & 128 & 199 & 270 & 355 & 454 & n.d. & 681 & 780 & 865 & 936 & 1035 & 1120.6 & 674.3 \\
\hline Tripleurin XVI & $0.3 \%$ & 1808 & 1809.0 & 1831.0 & 904.5 & 915.5 & 927.0 & 128 & 199 & 270 & 355 & 454 & n.d. & 695 & 780 & 879 & 950 & 1049 & 1133.8 & 674.3 \\
\hline
\end{tabular}

n.d.: not detected 
Table 14 | Diagnostic fragment ions of acylium ion $\left(\mathrm{y}_{6}\right)$ detected with Varian-MS ${ }^{2}$ measurements in plate cultures of $T$. pleuroti TPhu1 (SZMC 12454)

\begin{tabular}{|c|c|c|c|c|c|c|c|}
\hline $\begin{array}{l}\text { Name of } \\
\text { compound }\end{array}$ & $\mathbf{M}$ & $\mathbf{y}_{6}$ & $\mathrm{y}_{6}-\mathrm{H}_{2} \mathrm{O}$ & $\mathbf{y}_{6}-\mathbf{A A}(18)$ & $\mathbf{y}_{6}$-AA (18-17) & $\mathbf{y}_{6}$-AA (18-16) & $\mathrm{y}_{6}$-AA (18-15) \\
\hline Tripleurin Ia & 1767 & 660.3 & 642.3 & 509.3 & 381.3 & 296.3 & 211.3 \\
\hline Tripleurin II & 1767 & 674.3 & 656.3 & 523.3 & 395.3 & 296.3 & 211.3 \\
\hline Tripleurin Ib & 1767 & 660.3 & 642.3 & 509.3 & 381.3 & 296.3 & 211.3 \\
\hline Tripleurin IIIa & 1782 & 674.4 & 656.4 & 523.4 & 395.4 & 296.4 & 211.4 \\
\hline Tripleurin IIIb & 1782 & 674.4 & 656.4 & 523.4 & 395.4 & 296.4 & 211.4 \\
\hline Tripleurin IV & 1752 & 674.4 & 656.4 & 523.4 & 395.4 & 296.4 & 211.4 \\
\hline Tripleurin V & 1782 & 660.3 & 642.3 & 509.3 & 381.3 & 296.3 & 211.3 \\
\hline Tripleurin VI & 1782 & 674.3 & 656.3 & 523.3 & 395.3 & 296.3 & 211.3 \\
\hline Tripleurin VII & 1752 & 660.4 & 642.4 & 509.4 & 381.4 & 296.4 & 211.4 \\
\hline Tripleurin VIIIa & 1796 & 674.3 & 656.3 & 523.3 & 395.3 & 296.3 & 211.3 \\
\hline Tripleurin IXa & 1765 & 660.4 & 642.4 & 509.4 & 381.4 & 296.4 & 211.4 \\
\hline Tripleurin X & 1765 & 674.4 & 656.4 & 523.4 & 395.4 & 296.4 & 211.4 \\
\hline Tripleurin XI & 1796 & 660.3 & 642.3 & 509.3 & 381.3 & 296.3 & 211.3 \\
\hline Tripleurin VIIIb & 1796 & 674.3 & 656.3 & 523.3 & 395.3 & 296.3 & 211.3 \\
\hline Tripleurin IXb & 1765 & 660.4 & 642.4 & 509.4 & 381.4 & 296.4 & 211.4 \\
\hline Tripleurin XIIa & 1810 & 674.4 & 656.4 & 523.4 & 395.4 & 296.4 & 211.4 \\
\hline Tripleurin XIIb & 1810 & 674.4 & 656.4 & 523.4 & 395.4 & 296.4 & 211.4 \\
\hline Tripleurin XIIc & 1810 & 674.3 & 656.3 & 523.3 & 395.3 & 296.3 & 211.3 \\
\hline Tripleurin XIIIa & 1780 & 674.3 & 656.3 & 523.3 & 395.3 & 296.3 & 211.3 \\
\hline Tripleurin XIIIb & 1780 & 674.4 & 656.4 & 523.4 & 395.4 & 296.4 & 211.4 \\
\hline Tripleurin XIIIc & 1780 & 674.4 & 656.4. & 523.4 & 395.4 & 296.4 & 211.4 \\
\hline Tripleurin XIV & 1824 & 674.3 & 656.3 & 523.3 & 395.3 & 296.3 & 211.3 \\
\hline Tripleurin XV & 1794 & 674.3 & 656.3 & 523.3 & 395.3 & 296.3 & 211.3 \\
\hline Tripleurin XVI & 1808 & 674.3 & 656.3 & 523.3 & 395.3 & 296.3 & 211.3 \\
\hline
\end{tabular}


Table 15 I Relative amounts of the identified peptaibol compounds in the peptaibol profiles of T. aethiopicum, T. pinnatum, T. capillare, T. pseudokoningii, T. citrinoviride, T. longibrachiatum, T. bissettii, T. orientale and T. novae-zelandiae. The colours represent the extent of the production (percentage) of each strain from the lowest (yellow) to the highest (red)

\begin{tabular}{|c|c|c|c|c|c|c|c|c|c|c|c|c|}
\hline & $\begin{array}{c}\text { T. aethiopi- } \\
\text { cum }\end{array}$ & T. pinnatum & T. ghanense & T. capillare & $\begin{array}{c}\text { T. pseudo- } \\
\text { koningii }\end{array}$ & $\begin{array}{c}\begin{array}{c}\text { T. citrino- } \\
\text { viride }\end{array} \\
\end{array}$ & T. bissettii & $\begin{array}{c}\text { T. longibrachi- } \\
\text { atum }\end{array}$ & T. bissettii & T. bissettii & T. orientale & $\begin{array}{l}\text { T. novae- } \\
\text { zelandiae } \\
\end{array}$ \\
\hline Peptaibol & 22602 & 22603 & 22604 & 22605 & 22613 & 22618 & 1773 & 1775 & 1776 & 12546 & 12556 & 22612 \\
\hline \multirow{2}{*}{$\begin{array}{l}\text { Pept-A-Ia } \\
\text { Pept-A-Ib }\end{array}$} & & & & & & & & & & $2.01 \%$ & $5.19 \%$ & \\
\hline & & & & & & & & & & & & $3.19 \%$ \\
\hline \multirow{2}{*}{$\begin{array}{l}\text { Pept-A-IIa } \\
\text { Pept-A-IIb }\end{array}$} & & & & & & & $2.20 \%$ & $1.58 \%$ & $1.15 \%$ & & & \\
\hline & & & & & & & & & & $0.40 \%$ & & \\
\hline \multirow{3}{*}{$\begin{array}{l}\text { Pept-A-IIIa } \\
\text { Pept-A-IIIb } \\
\text { Pept-A-IIIc }\end{array}$} & & & & & $1.24 \%$ & & & & & & & \\
\hline & & & & & & & & & & & $2.06 \%$ & \\
\hline & & & & & & & & & & & & $1.99 \%$ \\
\hline \multirow{2}{*}{$\begin{array}{l}\text { Pept-A-IVa } \\
\text { Pept-A-IVb }\end{array}$} & $27.09 \%$ & $31.98 \%$ & & $29.78 \%$ & $16.71 \%$ & $8.97 \%$ & $25.40 \%$ & $42.77 \%$ & $14.52 \%$ & $43.21 \%$ & $47.08 \%$ & $26.43 \%$ \\
\hline & & & $19.67 \%$ & & & & & & & & & \\
\hline \multirow{2}{*}{$\begin{array}{l}\text { Pept-A-Va } \\
\text { Pept-A-Vb }\end{array}$} & & & & & $5.30 \%$ & & & & & & & \\
\hline & & & & & & & & & & & & $3.65 \%$ \\
\hline \multirow{2}{*}{$\begin{array}{l}\text { Pept-A-VIa } \\
\text { Pept-A-VIb }\end{array}$} & & & & $9.94 \%$ & $2.14 \%$ & $0.78 \%$ & $16.36 \%$ & $14.57 \%$ & $23.34 \%$ & $5.81 \%$ & $1.90 \%$ & \\
\hline & $6.89 \%$ & $10.39 \%$ & $28.06 \%$ & & & & & & & & & \\
\hline \multirow{2}{*}{$\begin{array}{l}\text { Pept-A-VIIa } \\
\text { Pept-A-VIIb }\end{array}$} & & & & & & $0.73 \%$ & & & & & & \\
\hline & $3.77 \%$ & & & & & & & & & & & \\
\hline \multirow{2}{*}{$\begin{array}{l}\text { Pept-A-VIIIa } \\
\text { Pept-A-VIIIb }\end{array}$} & & $10.50 \%$ & & & & & & & & & & \\
\hline & & & & & & & & $3.04 \%$ & & & & \\
\hline \multirow{2}{*}{$\begin{array}{l}\text { Pept-A-IXa } \\
\text { Pept-A-IXb }\end{array}$} & $3.05 \%$ & & & $21.94 \%$ & $30.27 \%$ & $24.51 \%$ & $12.00 \%$ & $1.98 \%$ & $7.79 \%$ & $16.72 \%$ & $34.48 \%$ & \\
\hline & & $1.60 \%$ & $22.55 \%$ & & & & & & & & & $47.01 \%$ \\
\hline Pept-A-Xa & & & & & $8.69 \%$ & & & & & & & \\
\hline \multirow{3}{*}{$\begin{array}{l}\text { Pept-A-XIa } \\
\text { Pept-A-XIb } \\
\text { Pept-A-XIc } \\
\end{array}$} & $2.05 \%$ & & & & & & & $1.29 \%$ & $0.35 \%$ & & & \\
\hline & & & & & $1.44 \%$ & & $0.69 \%$ & & & & & \\
\hline & & $3.76 \%$ & & & & & & & & & & \\
\hline Pept-A-XII & & & & & & & & & & & & $0.54 \%$ \\
\hline
\end{tabular}


Table 15 | continued

\begin{tabular}{|c|c|c|c|c|c|c|c|c|c|c|c|c|}
\hline & $\begin{array}{c}\begin{array}{c}\text { T. aethiopi- } \\
\text { cum }\end{array} \\
\end{array}$ & T. pinnatum & T. ghanense & T. capillare & $\begin{array}{c}\text { T. pseudo- } \\
\text { koningii }\end{array}$ & $\begin{array}{c}\begin{array}{c}\text { T. citrino- } \\
\text { viride }\end{array} \\
\end{array}$ & $\begin{array}{c}\begin{array}{c}\text { T. longibrachi- } \\
\text { atum f. bissettii }\end{array} \\
\end{array}$ & $\begin{array}{c}\text { T. longibrachi- } \\
\text { atum }\end{array}$ & T. bissettii & $\begin{array}{c}\text { T. longibrachi- } \\
\text { atum f. bissettii }\end{array}$ & T. orientale & $\begin{array}{l}\text { T. novae- } \\
\text { zelandiae }\end{array}$ \\
\hline Peptaibol & 22602 & 22603 & 22604 & 22605 & 22613 & 22618 & 1773 & 1775 & 1776 & 12546 & 12556 & 22612 \\
\hline \multirow{2}{*}{$\begin{array}{l}\text { Pept-A-XIIIa } \\
\text { Pept-A-XIIIb }\end{array}$} & & & & $6.78 \%$ & & & $5.01 \%$ & $1.42 \%$ & $7.70 \%$ & $0.79 \%$ & & \\
\hline & & & $17.97 \%$ & & & & & & & & & \\
\hline \multirow{2}{*}{$\begin{array}{l}\text { Pept-A-XIVa } \\
\text { Pept-A-XIVb }\end{array}$} & $0.48 \%$ & $0.36 \%$ & & & & & & & & & & $3.48 \%$ \\
\hline & & & & & $2.82 \%$ & $1.99 \%$ & & & & & & \\
\hline \multirow{2}{*}{$\begin{array}{l}\text { Pept-A-XVa } \\
\text { Pept-A-XVb }\end{array}$} & $0.29 \%$ & & & $2.88 \%$ & $2.68 \%$ & $2.55 \%$ & $1.86 \%$ & $0.31 \%$ & $1.96 \%$ & $1.68 \%$ & $6.67 \%$ & \\
\hline & & $0.56 \%$ & & & & & & & & & & $4.83 \%$ \\
\hline \multirow{2}{*}{$\begin{array}{l}\text { Pept-A-XVIa } \\
\text { Pept-A-XVIb }\end{array}$} & $36.48 \%$ & $24.23 \%$ & $1.61 \%$ & $12.08 \%$ & $8.19 \%$ & $14.79 \%$ & $15.26 \%$ & $23.21 \%$ & $11.18 \%$ & $19.80 \%$ & $1.45 \%$ & \\
\hline & & & & & & & & & & & & $3.00 \%$ \\
\hline \multirow{2}{*}{$\begin{array}{l}\text { Pept-A-XVIIa } \\
\text { Pept-A-XVIIb }\end{array}$} & & $0.16 \%$ & & & $5.10 \%$ & & $0.15 \%$ & & & & & \\
\hline & & & & & & $1.24 \%$ & & & $0.27 \%$ & & & \\
\hline Pept-A-XVIII & $0.32 \%$ & & & & & & & & & & & \\
\hline Pept-A-XIXa & $6.75 \%$ & $5.61 \%$ & $1.97 \%$ & $3.45 \%$ & $0.61 \%$ & $0.61 \%$ & $8.44 \%$ & $6.72 \%$ & $13.19 \%$ & $1.91 \%$ & & \\
\hline Pept-A-XX & $4.85 \%$ & $6.31 \%$ & & & & & & $1.47 \%$ & $0.40 \%$ & & & \\
\hline \multirow{2}{*}{$\begin{array}{l}\text { Pept-A-XXIa } \\
\text { Pept-A-XXIb }\end{array}$} & $3.51 \%$ & $1.39 \%$ & $2.54 \%$ & $8.80 \%$ & $14.80 \%$ & $35.47 \%$ & $7.28 \%$ & $0.93 \%$ & $6.06 \%$ & $6.80 \%$ & $1.16 \%$ & \\
\hline & & & & & & & & & & & & $5.87 \%$ \\
\hline \multirow{2}{*}{$\begin{array}{l}\text { Pept-A-XXIIa } \\
\text { Pept-A-XXIIb }\end{array}$} & $3.01 \%$ & $2.23 \%$ & & & & & & & & & & \\
\hline & & & & & & $0.50 \%$ & & & & & & \\
\hline Pept-A-XXIII & $0.31 \%$ & $0.26 \%$ & $1.49 \%$ & $2.54 \%$ & & & $2.84 \%$ & $0.49 \%$ & $4.23 \%$ & $0.23 \%$ & & \\
\hline Pept-A-XXIV & $0.75 \%$ & & & & & & & & & & & \\
\hline \multirow{2}{*}{$\begin{array}{l}\text { Pept-A-XXVa } \\
\text { Pept-A-XXVb }\end{array}$} & & $0.64 \%$ & & $1.80 \%$ & & & $1.76 \%$ & & $7.51 \%$ & $0.65 \%$ & & \\
\hline & & & & & & $4.24 \%$ & & $0.19 \%$ & & & & \\
\hline \multirow{2}{*}{$\begin{array}{l}\text { Pept-A-XXVIa } \\
\text { Pept-A-XXVIb }\end{array}$} & $0.40 \%$ & & & & & & & & & & & \\
\hline & & & & & & $2.47 \%$ & & & & & & \\
\hline \multirow{2}{*}{$\begin{array}{l}\text { Pept-A-XXVIII } \\
\text { Pept-A-XXVIIb }\end{array}$} & & & & & & & & & $0.34 \%$ & & & \\
\hline & & & & & & $1.14 \%$ & & & & & & \\
\hline
\end{tabular}


Table 16 I Relative amounts of the identified peptaibol compounds in the peptaibol profiles of T. reesei, T. saturnisporum, T. andinense, T. effusum, T. parareesei, T. flagellatum, T. sinense and T. konilangbra. The colours represent the extent of the production (percentage) of each strain from the lowest (yellow) to the highest (red).

\begin{tabular}{|c|c|c|c|c|c|c|c|c|c|c|}
\hline 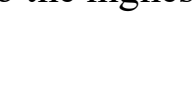 & T. reesei & T. reesei & T. reesei $\Delta$ & $\begin{array}{c}T . \\
\text { saturnisporum } \\
\end{array}$ & T. andinense & T. effusum & T. parareesei & T. flagellatum & T. sinense & T. konilangbra \\
\hline Peptaibol & 22614 & 22616 & 22617 & 22606 & 22610 & 22611 & 22615 & 22608 & 22609 & 22607 \\
\hline Pept-B-I & $0.62 \%$ & & & & & & & & & \\
\hline Pept-B-II & $0.55 \%$ & & & & & & & & & \\
\hline Pept-B-III & $0.37 \%$ & & & & & & & & & \\
\hline Pept-B-IV & $0.78 \%$ & & & & & & & & & \\
\hline Pept-B-V & $0.58 \%$ & & & & & & & & & \\
\hline Pept-B-VI & $0.98 \%$ & & & & & & & & & \\
\hline Pept-B-VII & $0.88 \%$ & & & & & & & & & \\
\hline Pept-B-VIII & & $1.47 \%$ & $2.33 \%$ & & & & & & & \\
\hline \multirow{2}{*}{$\begin{array}{l}\text { Pept-B-IXa } \\
\text { Pept-B-IXb }\end{array}$} & $3.61 \%$ & $4.23 \%$ & $3.59 \%$ & & & & & & & \\
\hline & & & & & & & $0.92 \%$ & & & \\
\hline Pept-B-X & $0.44 \%$ & & & & & & & & & \\
\hline Pept-B-XI & $0.65 \%$ & & & & & & & & & \\
\hline Pept-B-XII & $10.85 \%$ & $11.96 \%$ & $16.31 \%$ & $6.88 \%$ & $4.23 \%$ & $10.83 \%$ & $5.00 \%$ & $2.69 \%$ & & \\
\hline Pept-B-XIII & $0.54 \%$ & & & & & & & & & \\
\hline \multirow{2}{*}{$\begin{array}{l}\text { Pept-B-XIVa } \\
\text { Pept-B-XIVb }\end{array}$} & & & & $0.44 \%$ & $1.85 \%$ & $0.87 \%$ & $1.08 \%$ & $0.41 \%$ & & \\
\hline & $0.52 \%$ & $0.64 \%$ & $1.09 \%$ & & & & & & & \\
\hline \multirow{2}{*}{$\begin{array}{l}\text { Pept-B-XVa } \\
\text { Pept-B-XVb }\end{array}$} & $4.67 \%$ & $5.80 \%$ & $6.38 \%$ & & & & & & & \\
\hline & & & & & & & $0.95 \%$ & & & \\
\hline Pept-B-XVI & $0.19 \%$ & & & & & & & & & \\
\hline Pept-B-XVII & $13.80 \%$ & $17.22 \%$ & $21.61 \%$ & $27.43 \%$ & $9.41 \%$ & $19.57 \%$ & $7.10 \%$ & $1.20 \%$ & & \\
\hline Pept-B-XVIII & $0.65 \%$ & & & & & & & & & \\
\hline Pept-B-XIX & $1.02 \%$ & & & & & & & $0.29 \%$ & & \\
\hline Pept-B-XX & $15.04 \%$ & $15.88 \%$ & $17.04 \%$ & $9.33 \%$ & $13.51 \%$ & $16.03 \%$ & $11.55 \%$ & $9.54 \%$ & $7.41 \%$ & $4.75 \%$ \\
\hline Pept-B-XXI & & & & $0.53 \%$ & $1.25 \%$ & $1.21 \%$ & $0.69 \%$ & & & \\
\hline
\end{tabular}


Table 16 | continued

\begin{tabular}{|c|c|c|c|c|c|c|c|c|c|c|}
\hline \multirow[b]{2}{*}{ Peptaibol } & T. reesei & T. reesei & T. reesei 4 & $\begin{array}{c}T . \\
\text { saturnisporum } \\
\end{array}$ & T. andinense & T. effusum & T. parareesei & T. flagellatum & $T$. sinense & T. konilangbra \\
\hline & 22614 & 22616 & 22617 & 22606 & 22610 & 22611 & 22615 & 22608 & 22609 & 22607 \\
\hline Pept-B-XXII & $1.01 \%$ & & & & & & & & & \\
\hline Pept-B-XXIII & & & & & $4.01 \%$ & & $3.26 \%$ & & & \\
\hline Pept-B-XXIV & $0.50 \%$ & & & & & & & & & \\
\hline Pept-B-XXV & $1.08 \%$ & $1.11 \%$ & $1.48 \%$ & $0.60 \%$ & $4.15 \%$ & $0.67 \%$ & $4.12 \%$ & $1.76 \%$ & & \\
\hline Pept-B-XXVI & & & & & & & & $1.38 \%$ & $3.59 \%$ & \\
\hline Pept-B-XXVII & $22.12 \%$ & $24.75 \%$ & $19.40 \%$ & $40.50 \%$ & $21.07 \%$ & $36.54 \%$ & $17.23 \%$ & $5.60 \%$ & $1.96 \%$ & $3.70 \%$ \\
\hline Pept-B-XXVIII & & & & & & & & $9.50 \%$ & $14.33 \%$ & $7.97 \%$ \\
\hline \multirow{2}{*}{$\begin{array}{l}\text { Pept-B-XXIXa } \\
\text { Pept-B-XXIXb }\end{array}$} & & & & & $8.69 \%$ & & & & & \\
\hline & & & & & & & $7.10 \%$ & & & \\
\hline Pept-B-XXX & $1.49 \%$ & $2.40 \%$ & $0.70 \%$ & & & & & & & \\
\hline Pept-B-XXXI & & & & & $2.61 \%$ & & & $1.63 \%$ & & \\
\hline \multirow{2}{*}{$\begin{array}{l}\text { Pept-B-XXXIIIa } \\
\text { Pept-B-XXXIIb }\end{array}$} & $2.24 \%$ & $2.08 \%$ & $1.80 \%$ & & & & & & & \\
\hline & & & & & & & & $1.12 \%$ & $2.10 \%$ & \\
\hline \multirow{2}{*}{$\begin{array}{l}\text { Pept-B-XXXIIIa } \\
\text { Pept-B-XXXIIIb }\end{array}$} & & & & & $7.04 \%$ & & $8.55 \%$ & & & \\
\hline & $0.90 \%$ & & & & & & & & & \\
\hline \multirow{2}{*}{$\begin{array}{l}\text { Pept-B-XXXIIIc } \\
\text { Pept-B-XXXIIId }\end{array}$} & & $0.56 \%$ & $0.81 \%$ & & & & & & & \\
\hline & & & & & & & & $3.18 \%$ & & \\
\hline \multirow{2}{*}{$\begin{array}{l}\text { Pept-B-XXXIVa } \\
\text { Pept-B-XXXIVb }\end{array}$} & & & & & $1.66 \%$ & & & & & \\
\hline & & & & & & $1.05 \%$ & $1.89 \%$ & & & \\
\hline \multirow{2}{*}{$\begin{array}{l}\text { Pept-A-IVa } \\
\text { Pept-A-IVb }\end{array}$} & & & & $3.49 \%$ & & & & & & \\
\hline & & & & & & & & & & $22.06 \%$ \\
\hline \multirow{2}{*}{$\begin{array}{l}\text { Pept-B-XXXVa } \\
\text { Pept-B-XXXVb }\end{array}$} & & $0.82 \%$ & $1.47 \%$ & & & $2.63 \%$ & & & & \\
\hline & $0.93 \%$ & & & & $2.78 \%$ & & & & & \\
\hline
\end{tabular}


Table 16 | continued

\begin{tabular}{|c|c|c|c|c|c|c|c|c|c|c|}
\hline & T. reesei & T. reesei & T. reesei 4 & $\begin{array}{c}T . \\
\text { saturnisporum } \\
\end{array}$ & T. andinense & T. effusum & T. parareesei & T. flagellatum & T. sinense & T. konilangbra \\
\hline Peptaibol & 22614 & 22616 & 22617 & 22606 & 22610 & 22611 & 22615 & 22608 & 22609 & 22607 \\
\hline Pept-B-XXXVI & & & & & & & & $2.08 \%$ & $9.12 \%$ & \\
\hline Pept-B-XXXVII & & & & & $1.17 \%$ & & $1.86 \%$ & & & \\
\hline Pept-B-XXXVIII & & $1.35 \%$ & $0.84 \%$ & & & & & & & \\
\hline Pept-B-XXXIX & & & & & & & & $0.70 \%$ & & \\
\hline Pept-B-XL & $1.90 \%$ & $1.39 \%$ & $0.55 \%$ & $3.39 \%$ & & & & & & \\
\hline \multirow{2}{*}{$\begin{array}{l}\text { Pept-B-XLIa } \\
\text { Pept-B-XLIb }\end{array}$} & $3.09 \%$ & $2.63 \%$ & $0.71 \%$ & & $3.53 \%$ & & $3.75 \%$ & & & \\
\hline & & & & & & & & $9.36 \%$ & $5.44 \%$ & $7.47 \%$ \\
\hline \multirow{2}{*}{$\begin{array}{l}\text { Pept-B-XLIIa } \\
\text { Pept-B-XLIIb }\end{array}$} & $0.78 \%$ & & & & & & $0.44 \%$ & & & \\
\hline & & $0.65 \%$ & $0.82 \%$ & & & & & & & \\
\hline Pept-B-XLIII & & & & & & & & $6.53 \%$ & $14.94 \%$ & \\
\hline Pept-A-VIa & & & & $1.26 \%$ & & & & & & \\
\hline Pept-B-XLIV & & & & & & & & & & $10.56 \%$ \\
\hline \multirow{2}{*}{$\begin{array}{l}\text { Pept-B-XLVa } \\
\text { Pept-B-XLVb }\end{array}$} & $2.11 \%$ & $2.83 \%$ & $0.59 \%$ & $0.71 \%$ & $8.42 \%$ & $9.78 \%$ & $11.62 \%$ & & & \\
\hline & & & & & & & & & & $6.35 \%$ \\
\hline \multirow{2}{*}{$\begin{array}{l}\text { Pept-B-XLVIa } \\
\text { Pept-B-XLVIb }\end{array}$} & $0.16 \%$ & $0.34 \%$ & $0.33 \%$ & & & & & & & \\
\hline & & & & & & & $0.25 \%$ & & & \\
\hline Pept-B-XLVII & & & & & & & & $1.92 \%$ & & \\
\hline \multirow{2}{*}{$\begin{array}{l}\text { Pept-A-Xa } \\
\text { Pept-A-Xb }\end{array}$} & & & & $0.65 \%$ & & & & & & \\
\hline & $0.92 \%$ & & & & & & & & & \\
\hline \multirow{2}{*}{$\begin{array}{l}\text { Pept-B-XLVIIIa } \\
\text { Pept-B-XLVIIIb }\end{array}$} & & & & & $3.17 \%$ & & $1.24 \%$ & & & \\
\hline & & $1.05 \%$ & $1.78 \%$ & & & & & & & \\
\hline Pept-B-XLIX & & & & & & & & $2.70 \%$ & $4.60 \%$ & \\
\hline Pept-B-L & & & & & & & & $1.43 \%$ & & \\
\hline Pept-B-LI & & & & & & & & $1.86 \%$ & $11.70 \%$ & $4.69 \%$ \\
\hline Pept-B-LII & & & & & $1.45 \%$ & $0.83 \%$ & $1.28 \%$ & & & \\
\hline Pept-B-LIII & $0.26 \%$ & & & & & & $1.03 \%$ & & & \\
\hline
\end{tabular}


Table 16 | continued

\begin{tabular}{|c|c|c|c|c|c|c|c|c|c|c|}
\hline & T. reesei & T. reesei & T. reesei 4 & $\begin{array}{c}T . \\
\text { saturnisporum } \\
\end{array}$ & T. andinense & T. effusum & T. parareesei & T. flagellatum & T. sinense & T. konilangbra \\
\hline Peptaibol & 22614 & 22616 & 22617 & 22606 & 22610 & 22611 & 22615 & 22608 & 22609 & 22607 \\
\hline Pept-B-LIV & & & & & & & & $10.23 \%$ & $7.65 \%$ & $13.09 \%$ \\
\hline Pept-B-LV & $1.42 \%$ & $0.85 \%$ & $0.40 \%$ & & & & $0.90 \%$ & & & \\
\hline \multirow{2}{*}{$\begin{array}{l}\text { Pept-A-XVIa } \\
\text { Pept-A-XVIb }\end{array}$} & & & & $3.15 \%$ & & & & & & \\
\hline & $0.44 \%$ & & & & & & & & & $10.85 \%$ \\
\hline Pept-B-LVI & $0.49 \%$ & & & & & & $0.84 \%$ & & & \\
\hline Pept-B-LVII & & & & & & & & $2.28 \%$ & & \\
\hline Pept-B-LVIII & $0.31 \%$ & & & & & & $0.47 \%$ & & & \\
\hline Pept-B-LIX & & & & & & & & $4.13 \%$ & $6.85 \%$ & $6.20 \%$ \\
\hline \multirow{2}{*}{$\begin{array}{l}\text { Pept-B-LXa } \\
\text { Pept-B-LXb }\end{array}$} & $0.51 \%$ & & & & & & & & & \\
\hline & & & & & & & $2.41 \%$ & & & \\
\hline \multirow{2}{*}{$\begin{array}{l}\text { Pept-A-XIXa } \\
\text { Pept-A-XIXb }\end{array}$} & $0.12 \%$ & & & $0.89 \%$ & & & & & & \\
\hline & & & & & & & & & & $2.30 \%$ \\
\hline Pept-B-LXI & $0.47 \%$ & & & $0.76 \%$ & & & $0.99 \%$ & & & \\
\hline Brevicelsin I & & & & & & & $0.81 \%$ & $4.48 \%$ & $2.09 \%$ & \\
\hline Brevicelsin II & & & & & & & & & $1.81 \%$ & \\
\hline Brevicelsin III & & & & & & & & $0.95 \%$ & & \\
\hline Brevicelsin IV & & & & & & & $2.68 \%$ & $3.20 \%$ & $0.87 \%$ & \\
\hline Brevicelsin V & & & & & & & & & $0.42 \%$ & \\
\hline Brevicelsin VI & & & & & & & & $4.99 \%$ & $3.31 \%$ & \\
\hline Brevicelsin VII & & & & & & & & $0.42 \%$ & & \\
\hline Brevicelsin VIII & & & & & & & & $4.41 \%$ & $1.82 \%$ & \\
\hline
\end{tabular}


